Fernando Fernandes Fontes

\title{
ANÁLISE ESTRUTURAL DE ELEMENTOS LINEARES SEGUNDO A NBR 6118:2003
}

Dissertação apresentada à Escola de Engenharia de São Carlos, da Universidade de São Paulo, como parte dos requisitos para a obtenção do título de Mestre em Engenharia de Estruturas.

ORIENTADOR: Prof. Dr. Libânio Miranda Pinheiro 
Dedico este trabalho aos

meus pais, Arimatéia e Marisete. 


\section{AGRADECIMENTOS}

Aos meus pais, por me apoiarem em todas as minhas decisões e por serem verdadeiros exemplos de vida a serem seguidos.

Aos meus irmãos, por serem amigos tão especiais, com quem se pode contar sempre.

A Marianne, por todo o amor e carinho apesar da distância.

Ao Professor Libânio M. Pinheiro, pela orientação e apoio, pelo contínuo incentivo e pela verdadeira amizade.

A todos que compõem o Departamento de Estruturas pelo afetuoso acolhimento durante minha estadia em São Carlos.

Aos novos amigos, que tornaram o mestrado uma ótima experiência de vida.

Ao CNPq, pelo apoio financeiro. 


\section{SUMÁRIO}

LISTA DE FIGURAS $\quad$ ix

LISTA DE TABELAS $\quad$ xiii

LISTA DE SÍMBOLOS Xiv

$\begin{array}{lll}\text { RESUMO } & \text { xvii }\end{array}$

$\begin{array}{lll}\text { ABSTRACT } & \text { xviii }\end{array}$

1 INTRODUÇÃO

1.1 Considerações iniciais 1

1.2 Objetivos 2

1.3 Justificativa 3

1.4 Apresentação dos capítulos 3

1.5 Breve histórico $\quad 4$

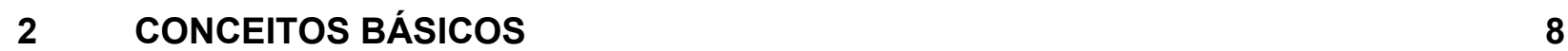

2.1 Elementos estruturais $\quad 8$

2.2 Modelos estruturais $\quad 9$

$\begin{array}{lll}2.2 .1 & \text { Vigas Contínuas } & 10\end{array}$

2.2.2 Pórticos Planos 13

$\begin{array}{lll}2.2 .3 & \text { Pórticos espaciais } & 14\end{array}$

$\begin{array}{lll}2.2 .4 & \text { Grelhas } & 15\end{array}$

$\begin{array}{lll}2.3 & \text { Trechos Rígidos } & 17\end{array}$

$\begin{array}{lll}2.4 & \text { Largura colaborante de vigas de seção T } & 19\end{array}$

$2.5 \quad$ Laje como diafragma rígido 20

$3 \quad$ TIPOS DE ANÁLISE ESTRUTURAL

$\begin{array}{lll}3.1 & \text { Análise linear } & 21\end{array}$

3.2 Análise linear com redistribuição 24

$\begin{array}{lll}3.3 & \text { Análise plástica } & 28\end{array}$

3.3.1 Rótulas plásticas $\quad 29$

3.3.2 Momento totalmente plástico 30 
3.3.3 Carga limite e mecanismo de colapso

3.3.4 Rotação necessária 33

3.3.5 Concreto armado e capacidade de rotação da rótula plástica 35

3.3.6 Considerações para elementos lineares 37

$\begin{array}{lll}3.3 .7 & \text { Aplicação } & 38\end{array}$

3.4 Análise não-linear 38

3.4.1 Tipos de não-linearidade 39

3.4.2 Modelos para análise não-linear $\quad 42$

$\begin{array}{lll}3.4 .3 & \text { Observações } & 46\end{array}$

3.5 Análise através de modelos físicos $\quad 46$

$\begin{array}{lll}3.6 & \text { Comentários } & 48\end{array}$

4 VIGA COM SEÇÃO RETANGULAR $\quad \mathbf{5 0}$

4.1 Análise linear $\quad 51$

$\begin{array}{lll}4.1 .1 & \text { Esforços } & 51\end{array}$

$\begin{array}{lll}4.1 .2 & \text { Flexão } & 52\end{array}$

$\begin{array}{lll}4.1 .3 & \text { Cisalhamento } & 52\end{array}$

4.1.4 Estado limite de formação de fissuras (ELS-F) 53

4.1.5 Estado limite de deformação excessiva (ELS - DEF) 54

4.1.6 Estado limite de abertura de fissuras (ELS-W) 55

$\begin{array}{lll}4.2 & \text { Análise linear com redistribuição } & 57\end{array}$

$\begin{array}{lll}\text { 4.2.1 } & \text { Esforços } & 58\end{array}$

$\begin{array}{lll}4.2 .2 & \text { Flexão } & 59\end{array}$

$\begin{array}{lll}\text { 4.2.3 Cisalhamento } & 59\end{array}$

4.2.4 Estado limite de formação de fissuras (ELS-F) 59

4.2.5 Estado limite de deformação excessiva (ELS - DEF) 60

4.2.6 Estado limite de abertura de fissuras (ELS-W) 60

$\begin{array}{lll}4.3 & \text { Análise plástica } & 60\end{array}$

$\begin{array}{lll}\text { 4.3.1 Primeira rótula plástica } & 60\end{array}$

$\begin{array}{lll}\text { 4.3.2 Segunda rótula plástica } & 61\end{array}$

$\begin{array}{lll}\text { 4.3.3 Rotação plástica } & 62\end{array}$

4.3.4 Capacidade de rotação plástica (NBR 6118:2003) 63 
$\begin{array}{lll}\text { 4.3.5 } & \text { Máxima redistribuição } & 63\end{array}$

$\begin{array}{lll}4.4 & \text { Consumo de aço } & 64\end{array}$

$5 \quad$ VIGA COM SEÇÃO T $\quad 65$

5.1 Análise Linear - Seção Retangular $\quad 68$

5.2 Análise Linear - Seção T $\quad 69$

5.3 Análise Linear com Redistribuição - Seção T 70

$\begin{array}{lll}5.4 & \text { Análise Plástica - Seção T } & 71\end{array}$

$\begin{array}{lll}5.5 & \text { Consumo de aço } & 73\end{array}$

6 REDISTRIBUIÇÃO DE MOMENTOS EM PILARES E ENVOLTÓRIA DE 75 ESFORÇOS

6.1 Análise linear - Seção retangular 76

$\begin{array}{lll}6.1 .1 & \text { Esforços } & 77\end{array}$

$\begin{array}{lll}6.1 .2 & \text { Flexão } & 79\end{array}$

$\begin{array}{lll}6.1 .3 & \text { Cisalhamento } & 80\end{array}$

$\begin{array}{lll}6.1 .4 & \text { Verificações de ELS na V2 } & 80\end{array}$

6.1.5 Esforços nos pilares e suas armaduras $\quad 81$

6.2 Análise linear com redistribuição - Seção T 82

6.2.1 Esforços $\quad 83$

$\begin{array}{lll}6.2 .2 & \text { Flexão } & 86\end{array}$

$\begin{array}{lll}\text { 6.2.3 Cisalhamento } & 87\end{array}$

$\begin{array}{ll}\text { 6.2.4 Verificações de ELS na V2 } & 87\end{array}$

6.2.5 Esforços nos pilares e suas armaduras 88

6.3 Consumo de aço $\quad 89$

7 ANÁLISE DE UM EDIFÍCIO POR VÁRIOS MODELOS ESTRUTURAIS 90

$\begin{array}{lll}7.1 & \text { Análise das ações verticais } & 92\end{array}$

$\begin{array}{lll}7.1 .1 & \text { Modelos } & 93\end{array}$

$\begin{array}{lll}7.1 .2 & \text { Resultados } & 95\end{array}$

$\begin{array}{lll}7.2 & \text { Análise das ações horizontais } & 97\end{array}$

$\begin{array}{lll}7.2 .1 & \text { Modelos } & 99\end{array}$

$\begin{array}{lll}7.2 .2 & \text { Resultados } & 101\end{array}$

$\begin{array}{lll}7.3 & \text { Análise das ações verticais e horizontais } & 106\end{array}$ 
8 CONSIDERAÇÕES FINAIS $\quad 108$

$\begin{array}{lll}8.1 & \text { Conclusões } & 108\end{array}$

$\begin{array}{lll}8.2 & \text { Sugestões de pesquisa } & 114\end{array}$

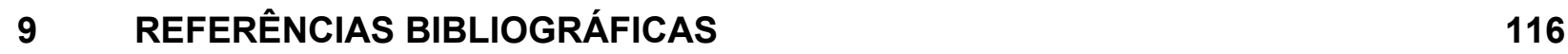

10 BIBLIOGRAFIA COMPLEMENTAR 119 


\section{LISTA DE FIGURAS}

Figura 1.1 - Problema de Galileo e sua consideração de tração uniformemente distribuída na seção

Figura 2.1 - Viga exemplo para esquemas estruturais

Figura 2.2 - Esquema estrutural primário (adaptada de FUSCO, 1976)

Figura 2.3 - Esquema estrutural secundário (adaptada de FUSCO, 1976)

Figura 2.4 - Esquema estrutural terciário (adaptada de FUSCO, 1976)

Figura 2.5 - Condição para o engastamento de apoios intermediários

Figura 2.6 - Esquema estrutural para obtenção dos coeficientes (adaptado da NBR 6118:2003)

Figura 2.7 - Associação de pórticos planos para análise de ações horizontais (análise da direção $\mathrm{x}$ )

Figura 2.8 - Pavimentos isolados

Figura 2.9 - Pórtico espacial

Figura 2.10 - Espaçamento entre as barras da grelha

Figura 2.11 - Trechos rígidos (adaptada da NBR 6118:2003)

Figura 2.12 - Trecho rígido visto em planta

Figura 2.13 - Trecho rígido na mudança de eixo de pilares (adaptada de CORRÊA, 1991)

Figura 2.14 - Distância a para o tramo da viga de comprimento $\ell$

Figura 3.1 - Diagrama tensão versus deformação

Figura 3.2 - Limite elástico da seção transversal

Figura 3.3 - Verificação do comportamento linear de uma estrutura

Figura 3.4 - Redistribuição de momentos fletores em viga contínua

Figura 3.5 - Diagrama tensão versus deformação

Figura 3.6 - Distribuição de curvatura com a carga limite (adaptada de PARK \& PAULAY, 1975) 
Figura 3.8 - Seção transversal retangular 31

Figura 3.9 - Viga hiperestática que se torna hipostática com a rótula no apoio simples 32

Figura 3.10 - Viga biengastada e grau de hiperestaticidade $3 \quad 32$

Figura 3.11 - Diagrama de corpo livre de metade da viga biengastada 33

Figura 3.12 - Viga biengastada carregada até o colapso 34

Figura 3.13 - Capacidade de rotação de rótulas plásticas (Adaptada da NBR 6118:2003) 36

Figura 3.14 - Diagrama tensão versus deformação de um material não-linear (NLF) 38

Figura 3.15 - Não-linearidade geométrica $\quad 42$

Figura 3.16 - Comparação entre os modelos de Branson e Ghali e Favre 46

Figura 3.17 - Instituto Brasileiro do Café (Fonte: LOREDO-SOUZA \& BLESSMANN, 2003)

Figura 4.1 - Viga V1 $(25 \mathrm{~cm} \times 50 \mathrm{~cm}) \quad 50$

Figura 4.2 - Detalhamento padrão da viga V1 51

Figura 4.3 - Momentos fletores de cálculo para a análise linear (kN.m) 52

Figura 4.4 - Esforços cortantes de cálculo para a análise linear (kN) 52

Figura 4.5 - Momentos fletores para a combinação rara com análise linear (kN.m) 53

Figura 4.6 - Disposição da armadura tracionada na seção 2

Figura 4.7 - Soma de diagramas para igualar os momentos do apoio e dos vãos 57

Figura 4.8 - Correção do momento positivo 58

Figura 4.9 - Momentos fletores de cálculo para a análise linear com redistribuição (kN.m) 58

Figura 4.10 - Esforços cortantes de cálculo para a análise linear com redistribuição (kN) 59

$\begin{array}{ll}\text { Figura } 4.11 \text { - Formação da primeira rótula plástica } & 61\end{array}$

Figura 4.12 - Momentos fletores gerados pelo acréscimo de carga $\Delta \mathrm{P}_{2 \mathrm{r}}$

Figura 4.13 - Formação do mecanismo de colapso $\quad 62$

Figura 5.1 - Pavimento ao qual pertence a viga $02 \quad 65$

Figura 5.2 - Esquema estático da V2 66

Figura 5.3 - Momentos fletores de cálculo para a análise linear (kN.m) 68

Figura 5.4 - Esforços cortantes de cálculo para a análise linear (kN) 68

Figura 5.5 - Verificações exigidas pela NBR 6118:2003 69 
Figura 5.6 - Seção T da viga V2 com largura colaborante da laje

Figura 5.7 - Momentos fletores de cálculo para a análise linear com redistribuição (kN.m) 71

Figura 5.8 - Esforços cortantes de cálculo para a análise linear com redistribuição $(\mathrm{kN})$ 71

Figura 6.1 - Pavimento ao qual pertence a viga V2 75

Figura 6.2 - Pórtico analisado em destaque 76

Figura 6.3 - Modelo clássico de vigas contínuas com combinação última (valores de cálculo)

Figura 6.4 - Esquema estático para a correção do momento negativo devido à solidariedade com os pilares de extremidade (valores de cálculo)

Figura 6.5 - Esquema estático para a correção do momento positivo devido ao engastamento perfeito dos apoios internos (valores de cálculo)

Figura 6.6 - Envoltória de momentos fletores (kN.m)

Figura 6.7 - Envoltória de esforços cortantes (kN)

Figura 6.8 - Detalhamento padrão da seção transversal dos pilares 79

Figura 6.9 - Momentos do P4 no tramo que suporta o último pavimento-tipo

Figura 6.10 - Seção T com largura colaborante da laje na viga V2 81

Figura 6.11 - Redução de $25 \%$ nos picos de momentos negativos do caso A

Figura 6.12 - Acréscimo de $25 \%$ nos picos de momento negativo ou até o momento de projeto, para o caso $\mathrm{B}$

Figura 6.13 - Envoltória de momentos fletores (kN.m)

Figura 6.14 - Envoltória de esforços cortantes (kN) 86

Figura 6.15 - Equilíbrio do nó de extremidade da V2 com o P4 88

Figura 7.1 - Planta de forma do pavimento-tipo 90

Figura 7.2 - Altura dos pavimentos

Figura 7.3 - Modelo Vigas Contínuas para vigas do pavimento-tipo e combinação última $1,4 \mathrm{~g}+1,4 \mathrm{q}$ (unidades: $\mathrm{kN}$ e $\mathrm{m}$ )

Figura 7.4 - Definição dos pórticos planos 94

Figura 7.5 - Modelo Pórticos Planos 94

Figura 7.6 - Modelo Pórtico Espacial 95

Figura 7.7 - Momentos fletores da V1 no pavimento térreo (kN.m) 
Figura 7.8 - Modelo Pórticos Planos Associados: conexão do PP4 com o PP5 100

Figura 7.9 - Renderização do modelo Pórtico Espacial com Lajes 101

Figura 7.10 - Trechos rígidos dos pilares P1 e P2 101

Figura 7.11 - Modelo Pórtico Espacial: vista superior dos deslocamentos devidos ao vento da direção y (deslocamentos aumentados em 100 vezes e legenda em cm)

Figura 7.12 - Modelo Pórtico Espacial com Lajes e Trechos Rígidos: vista superior dos deslocamentos devidos ao vento da direção x (deslocamentos aumentados em 400 vezes e legenda em $\mathrm{cm}$ )

Figura 7.13 - Modelo Pórtico Espacial com Lajes e Trechos Rígidos: vista superior dos deslocamentos devidos ao vento da direção y (deslocamentos aumentados em 100 103 vezes e legenda em $\mathrm{cm}$ )

Figura 7.14 - Configuração dos momentos fletores das vigas V6 e V7

Figura 7.15 - Momentos fletores nas vigas do pavimento térreo (kN.m)

Figura 8.1 - Gráfico: $\delta$ versus Diferença entre a capacidade de rotação e a rotação plástica necessária

Figura 8.2 - Consumo de aço com os diferentes tipos de análise do capítulo cinco

Figura 8.3 - Superfície de tendências dos valores de $x / d, \delta$ e área de armadura

Figura 8.4 - Consumo de aço com os diferentes tipos de análise do capítulo seis

Figura 8.5 - Deslocamentos horizontais pelos diferentes modelos $(\mathrm{cm})$ 


\section{LISTA DE TABELAS}

Tabela 2.1 - Coeficientes para consideração da solidariedade entre as vigas e os pilares externos

Tabela 3.1 - Tipos de análise estrutural e suas aplicações 49

Tabela 4.1 - Maior redistribuição possível com a análise plástica 63

Tabela 5.1 - Combinações de valores de $\mathrm{x} / \mathrm{d}$ e $\delta$

Tabela 5.2 - Consumo de aço

Tabela 6.1 - Consumo de aço $(\mathrm{kg})$ 89

Tabela 7.1 - Carregamento das lajes $\left(\mathrm{kN} / \mathrm{m}^{2}\right)$ 92

Tabela 7.2 - Forças normais junto à fundação $(\mathrm{kN})$ 95

Tabela 7.3 - Momentos fletores da V1 (kN.m) 96

Tabela 7.4 - Momentos fletores da V5 (kN.m) 96

Tabela 7.5 - Momentos fletores da V6 (kN.m) 97

Tabela 7.6 - Momentos fletores da V7 (kN.m) 97

Tabela 7.7 - Ações do vento 98

Tabela 7.8 - Ações decorrentes do desaprumo 99

Tabela 7.9 - Deslocamentos horizontais no topo da estrutura $(\mathrm{cm})$ 102

Tabela 7.10 - Valores de $\gamma_{z}$ 104

Tabela 7.11 - Forças normais junto à fundação, devidas ao vento em y $(\mathrm{kN})$ 104

Tabela 7.12 - Momentos fletores da V6 (kN.m) 105

Tabela 7.13 - Momentos fletores da V7 (kN.m) 106

Tabela 7.14 - Forças normais junto à fundação (kN) 107

Tabela 7.15 - Momentos fletores nas vigas V6 e V7 107 


\section{LISTA DE SÍMBOLOS}

b

$\mathrm{h}$

M

$\mathrm{M}_{\text {eng }}$

$r_{i}$

$\mathrm{I}_{\mathrm{i}}$

$\ell / L$

$b_{f}$

$b_{w}$

a

$\sigma$

$\varepsilon$

$\sigma_{e}$

E

$\sigma_{p}$

$v$

LN

$E_{c s}$

$\mathrm{E}_{\mathrm{ci}}$

$f_{c k}$

$\mathrm{x}$

d

$x / d$

$\mathrm{p}$

$\delta$

$\varepsilon_{\mathrm{e}}$

$\varepsilon_{\mathrm{p}}$

$\ell_{\mathrm{p}}$

$\mathrm{M}_{\mathrm{p}}$

El

$\mathrm{P}_{\ell} / \mathrm{p}_{\ell}$

$P$

$\theta$

largura da seção transversal

altura da seção transversal

momento fletor atuante em uma seção

momento de engastamento perfeito

rigidez do elemento $\mathrm{i}$

momento de inércia à flexão do elemento $\mathrm{i}$

comprimento de um elemento

largura colaborante

largura da alma de uma viga

distância entre pontos de momento fletor nulo em um tramo da viga (item 2.4) / distância entre pontos de momento nulo da região que contém a seção plastificada (item 3.3.5)

tensão

deformação

limite elástico do material (tensão)

módulo de elasticidade do material

limite de proporcionalidade do material (tensão)

coeficiente de Poisson

linha neutra

módulo de elasticidade secante

módulo de elasticidade tangente inicial

resistência característica à compressão do concreto

profundidade da linha neutra

altura útil da seção transversal

posição relativa da linha neutra

ação uniformemente distribuída

coeficiente de redistribuição

parcela recuperável elástica da deformação

parcela permanente plástica da deformação

comprimento de plastificação

momento totalmente plástico

rigidez

carga limite (concentrada / uniformemente distribuída)

ação concentrada

rotação 
deformação normal do concreto deformação normal da armadura longitudinal tracionada capacidade de rotação da rótula plástica momento de inércia da seção bruta de concreto. área da seção transversal da armadura longitudinal de compressão área da seção transversal da armadura longitudinal de tração esforço normal curvatura rigidez equivalente de Branson momento de fissuração momento fletor na seção crítica do vão considerado momento de inércia da seção fissurada de concreto no estádio II reação de apoio distância entre o CG da armadura de flexão e a face externa da viga centro geométrico

diâmetro de uma barra espaçamento entre estribos força cortante solicitante de cálculo força cortante resistente de cálculo, relativa à ruína das diagonais comprimidas de concreto resistência de cálculo à compressão do concreto parcela de força cortante absorvida por mecanismos complementares ao de treliça resistência de cálculo do concreto à tração direta taxa geométrica de armadura mínima resistência média à tração do concreto resistência característica ao escoamento do aço da armadura transversal força cortante resistida pela armadura mínima resistência de cálculo ao escoamento do aço da armadura transversal força cortante solicitante de cálculo mínima área da seção transversal da armadura transversal mínima ação permanente ação variável fator de redução da combinação quase permanente para ELS flecha imediata taxa geométrica da armadura longitudinal comprimida coeficiente função do tempo para obtenção da flecha diferida fator que multiplica a flecha imediata para o cálculo da flecha diferida flecha total fator de redução da combinação freqüente para ELS abertura de fissuras na superfície do concreto cobrimento 
$\mathrm{k}_{\mathrm{c}} \quad$ valor auxiliar para o cálculo de armadura simples

$k_{s}, k_{s 2}, k_{s} \quad$ valores auxiliares para o cálculo de armadura dupla

$f_{y d}$ resistência de cálculo ao escoamento do aço

$\sigma_{s}^{\prime} \quad$ tensão na armadura comprimida

$\mathrm{E}_{\mathrm{s}} \quad$ módulo de elasticidade do aço

'́s deformação normal da armadura longitudinal comprimida

$\mathrm{M}_{\text {vig }} \quad$ momento fletor na viga

$\mathrm{M}_{\text {sup }} \quad$ momento fletor no tramo superior do pilar

$M_{\text {inf }} \quad$ momento fletor no tramo inferior do pilar

$V_{x} \quad$ ação do vento na direção $x$

$V_{y} \quad$ ação do vento na direção $y$

$D_{x} \quad$ ação decorrente do desaprumo na direção $x$

$D_{y} \quad$ ação decorrente do desaprumo na direção y 


\section{RESUMO}

FONTES, F.F. (2005). Análise estrutural de elementos lineares segundo a NBR 6118:2003. Dissertação (Mestrado) - Escola de Engenharia de São Carlos, Universidade de São Paulo, São Carlos, 2005.

"O objetivo da análise estrutural é determinar os efeitos das ações em uma estrutura, com a finalidade de efetuar verificações de estados limites últimos e de serviço" (NBR 6118:2003 Projeto de estruturas de concreto). A análise estrutural consiste numa das principais etapas do projeto estrutural de um edifício, pois compreende a escolha dos modelos teóricos, que devem representar adequadamente a estrutura real, e do tipo de análise, com relação ao comportamento dos materiais. Visa-se, com este trabalho, aproximar o meio técnico do acadêmico, e tornar mais acessível a parte da NBR 6118:2003 que trata da análise estrutural. Neste trabalho consideram-se os modelos estruturais mais utilizados, no cálculo de edifícios, e os principais conceitos relativos aos diferentes tipos de análise permitidos pela Norma. Em seguida são realizados exemplos de elementos lineares, pelos diferentes tipos de análise, com ênfase na redistribuição de esforços, empregando-se análise linear com redistribuição ou análise plástica. Ressalta-se a importância da consideração de seção T nas vigas e os ajustes necessários quando da consideração de uma envoltória de carregamentos. Tem-se ainda um exemplo de um edifício de oito pavimentos, que visa demonstrar as diferenças nos esforços ou nos deslocamentos obtidos com modelos estruturais distintos.

Palavras-chave: concreto armado; análise estrutural; modelos estruturais; redistribuição; análise plástica. 


\section{ABSTRACT}

FONTES, F.F. (2005). Structural analysis of linear elements according to NBR 6118:2003. M.Sc. Dissertation - Escola de Engenharia de São Carlos, Universidade de São Paulo, São Carlos, 2005.

"The structural analysis objective is to determine the actions effects in a structure, with the purpose of verifying the ultimate limit states and serviceability" (Brazilian Code NBR 6118:2003 - Design of concrete structures). The structural analysis is one of the main parts of a building structural design, since it involves the choice of theoretical models that represent appropriately the real structure, and the type of analysis due to the materials behavior. This work intends to shorten the distance between design engineers and the academic world, providing a clearer vision of the NBR 6118:2003 structural analysis approach. This work considers the most common structural models used for buildings, and the theory concerning the different types of analysis permitted by the Brazilian Code. It presents simple examples of linear elements computed by different types of analysis, emphasizing the moment redistribution possibility, either with the linear analysis with redistribution or the plastic analysis. The importance of considering T-beam with moment redistribution is made clear, and lines of direction to consider alternate position of live loads are given. The last example presents an eight store building, and its differences relative to efforts and displacements, obtained by distinct structural models.

Keywords: reinforced concrete; structural analysis; structural models; moment redistribution; plastic analysis. 


\section{INTRODUÇÃO}

\subsection{Considerações iniciais}

Os edifícios são atualmente um dos mais importantes tipos de construção em concreto armado, visto que é cada vez maior a concentração de pessoas nos centros urbanos. A estrutura de um edifício é a parte responsável por resistir às ações impostas e transmiti-las para o solo, através das fundações. A primeira etapa de um projeto estrutural é, portanto, definir as partes da construção que farão parte da estrutura. Em um edifício de concreto armado, costuma-se considerar, quanto à superestrutura, somente o esqueleto, composto por vigas e pilares. As lajes têm a função de transmitir as forças verticais para as vigas e de distribuir as ações horizontais entre os pórticos. Despreza-se, portanto, a parcela resistente de paredes de alvenaria, divisórias e demais elementos da construção. Define-se nessa etapa, portanto, o sistema estrutural adotado, cujo representante tradicional é composto por pilares, vigas e lajes maciças. Como alternativas têm-se lajes nervuradas, lajes sem vigas, apoiadas diretamente nos pilares, lajes suspensas por tirantes, entre outros sistemas. O uso de cada um desses sistemas depende da disponibilidade de materiais, do conhecimento das técnicas de construção, do destino que se dará à obra e dos aspectos econômicos.

A análise da estrutura consiste em determinar os seus esforços solicitantes e deslocamentos, por meio de modelos matemáticos, após a idealização de diversos fatores, como o comportamento das ações, do material constituinte, das ligações entre os diversos elementos em que a estrutura pode ser dividida, e da resposta desses elementos frente às ações. Segundo a NBR 6118:2003, o objetivo da análise estrutural é determinar os efeitos das ações em uma estrutura, com a finalidade de efetuar verificações de estados limites últimos e de serviço (ELU e ELS).

Obviamente, para as condições usuais, não é fácil reproduzir a realidade do comportamento das estruturas, de seus esforços e dos deslocamentos, seja nos cálculos analíticos ou nos ensaios com modelos físicos. Dessa forma, o engenheiro se vê obrigado a admitir hipóteses que tornam as expressões de cálculo menos complexas e mais fáceis de serem resolvidas. FUSCO (1976) chega a afirmar que, de modo geral, o projeto estrutural é impraticável sem a aplicação de simplificações. Obviamente, muitas das simplificações utilizadas nas décadas passadas não são mais necessárias hoje em dia, com o avanço dos programas de análise 
estrutural. Há algum tempo, era essencial a subdivisão da estrutura em elementos estruturais simples, cujas hipóteses de cálculo não apresentavam maiores problemas para serem resolvidas manualmente. A tendência atual e futura é cada vez mais analisar a estrutura de forma global, considerando a interação dos diversos elementos, até mesmo com o solo.

A NBR 6118:2003, ainda chamada por muitos de NB-1, trouxe inovações significativas para o projeto de estruturas de concreto, inclusive na análise estrutural. A norma anteriormente em vigor, a NBR 6118:1980, tratava desse assunto de maneira tímida, sob o título de esforços solicitantes. Houve um rápido avanço do conhecimento em redistribuição de esforços, seja via análise linear com redistribuição ou via análise plástica, e em não-linearidades do comportamento dos materiais e das estruturas, como no caso do cálculo dos deslocamentos, em que se utiliza uma rigidez equivalente no cálculo das flechas, para considerar a fissuração do concreto. A NBR 6118:2003 traz indicações acerca dessas análises mais requintadas, bem como fornece diretrizes sobre o campo de validade e as condições especiais para aplicação de cada uma delas.

\subsection{Objetivos}

O principal objetivo deste trabalho consiste em detalhar alguns aspectos do capítulo 14 da NBR 6118:2003, sobre análise estrutural. Isto se faz necessário pelo fato do texto da Norma ser conciso e objetivo, o que torna útil exemplificar suas prescrições.

Apresentam-se os diferentes tipos de análise, com relação ao comportamento admitido para os materiais da estrutura. São considerados os elementos lineares e exemplos que se concentram nos tipos de análise que permitem o cálculo analítico, situação que corresponde à mais usual na prática de projetos. Os exemplos permitem maior familiarização dos projetistas com os tipos mais simples de análise estrutural.

Outro aspecto importante diz respeito à modelagem para a análise da estrutura. É também objetivo deste trabalho explicar as aproximações permitidas pela Norma para estruturas usuais de edifícios, e alertar para as suas vantagens e limitações. Pretende-se mostrar que tipos de erros são cometidos ao se considerar isolados os elementos de uma estrutura, partindo desde modelos mais simples, como o de vigas contínuas, até um modelo de pórtico espacial. Verificar-se-á a importância de conceitos como o de trecho rígido e de laje como diafragma rígido, na modelagem de pórticos, e como o da largura colaborante das lajes junto às vigas, quando associado com análises do tipo linear, linear com redistribuição e plástica. Quando necessário, os exemplos serão realizados com o auxílio de programa para projeto estrutural de edifícios. 


\subsection{Justificativa}

Um dos principais motivos para a realização deste trabalho é o da desmistificação da complexidade geralmente atribuída à Norma, por parte de alguns engenheiros, e tornar acessível os tipos de análise permitidos na NBR 6118:2003. Dessa maneira, tem-se um melhor conhecimento do comportamento das estruturas por parte dos projetistas, o que permite tomar providências que garantam a durabilidade das peças, assunto tão em destaque hoje em dia. Segundo GIONGO (2002), a estrutura de um edifício é responsável por cerca de 20 a $25 \%$ do custo total de uma obra. Assim sendo, são válidos todos os esforços, no sentido de aperfeiçoar as técnicas de análise estrutural, pois a economia gerada não será em vão. Não se pode esquecer ainda de um fator primordial que é a segurança, que exige o domínio dos tipos de análise estrutural e dos modelos matemáticos, para a concepção de projetos.

Com o crescente mercado de programas computacionais para projetos, os conceitos relacionados à análise estrutural assumem maior importância. Os principais programas ainda utilizam a análise linear para obtenção dos esforços, porém aplicada a uma maior parte do conjunto da estrutura, por meio de pórticos espaciais e de placas representadas por grelhas. $\mathrm{O}$ modelo matemático geralmente utilizado nesses casos envolve análise matricial com processo dos deslocamentos ou das forças. Alguns programas discretizam tanto as barras como as placas em elementos, e realizam o cálculo via métodos numéricos. Análises não-lineares já se encontram presentes em vários programas também, porém geralmente aplicadas ao cálculo de deslocamentos e de efeitos de segunda ordem (P- $\Delta$ ). É bem menor o tempo gasto nos projetos desenvolvidos com os programas, mas um erro pode facilmente passar desapercebido, sendo essencial conhecer bem os processos de análise utilizados pelos programas, para que se possa ter a capacidade de analisar criticamente os resultados obtidos.

\subsection{Apresentação dos capítulos}

O segundo capítulo traz uma breve descrição dos tipos de elementos estruturais encontrados em edifícios. Em seguida ele trata dos modelos estruturais mais utilizados na determinação dos esforços, e ressalta a importância dos conceitos de trecho rígido, largura colaborante e diafragma rígido, que permitem o aperfeiçoamento da modelagem da estrutura.

O terceiro capítulo aborda os tipos de análise estrutural, de acordo com o comportamento admitido para o material, permitidos pela NBR 6118:2003. A análise através de modelos físicos é brevemente comentada e maior ênfase é dada às demais análises. 
Os capítulos quatro, cinco e seis trazem o exemplo de uma viga de dois tramos, na qual analisa-se a redistribuição de esforços. O quarto capítulo considera a viga com seção retangular e análise linear, análise linear com redistribuição e análise plástica, verificando a capacidade de rotação da seção central, com a utilização de armadura simples. O quinto capítulo mostra as vantagens de se associar seção $T$ (largura colaborante da laje) à análise linear com redistribuição e à análise plástica, e como conseguir a redistribuição desejada, por meio da imposição de valores da posição relativa da linha neutra na seção central, com a utilização de armadura dupla. O sexto apresenta a mesma viga, agora apoiada em pilares nas suas extremidades, que também têm seus esforços modificados. Considera-se a envoltória de carregamentos devida à alternância da ação variável, e realiza-se uma análise linear com seção retangular e uma análise linear com redistribuição, utilizando a seção T.

O capítulo sete apresenta a análise de um edifício de oito pavimentos, por meio de diferentes modelos estruturais. Optou-se por apresentar separadamente modelos para ações verticais e modelos para ações horizontais, os quais são explicados e, em seguida, têm seus principais resultados expostos, como forças normais nos pilares junto à fundação, momentos fletores nas vigas e deslocamentos horizontais no topo da estrutura. Por último, comenta-se a importância da análise simultânea de ações verticais e horizontais.

O capítulo oito traz as considerações finais, com conclusões acerca dos exemplos realizados e sugestões para pesquisas que possam dar continuidade ao trabalho.

\subsection{Breve histórico}

Segundo TIMOSHENKO (1953), já na Antigüidade o homem se deparava com a necessidade de estabelecer regras para a determinação de dimensões seguras e econômicas, dos elementos constituintes das estruturas. Os egípcios, hábeis construtores, dispunham de regras empíricas. Os gregos desenvolveram a Estática e, mais de 200 anos antes de Cristo, Arquimedes provou as condições de equilíbrio de uma alavanca, bem como propôs meios para determinar o centro de gravidade dos corpos. Os romanos ergueram imponentes construções, e sabiam tirar proveito da forma dos arcos, porém, pelos pequenos vãos vencidos, vê-se que eles ainda não dominavam a análise de tensões.

Após um longo período de baixa produção científica, surge o período da Renascença e, em pleno século XV, Leonardo da Vinci talvez tenha sido o primeiro a encontrar, com a Estática, as forças atuantes nos elementos estruturais, e a realizar experimentos com o intuito de determinar a resistência de certos materiais. No entanto suas descobertas não foram aplicadas 
de imediato e, somente no século XVII, nasce a análise estrutural, com o famoso livro de Galileo Galilei, “Discorsi e dimonstrazioni matematicke: intorno à due nuoue scienze”, de 1638.

Galileo realizou ensaios com vigas de pedra e de madeira, e um deles tornou-se um clássico, conhecido como o Problema de Galileo. Este consistia em uma viga engastada em uma parede, sendo a viga submetida ao peso próprio, isoladamente ou em conjunto com uma força aplicada junto à sua extremidade livre (ver Figura 1.1). Desejava-se encontrar a força necessária à ruptura de uma seção perpendicular ao eixo da viga. Galileo identificou a seção de ruptura $A B$, cujo momento fletor é o maior, e apontou a ligação existente entre a altura da seção e sua resistência, um conceito de inércia à flexão, que ele chamou de resistência absoluta.

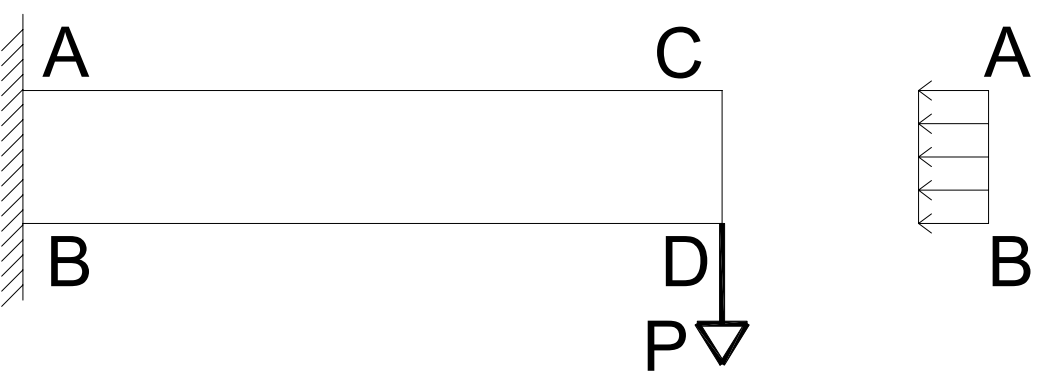

Figura 1.1 - Problema de Galileo e sua consideração de tração uniformemente distribuída na seção

No entanto, Galileo superestimava a capacidade resistente dessa viga ao imaginar que a seção transversal fosse uniformemente tracionada, ignorando a compressão de fibras longitudinais provenientes da flexão.

Em 1678, Robert Hooke, um inventivo e hábil ensaísta, lança seu trabalho "De Potentiâ Restitutiva", cujo conteúdo exibe resultados de seus experimentos com molas e com materiais diversos. A relação linear descoberta com esses ensaios, entre força e deformação, ficou conhecida como Lei de Hooke.

Mariotte, em 1680, por meio de experimentos com vigas de madeira e de vidro, chega à conclusão de que algumas fibras são tracionadas, antes da ruptura, enquanto outras são comprimidas, e aponta o erro de Galileo. Sem justificativa aparente, ele afirma que, em uma seção transversal, metade das fibras está comprimida e metade, tracionada, ou seja, que a linha neutra passa no meio da seção. Essa afirmação só é verdade no caso de simetria da seção e para níveis de solicitação em que ainda não houve algum tipo de deformação permanente. 
O século XVIII foi marcado pelo surgimento das primeiras escolas de Engenharia e pela publicação dos primeiros livros de Engenharia Estrutural. Esse período destacou-se ainda pelas novas descobertas no campo da Matemática, que viriam a ser decisivas na análise de estruturas. Euler começa seus estudos referentes às superfícies elásticas, e Jacques Bernoulli os adapta a uma equação diferencial que descrevia aproximadamente o comportamento das placas. A equação diferencial de placas elásticas, como a conhecemos hoje, só foi estabelecida em 1823, após passar por vários contribuintes, entre os quais destacam-se: Sophie Germain, Lagrange, Poisson e, finalmente, Navier.

De acordo com TODHUNTER \& PEARSON (1960), Navier pode ser considerado o pai da teoria moderna dos sólidos elásticos, visto que, em 1821, foi o primeiro a fornecer as equações gerais de equilíbrio e de movimento, que governam todos os pontos do interior e da superfície de um corpo. Em 1826, Navier lança um livro de Resistência dos Materiais, e nele destaca a importância de se conhecer o limite para o qual as estruturas se comportam de forma perfeitamente elástica, sem sofrer deformações permanentes.

Cauchy, contemporâneo de Navier, deu origem ao conceito de tensão e organizou sua teoria, ao estabelecer que a tensão em qualquer superfície infinitesimal, no interior de um corpo sólido ou de um fluido sem movimento, é a resultante das tensões das três projeções dessa superfície, em planos que passam por seu centro e que são perpendiculares entre si.

Saint-Venant, também no século XIX, impulsionou o desenvolvimento da Teoria da Elasticidade e, mais especificamente, dos estudos de torção. Além disso, foi o primeiro a estabelecer as equações fundamentais da plasticidade e a usá-las em diversos problemas práticos. TODHUNTER \& PEARSON (1960) escreveram acerca de Saint-Venant: "...fazer com que a Teoria da Elasticidade tenha um valor prático tem sido o trabalho da vida de Saint-Venant."

LEONHARDT \& MÖNNIG (1977) afirmam que, em 1855, o francês J.L. Lambot patenteou um barco com argamassa de cimento reforçada com tela de arame, dando origem ao concreto armado. Esse material viria, a partir de então, usufruir o desenvolvimento da análise estrutural, no seu dimensionamento.

TIMOSHENKO (1953) conta que, ainda no século XIX, Lord Rayleigh, grande estudioso de vibrações, juntamente com Walter Ritz, elaborou um método de calcular freqüências, diretamente da consideração de energia, sem resolver equações diferenciais. O método de solução aproximada de Rayleigh-Ritz passou a ser usado posteriormente, não só no estudo de vibrações, mas também em problemas de elasticidade, teoria das estruturas, entre outros. Os métodos numéricos começam a ganhar espaço na análise das estruturas. 
De acordo com LEONHARDT \& MÖNNIG (1977), em 1902, Emil Mörsch apresenta uma teoria para dimensionamento de peças de concreto armado. A teoria das estruturas, até então desenvolvida principalmente para a análise de treliças, vê-se obrigada a evoluir, na primeira metade do século $X X$, dado o rápido avanço do concreto armado na Engenharia Estrutural, e conseqüente aparecimento de estruturas aporticadas com alto grau de hiperestaticidade, cujos elementos trabalham predominantemente à flexão. Em 1932, Hardy Cross elabora o processo de Cross, largamente utilizado na resolução de vigas contínuas. O próximo passo seria a utilização de análises matriciais, responsáveis, principalmente após o aparecimento dos computadores, por considerável economia de tempo, no cálculo de estruturas. O método dos elementos finitos teve sua formulação estabelecida em 1956, mas seu uso só foi sentido, de forma mais incisiva, também com a rápida expansão da Informática.

Atualmente, há no mercado diversos programas de análise estrutural, segundo os mais variados métodos. No Brasil, onde o concreto armado predomina como material estrutural, surgem programas cada vez mais aperfeiçoados de análise e de dimensionamento de estruturas de edifícios. Recentemente, nosso país passa por um período de adaptação a uma nova norma técnica, referente ao projeto de estruturas de concreto, a NBR 6118:2003. 


\section{CONCEITOS BÁSICOS}

Serão apresentados, neste capítulo, conceitos considerados importantes, acerca de elementos e de modelos estruturais, de trechos rígidos, da largura colaborante de vigas de seção T e do comportamento das lajes como diafragmas rígidos.

\subsection{Elementos estruturais}

A decomposição da estrutura em partes, que possam ser associadas a uma teoria de cálculo já consolidada no meio técnico, dá origem aos elementos estruturais. A classificação dos elementos estruturais envolve a geometria e uma subclassificação, atrelada ao tipo de esforço predominante, como comentado a seguir.

A principal característica dos elementos lineares, ou barras, é possuir uma de suas dimensões bem maior que as restantes. Essa condição pode ser considerada satisfeita, por exemplo, quando o comprimento longitudinal é igual ou maior que o triplo da maior dimensão da seção transversal do elemento. O elemento linear pode ser representado por seu eixo longitudinal, e normalmente tem seu comprimento limitado pelo centro de seus apoios ou por interseção com o eixo longitudinal de um outro elemento. Destacam-se entre eles as vigas, os pilares, os arcos e os tirantes.

Nos elementos de superfície tem-se a situação inversa à dos elementos lineares, pois uma das dimensões (espessura) é bem menor que as demais. A representação de um elemento de superfície se dá pela sua superfície média. Os elementos de superfície subdividem-se em placas, chapas, cascas e pilares-parede.

Os elementos de volume não possuem nenhuma das dimensões desproporcional em relação às demais, e geralmente são chamados de blocos. Na verdade, se generalizada essa classificação, todos os elementos podem ser ditos elementos de volume, porém isso implica na utilização de modelos de cálculo mais complexos. Entre os mais comuns destacam-se os blocos de coroamento de tubulões, os blocos sobre estacas e as sapatas. 


\subsection{Modelos estruturais}

Com o fim de determinação de esforços, os modelos estruturais consideram composições de um ou mais tipos de elementos. Esses modelos, também denominados esquemas estruturais, devem contemplar os diferentes esforços que solicitam a estrutura, e têm seu uso determinado também pela disponibilidade de tempo, conhecimento e ferramentas computacionais por parte do projetista, ou por limitações de custo do projeto.

Um mesmo elemento pode fazer parte de mais de um esquema estrutural e, portanto, deve ser dimensionado para esforços produzidos por todos esses esquemas. FUSCO (1976) chama de esquema estrutural primário o primeiro comportamento associado a um elemento estrutural, e que provoca os maiores esforços. Porém, podem aparecer esforços não determinados pelo esquema estrutural primário, e devem ser idealizados tantos esquemas estruturais quantos forem necessários para que os esforços relevantes sejam conhecidos, para o dimensionamento das peças. Para uma viga contínua de um pavimento de edifício, indicada na Figura 2.1, são mostrados exemplos de esquemas estruturais da Figura 2.2 à Figura 2.4 .

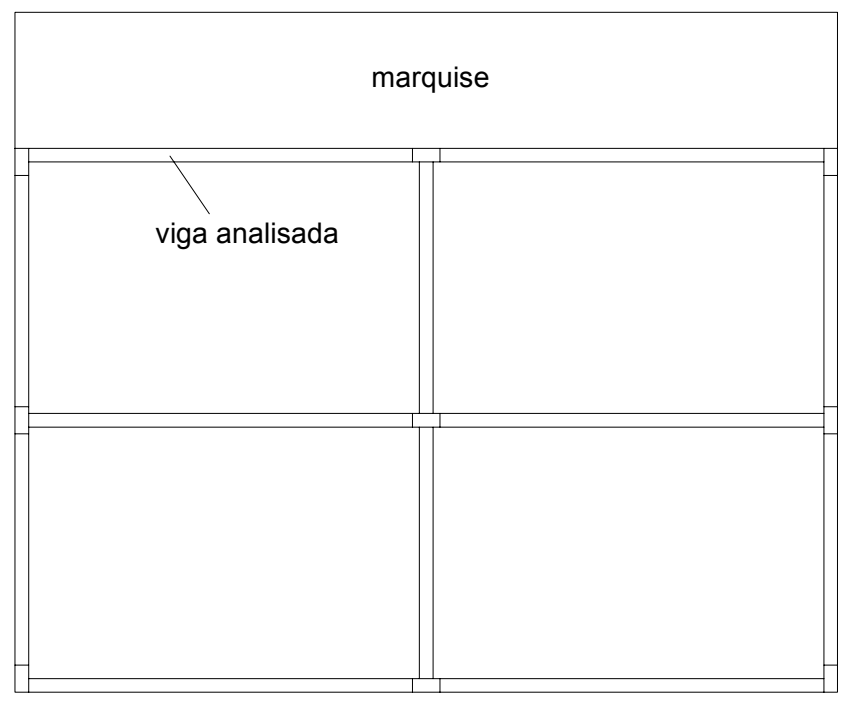

Figura 2.1 - Viga exemplo para esquemas estruturais

O esquema estrutural primário (Figura 2.2) trata, neste caso das ações verticais; o secundário (Figura 2.3), das ações horizontais, pois a viga faz parte de um pórtico que resiste a esses esforços; e o terciário (Figura 2.4) trata dos esforços de torção, devidos à excentricidade das cargas da marquise, e considera os dois tramos biengastados. 


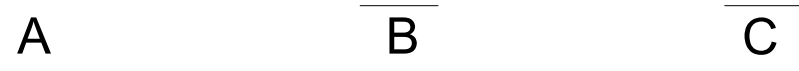

Figura 2.2 - Esquema estrutural primário (adaptada de FUSCO, 1976)

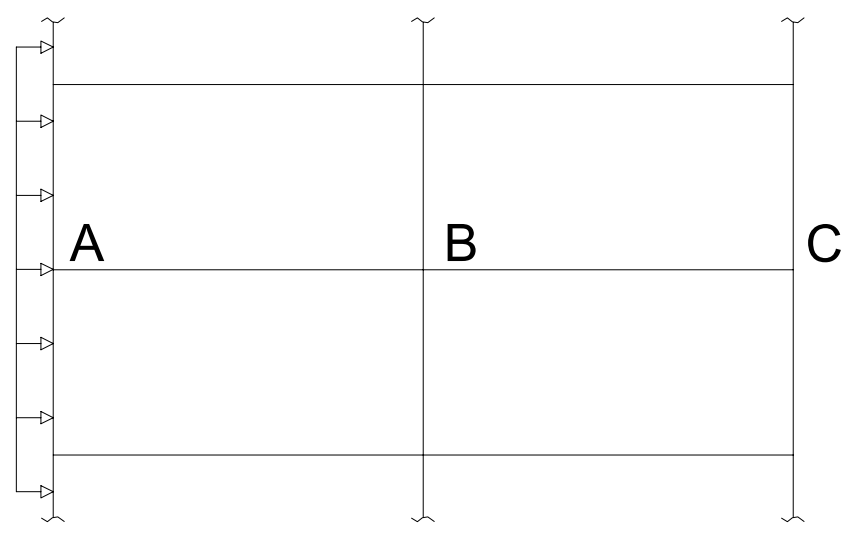

Figura 2.3 - Esquema estrutural secundário (adaptada de FUSCO, 1976)

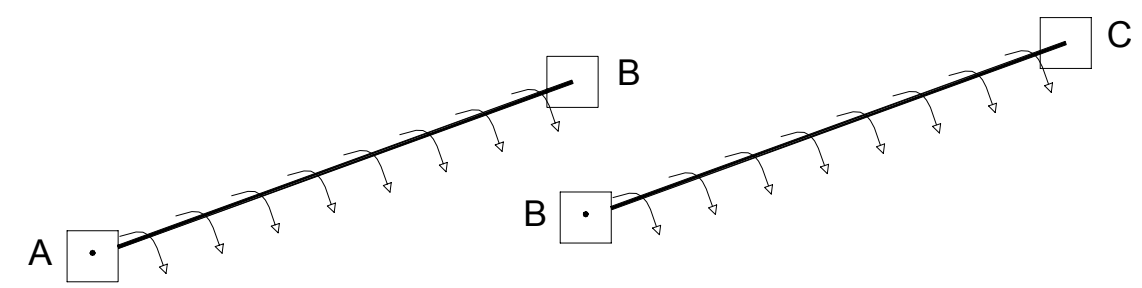

Figura 2.4 - Esquema estrutural terciário (adaptada de FUSCO, 1976)

A seguir são descritos os principais modelos estruturais compostos por elementos lineares identificados nos edifícios.

\subsubsection{Vigas Contínuas}

Entre os modelos estruturais originados de divisões da estrutura em partes, um dos mais corriqueiros é o de viga contínua, para a análise de estruturas solicitadas por ações verticais. $O$ modelo é simples e consiste em vigas isoladas que recebem os carregamentos provenientes de peso próprio, lajes, alvenarias, outras vigas, entre outros. As vigas são representadas por barras com pontos de apoios, e forças aplicadas no plano que contém o seu eixo de simetria. Os esforços predominantes são os momentos fletores e os esforços cortantes. A torção só precisa ser considerada nos casos em que é essencial ao equilíbrio da viga, e necessita de um outro modelo, já que a viga contínua situa-se em um plano que contém o seu eixo longitudinal e a torção atua num plano perpendicular a ele. Os esforços normais que porventura surjam são 
geralmente desprezados, porém podem ser importantes se considerados os efeitos de retração, de fluência e de variação de temperatura.

Os apoios das vigas contínuas são geralmente constituídos de pilares ou de outras vigas, e podem ser considerados como apoios simples, engastes, ou como apoios semi-rígidos, dependendo da rigidez e da precisão que se quer implementar ao modelo. O modelo clássico de viga contínua considera a viga simplesmente apoiada nos pilares, ou seja, como se não houvesse solidariedade ou transmissão de momentos entre esses elementos. No entanto, isso não é verdade, e só deve ser usado para certos apoios. Por exemplo, quanto mais os vãos e os carregamentos de uma viga contínua são parecidos e, portanto, maior a uniformidade na distribuição de esforços, mais os pilares internos aproximam-se da condição de apoios simples.

A NBR 6118:2003 permite o uso desse modelo clássico, desde que acompanhado das seguintes correções:

a) não devem ser considerados momentos positivos menores que os que se obteriam se houvesse engastamento perfeito da viga nos apoios internos;

b) quando a viga for solidária com o pilar intermediário, e a largura do apoio, medida na direção do eixo da viga, for maior que a quarta parte da altura do pilar, não pode ser considerado momento negativo de valor absoluto menor do que o de engastamento perfeito nesse apoio;

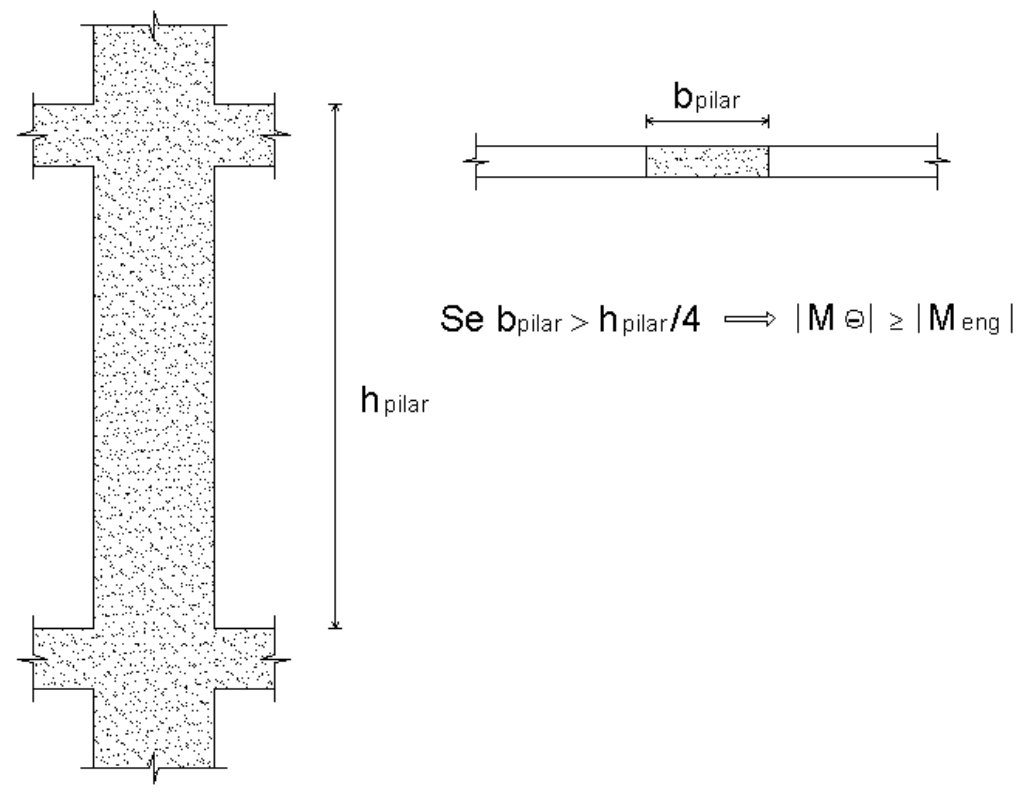

Figura 2.5 - Condição para o engastamento de apoios intermediários

c) quando não for realizado o cálculo exato da influência da solidariedade dos pilares com a viga, deve ser considerado, nos apoios de extremidade, momento fletor igual ao de 
engastamento perfeito (tramo biengastado), multiplicado pelos coeficientes dados na Tabela 2.1. Ressalta-se que esses coeficientes já se encontram adaptados para o esquema indicado na Figura 2.6, admitindo-se o tramo de extremidade da viga biengastado e os tramos do pilar engastados no nó e simplesmente apoiados nas outras extremidades.

Tabela 2.1 - Coeficientes para consideração da solidariedade entre as vigas e os pilares externos

\begin{tabular}{|c|c|c|c|}
\hline Local & Viga & Tramo superior do pilar & Tramo inferior do pilar \\
\hline Coeficiente & $\frac{3 r_{\text {inf }}+3 r_{\text {sup }}}{4 r_{v i g}+3 r_{\text {inf }}+3 r_{\text {sup }}}$ & $\frac{3 r_{\text {sup }}}{4 r_{v i g}+3 r_{\text {inf }}+3 r_{\text {sup }}}$ & $\frac{3 r_{\text {inf }}}{4 r_{v i g}+3 r_{\text {inf }}+3 r_{\text {sup }}}$ \\
\hline
\end{tabular}

$r_{i}$ é a rigidez do elemento i no nó considerado, dada por $r_{i}=I_{i} / \ell_{i}$ (momento de inércia dividido pelo vão).

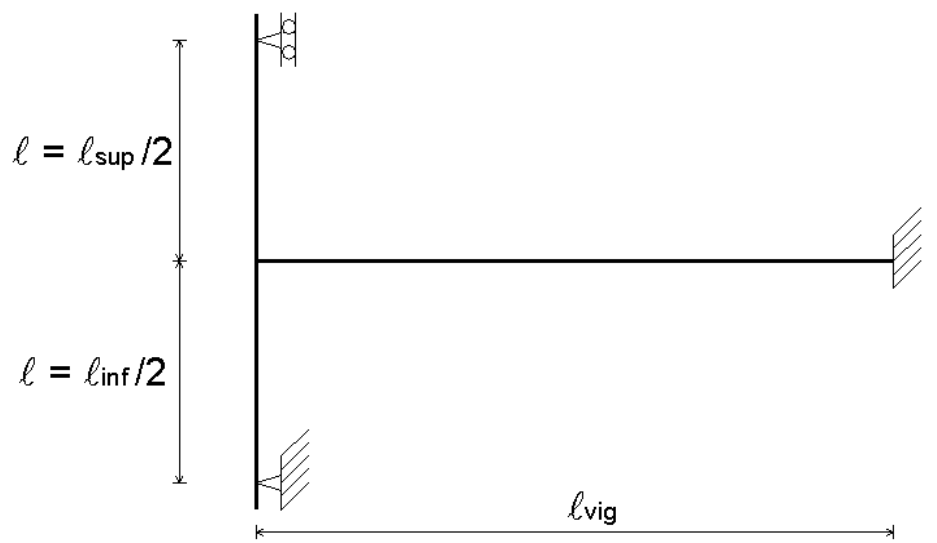

Figura 2.6 - Esquema estrutural para obtenção dos coeficientes (adaptado da NBR 6118:2003)

Feitas todas essas considerações, pode-se ou realizar uma compatibilização de momentos (com a correção dos momentos positivos), ou simplesmente sobrepor os diagramas com a consideração dos momentos mais desfavoráveis para o dimensionamento.

Com o rápido desenvolvimento de programas de cálculo estrutural, o modelo de vigas contínuas vem se tornando pouco utilizado. Seu desuso está relacionado também com o seu alto grau de simplificação. No entanto, para edifícios usuais de poucos pavimentos, esse modelo continua sendo apropriado, com aproximações satisfatórias se comparado com modelos mais requintados de cálculo, além de possibilitar cálculos manuais. Entre os diversos processos para cálculo de vigas contínuas, destacam-se a equação dos três momentos, o processo de Cross e o processo dos deslocamentos. 


\subsubsection{Pórticos Planos}

Os pórticos planos são composições de elementos lineares situados num mesmo plano. Nos edifícios, eles formam painéis compostos por vigas, pilares e possíveis tirantes. Os nós, pontos de interseção dos elementos, têm ligações rígidas, semi-rígidas ou flexíveis. No plano definido pelo pórtico, atuam as forças e ocorrem as translações, já os vetores de momento são normais a esse plano.

O modelo de pórticos planos considera, de maneira mais precisa que o de vigas contínuas, a resposta da estrutura frente às ações verticais, pois leva em conta a transmissão de esforços entre os elementos que constituem o pórtico. Os esforços internos analisados por esse modelo são os momentos fletores, os esforços cortantes e os esforços normais.

Há um especial interesse no uso de pórticos planos na análise de ações horizontais (análise de estabilidade global), dada a possibilidade de associação dos diferentes pórticos de uma mesma direção, por meio de barras articuladas nas extremidades, barras essas que simulam o efeito das lajes. Esse artifício visa considerar a laje como um diafragma rígido (ver item 2.5), ou seja, que os pontos situados no mesmo pavimento transladam de forma conjunta. Por isso, as deformações axiais dessas barras devem ser impedidas, por exemplo, aumentando-se a área de suas seções transversais. Bons resultados são obtidos considerando as lajes como barras de comprimento menor ou igual a um metro, e seção transversal de um metro de largura e altura igual à verdadeira espessura da laje. As ações horizontais são aplicadas em uma das extremidades da associação de pórticos.

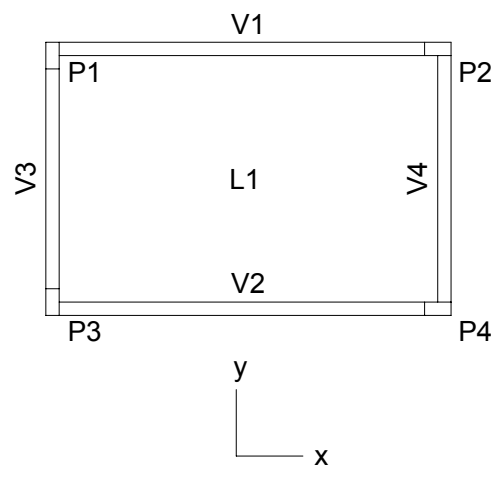

Pórtico $01=\mathrm{P} 1+\mathrm{V} 1+\mathrm{P} 2$

Pórtico 02 = P3+V2+P4

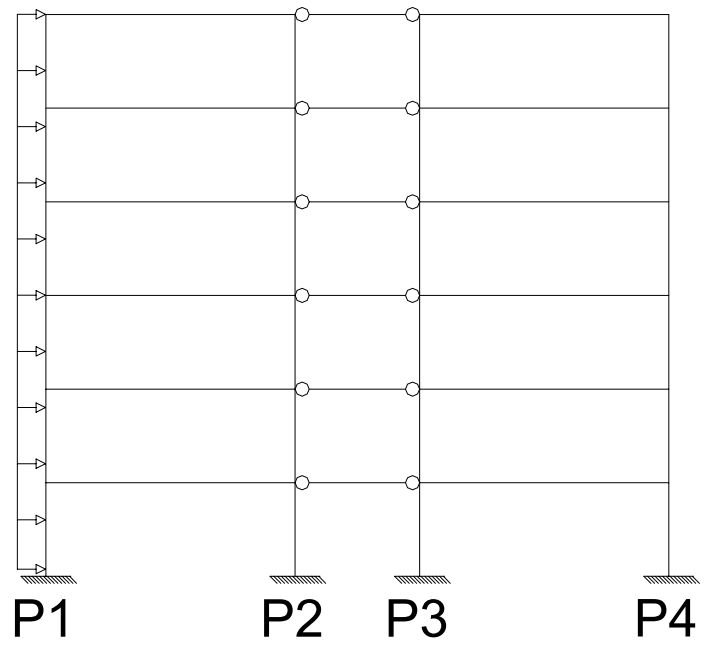

P4

Figura 2.7 - Associação de pórticos planos para análise de ações horizontais (análise da direção x) 
O modelo de pórticos planos tem como limitação, a incapacidade de avaliar os efeitos de torção. A mencionada associação de pórticos fica restrita a edifícios simétricos, quanto à geometria e aos carregamentos.

Uma forma de agilizar o cálculo por pórticos planos é tratar o edifício como que formado por pavimentos isolados (Figura 2.8). Partindo-se da cobertura, pequenos pórticos são calculados separadamente, obtendo-se os esforços nas vigas e as reações nos pilares a serem transmitidas para o pavimento inferior. Os pilares inferiores são considerados engastados, e os superiores com a extremidade livre, onde se aplicam as reações do pavimento de cima. Esse tipo de processamento é mais rápido, porém deve ser usado com cuidado, pois pode trazer grandes diferenças em relação ao modelo de pórtico plano completo.

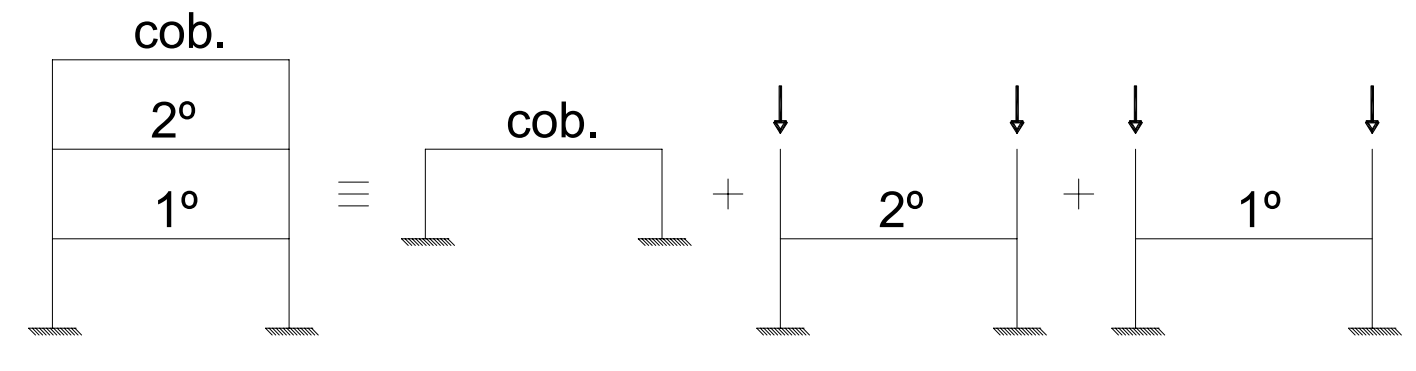

Figura 2.8 - Pavimentos isolados

Como vantagem da utilização de pórticos planos na análise estrutural de edifícios, BRANCO (2002) cita uma boa simplificação na implementação computacional, bem como na análise dos resultados, sem grandes perdas na modelagem da estrutura em relação ao seu comportamento real. Como já foi comentado, isto vale para edifícios pouco susceptíveis a efeitos de torção.

\subsubsection{Pórticos espaciais}

Os pórticos espaciais, assim como os pórticos planos, são formados por elementos lineares com ligações rígidas, semi-rígidas ou flexíveis. Uma melhor modelagem é alcançada com a inserção de trechos rígidos nas ligações entre as barras (ver item 2.3). A NBR 6118:2003 indica que, devido à fissuração, a rigidez das vigas à torção pode ser reduzida, simplificadamente, para $15 \%$ da rigidez elástica, assim como nas grelhas.

O modelo tridimensional é o mais completo para análise estrutural, visto que é capaz de determinar momentos fletores e de torção, e esforços cortantes e normais, de todos os elementos. Seu uso é adequado para a análise de carregamentos verticais ou horizontais, inclusive com assimetria. A análise considera rotações devidas à torção, que podem interferir 
nos esforços finais. Além disso, é possível a aplicação de forças em qualquer direção do espaço tridimensional.

Obviamente o ganho em precisão requer maior complexidade no cálculo, pois cada elemento passa a ter seis graus de liberdade por nó, ou seja, translação paralela aos três eixos principais e rotação em torno desses mesmos três eixos. A solução do problema geralmente exige o uso de programas de análise matricial.

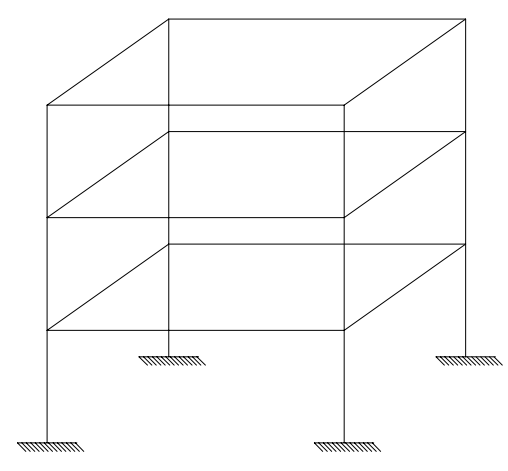

Figura 2.9 - Pórtico espacial

O diafragma rígido, formado pelas lajes, pode ser introduzido na modelagem de pórticos espaciais por meio de um artifício, conhecido como nó mestre. Este é um nó pertencente ao plano do pavimento, ao qual todos os demais nós têm seus graus de liberdade associados. Permite-se ao nó mestre, e conseqüentemente aos demais, apenas transladar no plano do pavimento e girar em torno de um eixo perpendicular a ele. As ações horizontais de uma determinada direção podem ser divididas em parcelas referentes a cada pavimento, que são aplicadas integralmente nos correspondentes nós mestres. Estes são posicionados no centro geométrico do pavimento, ou, simplificadamente, no centro geométrico do retângulo que circunscreve a planta do edifício, quando esta tiver uma forma mais complexa.

Atualmente, dentre os modelos estruturais existentes, o pórtico espacial é o que mais ganha espaço nos escritórios de projeto.

\subsubsection{Grelhas}

As grelhas são estruturas planas formadas por barras, e que recebem carregamento perpendicular ao seu plano. Em edifícios, as grelhas podem ser admitidas como formadas exclusivamente por vigas, ou associadas às lajes adjacentes. As ligações entre as vigas podem ser rígidas ou articuladas, admitindo apoio de uma viga em outra pouco rígida. 
A utilização de grelhas para o cálculo somente das vigas é pouco comum, a não ser em caso de lajes nervuradas, em que não são verificadas certas prescrições da NBR 6118:2003 quanto à geometria, no seu item 13.2.4.2, e que portanto exige a consideração da capa como uma laje maciça apoiada em grelha de vigas (nervuras).

As lajes podem ser satisfatoriamente modeladas como uma malha de barras, com rigidez à flexão e rigidez à torção referentes às das faixas de lajes por elas representadas. As vigas podem ser representadas por barras isoladas, com ou sem a consideração de largura colaborante por parte da laje. O problema passa a ser o de calcular a inércia à flexão e à torção de seções transversais retangulares, no caso de lajes maciças, e seções transversais do tipo T, para lajes nervuradas e vigas com largura colaborante (ver Figura 2.10).

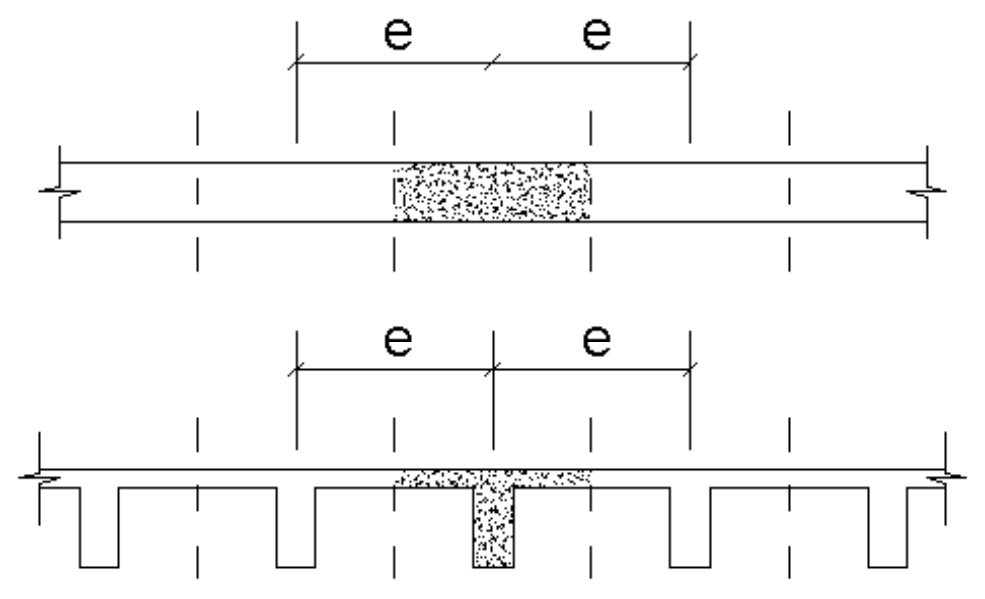

Figura 2.10 - Espaçamento entre as barras da grelha

Quanto menor o espaçamento e entre as barras da grelha, mais preciso o resultado dos esforços. No entanto, COELHO apud STRAMANDINOLI \& LORIGGIO (2004) alertam que o momento de inércia à torção, $\mathrm{J}$, diminui significativamente com o menor valor de e em lajes maciças. Por isso, costuma-se tomar o valor de $\mathrm{J}$ em função do momento de inércia à flexão, I, com $\mathrm{J}=2 \mathrm{l}$. Nas lajes nervuradas, o espaçamento entre as barras é igual à distância entre os eixos das nervuras, que funcionam como vigas de menor rigidez.

Com a fissuração, as peças fletidas de concreto armado sofrem sensível perda de rigidez à torção. Por isso, a NBR 6118:2003 permite, de maneira aproximada, a sua redução para 15\% da rigidez elástica. A rigidez à flexão dos pilares, que constituem os apoios da grelha, pode ser adotada de forma semelhante à prescrita para vigas contínuas, em ambas as direções da grelha. 
As cargas são distribuídas ao longo dos elementos ou concentradas nos nós, com parcelas dadas pelas áreas de influência referentes, respectivamente, às barras e aos seus pontos de interseção.

HAMBLY (1976) dá algumas diretrizes para a definição da malha de elementos lineares: devese ter o espaçamento entre as barras menor ou igual à quarta parte do vão, em caso de efeitos localizados (como cargas concentradas) um refinamento da malha é necessário na região em questão, em bordas livres as barras devem guardar uma distância de $0,3 \mathrm{~h}$ (30\% da espessura da laje) das mesmas e, para placas pouco esconsas, pode-se dispor as barras da grelha ortogonalmente.

\subsection{Trechos Rígidos}

Em estruturas reticuladas, ou seja, naquelas compostas por elementos lineares, é comum ter interseções dos eixos de dois ou mais elementos, representadas por nós. No entanto, há casos em que as dimensões das ligações entre os elementos não são desprezíveis, quando comparadas com vãos e pés-direitos. Costuma-se modelar esses nós de dimensões finitas como elementos infinitamente rígidos, ou elementos de rigidez significativamente maior que a dos demais, o que garante uma idealização mais realista do comportamento de edifícios. Esses trechos rígidos são também chamados de "offsets" e são determinados pelas dimensões dos elementos, relativas a cada direção, a partir do nó que representa a ligação.

Em edifícios de concreto armado, no caso de apoios de vigas em pilares, é mais comum considerar os trechos rígidos nas vigas que nos pilares, dada as dimensões usuais das peças. CORRÊA (1991) afirma que essa adoção está de acordo com a hipótese de manutenção da seção plana do pilar, e incorpora a consideração de excentricidades na aplicação de forças no pilar. No entanto, nem todo o trecho de interseção deve ser considerado como trecho rígido. A NBR 6118:2003 indica a parcela que deve ser tomada como trecho flexível (Figura 2.11).

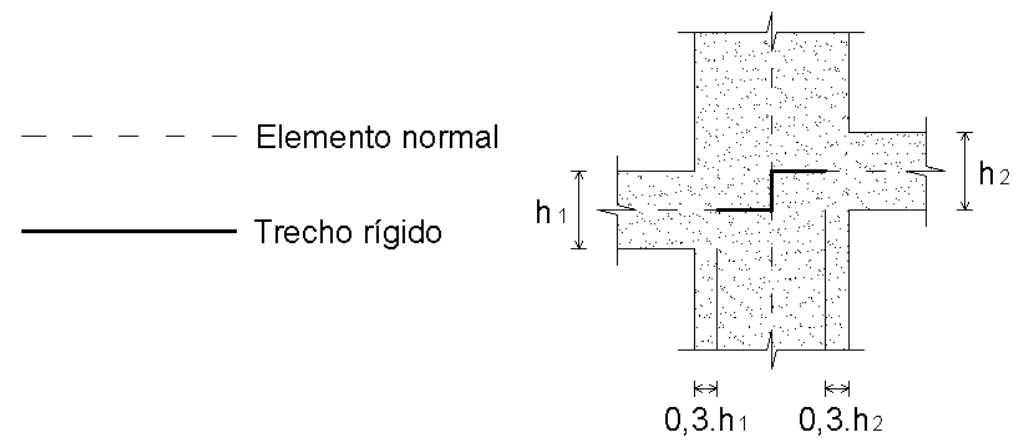

Figura 2.11 - Trechos rígidos (adaptada da NBR 6118:2003) 
A simulação de trechos rígidos de vigas pode ser feita por meio de elementos de grande rigidez, caso não se disponha de um programa com a opção de inserção de trechos rígidos. De acordo com CORRÊA (1991), essa inércia a ser adotada não pode ser exagerada, e um valor coerente já experimentado corresponde a implementar, nos trechos da viga tidos como rígidos, uma largura igual à do pilar e uma altura igual à do pé-direito.

O nó, onde serão aplicadas as condições de contorno, como restrições de movimento ou deslocamentos impostos, pode ser considerado no centro geométrico do pilar que serve de apoio às vigas. No caso da parcela 3/10 da altura da viga ser maior que a distância da face do pilar até o eixo de sua seção transversal, perpendicular à viga em questão, o trecho rígido resume-se a uma barra perpendicular a essa mesma viga (ver Figura 2.12).

Uma outra possível aplicação dos trechos rígidos é na mudança de eixos de pilares (Figura 2.13), com o nó definido na interseção do eixo da viga com o eixo do pilar inferior. A partir desse nó, o trecho rígido se estende até o eixo do pilar superior, e até o ponto distante $30 \%$ da altura da viga, em relação à face do pilar inferior. Além dessa possibilidade, utilizam-se trechos rígidos para a consideração da excentricidade de forma, cuja inobservância é comum em projetos. Essa excentricidade é decorrente de vigas com eixos desalinhados em relação aos eixos dos pilares que lhes servem de apoios, e costuma ter efeitos desprezíveis.

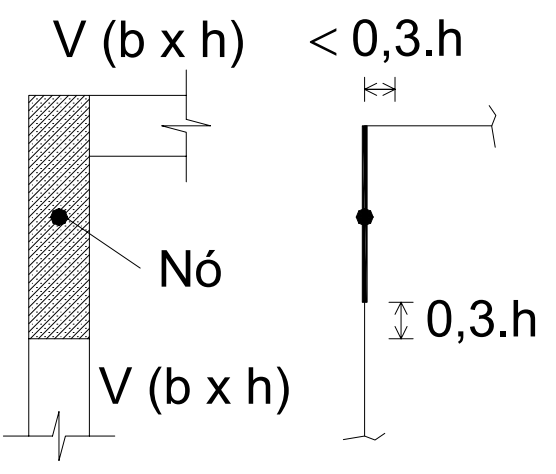

Figura 2.12 - Trecho rígido visto em planta

Figura 2.13 - Trecho rígido na mudança de eixo de pilares (adaptada de CORRÊA, 1991) 
A não consideração de trechos rígidos pode desviar o comportamento da estrutura de suas características reais, com diferentes distribuições de esforços e deslocamentos laterais maiores.

\subsection{Largura colaborante de vigas de seção T}

A seção transversal das vigas têm uma parcela comum às lajes e, dado o monolitismo da ligação entre ambos os elementos, os valores de deformações na interface são compatíveis. A distribuição de esforços internos, tensões, deformações e deslocamentos depende, portanto, da ação conjunta de vigas e lajes, que pode ser modelada por uma grelha de barras, de inércia equivalente a ambos os elementos estruturais. Uma outra forma de fazer essa consideração é adotar uma seção T para as vigas, composta por uma largura colaborante da laje.

A distribuição das tensões de compressão na laje, provenientes do cisalhamento na superfície de contato entre a laje e a viga, deve ser estudada considerando a laje como uma chapa, pela Teoria da Elasticidade. Simplificadamente, admite-se uma distribuição de tensões uniforme nessa interface e, para isso, limita-se a largura da laje que fará parte da viga $\mathrm{T}$.

A NBR 6118:2003 indica, para a largura colaborante $b_{f}$, o valor da largura da viga $b_{w}$ acrescido de no máximo $10 \%$ da distância a (ver Figura 2.14) entre pontos de momento fletor nulo do tramo, para cada lado da viga em que houver laje colaborante. É permitido estimar a distância a ao invés de verificá-la junto ao diagrama de momentos fletores, de acordo com os casos abaixo:

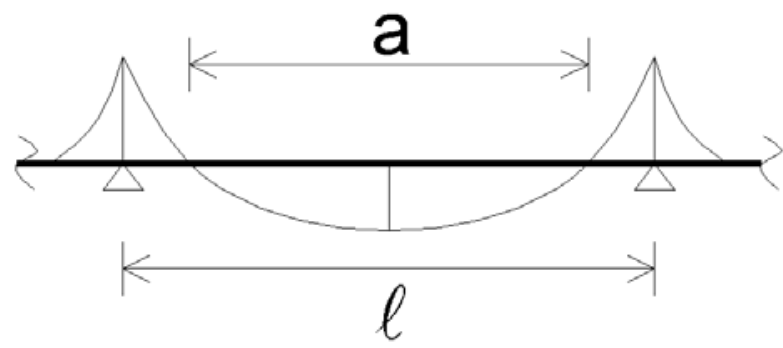

Figura 2.14 - Distância a para o tramo da viga de comprimento $\ell$

- viga simplesmente apoiada: $a=1,0 . \ell$

- tramo com momento em uma extremidade: $a=0,75 . \ell$

- tramo com momentos nas duas extremidades: $a=0,60 \cdot \ell$

- tramo em balanço: $a=2,0 . \ell$ 
LEONHARDT \& MÖNNIG (1977) destacam que, próximo a apoios extremos ou intermediários, e sob cargas concentradas, a largura $b_{f}$ é menor do que nos vãos. No entanto, a Norma Brasileira permite o cálculo de um único valor de $b_{f}$ para todas as seções de uma viga contínua, desde que esse cálculo seja realizado a partir do trecho de momentos positivos em que a largura resulte mínima.

Nas figuras 14.2 e 14.3 da NBR 6118:2003 constam recomendações quanto às limitações da largura colaborante, em relação à distância livre entre faces de vigas, e recomendações para a largura colaborante junto às aberturas nas lajes.

O dimensionamento de vigas, com a largura colaborante das lajes formando uma seção T, é interessante, pois há um acréscimo considerável de rigidez na viga e, com a maior área comprimida de concreto, em geral é dispensada a armadura de compressão. Com a redistribuição de momentos, essa vantagem é ainda maior, pois o vão recebe uma maior parcela dos esforços, e pode assim aproveitar melhor a maior área de concreto comprimido.

\subsection{Laje como diafragma rígido}

Sob a ação de forças horizontais (vento ou ações fictícias do desaprumo), as lajes, enrijecidas pelo vigamento, têm comportamento próximo ao de um diafragma rígido, ou seja, praticamente não se deformam axialmente. Tal fato se deve à grande rigidez da laje frente às ações horizontais, bastando, para melhor entender, imaginá-la como uma viga de grande altura, submetida à flexão. Como principal conseqüência, têm-se os nós de vigas e pilares, situados no mesmo plano da laje, deslocando-se horizontalmente (transladam) de forma idêntica. No entanto, dada uma assimetria do edifício, pode haver rotações diferenciadas dos nós.

A NBR 6118:2003 se manifesta sobre a questão dos diafragmas rígidos ao permitir a consideração da laje como uma chapa totalmente rígida em seu plano, desde que ela não apresente grandes aberturas, e que o maior lado do retângulo circunscrito ao pavimento em planta não supere em três vezes o valor de seu lado menor. Essa particularidade das lajes é imposta de diferentes maneiras na modelagem dos edifícios, dependendo do modelo estrutural adotado, e é de especial interesse para a avaliação da estabilidade global. 


\section{TIPOS DE ANÁLISE ESTRUTURAL}

Para que seja possível equacionar o problema de análise estrutural de um edifício, é necessário, anteriormente, idealizar o comportamento dos materiais que o constituirão. A NBR 6118:2003 permite cinco diferentes tipos de análise quanto a esse aspecto, e exige que o projeto apresente conformidade com pelo menos um deles. Em todos os tipos são admitidos pequenos deslocamentos para a estrutura.

O tipo de análise a ser utilizado, quanto ao comportamento do material adotado, depende principalmente do estado limite a ser verificado e da complexidade da estrutura em questão.

\subsection{Análise linear}

Esse tipo de análise considera os materiais elástico-lineares. A elasticidade de um material está associada à sua tendência de voltar à sua configuração inicial após ter sofrido deformações decorrentes de ações externas, com posterior alívio de carregamento (ver Figura 3.1-a). Se o corpo do material em questão consegue recuperar totalmente sua forma original, ele é dito perfeitamente elástico. Se apenas parte da deformação é revertida, ele passa a chamar-se parcialmente elástico. TIMOSHENKO \& GOODIER (1980) afirmam que, até um certo grau, todos os materiais utilizados na engenharia possuem a propriedade da elasticidade.

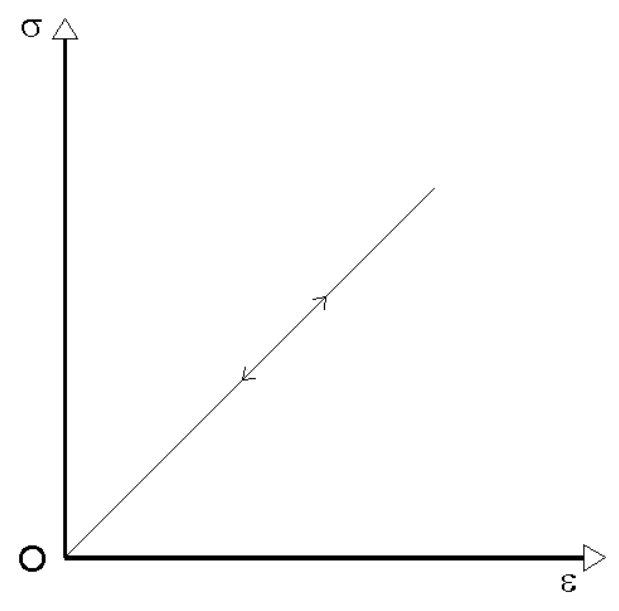

a) Material elástico perfeito e linear

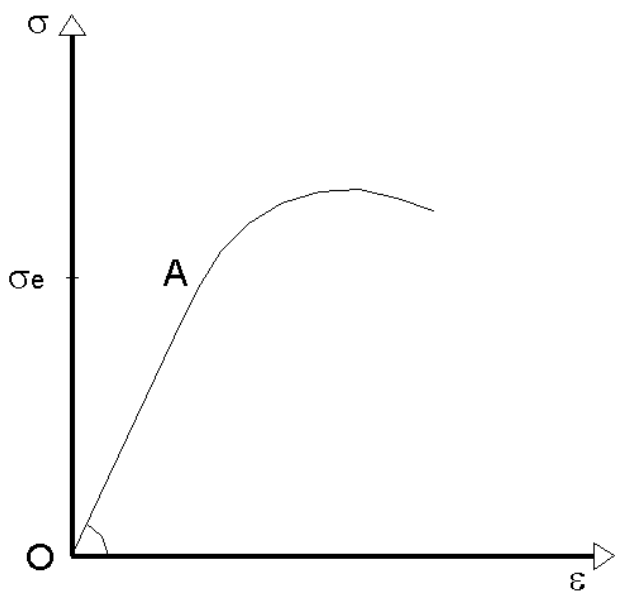

b) Material linear até o ponto $A$

Figura 3.1 - Diagrama tensão versus deformação 
Esse tipo de análise considera ainda uma relação linear entre as componentes de tensão e deformação do material, ou seja, que existe uma constante de proporcionalidade responsável por essa relação, e de valor característico para cada material. Essa constante é chamada de módulo de elasticidade, e é dada pela tangente do ângulo que a reta OA forma com o eixo das deformações (ver Figura 3.1-b) O cientista inglês Robert Hooke (1635-1703), em 1678, foi o primeiro a estabelecer experimentalmente essa relação, e por isso a Eq. (3.1) é conhecida como Lei de Hooke.

$\sigma=\mathrm{E} \varepsilon$

A tensão a partir da qual começam a aparecer deformações residuais, com o descarregamento de um corpo-de-prova, é chamada de limite elástico $\left(\sigma_{\mathrm{e}}\right)$ do material. Analogamente existe o limite de proporcionalidade $\left(\sigma_{\mathrm{p}}\right)$, que é a tensão a partir da qual deixa de haver uma relação linear entre tensão e deformação, e que não necessariamente coincide com o limite elástico.

Abaixo do limite elástico, é constante a relação entre as deformações transversal e longitudinal. O valor dessa constante é conhecido como coeficiente de Poisson (v), e varia, para o concreto, de 0,15 a 0,25 . Usualmente é empregado o valor médio de 0,2 para o concreto, inclusive no cálculo de placas (lajes) pela Teoria da Elasticidade.

Um elemento estrutural fletido encontra-se em regime elástico, até a primeira fibra longitudinal atingir o limite elástico (ver Figura 3.2). Até esse ponto, pode-se considerar a tensão variando linearmente ao longo da seção transversal.

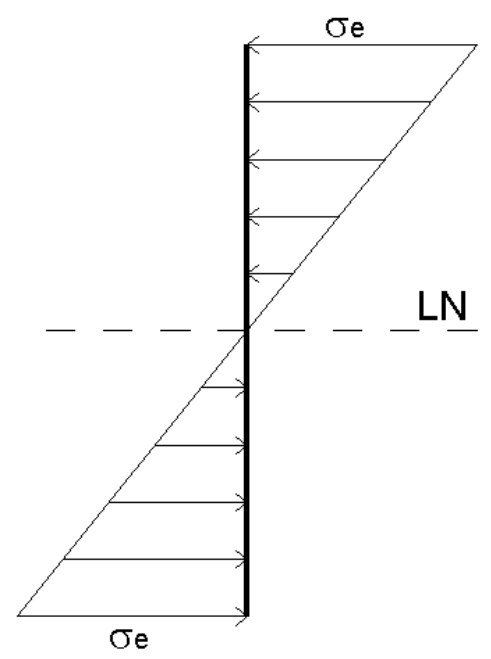

Figura 3.2 - Limite elástico da seção transversal

FUSCO (1976) define uma estrutura de comportamento linear como aquela em que os efeitos são obtidos como uma combinação linear e homogênea das causas. Para tal, a estrutura 
precisa ser constituída de um material perfeitamente elástico, e deve possuir uma geometria que permita que ela seja analisada com uma teoria de primeira ordem. Isso significa que as rotações dos elementos da estrutura são desprezíveis frente à configuração inicial da estrutura, e, portanto, pode-se proceder a análise estrutural tendo por base a configuração indeformada da estrutura. Como exemplo, tem-se a estrutura da Figura 3.3, onde, se o ângulo $\varphi$ puder ser considerado desprezível na determinação dos efeitos de flexão, admite-se o comportamento linear da estrutura.

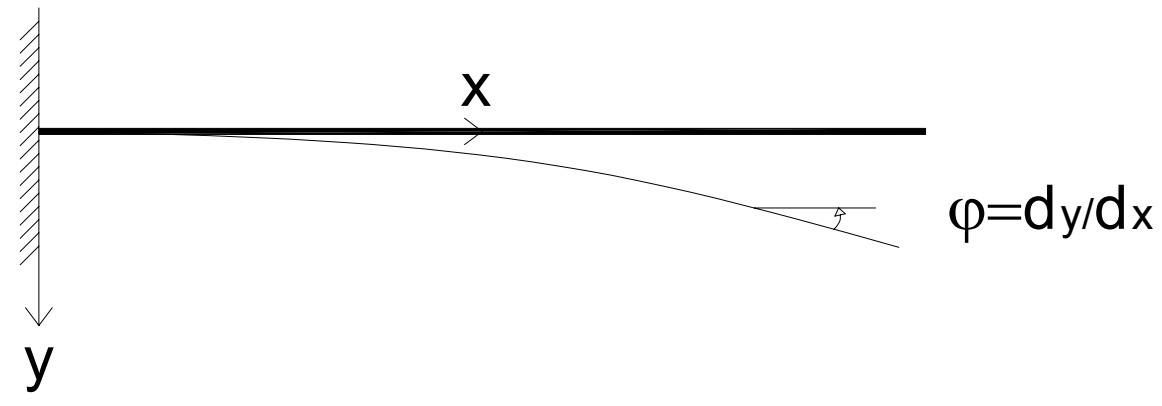

Figura 3.3 - Verificação do comportamento linear de uma estrutura

As deformações elásticas do concreto são provenientes de carregamentos externos e de variações de temperatura. LEONHARDT \& MÖNNIG (1977) afirmam que o concreto só tem um comportamento puramente elástico para tensões baixas e de curta duração. Até aproximadamente $1 / 3$ da resistência à compressão, as tensões podem ser consideradas baixas o suficiente para manter a propriedade elástica do material.

Como simplificação, pode-se utilizar, para cálculo da rigidez dos elementos estruturais lineares, o momento de inércia da seção bruta de concreto. $O$ valor do módulo de elasticidade, para o projeto de estruturas, deve ser obtido, quando possível, por ensaio descrito em uma norma específica (NBR 8522:1984). No caso da análise linear, para determinação de esforços solicitantes e verificação de estados limites de serviço, deve-se utilizar o módulo de elasticidade secante $\left(E_{c s}\right)$, cujo valor é $85 \%$ do módulo de elasticidade tangente inicial $\left(E_{c i}\right)$, correspondente à inclinação do início da curva tensão versus deformação. Alternativamente, a NBR 6118:2003 permite o uso de uma fórmula simplificada, em função da resistência do concreto, dada pela Eq. (3.2).

$E_{c s}=0,85 E_{c i}=0,85 \cdot 5600 f_{C K}^{1 / 2}$

A análise linear é geralmente empregada na verificação dos estados limites de serviço, sendo utilizada para verificações de estado limite último somente em situações que se possa garantir a dutilidade dos elementos estruturais. Pode-se considerar, como garantia de dutilidade, o 
dimensionamento dos elementos nos domínios 1, 2 e 3, e a limitação da posição relativa da linha neutra, $x / d$, junto aos apoios e regiões de ligação entre elementos estruturais. Esta limitação será apresentada no item 3.2, a seguir. O CEB-FIP MC90 permite uma análise linear, para verificação do estado limite último, no caso de vigas contínuas e pórticos de nós fixos (pórticos em que os efeitos de segunda ordem não ultrapassam 10\% dos efeitos de primeira ordem).

Para o cálculo de flechas, faz-se necessária a consideração da fissuração, que pode ser feita com a inércia equivalente de Branson (ver item 3.4.2), e da fluência. Se os esforços não ultrapassarem aqueles que determinam a fissuração, é possível admitir o concreto e o aço como materiais elástico-lineares, e verificar a flecha no estádio I.

CORRÊA (1991) cita alguns motivos que tornam a análise linear tão importante. Entre eles destacam-se: a possibilidade de superposição de efeitos e de utilização como primeira aproximação para a análise não-linear, o fato de alguns processos não-lineares basearem-se em sucessivas etapas lineares e, principalmente, a simplicidade da análise.

\subsection{Análise linear com redistribuição}

Uma vez realizada a análise linear de uma estrutura, pode-se proceder uma redistribuição dos esforços calculados, decorrente da variação de rigidez dos elementos estruturais. A fissuração, e a conseqüente entrada no estádio II, de determinadas seções transversais, provoca um remanejamento dos esforços solicitantes, para regiões de maior rigidez. É o caso de vigas contínuas, por exemplo. Ao aumentar-se progressivamente o carregamento de uma viga contínua, fissuras aparecerão primeiramente nos apoios, onde os momentos fletores são maiores. A região do apoio entra no estádio II quando o concreto tracionado deixa de contribuir na resistência, por ação das fissuras. Ainda sob o carregamento crescente, nota-se um aumento mais rápido dos momentos fletores nos vãos, que ainda estão no estádio I (seção não fissurada), do que nos apoios. Esse processo continua até a entrada também da região do vão no estádio II. PRADO \& GIONGO (1997) ressaltam que a rigidez à flexão pode diminuir de 20 a $70 \%$ com a fissuração da seção de concreto, dependendo da taxa de armadura.

O fenômeno descrito trata-se da redistribuição de momentos, cuja não consideração tem como maior efeito o sub-aproveitamento da armadura de flexão nos apoios. A redistribuição dos esforços é típica de estruturas hiperestáticas, pois, mesmo havendo a plastificação de uma seção da estrutura, a capacidade resistente não se esgota. Os esforços apenas passam a ser resistidos por regiões adjacentes. Esse assunto será melhor tratado no item 3.3, referente à análise plástica, que permite maiores redistribuições de esforços. 
Em termos práticos, a análise linear com redistribuição, por meio de um método simplificado, promove a redução de momentos fletores nos apoios de vigas contínuas, e o respectivo aumento dos momentos fletores nos vãos, sem a necessidade de uma análise plástica mais refinada. Dessa forma é possível obter economia de armadura, já que os valores de momentos negativos e positivos passam a ser mais próximos. Na análise linear sem redistribuição, as seções dos apoios e vãos, onde concentram-se os picos de momento, são armadas de modo que, na ruína, elas plastifiquem simultaneamente.

As garantias de dutilidade merecem especial atenção nas regiões de apoio das vigas ou de outras ligações entre elementos estruturais. Quanto menor o valor de x/d, calculado no ELU, menor a área de concreto comprimido, e mais o aço, material mais dúctil que o concreto, passa a ser o limitante da resistência da seção. Por isso, a NBR 6118:2003 limita o valor de x/d, nos apoios e nas regiões de ligação entre elementos estruturais lineares, mesmo que não sejam realizadas redistribuições de esforços solicitantes, aos seguintes valores:

$\mathrm{x} / \mathrm{d} \leq 0,50$ para concretos com $\mathrm{f}_{\mathrm{ck}} \leq 35 \mathrm{MPa}$

$\mathrm{x} / \mathrm{d} \leq 0,40$ para concretos com $\mathrm{f}_{\mathrm{ck}}>35 \mathrm{MPa}$

A redistribuição se dá pela multiplicação dos momentos nos apoios por um coeficiente de redistribuição $\delta$, e posterior correção dos momentos nos vãos, como na Figura 3.4:

$\mathrm{p}$
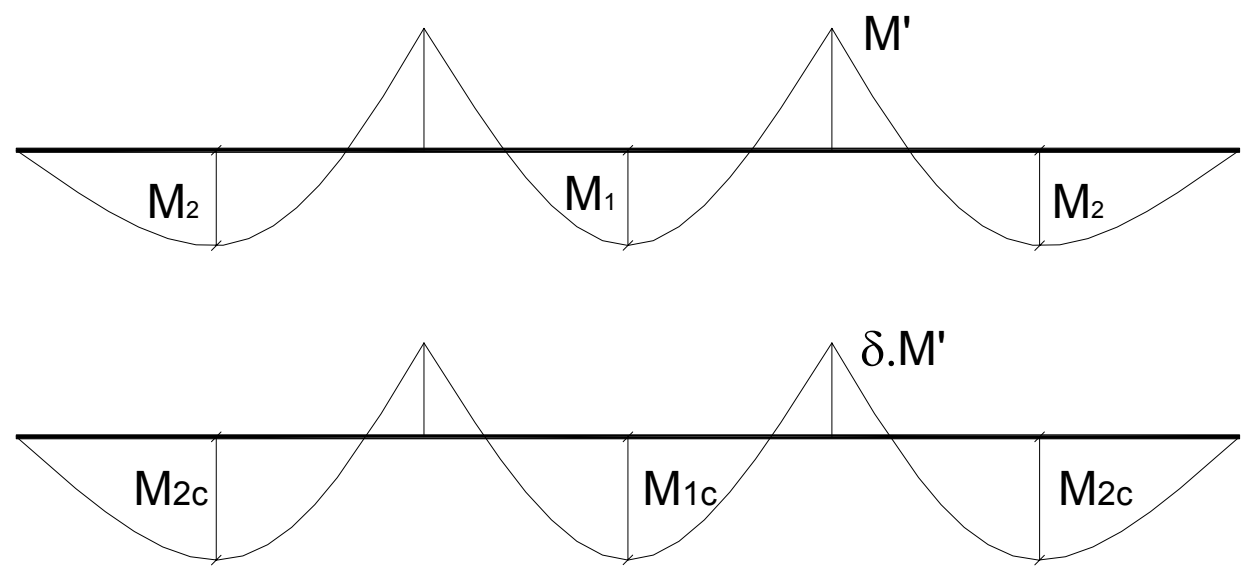

Figura 3.4 - Redistribuição de momentos fletores em viga contínua 
A NBR 6118:1980 era conservadora ao permitir a redução de 15\% dos momentos fletores nos apoios de vigas contínuas, e correção do momento fletor nos vãos, sem qualquer verificação adicional. A NBR 6118:2003 permite, para elementos lineares, redução de até $25 \%(\delta=0,75)$ para estruturas de nós fixos, e de até $10 \%(\delta=0,90)$ para estruturas de nós móveis (estruturas em que os efeitos de segunda ordem são relevantes), dependendo de $x / d$ e de $f_{c k}$, como indicado nas equações (3.5) e (3.6):

$\delta \geq 0,44+1,25 \mathrm{x} / \mathrm{d}$ para concretos com $\mathrm{f}_{\mathrm{ck}} \leq 35 \mathrm{MPa}$

$\delta \geq 0,56+1,25 \mathrm{x} / \mathrm{d}$ para concretos com $\mathrm{f}_{\mathrm{ck}}>35 \mathrm{MPa}$

A correção dos momentos fletores nos vãos pode ser feita isolando os tramos e, com os novos momentos reduzidos aplicados nos apoios pertinentes, calcular as reações e momentos positivos.

Em pilares, consolos e elementos lineares com preponderância de compressão, a redistribuição de esforços só deve ser feita se por conseqüência de redistribuições em vigas ligadas a eles, uma vez que essas peças não apresentam grande dutilidade.

Nota-se que, com as prescrições da NBR 6118:2003, as condições de dutilidade exigidas estão mais rigorosas. Para o concreto de resistência igual ou inferior a $35 \mathrm{MPa}$, exige-se uma posição relativa da linha neutra, $\mathrm{x} / \mathrm{d}$, menor que 0,448 para que possa ser efetuada alguma redistribuição (para que se possa ter $\delta<1$ ) na análise linear. Para resistências acima de 35 MPa, o que implica em um material mais frágil, o valor de $x / d$ necessita ser menor que 0,352, o que caracteriza muito bem as peças sub-armadas, próximas do domínio 2, que são de interesse dos projetistas estruturais.

No caso de vigas $T$, o efeito da redistribuição é ainda mais benéfico, já que nos vãos (momento fletor positivo) a área comprimida de concreto é maior, pois conta com a mesa da seção $\mathrm{T}$. Dessa forma é interessante que parte do momento absorvido pelos apoios seja transferida para os vãos, economizando armadura. LEONHARDT \& MÖNNIG (1979) mostram que é possível reduzir $50 \%$ dos momentos nos apoios, em vigas com a largura da mesa em torno de três vezes maior que a largura da alma, e com isso melhorar a capacidade de carga da viga. Há especial interesse no uso desse conhecimento, na consideração da largura colaborante da laje associada à viga, o que é permitido pela NBR 6118:2003, quando a modelagem da estrutura não levar em conta a ação conjunta de lajes e vigas. 
O ACl Building Code (ACl 318-89) permite até $20 \%$ de modificação dos momentos nos apoios de elementos contínuos fletidos. A própria Norma americana admite seu conservadorismo ao mencionar os estudos feitos por Cohn e Mattock sobre a capacidade de rotação de elementos fletidos de concreto armado. A percentagem é dada pela Eq.(3.7).

$20\left(1-\frac{\rho-\rho^{\prime}}{\rho_{b}}\right)$

$\rho$ é a taxa de armadura tracionada, $\rho$ ' é a taxa de armadura comprimida e $\rho_{b}$ é a taxa de armadura que produz condições balanceadas de deformação, ou seja, quando a deformação máxima na fibra mais comprimida atinge 0,003 simultaneamente à deformação de escoamento, $f_{y} / E_{s}$, ser atingida na armadura tracionada. $\rho_{b}$ pode ser calculado pela Eq. (3.8).

$\rho_{b}=\frac{0,85 \beta_{1} f_{c}^{\prime}}{f_{y}} \cdot \frac{87000}{87000+f_{y}}$

A redistribuição de momentos negativos fica restrita, pelo ACl Building Code (ACI 318-89), aos casos em que, na seção cujo momento é reduzido, os valore de $\rho$ ou ( $\rho$ - $\rho$ ') são menores ou iguais a $0,50 \rho_{b}$. $f_{c}^{\prime}$ e $f_{y}$ são, respectivamente, a resistência à compressão do concreto e a resistência ao escoamento do aço, dados ambos em psi. $\beta_{1}$ vale 0,85 para valores de $f_{c}$ menores ou iguais a 4000psi, e é reduzido continuamente a intervalos de 0,05 para cada 1000 psi que excede os 4000 psi. No entanto, o valor de $\beta_{1}$ deve sempre se manter maior ou igual a 0,65 .

PARK \& PAULAY (1975) citam, como vantagens da redistribuição de momentos, o fato do projetista poder selecionar distribuições de momentos que evitem congestionamentos de armadura nos apoios, e a possibilidade de reduzir os picos do diagrama de momentos fletores, para as diferentes combinações de carga acidental. Com bons ajustes de momentos máximos, quanto maior a relação entre a ação variável e a permanente, maior a economia de armadura.

O CEB-FIP MC90 afirma que, para uma estrutura sujeita a vários casos de carregamento, somente uma redistribuição pode ser feita. Deve-se dar preferência à situação mais desfavorável. A NBR 6118:2003 prescreve que não é desejável que haja redistribuição de esforços em serviço, e que as verificações de estados limites de serviço podem ser baseadas na análise linear. Essa recomendação procede do fato de que, em serviço, o carregamento é geralmente da ordem da metade daquele que provoca o estado limite último, e, portanto, não torna possível a redistribuição de esforços. 
Com uma análise plástica, permite-se qualquer distribuição de momentos em uma viga contínua, por exemplo, desde que sejam satisfeitas as condições a seguir:

- equilíbrio: a distribuição de momentos resultante deve ser estaticamente possível;

- compatibilidade de rotação: as rótulas plásticas que se formam devem ter suficiente capacidade de rotação;

- atendimento dos estados limites de serviço: não devem ocorrer fissuração, deslocamentos ou vibrações excessivos.

A análise linear com redistribuição é, portanto, uma simplificação de uma análise mais complexa, a ser desenvolvida com os conhecimentos advindos da plasticidade.

\subsection{Análise plástica}

Ao se aumentar continuamente a intensidade das solicitações sobre um determinado corpo, e após ser atingido o limite elástico de seu material constituinte, deformações permanentes aparecerão com o alívio do carregamento. Essa propriedade de guardar deformações residuais é chamada de plasticidade. A deformação total do elemento estrutural passa a ser composta por uma parcela recuperável elástica, $\varepsilon_{\mathrm{e}}$, e uma parcela permanente plástica, $\varepsilon_{\mathrm{p}}$.

Normalmente, procura-se idealizar o material envolvido em uma análise plástica, aproximando seu comportamento do elastoplástico perfeito (Figura 3.5-a), ou elastoplástico com encruamento (Figura 3.5-b). A primeira hipótese prevê, no diagrama tensão-deformação, uma zona elástico-linear, e uma zona perfeitamente plástica (sem encruamento, ou seja, escoamento sem aumento de tensão). Já a segunda hipótese considera que o material escoa com um aumento de tensão, e que uma vez plastificado, e aliviado o carregamento, é necessária uma tensão maior que a tensão de escoamento, $\sigma_{e}+\Delta$, tanto na compressão como na tração, para que esse material volte a plastificar.

Quando se permite, no projeto, que elementos estruturais sofram certas deformações permanentes, com tensões acima do limite de escoamento, há um melhor aproveitamento do material e passa-se a fazer uma análise limite da estrutura. De acordo com NASH (1982), o projeto passa a ser denominado projeto plástico. As principais teorias envolvidas são a teoria das rótulas plásticas, para elementos lineares, e a teoria das charneiras plásticas, para elementos de superfície que trabalhem como placas. 


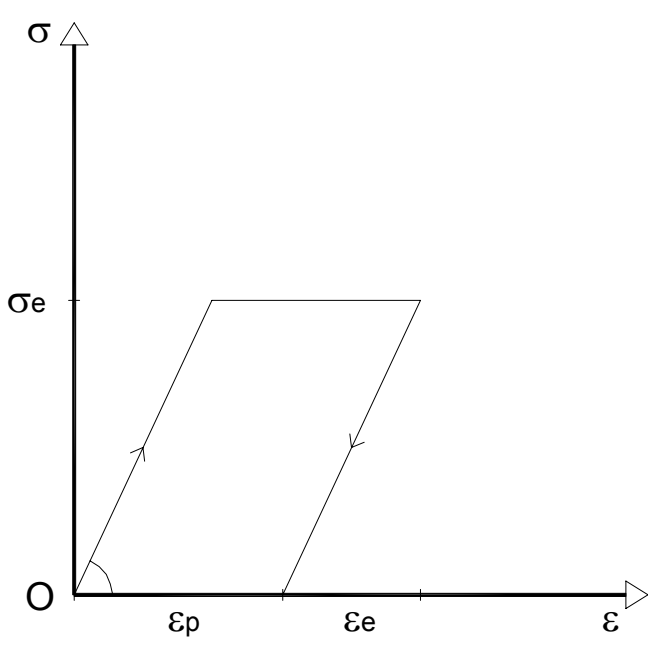

a) Elastoplástico

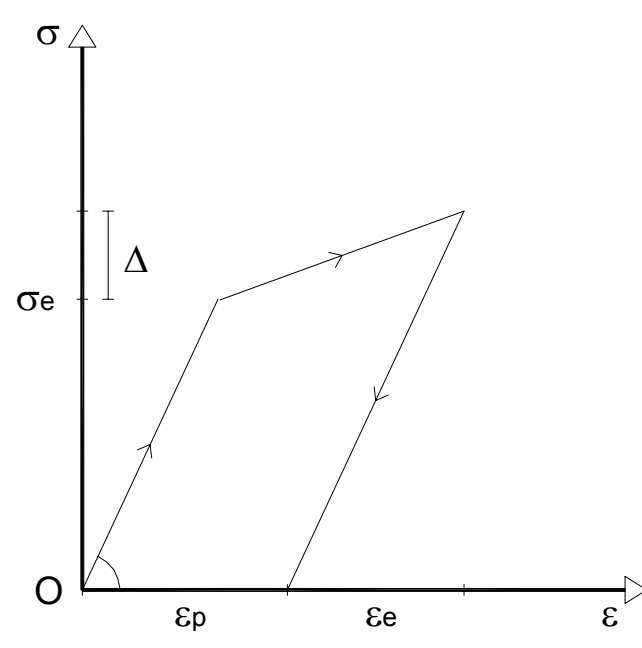

b) Elastoplástico com encruamento

Figura 3.5 - Diagrama tensão versus deformação

Constata-se que a grande maioria das estruturas usuais entra em colapso ainda em regime de pequenos deslocamentos, o que, além de facilitar a análise plástica, faz com que esse tipo de análise possa ser utilizada na prática. Caso as estruturas só plastificassem sob grandes deslocamentos, elas teriam sempre o estado limite de serviço como barreira para a realização de uma análise plástica.

\subsubsection{Rótulas plásticas}

Ao se aumentar continuamente o carregamento de uma viga, por exemplo, um ou mais pontos críticos de momento máximo entrarão em escoamento, dando origem a articulações, ou rótulas plásticas. A rótula plástica é caracterizada por um aumento plástico da curvatura, que pode chegar de duas a três vezes o valor calculado elasticamente. Esse efeito restringe-se a um comprimento de plastificação, $\ell_{p}$, em cada lado do ponto de momento máximo. Nesses pontos o momento fletor se estabiliza (não aumenta mais) e passa a ser chamado de momento totalmente plástico, $\mathrm{M}_{\mathrm{p}}$. Na viga contínua de rigidez El constante, da Figura 3.6, a carga limite, que será explicada mais adiante, faz surgir, primeiramente no apoio central, uma rótula plástica e o trecho de curvatura plástica.

PARK \& PAULAY (1975) fornecem expressões empíricas para o cálculo do comprimento de plastificação $\ell_{p}$, desenvolvidas por vários pesquisadores, como Baker, Mattock e Sawyer.

A rótula plástica ocorre quando uma seção, outrora num regime elastoplástico, entra no regime totalmente plástico, ou seja, todas suas fibras atingem o limite de escoamento $\sigma_{\mathrm{e}}$ (ver Figura 3.7-b). Ainda no regime elastoplástico, a seção continua a absorver momento fletor, devido à 
existência de um núcleo elástico (ver Figura 3.7-a). O aumento contínuo do carregamento provoca a extensão da plastificação para dentro da seção, e esse processo faz com que o momento de inércia à flexão e o módulo de elasticidade caminhem para se anular. Uma vez atingido o momento totalmente plástico numa seção crítica, não há mais aumento de momento nesse ponto, e o valor fica constante e igual a $M_{p}$.

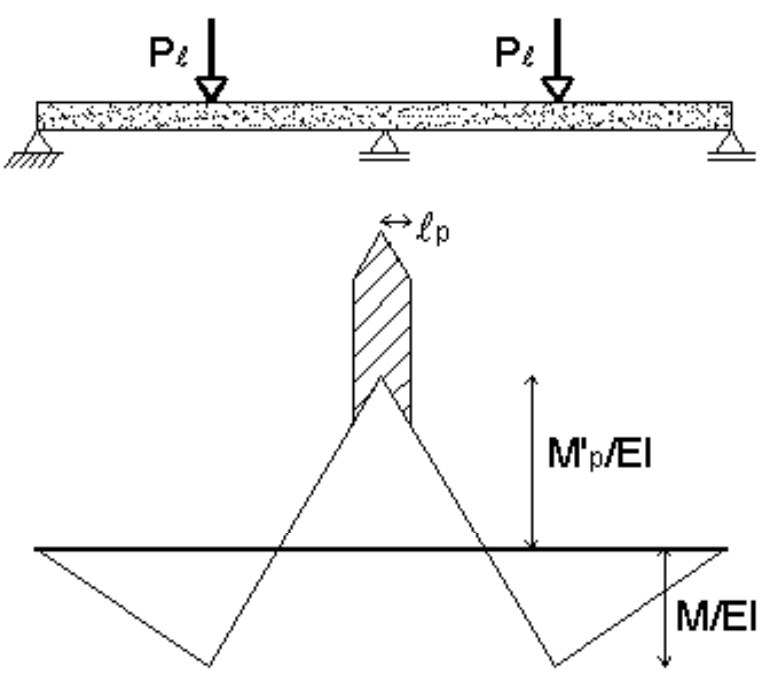

Figura 3.6 - Distribuição de curvatura com a carga limite (adaptada de PARK \& PAULAY, 1975)

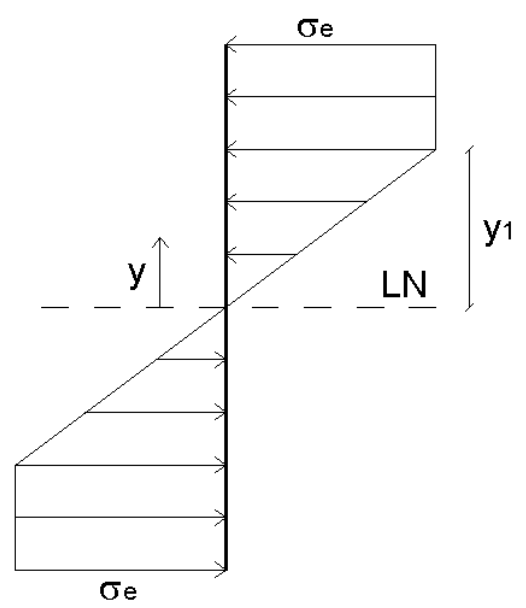

a)

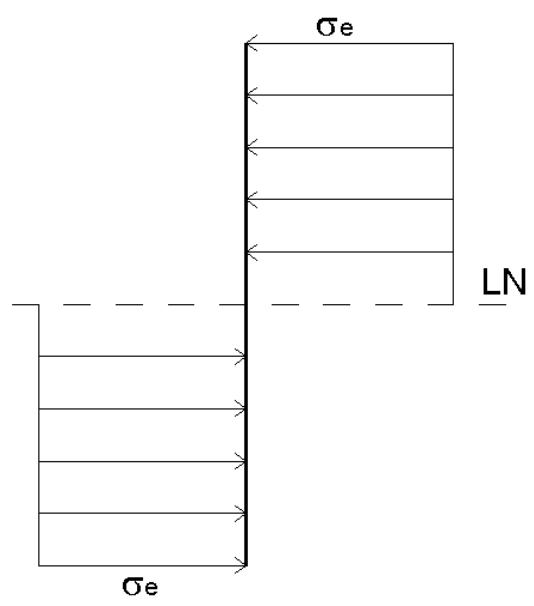

b)

Figura 3.7 - Comportamento elastoplástico e totalmente plástico das seções

\subsubsection{Momento totalmente plástico}

A partir da Figura 3.7 - a, utilizando-se a semelhança de triângulos, pode-se concluir que:

Para $\mathrm{y}<\mathrm{y}_{1} \rightarrow \sigma=\frac{\sigma_{\mathrm{e}} \mathrm{y}}{\mathrm{y}_{1}}$ 
Para $y>y_{1} \rightarrow \sigma=\sigma_{e}=$ constante

\section{b}

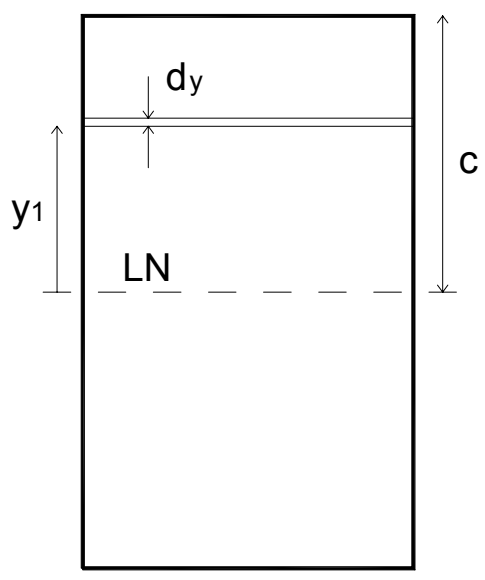

Figura 3.8 - Seção transversal retangular

Se for integrada a expressão $M=\int \sigma . y d A$, ao longo da área da seção da Figura 3.8, com dA = $b d_{y}$, tem-se ao seguinte valor de momento:

$M=\left(b c^{2}-\frac{b}{3} \cdot y_{1}^{2}\right) \cdot \sigma_{e}$

$\mathrm{O}$ momento totalmente plastificado $\mathrm{M}_{\mathrm{p}}$ é calculado fazendo $\mathrm{y}_{1}=0$, e o máximo momento elástico possível $\mathrm{M}_{\mathrm{e}}$ (apenas as fibras externas plastificadas) fazendo $\mathrm{y}_{1}=\mathrm{c}$. Ao se considerar $\mathrm{c}$ $=\mathrm{h} / 2$, tem-se para seções retangulares:

$\mathrm{M}_{\mathrm{p}}=\frac{\mathrm{bh}^{2}}{4} \cdot \sigma_{\mathrm{e}}$

$\mathrm{M}_{\mathrm{e}}=\frac{\mathrm{bh^{2 }}}{6} \cdot \sigma_{\mathrm{e}}$

Esses momentos encontrados admitem um material homogêneo, com patamar de escoamento e momento de plastificação bem definidos.

\subsubsection{Carga limite e mecanismo de colapso}

A mínima carga capaz de provocar na estrutura um escoamento sem contenção, ou responsável pela formação de um determinado número de rótulas plásticas, que torne a estrutura, ou parte dela, em um sistema hipostático (situação que impossibilita o equilíbrio), dá 
origem a um mecanismo de colapso, e é chamada de carga limite $\left(\mathrm{p}_{\ell}\right)$. Um projeto concebido com esse fator limitante é conhecido como projeto limite. Assim sendo, para uma estrutura isostática, basta a ocorrência de uma rótula plástica para que seja determinado o seu colapso.

Em estruturas hiperestáticas, existe uma reserva de capacidade resistente, visto que, geralmente, é necessária a formação de mais de uma rótula plástica para que se forme um mecanismo de colapso. O número de rótulas plásticas para que se forme tal mecanismo depende do grau de hiperestaticidade da estrutura (número de vínculos que precisam ser liberados para tornar a estrutura isostática), de sua configuração geométrica e do carregamento atuante. Na Figura 3.9 tem-se uma viga hiperestática, na qual, se a rótula plástica se formar primeiramente no apoio simples, ocorre o colapso de parte da estrutura. Se a rótula plástica ocorrer primeiro no engaste, a peça passa a ser uma viga biapoiada com balanço e não entra em colapso, se tiver capacidade de se acomodar à nova situação.

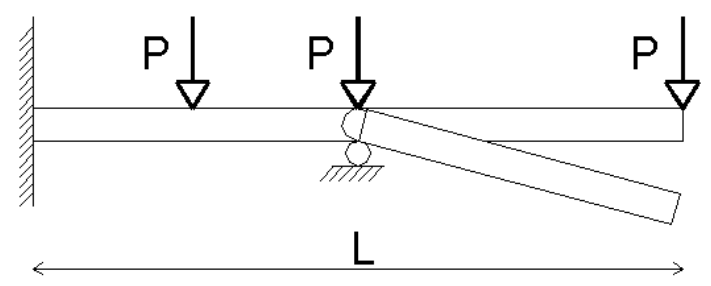

Figura 3.9 - Viga hiperestática que se torna hipostática com a rótula no apoio simples

Para a viga biengastada da Figura 3.10, é necessário o aparecimento de três articulações plásticas para a formação de um mecanismo de colapso.

A
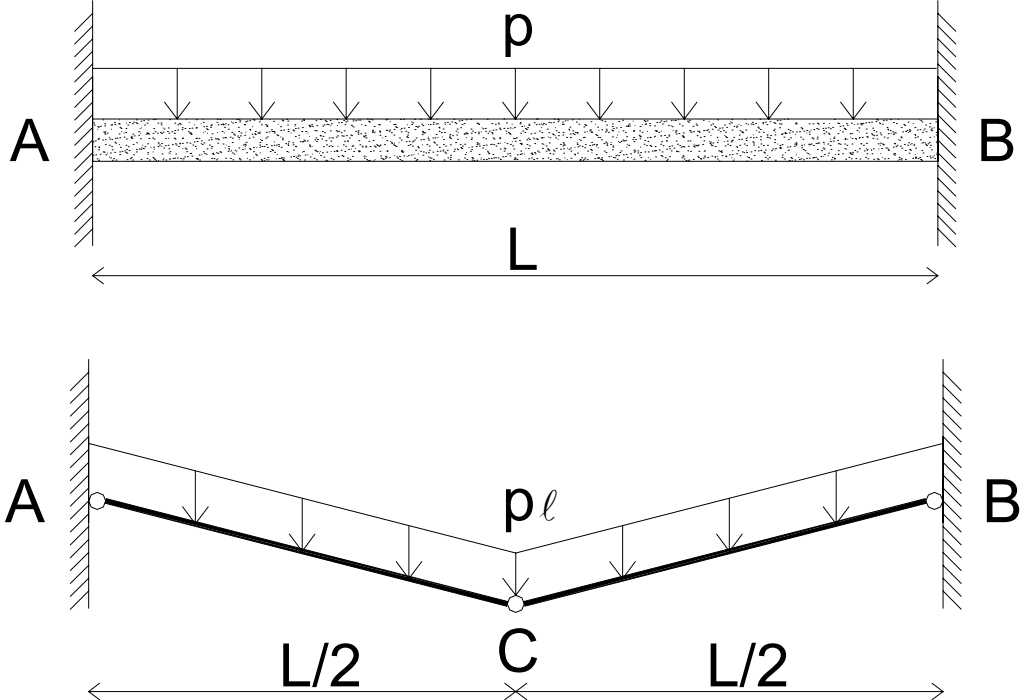

Figura 3.10 - Viga biengastada e grau de hiperestaticidade 3 
Na Figura 3.11 tem-se o diagrama de corpo livre da metade esquerda da viga biengastada da Figura 3.10. Se for feita a somatória de momentos em $\mathrm{A}$ igual a zero, chega-se à carga limite $\mathrm{p}_{\ell}$ na Eq. (3.12):

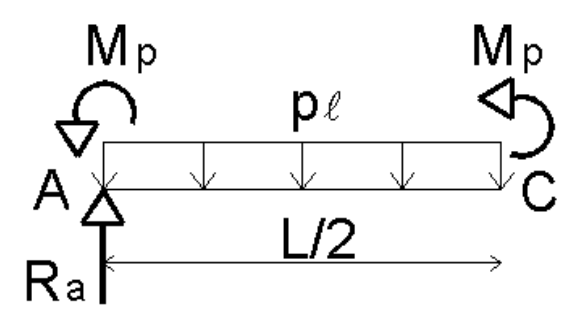

Figura 3.11 - Diagrama de corpo livre de metade da viga biengastada

$\mathrm{p}_{\ell}=\frac{16 \cdot \mathrm{M}_{\mathrm{p}}}{\mathrm{L}^{2}}$

Por meio de tabelas para vigas, encontradas em livros de resistência dos materiais ou de análise estrutural hiperestática, tem-se que o momento elástico no engaste, para uma viga biengastada, com carga uniformemente distribuída, é $M_{e}=\left(p L^{2}\right) / 12$. Assim, a carga permitida numa análise elástica é $p_{e}=12 M_{e} / L^{2}$. Com a substituição dos valores de $M_{p}$ e $M_{e}$, da Eq. (3.10) e da Eq. (3.11), respectivamente, mostra-se que a relação entre as cargas permitidas na análise plástica e elástica, $\mathrm{p}_{\ell} / \mathrm{p}_{\mathrm{e}}$, é igual a 2 . O projeto limite mostra que é possível dobrar a carga nesse caso.

\subsubsection{Rotação necessária}

Segue-se analisando a estrutura da Figura 3.10.

Dentro do regime de pequenos deslocamentos, o diagrama de momentos fletores mantém uma relação constante com o carregamento, até a iminência do colapso. Esse fenômeno fica claro na Figura 3.12-b e Figura 3.12-c, que mostram uma soma constante dos momentos fletores negativo e positivo, igual a $\left(p L^{2}\right) / 8$.

Com o aumento progressivo da ação p, na viga da Figura 3.12-a, notar-se-ão as primeiras rótulas plásticas nos apoios extremos, que é onde estão os maiores momentos fletores em módulo. A carga que faz o momento nos apoios chegar ao valor de $M_{p}$ é a carga de escoamento, já que se considera o material elastoplástico perfeito, e é chamada aqui de $p_{y}$.

$p_{y}=\left(12 M_{p}\right) / L^{2}$ 
É possível admitir que o comprimento de plastificação $\ell_{p}$ seja pequeno, para fins de estimar a flecha. Dessa maneira, na iminência do colapso, pode-se considerar praticamente toda a viga em regime elástico. Portanto, já que se formaram rótulas plásticas nas extremidades da viga, a flecha deve ser calculada como para uma viga simplesmente apoiada. Para a carga $p_{y}$ tem-se o deslocamento dado na Eq. (3.14):

$\delta_{y}=\left(5 p_{y} L^{4}\right) /(384 E I)$

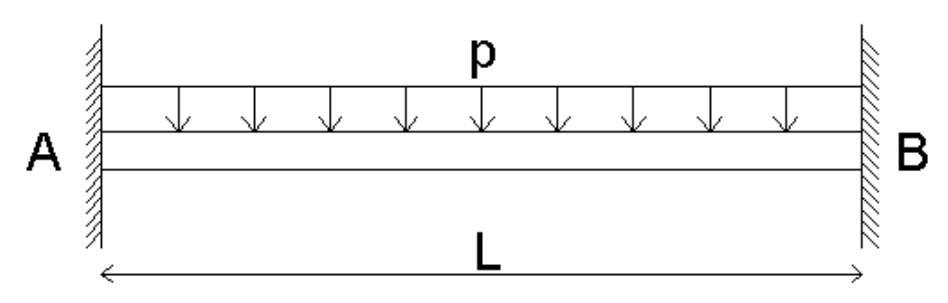

a) Viga biengastada

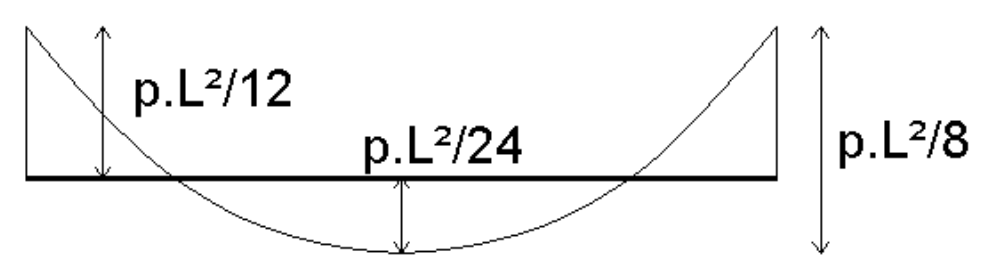

b) DMF elástico

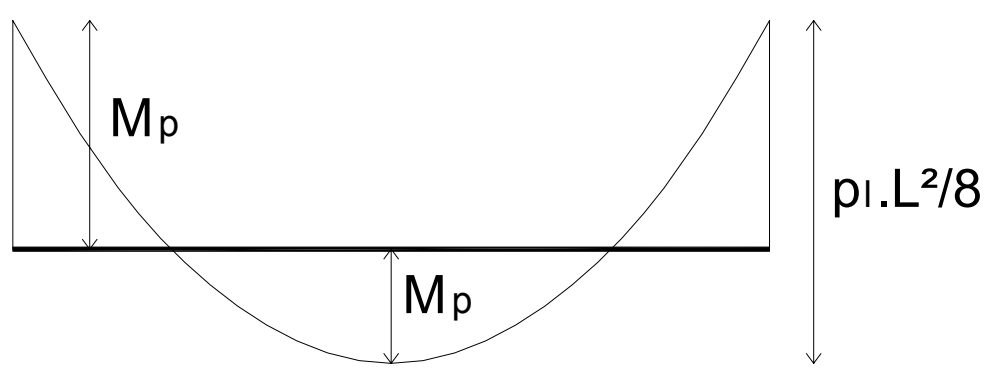

c) DMF no colapso

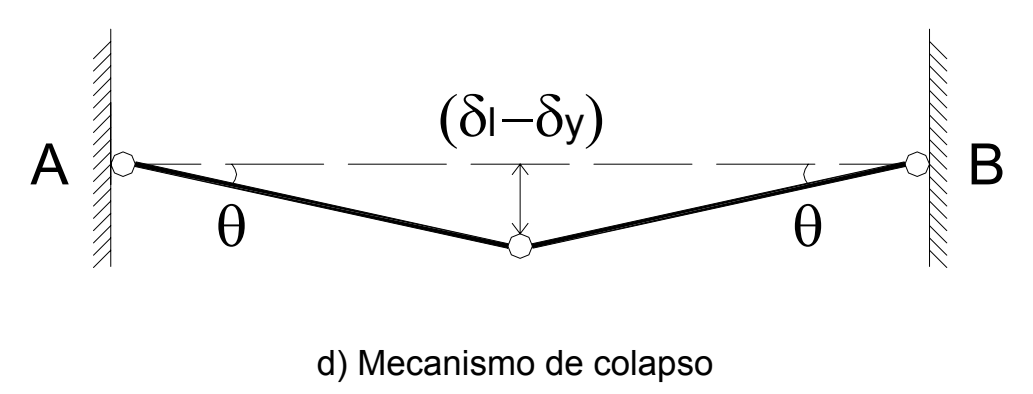

Figura 3.12 - Viga biengastada carregada até o colapso 
A Figura 3.12-d representa a rotação nas rótulas extremas para se atingir a carga última $\mathrm{p}_{\ell}$, ou seja, as mudanças de deformação ocorridas entre o escoamento dos apoios, com a carga $p_{y}$, e a formação da rótula plástica no meio da viga, com a carga $\mathrm{p}_{\ell}$. A diferença das flechas é dada por:

$\delta_{\ell}-\delta_{\mathrm{y}}=\frac{5 \cdot\left(\mathrm{p}_{\ell}-\mathrm{p}_{\mathrm{y}}\right) \cdot \mathrm{L}^{4}}{384 . \mathrm{El}}$

$\left(\mathrm{p}_{\ell}-\mathrm{p}_{\mathrm{y}}\right)=\frac{16 \cdot \mathrm{M}_{\mathrm{p}}}{\mathrm{L}^{2}}-\frac{12 \cdot \mathrm{M}_{\mathrm{p}}}{\mathrm{L}^{2}}=\frac{4 \cdot \mathrm{M}_{\mathrm{p}}}{\mathrm{L}^{2}}$

$\delta_{\ell}-\delta_{\mathrm{y}}=\frac{5 \cdot \mathrm{M}_{\mathrm{p}} \cdot \mathrm{L}^{2}}{96 . \mathrm{EI}}$

Com a consideração de que $\theta$ é bem pequeno, sua tangente pode ser igualada a $\theta$. Daí decorre que:

$\delta_{\ell}-\delta_{\mathrm{y}}=\frac{1}{2} \cdot$ L. $\theta$

$\theta=\frac{5 \cdot M_{p} \cdot L}{48 \cdot E l}$

A rotação dada pela Eq. (3.19), relativa aos apoios engastados, é a necessária para que se forme o mecanismo de colapso.

\subsubsection{Concreto armado e capacidade de rotação da rótula plástica}

No caso do concreto armado, o momento de plastificação pode ser considerado como aquele que provoca o aparecimento do estado limite último $\left(\varepsilon_{\mathrm{c}}=-0,35 \%\right.$ ou $\left.\varepsilon_{\mathrm{s}}=1 \%\right)$.

Por ser um material de natureza frágil, para a ocorrência de um tal número de rótulas plásticas, até que se forme um mecanismo de colapso, é necessária a verificação da capacidade de rotação. A rotação necessária de uma rótula plástica pode ser quantificada pela diferença entre a sua rotação total no colapso e aquela que dá início à sua plastificação. A capacidade de rotação dessas seções é tão maior quanto maior a capacidade de deformabilidade da zona comprimida do elemento estrutural na flexão. LEONHARDT \& MÖNNIG (1979) sugerem uma taxa maior de armadura transversal envolvendo a zona comprimida, ou um cintamento dessa 
zona com uma armadura em espiral de formato retangular, como formas de atingir maiores curvaturas na flexão.

A NBR 6118:2003 traz a consideração de que, quanto menor for a posição relativa da linha neutra, x/d, (até 0,17 para a curva 1 e até 0,15 para a curva 2; ver Figura 3.13), maior a capacidade de rotação do elemento estrutural. Em função desse parâmetro é fornecido um gráfico de capacidade de rotação da rótula plástica, $\theta_{\mathrm{pl}}$.

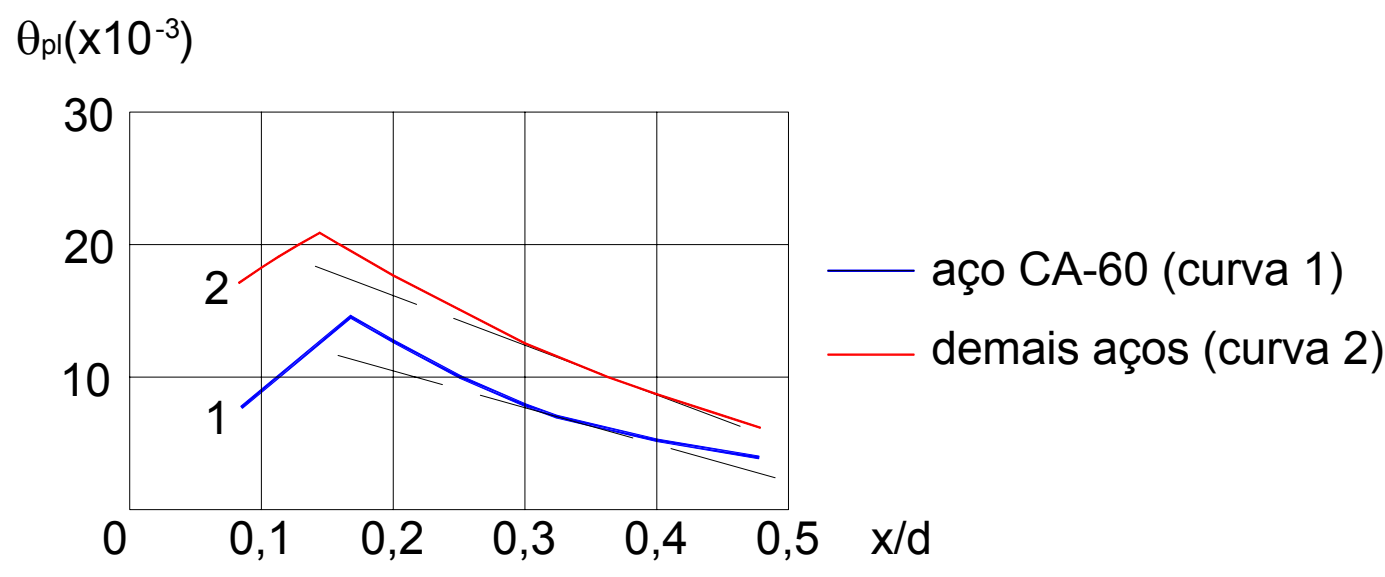

$$
\text { Curva 1: } \theta_{\mathrm{pl}}=0,2 \% \mathrm{~d} / \mathrm{x} \quad \mathrm{p} / \mathrm{x} / \mathrm{d} \geq 0,17
$$

Curva 2: $\theta_{p l}=0,35 \% d / x \quad p / x / d \geq 0,15$

Figura 3.13 - Capacidade de rotação de rótulas plásticas (Adaptada da NBR 6118:2003)

O gráfico da Figura 3.13 é válido para uma relação a/d igual a 6 (a é a distância entre pontos de momento nulo da região que contém a seção plastificada). Para outras relações a/d, devese multiplicar os valores extraídos do gráfico por $\sqrt{(\mathrm{a} / \mathrm{d}) / 6}$. A rotação necessária à rótula plástica deve ser menor ou igual à capacidade de rotação dada pela Norma.

É bom lembrar que as considerações feitas até aqui, sobre a análise plástica, basearam-se em hipóteses simplificadoras de que o material concreto possui um patamar de escoamento bem definido (momento último igual ao momento de escoamento), e de que a rigidez à flexão El permanece constante. A incorporação de métodos de análise não-linear à análise plástica pode trazer melhores resultados. Para tal pode-se reduzir a rigidez El, via modelos de Branson ou de Ghali \& Favre, ou mesmo utilizar a rigidez El referente ao estádio II.

A plastificação em concreto armado se dá pelo escoamento da armadura, elevando a linha neutra e aumentando o braço de alavanca obtido em regime elástico. No entanto, o momento resistente permanece praticamente constante até a ruptura, pois o aumento do braço de alavanca apenas compensa a diminuição da zona comprimida de concreto. A partir desses 
fatos, MORETTO (1970) observa a semelhança entre diagramas momento versus curvatura do concreto armado e do aço, o que permite simplificá-los para duas retas, formando um patamar de escoamento e facilitando cálculos plásticos. A análise plástica em estruturas metálicas já se encontra bem sedimentada no meio técnico, por isso o interesse de se aproximar o comportamento do concreto armado ao do aço. As diferenças incluem a fissuração presente no concreto, que provoca deformações plásticas locais, e a necessidade de verificação da capacidade de rotação das rótulas plásticas, que no aço geralmente não constituem problema sério.

A redistribuição de esforços pode ser feita com maior intensidade que na análise linear com redistribuição, desde que as rótulas plásticas apresentem as devidas capacidades de rotação plástica. KOMATSU (1985) comenta que a possibilidade de alterar as taxas de armadura e sua distribuição favorece a aplicação do cálculo plástico em estruturas de concreto armado. OLIVEIRA (2001) indica duas maneiras de impor a plastificação, diminuindo a taxa de armadura de flexão ou as dimensões de determinadas seções transversais. A primeira maneira torna-se mais indicada, pois aproxima a seção do domínio 2 (maior dutilidade), enquanto a segunda aproxima a seção do domínio 4 , o que aumenta a chance de uma ruptura frágil.

\subsubsection{Considerações para elementos lineares}

Nota-se, pelo que foi exposto, que o cálculo plástico tem boa aplicabilidade em estruturas simples de elementos lineares, em que se conhece previamente a posição preferencial de formação das rótulas plásticas (essa posição pode ser imposta pela disposição da armadura). A análise plástica de estruturas reticuladas não é permitida quando se consideram os efeitos de segunda ordem globais.

Na teoria das rótulas plásticas, deve-se procurar, dentre os possíveis mecanismos de colapso, aquele que se formar com a menor intensidade das forças externas, caso contrário os resultados estarão contra a segurança. Isso ocorre porque a análise plástica baseia-se no processo cinemático, ou do limite superior, em que são verificados os possíveis mecanismos de colapso, normalmente em equilíbrio, a fim de que não haja momentos superiores ao de plastificação fora das rótulas plásticas. A carga última obtida é igual (situação desejada, em que se encontra a menor carga última) ou superior (contra a segurança) à real. 


\subsubsection{Aplicação}

$\mathrm{Na}$ análise plástica, preocupa-se com o estado limite último e não se conhece o comportamento em serviço. A verificação de ELS deve ser efetuada com uma análise linear ou não-linear.

\subsection{Análise não-linear}

Um material dito não-linear é aquele que apresenta uma relação não-linear entre tensões e deformações (ver Figura 3.14), ou seja, essa relação não pode ser definida por uma constante. Apesar de se saber que o comportamento do concreto armado é não-linear, acima de certos limites de tensão, na prática é comum a utilização da análise linear, devido à sua maior simplicidade e à maior familiaridade dos projetistas. No entanto, dada a importância da consideração da não-linearidade em alguns casos, a sua implementação vem sendo feita no cálculo usual, de forma lenta, mas constante. A princípio foram desenvolvidos métodos simplificados que, acoplados à análise linear, já trazem resultados mais fiéis à realidade.

Uma análise completamente não-linear ainda exige esforços computacionais muito grandes, mas deverá fazer parte do cálculo estrutural de concreto armado em um futuro próximo. Sua maior complexidade deve-se principalmente ao fato de que toda a geometria da estrutura, bem como suas armaduras (estimadas por análise linear), devem ser previamente conhecidas, o que requer um cálculo iterativo. Ao final da análise não-linear, têm-se novos esforços, que permitem o cálculo de uma armadura diferente. Essa nova armadura passa a ser utilizada na iteração seguinte. O processo se repete até que a armadura obtida seja próxima da relativa à iteração anterior. Por ser muito trabalhoso, é indispensável a utilização de programas computacionais, para esse tipo de análise. A hipótese de superposição de efeitos não é válida para a análise não-linear.

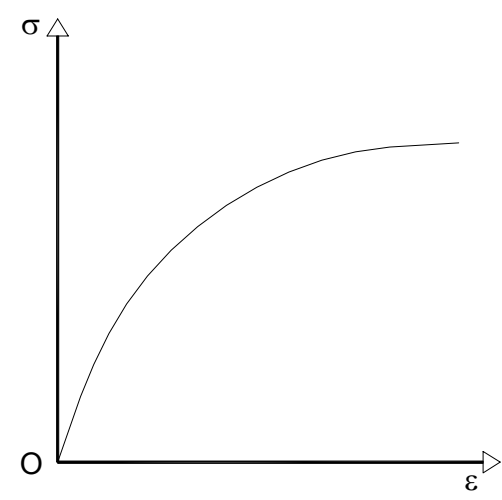

Figura 3.14 - Diagrama tensão versus deformação de um material não-linear (NLF) 
O CEB-FIP Bulletin d'Information n. 229 (1995) ressalta que uma análise não-linear é o procedimento em que:

- o equilíbrio e a compatibilidade de deformações são explicitamente impostos;

- as relações constitutivas dos materiais aço e concreto são consideradas como não-linear, ou relações momento versus curvatura não-lineares são admitidas de forma simplificada;

- se relevantes, as não-linearidades geométricas são levadas em conta.

O CEB-FIP MC90 confirma a importância da análise não-linear, ao dizer que ela constitui um método consistente e que deve servir de referência para as abordagens mais simplificadas. Não é por acaso que a NBR 6118:2003 indica o uso da análise não-linear, tanto para a verificação dos estados limites últimos, como dos estados limites de serviço, para elementos lineares, de superfície e de volume. No entanto, dentre os tipos de análise (além da análise através de modelos físicos), a análise não-linear ainda é a que carece maiores detalhes, junto à NBR 6118:2003.

\subsubsection{Tipos de não-linearidade}

A resposta não-linear das estruturas, às solicitações que the são impostas, deve-se a diversos fatores. Porém, é usual a divisão em não-linearidade física (NLF) e não-linearidade geométrica (NLG). A NLF refere-se ao comportamento não-linear entre tensões e deformações dos materiais. Já a NLG considera a relação não-linear entre deformações e deslocamentos, e o equilíbrio na posição deformada das estruturas.

\section{a) Não-linearidade física}

A NLF desenvolve-se a partir de fissuração, fluência, deformação plástica do concreto, escoamento das armaduras, entre outros fatores, e está associada ao comportamento do material. A sua consideração envolve a determinação da rigidez de cada elemento estrutural, para cada seção transversal com variação da quantidade e da disposição de armadura, e do grau de solicitação, a partir das relações constitutivas dos materiais. É possível implementar a NLF por meio de sucessivas análises lineares, com a utilização de um carregamento incremental. A rigidez dos elementos é alterada de acordo com o nível de solicitação da etapa anterior, como, por exemplo, ao se atingir o momento de fissuração de determinada seção. Um outro modo de considerar a NLF, menos preciso, porém mais simples, é embutindo-a na análise linear, com uma redução na inércia bruta da seção transversal dos elementos estruturais. 
A redução da rigidez de uma seção está relacionada à diminuição do módulo de deformação "E" do concreto, com o aumento da tensão, e com a redução do momento de inércia "I", provocada pela fissuração.

A redução simplificada da rigidez, permitida pela NBR 6118:2003 para consideração da NLF, é mostrada adiante. Ela se aplica à análise dos esforços globais de segunda ordem e é vetada para esforços locais de segunda ordem.

- Lajes: $(E I)_{\sec }=0,3 E_{c i} I_{c}$

- Vigas: $(E I)_{\sec }=0,4 E_{c i} I_{c}$ para $A_{s}^{\prime} \neq A_{s} e$

$$
(E I)_{s e c}=0,5 E_{c i} I_{c} \text { para } A_{s}^{\prime}=A_{s}
$$

- Pilares: $(E I)_{s e c}=0,8 E_{c i} I_{c}$

- Estruturas de contraventamento formadas somente por vigas e pilares: $(E \mathrm{I})_{\mathrm{sec}}=0,7 \mathrm{E}_{\mathrm{ci}} \mathrm{I}_{\mathrm{c}}$

$E_{c i}$ é o módulo de deformação tangente inicial e $I_{c}$ é o momento de inércia da seção bruta de concreto.

Em termos de elementos isolados, também existem algumas indicações de redução da rigidez, para consideração da NLF. O ACI Building Code (ACI 318-89) fornece a Eq. (3.20) ou a Eq. (3.21) para o cálculo de uma rigidez efetiva a ser utilizada no dimensionamento de pilares esbeltos, especificamente.

$E I_{\text {ef }}=\frac{\left(0,2 \cdot E_{c} \cdot I_{g}+E_{s} \cdot I_{s e}\right)}{1+\beta_{d}}$

ou, de forma mais conservadora,

$\mathrm{EI}_{\mathrm{ef}}=\frac{0,4 \cdot \mathrm{E}_{\mathrm{c}} \mathrm{I}_{\mathrm{g}}}{1+\beta_{\mathrm{d}}}$

Esse método simplificado utiliza o carregamento axial, advindo de uma análise elástico-linear, e um momento majorado, que inclui os efeitos da NLG. $\beta_{d}$ é a relação entre a parcela permanente e o carregamento total aplicado, $E_{c}$ é o módulo de elasticidade do concreto (secante), $I_{g}$ é o momento de inércia da seção bruta de concreto, $I_{\text {se }}$ é o momento de inércia das barras de aço, em relação ao centróide da seção transversal, e $E_{s}$ é o módulo de elasticidade longitudinal do aço. 
A consideração rigorosa da NLF é mais bem entendida, se analisada em termos matriciais. Supondo uma estrutura de matriz de rigidez $\mathrm{K}$, cuja função é relacionar os vetores de deslocamentos u e de carregamentos $F$, tem-se para uma análise linear a Eq. (3.22):

K.U $-\mathrm{F}=0$

De acordo com SANCHES JR. (1998), a partir do momento em que a NLF é considerada, os esforços internos e os externos não estarão mais em equilíbrio, o que gera um processo iterativo com $\mathrm{K}$ em função de $u$.

$\mathrm{K}(\mathrm{u}) \cdot \mathrm{u}-\mathrm{F}=\psi$

$\psi$ é um vetor de esforços residuais, proveniente de erros da resposta iterativa, e que deve ter seu valor mantido sob certa tolerância para que se possa passar ao incremento de carga seguinte.

\section{b) Não-linearidade geométrica}

A NLG é decorrente da consideração dos efeitos de segunda ordem, provenientes da análise da estrutura em sua posição deformada, e que devem ser somados aos efeitos de primeira ordem. Normalmente as estruturas apresentam uma resposta não-linear aos efeitos de segunda ordem, ou seja, os deslocamentos extras não são diretamente proporcionais ao carregamento aplicado. Um exemplo simples de efeito de segunda ordem é o aumento de momentos fletores nos pilares de edifícios, resultado da combinação das ações verticais com deslocamentos horizontais provocados pelo vento. Essa análise de segunda ordem pode ser global (edifício como um todo) ou local (elementos isolados, como os tramos de pilares). $\mathrm{Na}$ Figura 3.15 vê-se um pilar, que ao ser submetido a uma força horizontal que provoque deslocamentos horizontais relevantes, tem seu momento, na seção da base, aumentado pela parcela de segunda ordem constituída pelo produto entre a força vertical e o deslocamento horizontal.

A consideração da NLG, assim como na NLF, deve ser feita por meio de uma análise incremental, iterativa, ou incremental-iterativa, a partir da qual se tem a atualização da geometria deformada para cada passo de carga ou iteração. 


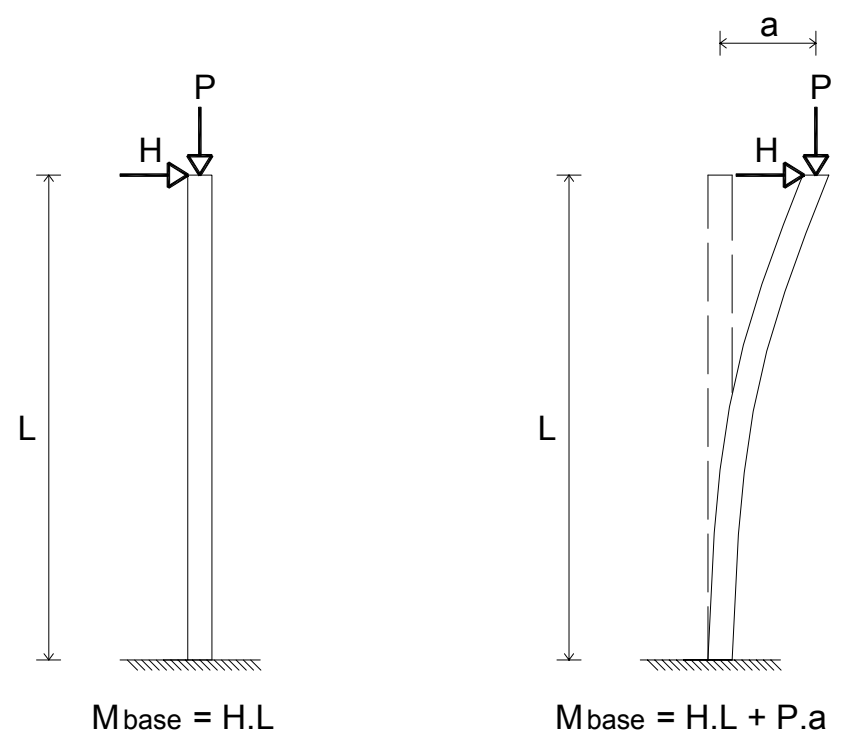

Figura 3.15 - Não-linearidade geométrica

No caso de elementos comprimidos isolados, os efeitos de segunda ordem chamados locais podem ser desprezados quando o índice de esbeltez $(\lambda)$ do elemento não ultrapassar um valor limite estabelecido pela Norma $\left(\lambda_{1}\right)$, dado em função da excentricidade relativa de primeira ordem, da vinculação dos extremos da barra, e da forma do diagrama de momentos de primeira ordem. Se ultrapassado esse limite, mas respeitado o de que $\lambda \leq 90$, a NBR 6118:2003 permite a utilização de métodos simplificados, em que a NLG é considerada de forma aproximada, supondo, por exemplo, que a deformação da barra seja senoidal. Esses métodos são o do pilar-padrão com curvatura aproximada, e o do pilar padrão com rigidez $\kappa$ aproximada. Para um índice de esbeltez além dos já citados, ainda existem o método do pilarpadrão acoplado a diagramas $\mathrm{M}, \mathrm{N}, 1 / \mathrm{r}$ e o método geral.

\subsubsection{Modelos para análise não-linear}

O comportamento não-linear físico do concreto armado em serviço pode ser modelado de duas maneiras: por meio das relações entre tensões e deformações do concreto e do aço, ou via diagramas momento versus curvatura, de uma seção transversal. A NBR 6118:2003 e o CEBFIP MC90 apresentam modelos do primeiro tipo para o concreto e para o aço. A NBR 6118:2003 propõe, para o concreto comprimido, um diagrama parábola-retângulo, de aplicação ao estado limite último, e o CEB-FIP MC90, para o mesmo caso, propõe uma função que permite estimar inclusive o comportamento do concreto no trecho descendente do diagrama tensão-deformação. Já o segundo tipo de modelagem tem como alguns dos representantes os modelos de Branson, de Ghali \& Favre e de Debernardi, além de um proposto por CORREA 
(1991). Uma alternativa além desses é o modelo de dano, também baseado em tensões e deformações, com boa representação para o concreto armado.

Os modelos baseados em relações entre tensões e deformações podem ser chamados de modelos constitutivos, e exigem, além da discretização dos elementos estruturais em trechos de armadura constante, a estratificação das seções em camadas, ao longo das quais é realizada a integração das tensões normais. As seções são divididas em chamados pontos de Gauss, os quais, em maior número, fornecem resultados mais precisos de esforços internos. Já os modelos baseados em diagramas momento versus curvatura são chamados de modelos mecânicos, e trazem o problema não-linear para o âmbito mais macroscópico de seções, e não mais de pontos quaisquer na estrutura. Essa premissa os torna mais acessíveis e por isso terão mais ênfase no presente trabalho, que apresenta os modelos de Branson e de Ghali \& Favre.

Para melhor entender os modelos baseados em diagramas momento versus curvatura, faz-se necessária uma breve explicação dos estádios de solicitação do concreto. Esses estádios podem ser definidos como fases por quais passa o concreto, quando solicitado por um carregamento com valor variando de zero àquele que provoca a ruptura da peça em questão. O estádio I admite a seção não fissurada, e a proporcionalidade entre tensões e deformações para qualquer fibra da seção. O estádio II, quando chamado de estádio II "puro", considera o concreto tracionado totalmente fissurado e sem contribuição na resistência da seção. Já o estádio III aplica-se a ações elevadas, e ocorre quando se tem a ruptura do concreto comprimido.

Os estádios de solicitação são na verdade estágios idealizados do comportamento do concreto, assim como rótulas e engastes perfeitos são idealizações das condições de apoio de uma viga, que na realidade poderiam ser melhor representadas por apoios semi-rígidos. Analogamente, as seções transversais de peças de concreto armado, que se encontram fissuradas em serviço (situação desejada, desde que sem aberturas excessivas que comprometam a durabilidade), têm comportamento pertencente a uma faixa intermediária entre os estádios I e II. Isso ocorre por elas serem dimensionadas no estádio III, com coeficientes de segurança de valores consideráveis. Outra razão para esse comportamento é a contribuição do concreto intacto entre fissuras na resistência à tração, também conhecida como "tension stiffening". A NBR 6118:2003 recomenda o modelo empírico de Branson, para determinar o valor de uma rigidez equivalente à flexão, a ser posteriormente utilizada na verificação do estado limite de deformações excessivas (ELS-DEF). 


\section{a) Modelo de Branson}

A rigidez equivalente de Branson é dada pela Eq. (3.24):

$(E I)_{e q}=E_{c s} \cdot\left\{\left(\frac{M_{r}}{M_{a}}\right)^{3} I_{c}+\left[1-\left(\frac{M_{r}}{M_{a}}\right)^{3}\right] I_{l l}\right\} \leq E_{c s} I_{c}$

$\mathrm{I}_{\mathrm{C}}$ refere-se à inércia bruta da seção, desprezando a existência da armadura. $I_{\|}$é o momento de inércia do estádio II "puro", com consideração das armaduras. $M_{a}$ é o momento fletor na seção crítica do vão considerado, com valor dado pela combinação adequada de ações (combinação quase-permanente para verificações do estado limite de deformações excessivas). $M_{r}$ é o momento de fissuração do elemento estrutural dado na Eq. (3.25); seu valor é atingido quando a fibra mais tracionada da seção tem a sua tensão superior à resistência do concreto à tração.

$M_{r}=\frac{\alpha \cdot f_{c t} I_{c}}{y_{t}}$

$\alpha$ é um fator que correlaciona a resistência à tração na flexão com a resistência à tração direta, e vale 1,2 para seções T ou duplo T, e 1,5 para seções retangulares. $y_{t}$ é a distância do centro de gravidade da seção à fibra mais tracionada. $f_{c t}$ é a resistência do concreto à tração direta, dada por $f_{c t, m}$, no caso de verificação do estado limite de deformação excessiva, ou $f_{c t k, i n f}$, para estado limite de formação de fissura, cujos valores são fornecidos pelas Eqs. (3.26) e (3.27), com valores em MPa.

$$
\begin{aligned}
& \mathrm{f}_{\mathrm{ct}, \mathrm{m}}=0,3 \mathrm{f}_{\mathrm{ck}}^{2 / 3} \\
& \mathrm{f}_{\mathrm{ctk}, \mathrm{inf}}=0,7 \mathrm{f}_{\mathrm{ct}, \mathrm{m}}
\end{aligned}
$$

\section{b) Modelo de Ghali e Favre}

Apesar de não ser mencionado pela NBR 6118:2003, o modelo de Ghali \& Favre está presente nas indicações fornecidas pelo IBRACON (2003).

Assim como no modelo de Branson, o modelo de Ghali e Favre propõe uma interpolação direta entre as curvaturas dos estádios I e II. Sua aplicação não apresenta maiores complexidades, e os resultados obtidos são condizentes com os experimentais. Da Eq. (3.28) à Eq. (3.33) tem-se desenvolvida a formulação do modelo de Ghali e Favre. 


$$
\begin{aligned}
& M_{r}=\frac{f_{c t, m} \cdot l_{l}}{\left(h-x_{l}\right)} \\
& \zeta=1-\beta_{1} \cdot \beta_{2} \cdot\left(\frac{M_{r}}{M}\right)^{2} \\
& \frac{1}{r_{1}}=\frac{M}{E_{c s} \cdot l_{l}} \\
& \frac{1}{r_{I I}}=\frac{M}{E_{c s} \cdot l_{\| l}} \\
& \frac{1}{r_{m}}=(1-\zeta) \cdot \frac{1}{r_{l}}+\zeta \cdot \frac{1}{r_{\|}}
\end{aligned}
$$

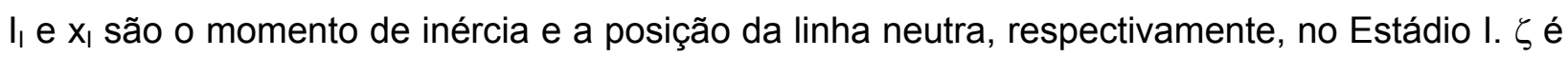
o coeficiente ponderador dos estádios I e II. M é o momento fletor na seção crítica do vão considerado, com valor dado pela adequada combinação de ações. $\beta_{1}$ e $\beta_{2}$ são coeficientes para levar em conta as condições de aderência e o tipo do carregamento, respectivamente.

$\beta_{1}=1,0$ para barras de alta aderência;

$\beta_{1}=0,5$ para barras lisas;

$\beta_{2}=1,0$ para o primeiro carregamento, ou para cargas pouco repetitivas, não permanentes;

$\beta_{2}=0,5$ para cargas permanentes ou com grande número de ciclos.

$1 / r_{1}, 1 / r_{\|}$e $1 / r_{m}$ são as curvaturas da seção referentes ao estádio I, ao estádio II e a um valor médio entre esses dois estádios, respectivamente. A rigidez média $(E I)_{m}$ da Eq. (3.33) faz o papel da rigidez equivalente dada por Branson.

$$
(E I)_{m}=\frac{M}{\frac{1}{r_{m}}}
$$

Uma comparação entre os modelos de Branson, de Ghali e Favre e os estádios I e II pode ser vista na Figura 3.16. 


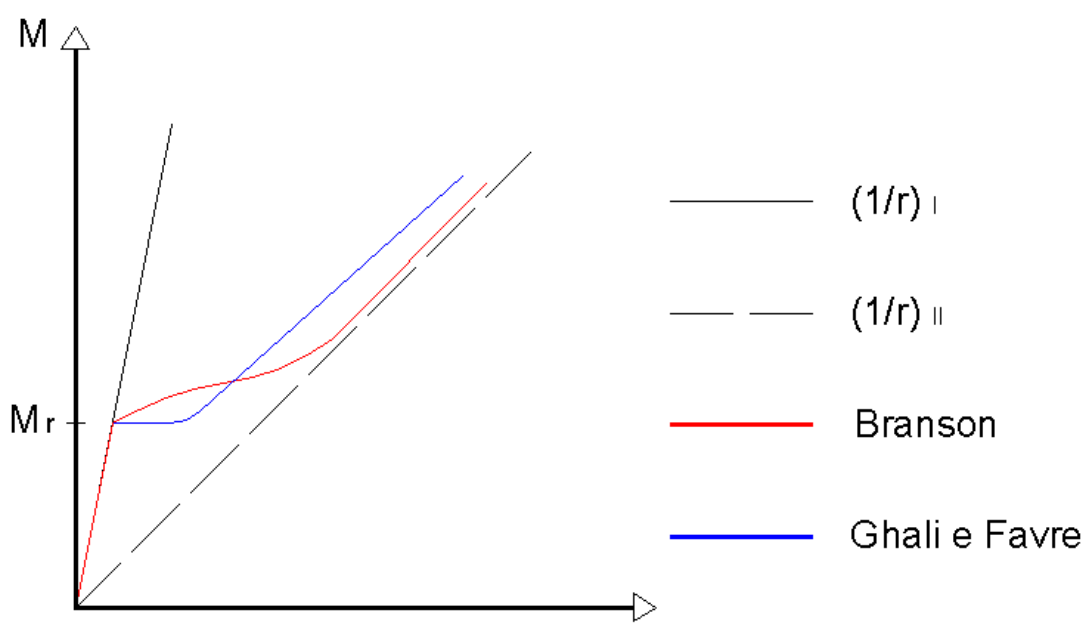

$(1 / r)$

Figura 3.16 - Comparação entre os modelos de Branson e Ghali e Favre

\subsubsection{Observações}

SILVA (1996) ressalta como essencial a análise não-linear em estruturas esbeltas de edifícios, em estruturas nas quais se assume um comportamento elastoplástico, plastificações e outros comportamentos não-lineares, e nas quais se realizam análises de mecanismos de colapso e reservas de segurança.

\subsection{Análise através de modelos físicos}

O uso de modelos físicos, na análise estrutural, tem diversos objetivos, destacando-se entre eles:

- demonstrar o comportamento de certas estruturas, seja com o caráter pedagógico ou o de pesquisa;

- checar a validade de procedimentos analíticos utilizados, geralmente no caso de estruturas cuja teoria ainda não se encontra consolidada no meio técnico;

- participar diretamente na concepção de estruturas, sendo este objetivo o que mais exige precisão na semelhança mecânica entre modelo e estrutura real, e na interpretação dos dados obtidos.

O último objetivo citado é exatamente ao qual se refere a NBR 6118:2003. PREECE \& DAVIES (1964) atestam que em obras de grande importância, em termos de prestígio público ou de quantidade de capital investido, os modelos físicos servem, analogamente à medicina, como uma segunda opinião para projetos baseados em cálculos analíticos. 
Os fatores de escala são obtidos por leis de similaridade. As semelhanças físicas entre o protótipo (estrutura real) e o modelo (estrutura reduzida) englobam as escalas de comprimentos, de massas e de tempo. O material do modelo não precisa ser necessariamente o mesmo da estrutura real, porém deve apresentar as mesmas respostas que o protótipo, proporcionalmente à geometria alterada do modelo, ou seja, é necessário que haja semelhança mecânica entre os dois sistemas. Modelos em tamanho real, ou ampliados, também são possíveis. É o caso do estudo de ligações, como os nós de pórticos. Modelos de estruturas de grande porte, em tamanho real, só compensam se for bastante elevado o número de repetições da construção.

A escolha das escalas e dos materiais dos modelos deve ser tal, que permita a realização de medições de tensões e de deslocamentos, com relativa facilidade e suficiente precisão. Escalas muito pequenas dificultam a medida dos alongamentos das fibras do material, um dos principais métodos de cálculo das tensões, no modelo reduzido. Entre os materiais utilizados destacam-se os celulóides, os plásticos, o gesso, os metais, o concreto, entre outros.

A NBR 6118:2003 prescreve que, as margens de segurança por ela definidas, só podem ser adotadas para modelos físicos, se for possível realizar uma avaliação adequada da variabilidade dos resultados. Além disso, a Norma exige resultados para todos os estados limites últimos e de serviço, a serem empregados na análise da estrutura.

Para estruturas de formas complexas, em que o modelo físico representa a estrutura inteira, utilizam-se modelos reduzidos, como o da Figura 3.17, em que se vê o modelo do Instituto Brasileiro do Café, que não chegou a ser construído. No Brasil, os modelos físicos têm sido usados principalmente na concepção de barragens e de coberturas.

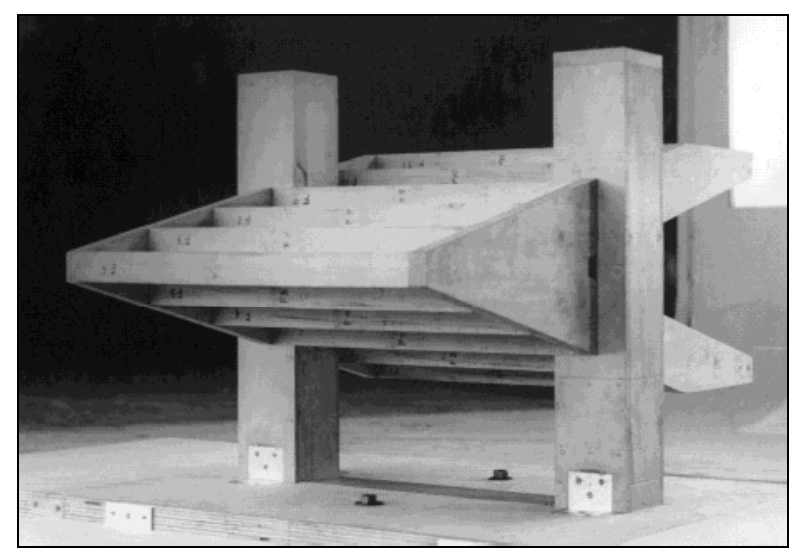

Figura 3.17 - Instituto Brasileiro do Café (Fonte: LOREDO-SOUZA \& BLESSMANN, 2003)

TRINDADE (1982) apresenta o cálculo via modelo físico de uma ponte sobre o rio Guanhanhã, no município de Itariri. O modelo foi construído em acrílico, na escala geométrica 1:50. A escala 
de forças era de 1:1000 e a relação entre os módulos de elasticidade do protótipo e do modelo era de 1:3928. Os esforços internos foram obtidos por meio da medição dos alongamentos das fibras, feita por sensores elétricos, colados em pontos críticos e leves o suficiente para não interferir nos resultados. A linha de influência dos momentos fletores foi obtida fazendo passar uma carga móvel unitária, pelo plano principal da seção transversal do modelo físico.

Apesar do trabalho mencionado visar também a comparação entre os modelos físico e analítico, tem-se a utilização do modelo na análise estrutural. O modelo físico se mostrou mais rígido que o analítico, e as discrepâncias de resultados só foram significativas quanto aos esforços de torção.

O emprego de modelos físicos ainda é bem reduzido, pois geralmente seu custo é maior e sua utilização requer equipamentos sofisticados de laboratório e pessoal especializado. $A$ análise puramente analítica de estruturas prevalece também por ser de fácil automação. A NBR 6118:2003 sugere a análise através de modelos físicos quando os modelos de cálculo forem insuficientes, ou estiverem fora do escopo da Norma. Aconselha-se, para a utilização de modelos físicos na análise estrutural, um estudo mais aprofundado da bibliografia pertinente ao assunto.

\subsection{Comentários}

Deve-se ter em mente, ao final da apresentação dos possíveis tipos de análise estrutural, que cada estrutura merece um estudo individual, à qual se deve aplicar as teorias que mais the convierem para a sua resolução. Custos computacionais altos e a demasiada complexidade dos cálculos, por exemplo, não podem estar presentes na resolução de estruturas simples. Os benefícios trazidos com uma análise mais refinada podem ser em vão, se comparados com os gastos relativos ao tempo despendido.

No entanto, buscas por análises mais realistas devem estar sempre presentes nos projetos estruturais, tomando-se sempre precauções quanto à segurança. A utilização de uma análise plástica, não-linear ou linear com redistribuição, só deve ser realizada se amparada pelo amplo domínio do assunto. Por mais que as estruturas de concreto armado apresentem reservas de capacidade resistente e poder de redistribuição de esforços, adaptando-se para corresponder às hipóteses simplificadoras, a folga dos projetos estruturais tem o seu limite. Em uma estrutura diversas vezes hiperestática, como um pórtico espacial de um edifício, por exemplo, pode ser quase impraticável a determinação do mecanismo crítico de colapso, ainda mais com a gama de combinações de carregamento a ser considerada. Dessa maneira, o uso de uma análise 
mais complicada em um caso como esse, como a análise plástica, pode não ser a melhor opção.

Quanto aos estados limites, a Tabela 3.1 indica resumidamente a que verificação se destinam os vários tipos de análise estrutural.

Tabela 3.1 - Tipos de análise estrutural e suas aplicações

\begin{tabular}{|c|c|}
\hline Análise & Verificação \\
\hline Linear & ELU* e ELS \\
\hline Linear com Redistribuição & ELU \\
\hline Plástica & ELU \\
\hline Não-Linear & ELU e ELS \\
\hline Através de Modelos Físicos & ELU e ELS \\
\hline${ }^{*}$ se garantida a dutilidade dos elementos estruturais \\
\hline
\end{tabular}




\section{VIGA COM SEÇÃO RETANGULAR}

Será realizada a análise estrutural e o dimensionamento da viga V1, indicada na Figura 4.1, por meio da análise linear, análise linear com redistribuição e análise plástica. Essa viga se encontra com suas extremidades apoiadas em outras duas vigas (serão considerados apoios simples nas seções 1 e 3), um apoio central em um pilar (seção 2), e recebe duas cargas concentradas provenientes de dois pilares que nascem nos pontos médios de seus tramos (seções 4 e 5 , onde ocorrem os máximos momentos positivos). Este será o único carregamento considerado, supondo-o constituído por ações permanentes.

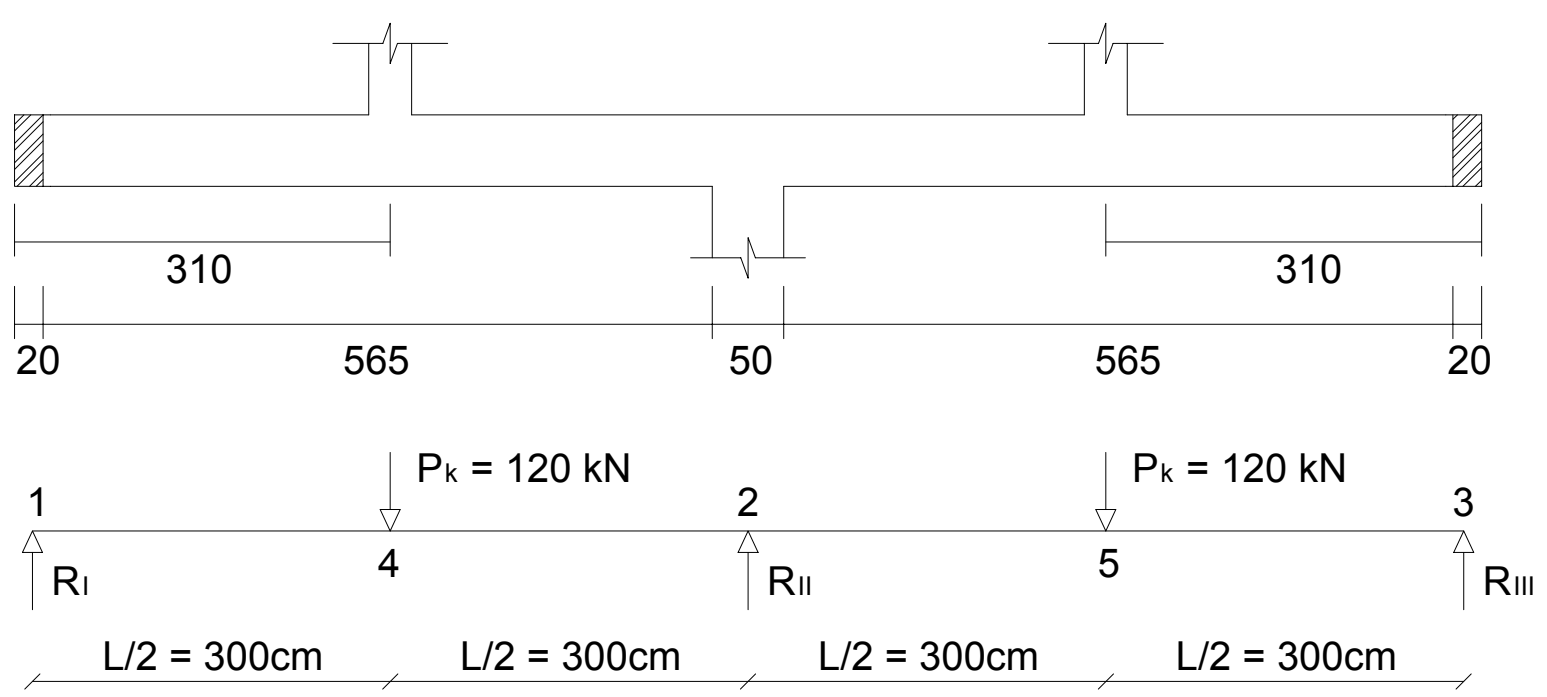

Figura 4.1 - Viga V1 $(25 \mathrm{~cm} \times 50 \mathrm{~cm})$

Admite-se a viga V1 em ambiente interno (Classe de Agressividade Ambiental I para ambientes urbanos) e participante de uma estrutura de nós fixos, concreto $\mathrm{C} 25$, aço CA-50 para a armadura longitudinal e CA-60 para a armadura transversal. O cobrimento é de $2,5 \mathrm{~cm}$. O d' (distância entre o CG da armadura de flexão e a face externa da viga) foi inicialmente considerado como $4 \mathrm{~cm}$. Adotou-se um detalhamento padronizado (ver Figura 4.2) para todas as análises, sempre com quatro barras de mesmo diâmetro fictício, para a armadura de flexão, e estribos também de diâmetro fictício, que proporcionassem o maior espaçamento possível. $O$ mesmo diâmetro fictício dos estribos foi utilizado para os porta-estribos. $\phi_{t}$ e $s_{t}$ referem-se respectivamente ao diâmetro e espaçamento dos estribos. $\phi_{2}$, $\phi_{4}$ e $\phi_{5}$ são os diâmetros fictícios calculados para as seções 2,4 e 5, respectivamente. 


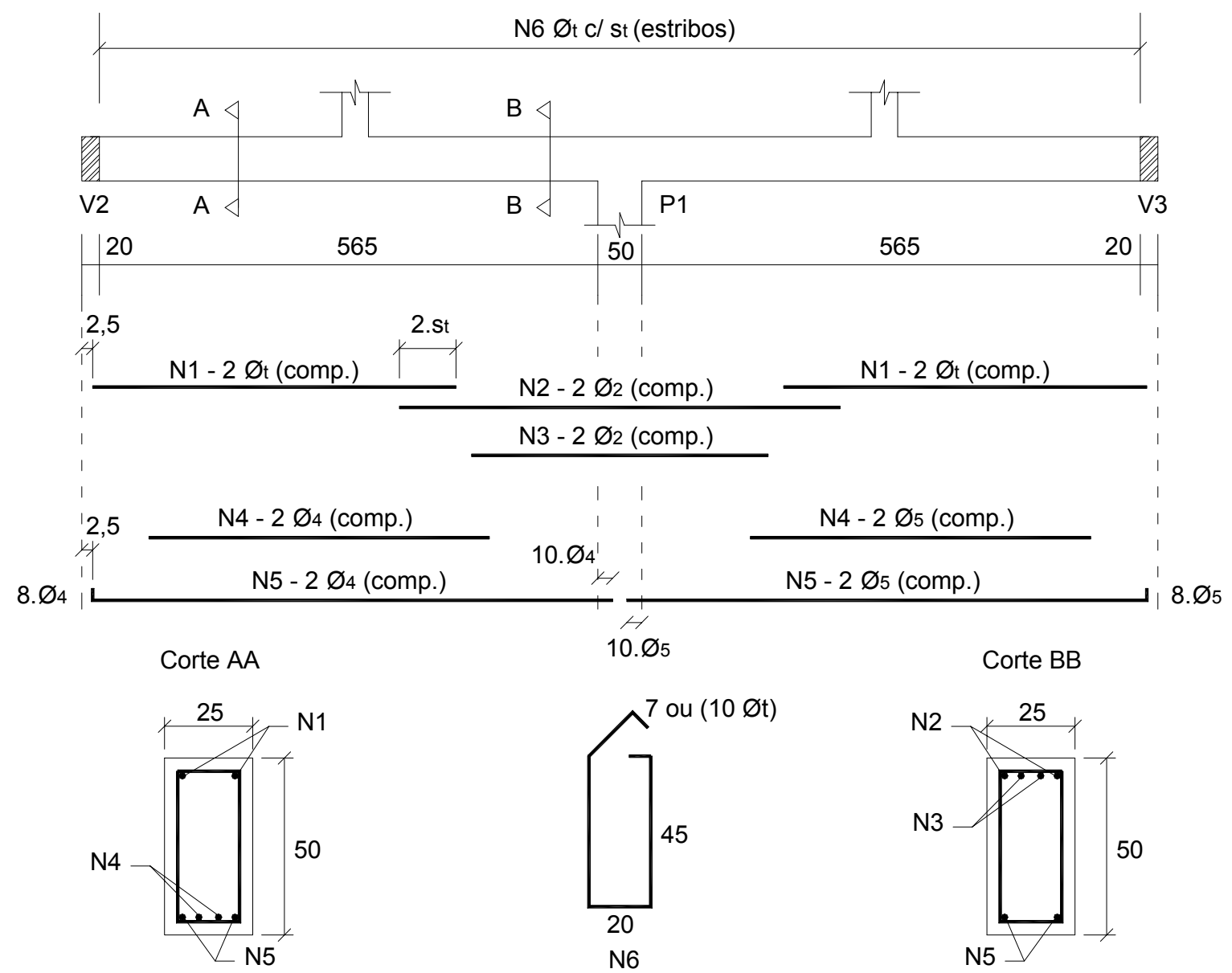

Figura 4.2 - Detalhamento padrão da viga V1

\subsection{Análise linear}

Apresentam-se os esforços, obtidos em uma análise linear, e os dimensionamentos à flexão e ao cisalhamento.

\subsubsection{Esforços}

A partir do método da superposição, advindo da Resistência dos Materiais, pode-se determinar as reações de apoio para os esforços solicitantes de cálculo nas equações (4.2) e (4.3), e em seguida os diagramas de momento fletor e de esforço cortante (Figura 4.3 e Figura 4.4).

$P_{d}=1,4 P_{k}=1,4 \cdot 120=168 k N$

$R_{1}=R_{3}=(5 / 16) P_{d}=(5 / 16) .168=52,5 k N$ 


$$
R_{2}=(11 / 8) P_{d}=(11 / 8) \cdot 168=231 k N
$$

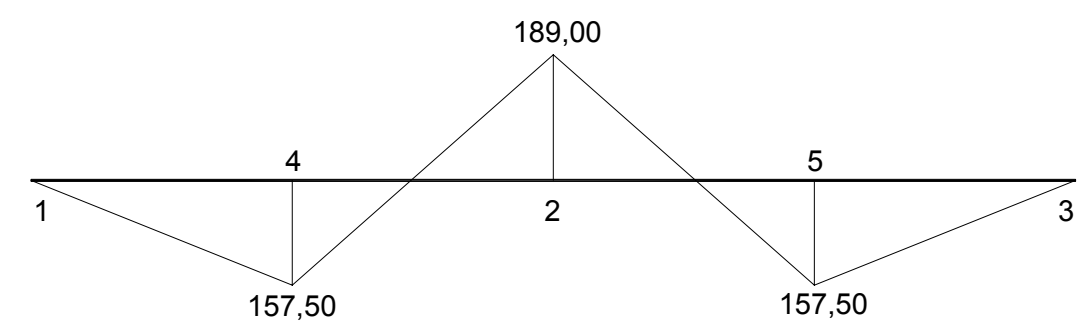

Figura 4.3 - Momentos fletores de cálculo para a análise linear (kN.m)

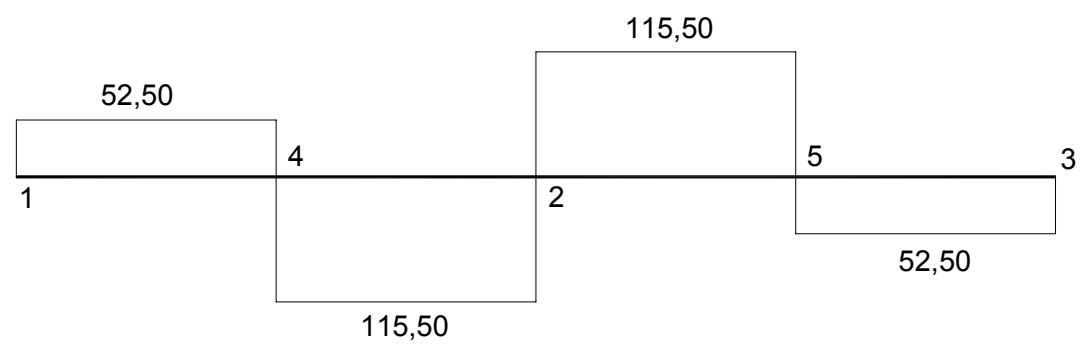

Figura 4.4 - Esforços cortantes de cálculo para a análise linear (kN)

\subsubsection{Flexão}

Seção 4 = Seção 5

$M_{d}=157,5 \mathrm{kN} \cdot \mathrm{m} ; \mathrm{x} / \mathrm{d}=0,276 ; \mathrm{A}_{\mathrm{s}}=8,85 \mathrm{~cm}^{2}\left(\phi_{4}=\phi_{5}=16,8\right)$

Seção 2

$M_{d}=189 k N \cdot m ; x / d=0,341 ; A_{s}=10,94 \mathrm{~cm}^{2}\left(\phi_{2}=18,7\right)$

\subsubsection{Cisalhamento}

$\mathrm{V}_{\mathrm{Sd}}=115,5 \mathrm{kN}$

$V_{R d 2}=0,27 .\left[1-\left(f_{c k} / 250\right)\right] f_{c d} b d=499,01 k N$

$\mathrm{V}_{\mathrm{Sd}}<\mathrm{V}_{\mathrm{Rd} 2} \rightarrow$ ok

$V_{c}=0,6 f_{c t d} b d=0,6 \cdot 0,1282.25 .46=88,49 k N$

$\rho_{\mathrm{sw}, \min }=0,2\left(\mathrm{f}_{\mathrm{ctm}} / \mathrm{f}_{\mathrm{ywk}}\right)=0,2 \cdot(2,565 / 500)=0,001026$ 
$\mathrm{V}_{\mathrm{sw}, \min }=0,9 \rho_{\mathrm{sw}, \min } \mathrm{b} \mathrm{df}_{\mathrm{ywd}}=46,17 \mathrm{kN}$

$V_{S d, \text { min }}=V_{c}+V_{s w, \text { min }}=88,49+46,17=134,66 \mathrm{kN}$

Como $\mathrm{V}_{\mathrm{Sd}}$ é menor que $\mathrm{V}_{\mathrm{Sd} \text {,min }}$, será utilizada armadura mínima ao longo de toda a viga. $\mathrm{A}$ área da Eq.(4.11) refere-se a estribos de dois ramos.

$a_{s w, \min }=\left(100 \rho_{s w, \min } b\right) / 2=1,28 \mathrm{~cm}^{2} / \mathrm{m}$

Se $V_{S d}<0,67 V_{R d 2}$, o espaçamento máximo entre estribos é dado por $s_{\text {tmáx }}=0,6 d$, obrigatoriamente menor ou igual a $30 \mathrm{~cm}$.

$0,67 \mathrm{~V}_{\mathrm{Rd} 2}=0,67.499,01=334,34 \mathrm{kN}$

$\mathrm{S}_{\text {tmáx }}=0,6.46 \cong 27 \mathrm{~cm}$

Para esse espaçamento e armadura mínima, tem-se um $\phi_{\mathrm{t}}=6,6 \mathrm{~mm}$, que será o mesmo usado nos porta-estribos. Esse diâmetro de estribos, juntamente com os diâmetros encontrados para a armadura de flexão, fazem com que a adoção inicial de d' $=4 \mathrm{~cm}$ tenha tido uma boa aproximação.

\subsubsection{Estado limite de formação de fissuras (ELS-F)}

Deve ficar bem claro que os esforços em serviço são menores, o que exige combinações de serviço para os carregamentos e fazem da análise linear uma boa ferramenta de análise.

Para a verificação do ELS-F deve ser tomada a combinação rara de ações, ou seja, $g_{k}+q_{k}$, em que $g_{k}$ é a ação permanente com valor característico e $q_{k}$ é a ação variável com valor característico. Neste caso específico, tem-se apenas $g_{k}$. Os momentos fletores em serviço são indicados na Figura 4.5.

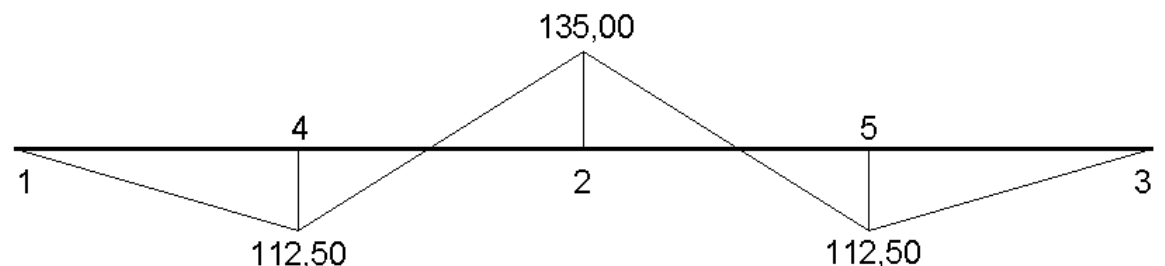

Figura 4.5 - Momentos fletores para a combinação rara com análise linear (kN.m)

O momento de fissuração é calculado na Eq.(4.14). 
$M_{r}=\frac{\alpha f_{c t k, i n f} I_{c}}{y_{t}}=\frac{1,5 \cdot 0,1795 \cdot 260417}{25}=2805 \mathrm{kN} \cdot \mathrm{cm}$

Seção 2: $13500 \mathrm{kN} . c m>M_{r} \rightarrow$ há a formação de fissuras.

\subsubsection{Estado limite de deformação excessiva (ELS - DEF)}

O momento em serviço para o ELS-DEF é calculado com a combinação quase-permanente, em que $\psi_{2}$ para edifícios residenciais é 0,3 . O carregamento passa a ser dado por $g_{k}+0,3 q_{k}$, ou, neste caso específico, por $g_{k}$. Portanto, os momentos fletores são os mesmos utilizados na verificação do ELS-F.

a) Momento de fissuração

$\mathrm{M}_{\mathrm{r}}=\frac{\alpha \mathrm{f}_{\mathrm{ct}, \mathrm{m}} \mathrm{I}_{\mathrm{c}}}{\mathrm{y}_{\mathrm{t}}}=\frac{1,5 \cdot 0,2565 \cdot 260417}{25}=4008 \mathrm{kN} \cdot \mathrm{cm}$

b) Rigidez equivalente de Branson

$(E I)_{\text {eq }}=E_{c s}\left\{\left(\frac{M_{r}}{M_{a}}\right)^{3} I_{c}+\left[1-\left(\frac{M_{r}}{M_{a}}\right)^{3}\right] I_{I I}\right\} \leq E_{c s} I_{c}$
$(E I)_{\text {eq }}=2380 \cdot\left\{\left(\frac{4008}{11250}\right)^{3} \cdot 260417+\left[1-\left(\frac{4008}{11250}\right)^{3}\right] \cdot 102824\right\}$

$(\mathrm{EI})_{\mathrm{eq}}=261677301 \mathrm{kN} \cdot \mathrm{cm}^{2}=26168 \mathrm{kN} \cdot \mathrm{m}^{2}$

c) Flecha imediata

$\mathrm{Na}$ Eq.(4.19) tem-se a flecha imediata calculada para o ponto de momento máximo positivo (sob as cargas), a partir de tabelas para vigas isostáticas. Neste cálculo as ações são dadas pela combinação quase-permanente.

$a_{i}=\frac{P_{k} L^{3}-3 M_{2} L^{2}}{48(E I)_{e q}}=\frac{120 \cdot 600^{3}-3 \cdot 13500 \cdot 600^{2}}{48 \cdot 261677301}=0,90 \mathrm{~cm}$

d) Flecha total 
Para o cálculo da flecha diferida (consideração da fluência), será desprezada a presença dos porta-estribos, e considerar-se-á a aplicação da carga de longa duração aos 30 dias de idade. Deseja-se estimar o valor da flecha $a_{t}$ para um tempo maior que 70 meses, estipulado pela NBR 6118:2003 como o necessário para a estabilização dos deslocamentos por fluência. Por se tratar de armadura simples, tem-se:

$\rho^{\prime}=\frac{A_{s}^{\prime}}{b d}=0$

O efeito da fluência e a flecha total serão dados por:

$$
\begin{aligned}
& \Delta \xi=\xi(\mathrm{t})-\xi\left(\mathrm{t}_{0}\right)=2-0,68=1,32 \\
& \mathrm{a}_{\mathrm{f}}=\frac{\Delta \xi}{1+50 \rho^{\prime}}=1,32 \\
& a_{\mathrm{t}}=\mathrm{a}_{\mathrm{i}}\left(1+\mathrm{a}_{\mathrm{f}}\right)=0,90 \cdot(1+1,32) \\
& a_{t}=2,09 \mathrm{~cm}<\frac{\mathrm{L}}{250}=\frac{600}{250}=2,4 \mathrm{~cm}
\end{aligned}
$$

A flecha encontrada é igual para os dois vãos, e menor que a flecha admissível.

\subsubsection{Estado limite de abertura de fissuras (ELS-W)}

O momento em serviço é calculado com a combinação freqüente, em que $\psi_{1}$ para edifícios residenciais é 0,4 . O carregamento passa a ser dado por $g_{k}+0,4 q_{k}$, ou, neste caso específico, por $\mathrm{g}_{\mathrm{k}}$. Portanto, o diagrama de momentos fletores é o mesmo utilizado na verificação do ELSF. A verificação do ELS-W é realizada na seção 2, e a partir da disposição da armadura mostrada na Figura 4.6, pode-se estimar a abertura de fissuras.

Considera-se a abertura das fissuras, w, a menor entre as obtidas com as equações (4.25) e (4.26):

$$
\begin{aligned}
& w=\frac{\phi_{i}}{12,5 \eta_{i}} \cdot \frac{\sigma_{s i}}{E_{s i}} \cdot \frac{3 \sigma_{s i}}{f_{c t, m}} \\
& w=\frac{\phi_{i}}{12,5 \eta_{i}} \cdot \frac{\sigma_{s i}}{E_{s i}} \cdot\left(\frac{4}{\rho_{r i}}+45\right)
\end{aligned}
$$




\section{$3,73 \mathrm{~cm}$}

\section{$4,10 \mathrm{~cm}$}

$4 \varnothing 1,87 \mathrm{~cm}$

$\mathrm{c}=2,5 \mathrm{~cm}$

$\varnothing_{\mathrm{t}}=0,66 \mathrm{~cm}$

Figura 4.6 - Disposição da armadura tracionada na seção 2

$A_{c r}=$ área de região de envolvimento protegida pelas barras longitudinais dada por:

- Para uma camada de barras $\rightarrow \mathrm{A}_{\mathrm{cr}}=\mathrm{b}_{\mathrm{w}}\left(\mathrm{d}^{\prime}+7,5 \phi_{\mathrm{i}}\right)$;

- Para duas ou mais camadas de barras $\rightarrow A_{c r}=b_{w}\left(y_{i}+7,5 \phi_{i}\right)$;

$y_{i}=$ posição do eixo das barras tracionadas mais externas

$A_{c r}=25 \cdot[4+(7,5 \cdot 1,87)]=450,62 \mathrm{~cm}^{2}$

$\sigma_{\mathrm{si}}=$ tensão de tração no centro de gravidade da armadura considerada, calculada no estádio II. Utiliza-se o momento de serviço calculado com a combinação freqüente, e o braço de alavanca $\left(\mathrm{z}_{2}\right)$ é dado por $\mathrm{d}$ menos um terço de $\mathrm{x}_{2}$ (referente ao estádio II), para levar em conta a distribuição triangular de tensões no concreto comprimido do estádio II.

$\mathrm{O} \mathrm{x}_{2}$ é calculado fazendo o momento estático da seção de concreto armado igual a zero, o que resulta em uma equação do segundo grau, com $\alpha_{e}$ dado pela relação $E_{s} / E_{c}$ :

$\frac{b}{2} x_{2}^{2}+\left[\left(\alpha_{e} A_{s}^{\prime}\right)+\left(\alpha_{e} A_{s}\right)\right] \cdot x_{2}-\alpha_{e}\left[\left(A_{s}^{\prime} d^{\prime}\right)+\left(A_{s} d\right)\right]=0 \rightarrow x_{2}=15,38 c m$

$\sigma_{\mathrm{si}}=\frac{M_{\mathrm{ser}}}{\mathrm{z}_{2} \mathrm{~A}_{\mathrm{s}}}=\frac{13500}{\left(46-\frac{15,38}{3}\right) \cdot 10,94}=30,19 \mathrm{kN} / \mathrm{cm}^{2}$

$\eta_{i}=2,25$ (coeficiente de conformação superficial da armadura considerada);

$f_{c t, m}=0,256 \mathrm{kN} / \mathrm{cm}^{2}$ (resistência média do concreto à tração, dada por $0,3 \mathrm{f}_{\mathrm{ck}}^{2 / 3}$ );

$\mathrm{E}_{\mathrm{si}}=21000 \mathrm{kN} / \mathrm{cm}^{2}$ (módulo de elasticidade do aço da barra considerada); 
$\rho_{\mathrm{ri}}=\mathrm{A}_{\mathrm{s}} / \mathrm{A}_{\mathrm{cr}}=10,94 / 450,62=0,0243$

Substituindo esses valores nas equações (4.25) e (4.26), tem-se as equações (4.31) e (4.32):

$w=\frac{1,87}{12,5 \cdot 2,25} \cdot \frac{30,19}{21000} \cdot \frac{3 \cdot 30,19}{0,256}=0,034 \mathrm{~cm}=0,34 \mathrm{~mm}$

$w=\frac{1,87}{12,5 \cdot 2,25} \cdot \frac{30,19}{21000} \cdot\left(\frac{4}{0,0243}+45\right)=0,020 \mathrm{~cm}=0,20 \mathrm{~mm}$

Considerando o menor desses valores, verifica-se que não há problemas de abertura de fissuras:

$\mathrm{w}=0,20 \mathrm{~mm}<\mathrm{W}_{\text {lim }}(0,40 \mathrm{~mm}$ para classe de agressividade ambiental I).

\subsection{Análise linear com redistribuição}

Ao realizar-se uma redistribuição de momentos em uma viga, uma boa opção consiste em equilibrar as áreas de armadura do vão e dos apoios. Para tal, calcula-se primeiramente o coeficiente de redistribuição $\delta$ que iguala os momentos das seções 2,4 e 5 , a partir da soma dos dois primeiros diagramas que constam na Figura 4.7 .
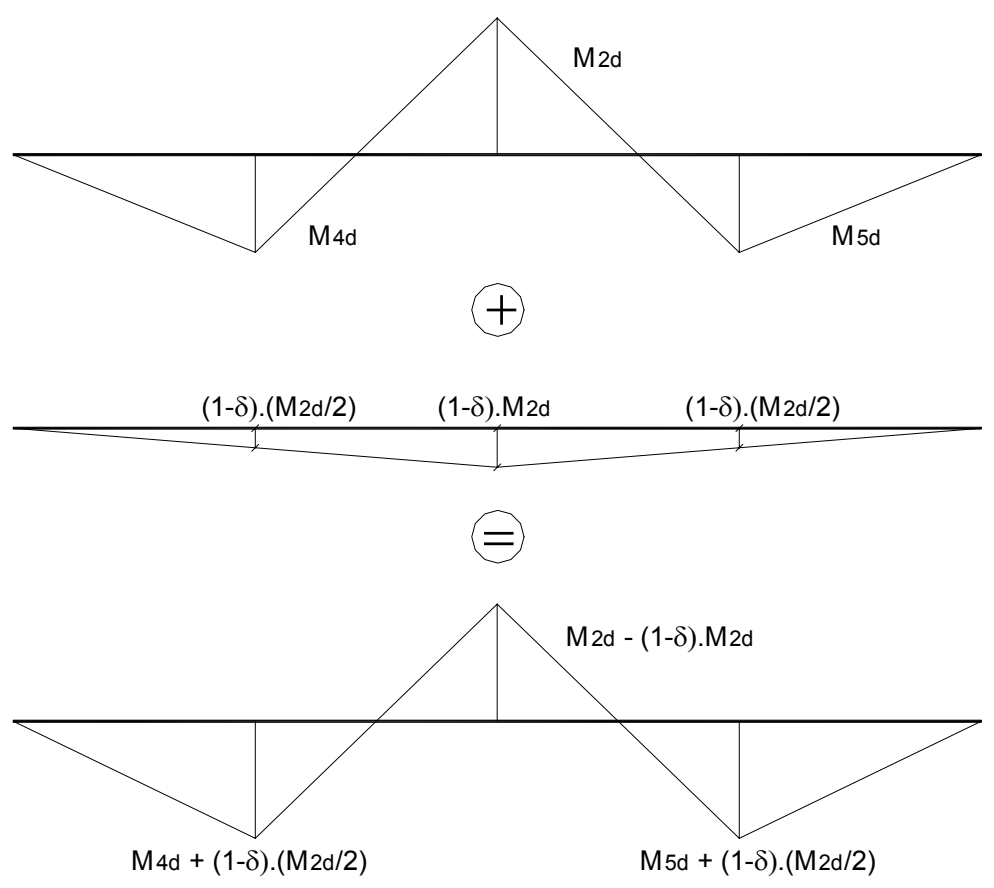

Figura 4.7 - Soma de diagramas para igualar os momentos do apoio e dos vãos 
$\mathrm{M}_{2 \mathrm{~d}}-(1-\delta) \mathrm{M}_{2 \mathrm{~d}}=\mathrm{M}_{4 \mathrm{~d}}+\frac{(1-\delta) \mathrm{M}_{2 \mathrm{~d}}}{2}$

Substituindo os valores dos momentos de cálculo, provenientes da análise elástica, na Eq. (4.33), tem-se que $\delta=8 / 9$. Verifica-se a possibilidade de uso deste valor de $\delta$ somente após o cálculo da armadura de flexão da seção 2, quando se conhece o valor da altura relativa da linha neutra, $x / d$, nessa seção. O momento reduzido na seção 2 é calculado pelo produto entre $\delta$ e $\mathrm{M}_{2 \mathrm{~d}}$, já o momento máximo nos vãos é dado pela parcela à direita da igualdade na Eq.(4.33). De uma maneira mais geral, os momentos positivos são corrigidos pela análise do tramo isolado, com os momentos de apoio reduzidos aplicados em seus extremos, e com as ações externas atuando ao longo da viga, como na Figura 4.8. Neste caso específico, o ponto de momento máximo no vão não muda, permanecendo sob os pontos de aplicação das forças.

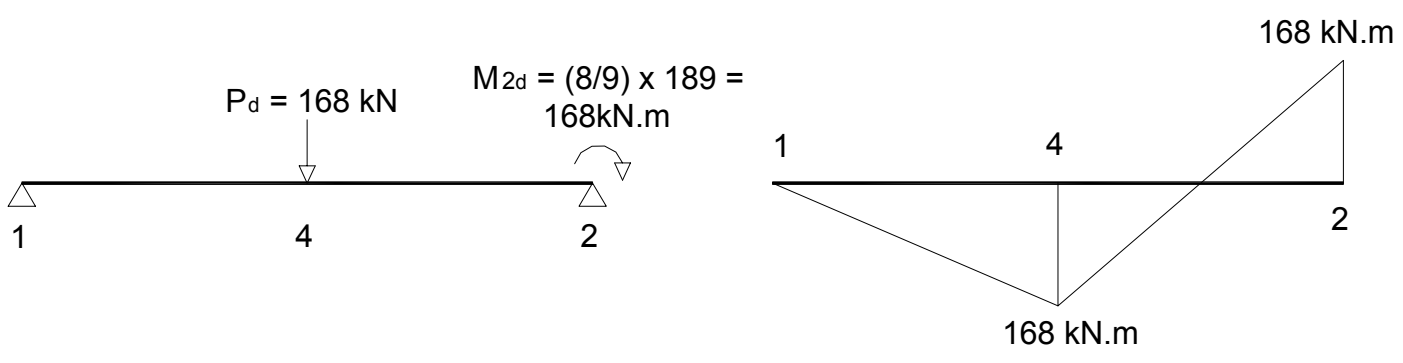

Figura 4.8 - Correção do momento positivo

\subsubsection{Esforços}

$R_{1}=R_{3}=P_{d} / 3=168 / 3=56 k N$

$R_{2}=(4 / 3) P_{d}=(4 / 3) .168=224 k N$

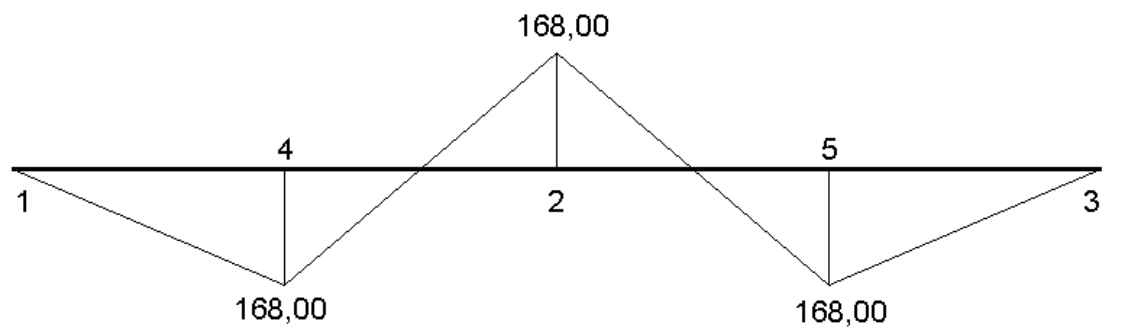

Figura 4.9 - Momentos fletores de cálculo para a análise linear com redistribuição (kN.m) 


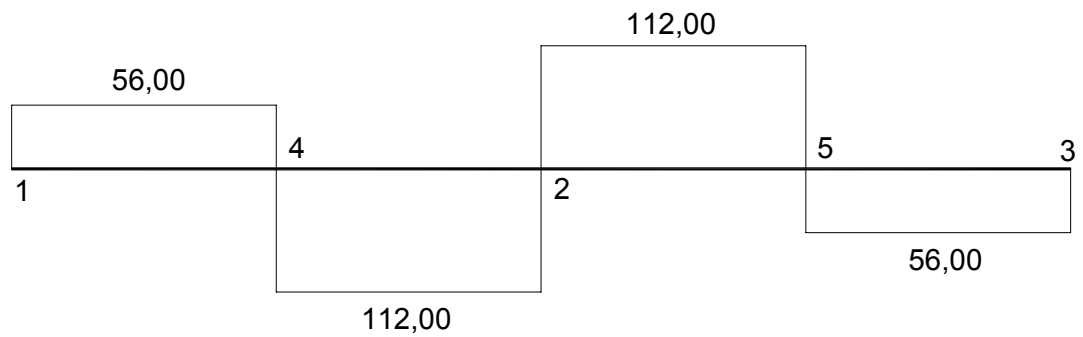

Figura 4.10 - Esforços cortantes de cálculo para a análise linear com redistribuição (kN)

\subsubsection{Flexão}

Seção 2 = Seção $4=$ Seção 5

$M_{d}=168 \mathrm{kN} \cdot \mathrm{m} ; \mathrm{x} / \mathrm{d}=0,297 ; \mathrm{A}_{\mathrm{s}}=9,53 \mathrm{~cm}^{2}\left(\phi_{2}=\phi_{4}=\phi_{5}=17,4\right)$

Verificação do valor de $\delta$ para $\mathrm{f}_{\mathrm{ck}} \leq 35 \mathrm{MPa}$ :

$\delta \geq 0,44+1,25(\mathrm{x} / \mathrm{d})=0,44+(1,25.0,297) \rightarrow \delta \geq 0,81$

O coeficiente utilizado, $\delta=8 / 9$, está acima do limite estabelecido pela relação $\mathrm{x} / \mathrm{d}$ na Eq.(4.36), e acima do limite estabelecido para estruturas de nós fixos $(\delta \geq 0,75)$. Portanto, pode ser utilizado.

\subsubsection{Cisalhamento}

$\mathrm{V}_{\mathrm{Sd}}=112 \mathrm{kN}$

$\mathrm{V}_{\mathrm{Sd}, \min }=134,66 \mathrm{kN}$

Como $\mathrm{V}_{\mathrm{Sd}}$ é menor que $\mathrm{V}_{\mathrm{Sd} \text {,min }}$, será utilizada armadura mínima ao longo de toda a viga.

$a_{\mathrm{sw}, \min }=1,28 \mathrm{~cm}^{2} / \mathrm{m}$ (estribos de 2 ramos); $\phi 6,6 \mathrm{c} / 27$.

\subsubsection{Estado limite de formação de fissuras (ELS-F)}

A verificação do estado limite de serviço para a análise linear com redistribuição se dá da mesma forma que para a análise linear, pois os esforços advém de combinações de serviço, rara, quase-permanente ou freqüente (ver Figura 4.5). A diferença se encontra somente na armadura que foi dimensionada para os momentos redistribuídos.

A mudança de armadura não influencia essa verificação, portanto há a formação de fissuras. 


\subsubsection{Estado limite de deformação excessiva (ELS - DEF)}

Com a redistribuição de momentos, tem-se o aumento dos momentos nos vãos, e, portanto, uma maior área de armadura positiva de flexão, o que colabora para o aumento da inércia equivalente. Uma vez que os esforços para a verificação do ELS-DEF continuam sendo os da combinação quase-permanente, há uma redução no valor da flecha em 4,3\%.

$(E \mathrm{El})_{\mathrm{eq}}=275351092 \mathrm{kN} \cdot \mathrm{cm}^{2}=27535 \mathrm{kN} \cdot \mathrm{m}^{2}$

$a_{i}=0,86 \mathrm{~cm}$

$\mathrm{a}_{\mathrm{t}}=2,00 \mathrm{~cm}<\frac{\mathrm{L}}{250}=\frac{600}{250}=2,4 \mathrm{~cm}$

\subsubsection{Estado limite de abertura de fissuras (ELS-W)}

As seções 2, 4 e 5 possuem agora a mesma armadura, e com os momentos fletores da combinação freqüente, a seção 2 é a mais crítica quanto à abertura de fissuras. A tendência é sempre aumentar a abertura de fissuras nos apoios, com uma crescente redistribuição de momentos. Neste caso, o aumento da abertura de fissura na seção 2 foi de $15 \%$.

Seção $2: \mathrm{w}=0,23 \mathrm{~mm}<\mathrm{w}_{\lim }(0,4 \mathrm{~mm}$ para classe de agressividade ambiental $\mathrm{I})$.

\subsection{Análise plástica}

Deseja-se, com a análise plástica, chegar à mesma disposição de armaduras que se mostrou possível por meio da análise linear com redistribuição $\left(M_{2 d}=M_{4 d}=M_{5 d}\right)$. Portanto, as armaduras e o detalhamento são os mesmos, inclusive a verificação dos estados limites de serviço pode-se considerar realizada. Necessita-se, no entanto, verificar a capacidade de rotação plástica da viga no apoio central e, apesar de não ser vantajoso para seções retangulares (desequilíbrio entre armaduras negativas e positivas), se testará, no item 4.3.5, a máxima redistribuição permitida com armadura simples, e seu fator limitante.

\subsubsection{Primeira rótula plástica}

Para o melhor entendimento da análise plástica imagina-se que as cargas $P$ aumentem gradualmente de valor. Dada uma viga sem problemas de concretagem, com suas seções críticas (2, 4 e 5) igualmente armadas (momentos plásticos iguais, ou seja, $M_{2 p}=M_{4 p}=M_{5 p}$ ), a 
primeira seção a entrar em plastificação é a seção 2, do apoio central. Se essa seção tiver capacidade de acomodação plástica, origina-se um novo esquema estático, formado por dois tramos simplesmente apoiados. O momento nesse apoio passa a ser constante e igual a $\mathrm{M}_{2 \mathrm{p}}$, e no instante da formação da rótula plástica, para este esquema estático, os momentos nas seções 4 e 5 correspondem a 5/6 do momento na seção 2 .

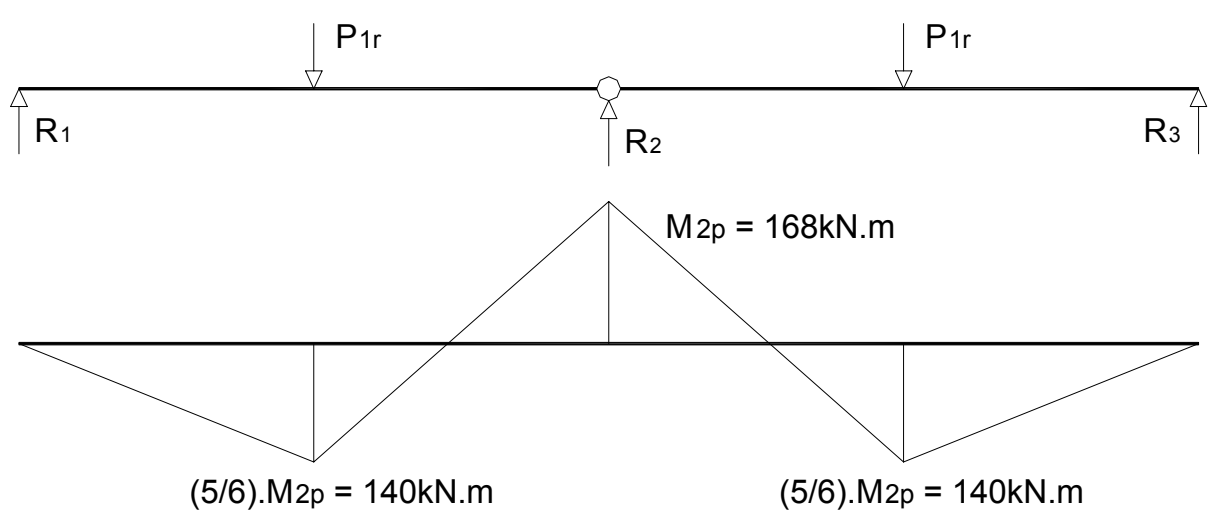

Figura 4.11 - Formação da primeira rótula plástica

A força necessária para formar a primeira rótula plástica, $P_{1 r}$, é dada na Eq.(4.42) em função do momento fletor $M_{2 p}$ que plastifica a seção 2:

$P_{1 \mathrm{r}}=\frac{16 \cdot \mathrm{M}_{2 \mathrm{p}}}{3 . \mathrm{L}}=\frac{16 \cdot 16800}{3.600}=149,33 \mathrm{kN}$

\subsubsection{Segunda rótula plástica}

$\mathrm{Na}$ verdade serão duas rótulas a se formar simultaneamente, mantendo-se o aumento gradual das forças $P$ e o valor constante do momento na seção 2, $M_{2 p}$. Para que sejam formadas rótulas plásticas nas seções 4 e 5 é necessário dar um acréscimo de força $\Delta P_{2 r}$, à força $P_{1 r}$, acréscimo este responsável, isoladamente, pelo diagrama de momento fletor da Figura 4.12.

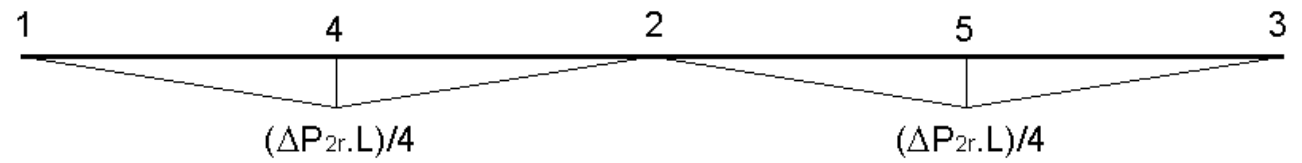

Figura 4.12 - Momentos fletores gerados pelo acréscimo de carga $\Delta \mathrm{P}_{2 \mathrm{r}}$

O momento de plastificação das seções 4 e 5 é, portanto, igual à soma entre o momento que existia, ao se formar a primeira rótula plástica, e o momento causado unicamente pelo acréscimo $\Delta \mathrm{P}_{2 \mathrm{r}}$, dada na Eq.(4.43). 


$$
\begin{aligned}
& \mathrm{M}_{4 \mathrm{p}}=\frac{5 \mathrm{M}_{2 \mathrm{p}}}{6}+\frac{\Delta \mathrm{P}_{2 \mathrm{r}} \mathrm{L}}{4} \\
& \Delta \mathrm{P}_{2 \mathrm{r}}=\frac{4.16800}{6.600}=18,67 \mathrm{kN}
\end{aligned}
$$

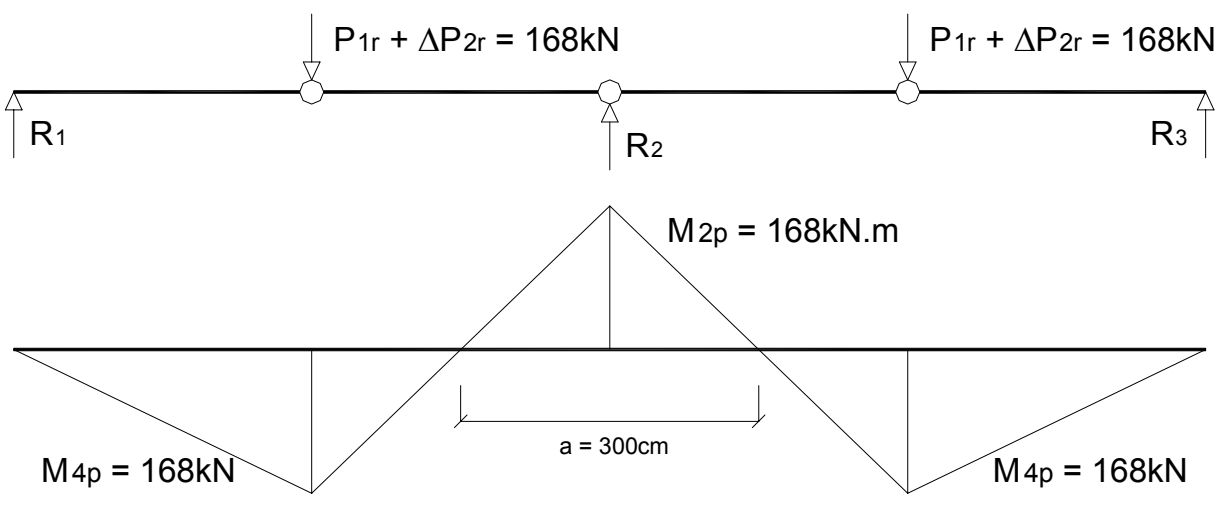

Figura 4.13 - Formação do mecanismo de colapso

\subsubsection{Rotação plástica}

A soma das rotações, à esquerda e à direita do apoio da seção 2 , decorrentes do acréscimo $\Delta \mathrm{P}_{2 \mathrm{r}}$, fornece o valor da rotação necessária $\theta_{\mathrm{p} 2}$ nesse apoio, para a formação do mecanismo de colapso, que ocorre com o surgimento das rótulas plásticas no meio dos dois tramos. A rotação da seção 2 , tanto à esquerda, $\theta_{\mathrm{p} 2 \mathrm{e}}$, como à direita, $\theta_{\mathrm{p} 2 \mathrm{~d}}$, é calculada elasticamente, com a consideração de uma força concentrada de valor $\Delta \mathrm{P}_{2 r}$ atuando na seção central de uma viga biapoiada de vão L. Esses valores são facilmente encontrados em livros de Resistência dos Materiais; ver TIMOSHENKO \& GERE (1994). Tem-se para a rotação plástica necessária do apoio 2:

$\theta_{\mathrm{p} 2}=\theta_{\mathrm{p} 2 \mathrm{e}}+\theta_{\mathrm{p} 2 \mathrm{~d}}$

$\theta_{\mathrm{p} 2}=\frac{\Delta \mathrm{P}_{2 \mathrm{r}} \mathrm{L}^{2}}{16 \mathrm{El}}+\frac{\Delta \mathrm{P}_{2 \mathrm{r}} \mathrm{L}^{2}}{16 \mathrm{El}}$

Uma vez que o concreto já se encontra fissurado, na formação de uma rótula plástica, utiliza-se o produto de inércia El referente ao estádio II:

$\theta_{\mathrm{p} 2}=\frac{2 \cdot 18,67 \cdot 600^{2}}{16 \cdot 2380 \cdot 108841}=3,24 \cdot 10^{-3} \mathrm{rad}$ 


\subsubsection{Capacidade de rotação plástica (NBR 6118:2003)}

A capacidade de rotação plástica $\left(\theta_{p_{\ell}}\right)$ da seção é função da posição relativa da linha neutra, $\mathrm{x} / \mathrm{d}$, calculada para a seção 2 , com o momento já redistribuído. $\theta_{\mathrm{p} \ell}$ é calculado a partir da Figura 3.14 adaptada da NBR 6118:2003, que permite o uso da Eq.(4.49), para o aço CA-50.

$a \rightarrow$ distância entre pontos de momento nulo da região que contém a seção plastificada, no diagrama com os momentos já redistribuídos (ver Figura 4.13);

$a / d=300 / 46=6,52$

$1000 \theta_{p l}=3,5 \frac{d}{x} \sqrt{\frac{(a / d)}{6}}=3,5 \cdot \frac{1}{0,297} \cdot \sqrt{\frac{6,52}{6}}$

$\theta_{\mathrm{pl}}=12,29 \cdot 10^{-3} \mathrm{rad}$

$\theta_{\mathrm{p} 2}<\theta_{\mathrm{p} \ell} \rightarrow$ a capacidade de rotação atende à rotação necessária à redistribuição.

\subsubsection{Máxima redistribuição}

Nota-se uma certa folga por parte da rotação necessária, em relação à capacidade de rotação da seção 2. No entanto, não interessa nesse caso diminuir mais o momento no apoio em prol de um aumento dos momentos nos vãos, já que é possível manter o equilíbrio entre ambos, bem como o equilíbrio da armadura. Mas, com o intuito de analisar a máxima redistribuição permitida pela análise plástica, diminui-se gradativamente o coeficiente de redistribuição $\delta$ a intervalos de 0,05 ( $\delta=0,80 ; 0,75 ; 0,70 \ldots)$. O valor limite encontrado foi $\delta=0,65$, bem abaixo, portanto, daquele permitido por uma análise linear com redistribuição.

Tabela 4.1 - Maior redistribuição possível com a análise plástica

\begin{tabular}{|c|c|c|c|c|c|}
\hline$\delta$ & 0,80 & 0,75 & 0,70 & 0,65 & 0,60 \\
\hline$P_{1 r}(k N)$ & 134,40 & 126,00 & 117,60 & 109,20 & 100,80 \\
\hline$\Delta P_{2 r}(k N)$ & 33,60 & 42,00 & 50,40 & 58,80 & 67,20 \\
\hline $\mathrm{M}_{2 \mathrm{p}}$ (kN.m) & 151,20 & 141,75 & 132,30 & 122,85 & 113,40 \\
\hline$A_{s}\left(\mathrm{~cm}^{2}\right)$ - Seção 2 & 8,45 & 7,86 & 7,27 & 6,70 & 6,14 \\
\hline x/d - Seção & 0,263 & 0,245 & 0,226 & 0,209 & 0,1 \\
\hline $\mathrm{M}_{4 \mathrm{p}}$ (kN.m) & 176,40 & 181,13 & 185,85 & 190,58 & 195,30 \\
\hline$A_{s}\left(\mathrm{~cm}^{2}\right)$ - Seção 4 & 10,09 & 10,40 & 10,73 & 11,05 & 11,38 \\
\hline$a(m)$ & 2,77 & 2,63 & 2,50 & 2,35 & 2,20 \\
\hline$\theta_{2 p}\left(\times 10^{-3} \mathrm{rad}\right)$ & 6,40 & 8,47 & 10,80 & 13,45 & 16,50 \\
\hline$\theta_{\mathrm{p} \ell}\left(\times 10^{-3} \mathrm{rad}\right)$ & 13,33 & 13,98 & 14,69 & 15,48 & 16,36 \\
\hline
\end{tabular}


Para $\delta=0,60$, a rotação necessária da seção 2 é maior que a sua capacidade de rotação, e este fato impede a redistribuição de momentos até esse ponto, excetuando-se a possibilidade de utilizar armadura dupla, com o intuito de diminuir o valor de $x / d$ (isso será realizado no próximo exemplo). O próximo fator a limitar uma maior redistribuição seria indubitavelmente o ELS-W da seção 2, pois, à medida que o momento negativo é reduzido, sua armadura de flexão também diminui. No entanto, o ELS-W continua sendo verificado com a combinação freqüente de serviço. Para o $\delta=0,60$ obteve-se uma abertura de $0,35 \mathrm{~mm}$, ainda menor que a abertura limite de $0,40 \mathrm{~mm}$. A verificação do ELS-DEF nos vãos não apresenta problemas neste caso, já que o esforço continua o mesmo (combinação quase-permanente) e a armadura aumenta com a redistribuição.

\subsection{Consumo de aço}

Com a análise linear, o detalhamento da viga V1 apresentou um consumo de aço de 127,09kg. Já com a análise linear com redistribuição $(\delta=8 / 9)$ e com a análise plástica $(\delta=8 / 9)$, o consumo foi de $126,50 \mathrm{~kg}$, ou seja, praticamente o mesmo da análise linear. Nota-se, para este exemplo (seção retangular), que a economia em termos de consumo de armadura é irrisória, com apenas $0,46 \%$ de redução, e que a vantagem é apenas a de se conseguir um detalhamento mais equilibrado, evitando o congestionamento de armadura nos apoios e modificando o modo do elemento estrutural trabalhar. 


\section{VIGA COM SEÇÃO T}

Há um especial interesse na combinação de seções $T$ em vigas com a redistribuição de momentos, uma vez que, com a transferência para os vãos, de parte dos momentos localizados em apoios, a seção T é melhor aproveitada e proporciona uma economia de armadura. Será analisada a viga V2 do pavimento da Figura 5.1, com análise linear e seção retangular, com análise linear e seção $T$, com análise linear com redistribuição e seção $T$, e com análise plástica e seção $\mathrm{T}$.

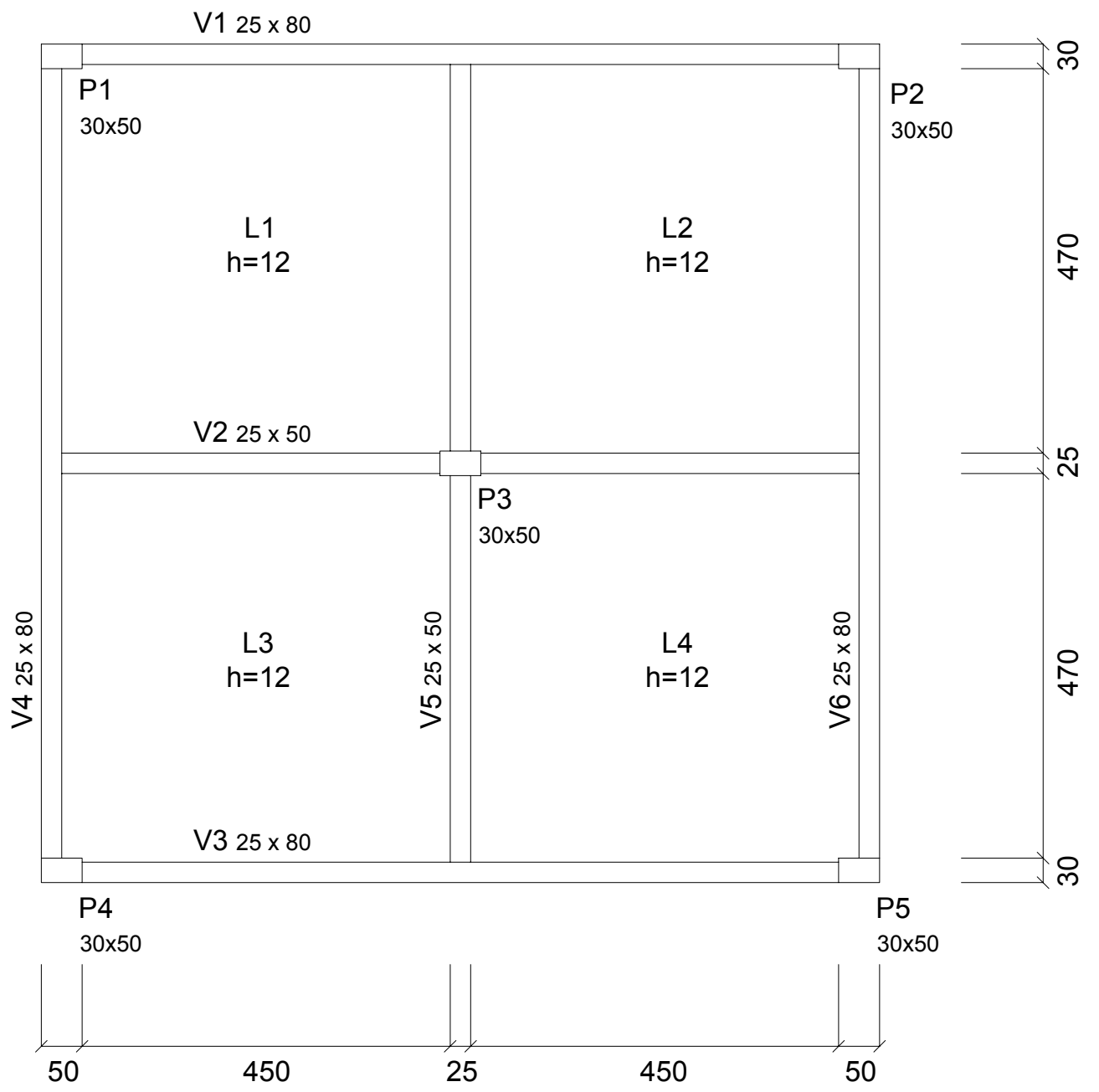

Figura 5.1 - Pavimento ao qual pertence a viga V2

A viga V2 está localizada em ambiente interno (Classe de Agressividade Ambiental I para ambientes urbanos), participa de uma estrutura de nós fixos, com concreto C25, aço CA-50 para a armadura longitudinal e CA-60 para a armadura transversal. $O$ cobrimento é de $2,5 \mathrm{~cm}$ e 
a distância d', do centro de gravidade da armadura longitudinal à borda mais próxima, foi inicialmente adotada igual a $4 \mathrm{~cm}$. Adotou-se um detalhamento padronizado para todas as análises, como no exemplo anterior, sempre com quatro barras de mesmo diâmetro fictício para a armadura de flexão (inclusive para a armadura comprimida, no caso de armadura dupla), e estribos também de diâmetro fictício que proporcionassem o maior espaçamento possível. O mesmo diâmetro fictício dos estribos foi utilizado para os porta-estribos. Considerou-se na laje carga de uso de $2,0 \mathrm{kN} / \mathrm{m}^{2}$ e revestimento de $1,0 \mathrm{kN} / \mathrm{m}^{2}$, pé-direito de $2,80 \mathrm{~m}$ e a alvenaria sobre as vigas com $2,50 \mathrm{kN} / \mathrm{m}^{2}$ de parede pronta.

Na Figura 5.2 tem-se o esquema estático para a viga $\mathrm{V} 2$, no qual será analisada somente a combinação última de carregamentos $1,4(\mathrm{~g}+\mathrm{q})$. As seções 4 e 5 são as seções do primeiro e segundo vãos, respectivamente, em que o momento positivo é máximo.

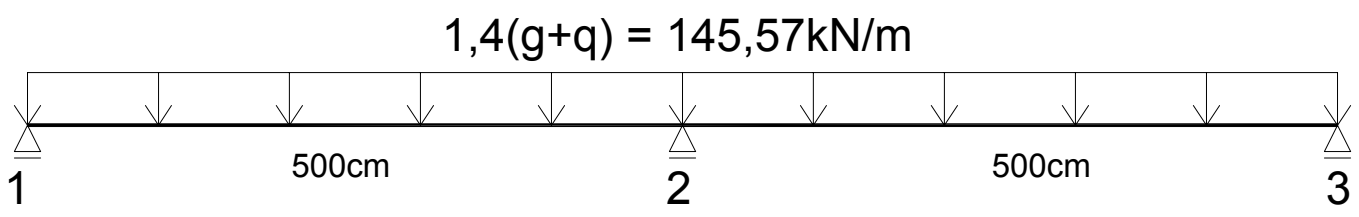

Figura 5.2 - Esquema estático da V2

Neste exemplo adota-se uma estratégia de resolução diferente quanto à aplicação da redistribuição. No exemplo anterior escolheu-se um $\delta$ que igualasse os momentos positivos e negativos, para em seguida verificar se, dimensionando com armadura simples, a posição relativa da linha neutra $\mathrm{x} / \mathrm{d}$ atendia às prescrições normativas. No presente exemplo, será imposta a redistribuição desejada e, caso a armadura simples não seja suficiente para se ter o valor de $\mathrm{x} / \mathrm{d}$ necessário, será utilizada armadura dupla a fim de diminuir a distância da linha neutra, conforme os passos a seguir:

- Define-se o valor de $\mathrm{x} / \mathrm{d}$ necessário e com ele calcula-se o valor limite de $\mathrm{k}_{\mathrm{c}}$ para armadura simples e os valores de $k_{s}, k_{s 2}$ e $k_{s}$ :

$$
\begin{aligned}
& \mathrm{k}_{\text {clim }}=\frac{1}{0,68 \mathrm{fcd} \frac{\mathrm{x}}{\mathrm{d}}\left(1-0,4 \frac{\mathrm{x}}{\mathrm{d}}\right)} \\
& \mathrm{k}_{\mathrm{s}}=\frac{1}{\left(1-0,4 \frac{\mathrm{x}}{\mathrm{d}}\right) \mathrm{f}_{\mathrm{yd}}}
\end{aligned}
$$


$k_{s 2}=\frac{1}{f_{y d}}$

$k_{s}^{\prime}=\frac{1}{\sigma_{s}^{\prime}}$

- Considera-se a armadura tracionada com tensão de escoamento $f_{y d}$, porém a armadura comprimida pode ter uma tensão $\left(\sigma_{s}^{\prime}\right)$ menor que a de escoamento.

$\operatorname{Se}\left(\varepsilon^{\prime}{ }_{s} E_{s}\right) \geq f_{y d} \Rightarrow \sigma_{s}^{\prime}=f_{y d}$

$\operatorname{Se}\left(\varepsilon_{s}^{\prime} E_{s}\right)<f_{y d} \Rightarrow \sigma_{s}^{\prime}=\varepsilon_{s}^{\prime} E_{s}$

- O valor da deformação da armadura comprimida, $\varepsilon_{\text {s }}$, depende do domínio em que se encontra a seção. Para que haja a possibilidade de redistribuição, o domínio deve ser o 2 ou o 3, até certo valor de $\mathrm{x} / \mathrm{d}$.

Se $0 \leq\left(\frac{x}{d}\right) \leq\left(\frac{x}{d}\right)_{2,3} \Rightarrow \varepsilon_{s}^{\prime}=\frac{0,010\left(\frac{x}{d}-\frac{d^{\prime}}{d}\right)}{1-\frac{x}{d}}$

$\operatorname{Se}\left(\frac{x}{d}\right)_{2,3} \leq\left(\frac{x}{d}\right) \leq\left(\frac{x}{d}\right)_{3,4} \Rightarrow \varepsilon^{\prime}{ }_{s}=\frac{0,0035\left(\frac{x}{d}-\frac{d^{\prime}}{d}\right)}{\frac{x}{d}}$

- Calculam-se então as parcelas do momento solicitante $M_{d}$, denominadas $M_{1}$ e $M_{2}$, cuja soma será resistida pela armadura tracionada, com tensão de escoamento, enquanto a armadura comprimida resiste à parcela $\mathrm{M}_{2}$, com tensão $\sigma^{\prime}$ :

$\mathrm{M}_{1}=\frac{\mathrm{bd}_{\mathrm{inf}}^{2}}{\mathrm{k}_{\mathrm{clim}}}$

$M_{2}=M_{d}-M_{1}$

- As armaduras tracionada e comprimida são, então, dadas respectivamente pelas equações (5.7) e (5.8). 
$A_{s}=\frac{k_{s} M_{1}}{d}+\frac{k_{s 2} M_{2}}{d-d^{\prime}}$

$A_{s}^{\prime}=\frac{k_{s}^{\prime} M_{2}}{d-d^{\prime}}$

\subsection{Análise Linear - Seção Retangular}

Para a análise linear, têm-se os diagramas de esforços de cálculo indicados na Figura 5.3 e Figura 5.4:

454,93

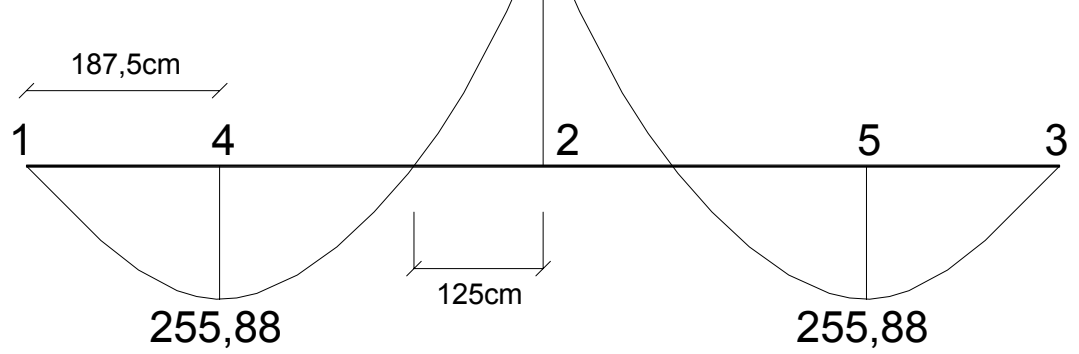

Figura 5.3 - Momentos fletores de cálculo para a análise linear (kN.m)

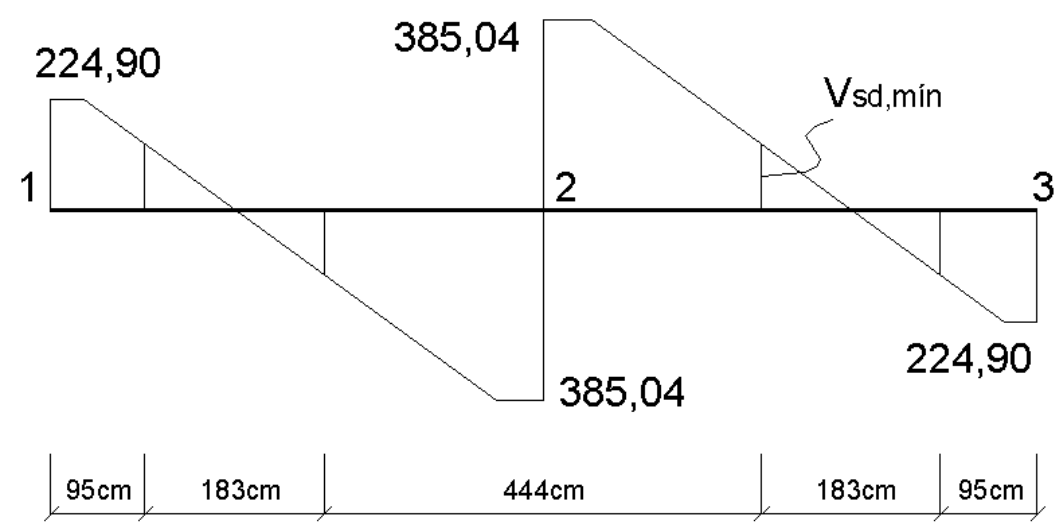

Figura 5.4 - Esforços cortantes de cálculo para a análise linear $(\mathrm{kN})$

As verificações de ELU e ELS são feitas da mesma maneira que na análise linear do exemplo anterior. Ressalta-se apenas a importância de, no cálculo da armadura de flexão da seção 2, limitar o valor de x/d a no máximo 0,500, como prescreve a NBR 6118:2003, para apoios.

Seção 2

$M_{d}=454,93 k N . m ; x / d=0,500 ; A_{s}=26,90 \mathrm{~cm}^{2}(4 \phi 29,3) ; A_{s}^{\prime}=10,84 \mathrm{~cm}^{2}(4 \phi 18,6)$ 


\subsection{Análise Linear - Seção T}

A definição da seção $T$ é feita para o tramo da viga que fornece a menor largura colaborante. No caso da viga V2 pode ser qualquer um dos dois tramos, já que são simétricos. Os diagramas de esforços solicitantes são os mesmos apresentados para a seção retangular na Figura 5.3 e na Figura 5.4. Portanto, a distância "a" entre os pontos de momento nulo, em um dos tramos da viga, é igual a 3,75m. A largura colaborante $b_{f}$ é dada pela Eq.(5.9).

$b_{f}=b_{w}+2(0,10 a)=25+2(0,10 \cdot 375)=100 \mathrm{~cm}$

Considera-se a viga V1 (igual à viga V3) servindo de apoio à viga V2, e com momentos em ambas as extremidades, por estar apoiada em pilares. Portanto, ela pode ter a sua distância "a" estimada por $0,60 \ell$, ou seja, $600 \mathrm{~cm}$. Sua largura colaborante é calculada na Eq.(5.10).

$b_{f}=b_{w}+1(0,10 a)=25+1(0,10 \cdot 600)=85 \mathrm{~cm}$

Com essas informações acerca da viga V1 podem ser realizadas as demais verificações concernentes à geometria, exigidas pela Norma, da seção T da viga V2, na Figura 5.5 e nas equações (5.11) e (5.12).

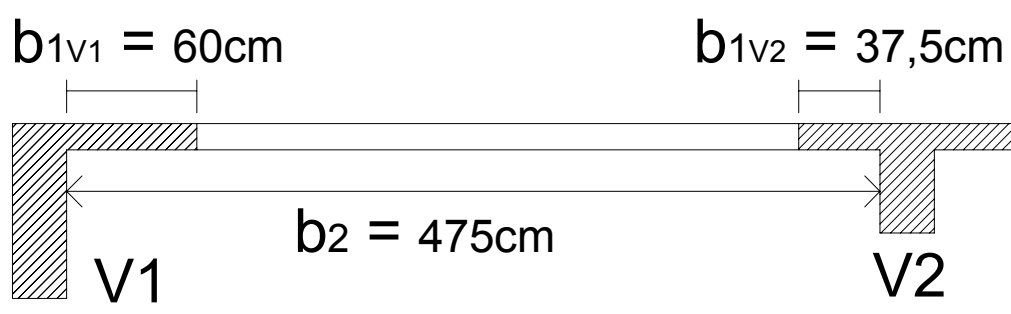

Figura 5.5 - Verificações exigidas pela NBR 6118:2003

$\left(b_{l_{v 1}}=0,60 m\right)<\left(b_{2} / 2=2,375 m\right) \rightarrow$ ok

$\left(\mathrm{b}_{1_{\mathrm{v} 2}}=0,375 \mathrm{~m}\right)<\left(\mathrm{b}_{2} / 2=2,375 \mathrm{~m}\right) \rightarrow$ ok

Dessa maneira, tem-se a seção $T$ da Figura 5.6, que se fará notar, para análise linear, no cálculo da armadura positiva nos vãos, com maior área de contribuição de concreto comprimido, e na verificação do ELS-DEF, com a contribuição de maior inércia à flexão.

No dimensionamento das seções 4 e 5 tem-se:

$M_{d}=255,88 \mathrm{kN} \cdot \mathrm{m} ; \mathrm{x} / \mathrm{d}=0,104 ; A_{s}=13,35 \mathrm{~cm}^{2}(4 \phi 20,6)$ 
A linha neutra passa pela mesa da seção. Portanto, pode-se considerar, no cálculo, uma seção retangular de $100 \mathrm{~cm} \times 50 \mathrm{~cm}$.

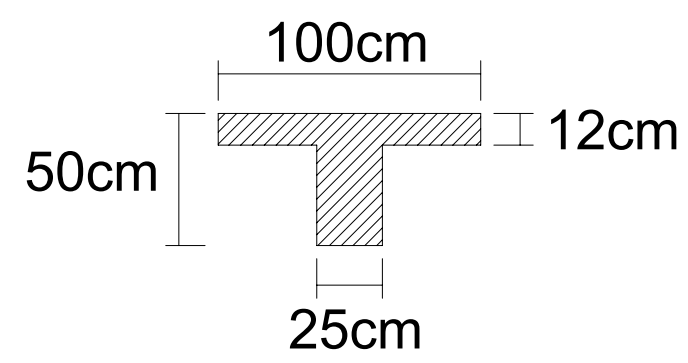

Figura 5.6 - Seção T da viga V2 com largura colaborante da laje

No cálculo da armadura de flexão da seção 2 e da armadura transversal, tem-se a seção retangular de $25 \mathrm{~cm} \times 50 \mathrm{~cm}$. Portanto, os resultados são os mesmos da análise linear com seção retangular. Considera-se ainda, neste exemplo, que a armadura de flexão das lajes vizinhas à viga V2, que corta a mesa, é suficiente para atender às especificações de armadura de ligação mesa-alma, do item 18.3.7 da NBR 6118:2003. Essa armadura de ligação deve ter no mínimo $1,5 \mathrm{~cm}^{2} / \mathrm{m}$.

\subsection{Análise Linear com Redistribuição - Seção T}

Como se pode ver no diagrama de momentos fletores da Figura 5.3, o momento negativo da seção 2 é acentuadamente maior em módulo que os momentos positivos máximos nos vãos. Além disso, há o interesse em se aproveitar ao máximo a seção $T$, e por isso será utilizada a máxima redistribuição permitida pela análise linear com redistribuição, para estruturas de nós fixos, ou seja, $\delta$ igual a 0,75 . Para tal, o valor de $x / d$ necessário é dado pelas equações (5.13) e (5.14).

$\delta \geq 0,44+1,25(x / d)$

$\mathrm{x} / \mathrm{d}=(0,75-0,44) / 1,25=0,250$

$\mathrm{Na}$ Figura 5.7 tem-se o diagrama de momentos redistribuídos, com o momento negativo reduzido e os momentos positivos corrigidos por meio da análise dos tramos isolados (ver Figura 4.8). Os esforços cortantes também são modificados, com a redistribuição de momentos.

A distância "a" entre pontos de momento nulo no tramo, para o cálculo da largura $b_{f}$ da seção $T$, muda com a redistribuição. Porém, manteve-se o valor previamente calculado de $b_{f}=100 \mathrm{~cm}$ (a favor da segurança). 


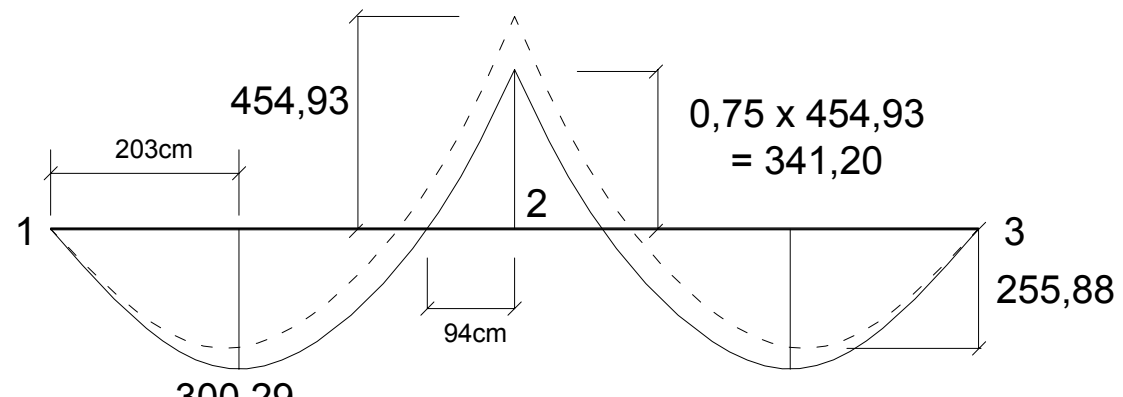

300,29

Figura 5.7 - Momentos fletores de cálculo para a análise linear com redistribuição (kN.m)

362,32

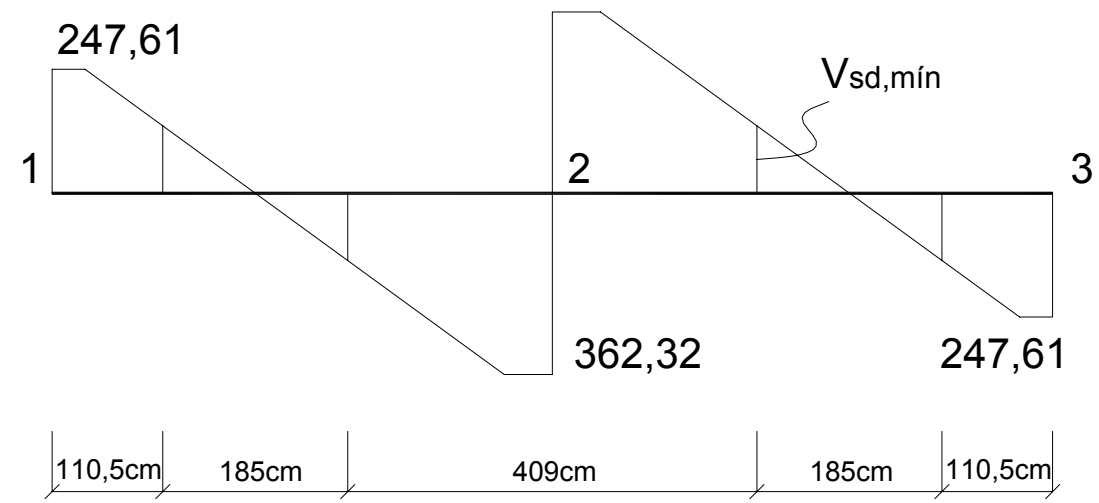

Figura 5.8 - Esforços cortantes de cálculo para a análise linear com redistribuição $(\mathrm{kN})$

a) Seção $2(25 \times 50)$

$M_{d}=341,20 k N \cdot m ; x / d=0,250 ; A_{s}=18,80 \mathrm{~cm}^{2}(4 \phi 24,5) ; A_{s}^{\prime}=10,77 \mathrm{~cm}^{2}(4 \phi 18,5)$

b) Seção 4 = Seção 5 (100x50)

$M_{d}=300,29 k N \cdot m ; x / d=0,123$ (linha neutra na mesa); $A_{s}=15,79 \mathrm{~cm}^{2}(4 \phi 22,4)$

Lembra-se aqui, que os estados limites de serviço foram verificados com as combinações rara (ELS-F), quase-permanente (ELS-DEF) e freqüente (ELS-W), sem redistribuição.

\subsection{Análise Plástica - Seção T}

A análise plástica pode ser feita de modo análogo à análise linear com redistribuição, apenas com uma modificação no tipo de verificação a ser feita com o valor de x/d. Uma vez reduzido o valor de $M_{2}$, tem-se o valor de $M_{2 p}$, que será atingido com a formação da primeira rótula e permanecerá constante até a formação da segunda rótula. 
$M_{2 p}=\delta M_{2}$

Para a viga V2, em que $L=5 m$ e $p_{d}$ é o valor de cálculo do carregamento $(145,57 \mathrm{kN} / \mathrm{m})$, a ação distribuída responsável pela formação da primeira rótula e o seu acréscimo que provoca a segunda rótula, são dados pelas equações (5.16) e (5.17), respectivamente.

$p_{1 r}=\frac{8 M_{2 p}}{L^{2}}$

$\Delta \mathrm{p}_{2 \mathrm{r}}=\mathrm{p}-\mathrm{p}_{1 \mathrm{r}}$

Isolando um dos tramos, aplica-se o carregamento total $p_{d}\left(p_{1 r}+\Delta p_{2 r}\right)$ ao longo da barra e o momento $M_{2 p}$ junto ao apoio, para obter os seguintes momentos para as seções 4 e 5 , quando se formam as segundas rótulas plásticas:

$M_{4 p}=M_{5 p}=\frac{p L^{2}}{8}-\frac{M_{2 p}}{2}+\frac{M_{2 p}^{2}}{2 p L^{2}}$

Como no exemplo anterior, a rotação necessária do apoio da seção 2, para a formação do mecanismo de colapso, é calculada com o acréscimo de carregamento $\Delta \mathrm{p}_{2 \mathrm{r}}$. Devido à primeira rótula plástica, consideram-se os dois tramos biapoiados e calcula-se a rotação à esquerda e à direita da seção 2. Para ações uniformemente distribuídas tem-se:

$\theta_{\mathrm{p} 2}=\theta_{\mathrm{p} 2 \mathrm{e}}+\theta_{\mathrm{p} 2 \mathrm{~d}}=2\left(\frac{\Delta \mathrm{p}_{2 \mathrm{r}} \mathrm{L}^{3}}{24 \mathrm{El}}\right)$

O produto de inércia El refere-se ao estádio II e, portanto, depende da armadura calculada para a seção 2. Já a armadura depende do valor de $x / d$ fixado e do valor de $M_{2 p}$. $A$ capacidade de rotação, $\theta_{p \ell}$, depende também do valor de $x / d$ e da distância "a" entre pontos de momento nulo da região que contém a seção 2 . Deve-se tomar cuidado para não confundi-la com a distância "a" entre pontos de momento nulo no tramo, utilizada no cálculo da largura $b_{f}$ da seção $T$, que será mantida igual a $100 \mathrm{~cm}$. A altura útil da seção também será mantida constante e igual a $46 \mathrm{~cm}$.

$\mathrm{a}=\frac{4 \mathrm{M}_{2 \mathrm{p}}}{\mathrm{pL}}$ 
$\theta_{p l}=0,0035 \frac{d}{x} \sqrt{\frac{(a / d)}{6}}$

A Tabela 5.1 traz combinações de resultados para valores pré-fixados de $x / d$, a partir dos quais se procura o mínimo valor possível de $\delta$ (maior redistribuição possível), sem que $\theta_{2 p}$ ultrapasse $\theta_{\mathrm{p} \ell}$. O valor de $\mathrm{x} / \mathrm{d}$ igual a 0,150 , para o aço CA-50, é o que garante a maior capacidade de rotação plástica, como mostra a Figura 3.14, no entanto pode não ser o mais econômico.

Tabela 5.1 - Combinações de valores de $x / d$ e $\delta$

\begin{tabular}{|c|c|c|c|c|c|c|c|c|c|c|c|}
\hline x/d - Seção 2 & 0,150 & 0,170 & 0,190 & 0,210 & 0,230 & 0,250 & 0,270 & 0,290 & 0,310 & 0,330 & 0,350 \\
\hline$\delta$ & 0,56 & 0,60 & 0,63 & 0,65 & 0,67 & 0,69 & 0,71 & 0,72 & 0,73 & 0,74 & 0,75 \\
\hline$p_{1 \mathrm{r}}(k N / m)$ & 81,52 & 87,34 & 91,71 & 94,62 & 97,53 & 100,44 & 103,35 & 104,81 & 106,27 & 107,72 & 109,18 \\
\hline$\Delta p_{2 r}(k N / m)$ & 64,05 & 58,23 & 53,86 & 50,95 & 48,04 & 45,13 & 42,22 & 40,76 & 39,30 & 37,85 & 36,39 \\
\hline$M_{2 p}(k N . m)$ & $-254,75$ & $-272,94$ & $-286,59$ & $-295,69$ & $-304,79$ & $-313,89$ & $-322,98$ & $-327,53$ & $-332,08$ & $-336,63$ & $-341,18$ \\
\hline$A_{s}\left(\mathrm{~cm}^{2}\right)$ - Seção 2 & 13,81 & 14,83 & 15,62 & 16,17 & 16,73 & 17,30 & 17,89 & 18,23 & 18,59 & 18,96 & 19,34 \\
\hline$A_{s}^{\prime}\left(\mathrm{cm}^{2}\right)$ - Seção 2 & 25,10 & 19,40 & 15,49 & 12,53 & 10,41 & 9,27 & 9,22 & 8,92 & 8,63 & 8,36 & 8,10 \\
\hline$M_{4 p}(k N . m)$ & 336,45 & 328,67 & 322,90 & 319,07 & 315,28 & 311,50 & 307,75 & 305,88 & 304,02 & 302,16 & 300,31 \\
\hline$A_{s}\left(\mathrm{~cm}^{2}\right)$ - Seção 4 & 17,81 & 17,37 & 17,05 & 16,84 & 16,62 & 16,41 & 16,21 & 16,10 & 16,00 & 15,89 & 15,79 \\
\hline $\begin{array}{l}\text { Soma das áreas de } \\
\text { armaduras }\left(\mathrm{cm}^{2}\right)\end{array}$ & 56,72 & 51,60 & 48,16 & 45,54 & 43,76 & 42,98 & 43,32 & 43,25 & 43,22 & 43,21 & 43,22 \\
\hline$a(m)$ & 1,40 & 1,50 & 1,58 & 1,63 & 1,68 & 1,73 & 1,78 & 1,80 & 1,83 & 1,85 & 1,88 \\
\hline$\theta_{2 p}\left(\times 10^{-3} \mathrm{rad}\right)$ & 16,60 & 14,65 & 13,31 & 12,50 & 11,67 & 10,79 & 9,86 & 9,41 & 8,97 & 8,54 & 8,12 \\
\hline$\theta_{\mathrm{p} \ell}\left(\times 10^{-3} \mathrm{rad}\right)$ & 16,62 & 15,18 & 13,92 & 12,79 & 11,85 & 11,07 & 10,40 & 9,75 & 9,18 & 8,68 & 8,24 \\
\hline
\end{tabular}

O par de valores de $\mathrm{x} / \mathrm{d}$ e $\delta$, que resulta na menor soma das áreas de armadura, é $\mathrm{o} \mathrm{x} / \mathrm{d}=$ 0,250 e o $\delta=0,69$. Apesar do valor de $x / d$ ter sido o mesmo utilizado na análise linear com redistribuição, vê-se que com a análise plástica permite-se uma maior redução do momento negativo.

Já para $x / d=0,350$ na seção 2 , a máxima redistribuição possível é com $\delta=0,75$, o mesmo valor de $\delta$ utilizado na análise linear com redistribuição. Nota-se que a análise plástica, para esse valor de $\delta$, resultará mais econômica devido à possibilidade de usar um valor de $\mathrm{x} / \mathrm{d}$ maior para a seção 2.

\subsection{Consumo de aço}

Nota-se, na Tabela 5.2, que a diferença entre o consumo de aço das análises linear com redistribuição e da análise plástica é muito pequena, enquanto a complexidade da análise plástica é bem maior. Vê-se ainda que, com o menor o valor de $\delta$ (maior redistribuição) e conseqüente aumento dos momentos positivos, a economia gerada pelo maior aproveitamento da seção $T$ não compensa o fato de haver um maior comprimento da armadura positiva, necessário para a correta ancoragem nos apoios extremos. 
Tabela 5.2 - Consumo de aço

\begin{tabular}{|c|c|c|c|}
\hline Tipo de análise & Seção transversal & $\begin{array}{c}\text { Consumo } \\
\mathbf{( k g )}\end{array}$ & $\begin{array}{c}\text { Diferença em relação à análise } \\
\text { linear com seção retangular (\%) }\end{array}$ \\
\hline Análise linear & Retangular & 278,2 & 0 \\
\hline Análise linear & $\mathrm{T}$ & 259,7 & $-6,7$ \\
\hline Análise linear com redistribuição $(\delta=0,75)$ & $\mathrm{T}$ & 241,5 & $-13,2$ \\
\hline Análise plástica $(\delta=0,69)$ & $\mathrm{T}$ & 242,9 & $-12,7$ \\
\hline Análise plástica $(\delta=0,75)$ & $\mathrm{T}$ & 237,0 & $-14,8$ \\
\hline
\end{tabular}

No entanto, vale a pena ressaltar a utilização conjunta da seção $T$ com uma análise que permita a redistribuição de momentos, seja a análise linear com redistribuição, seja a análise plástica, o que traz uma economia considerável em relação à análise linear com seção retangular. Somente a utilização da seção T junto à análise linear, já traz uma certa economia, de $6,7 \%$ em relação à seção retangular. Com os conceitos de redistribuição de esforços essa economia dobra. 


\section{REDISTRIBUIÇÃO DE MOMENTOS EM PILARES E ENVOLTÓRIA DE ESFORÇOS}

Conforme foi explicitado no item 3.2, a NBR 6118:2003 é clara ao afirmar que, em pilares, consolos e elementos lineares com preponderância de compressão, a redistribuição de esforços só deve ser feita se por conseqüência de redistribuições em vigas ligadas a eles, uma vez que essas peças não apresentam grande dutilidade. Dessa forma, será analisada neste exemplo, a mesma viga V2 do exemplo anterior, porém agora apoiada em pilares nas suas extremidades (ver Figura 6.1). Os dados permanecem os mesmos, com pequenas mudanças apenas nos vãos efetivos das vigas. Além disso, considera-se que as lajes L1 e L3 estão submetidas a ações variáveis ou não, simultaneamente, bem como as lajes L2 e L4, criando três situações a serem abrangidas pela envoltória de carregamentos.

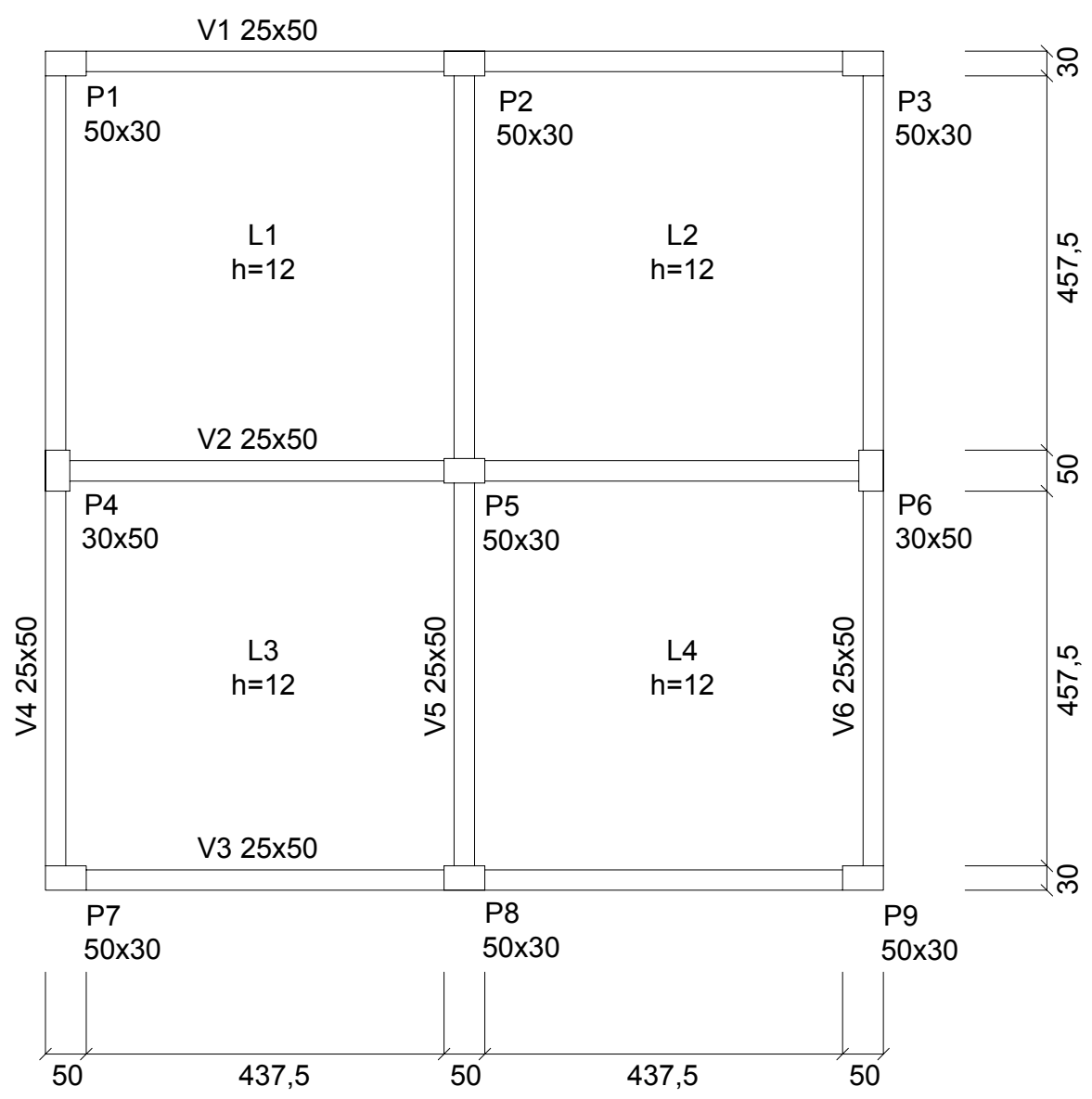

Figura 6.1 - Pavimento ao qual pertence a viga V2 
Admite-se que o pavimento analisado é o último pavimento-tipo. Portanto, os tramos calculados dos pilares recebem as ações provenientes da cobertura (considerada com $60 \%$ do peso de um pavimento-tipo) e do próprio pavimento. Ter-se-á portanto a análise do pórtico formado pela viga V2 e pelos pilares P4, P5 e P6, neste último andar (ver Figura 6.2). O detalhamento dos pilares foi padronizado em seis barras, com três delas localizadas em cada uma das faces de maior dimensão da seção e diâmetro fictício. O detalhamento da viga V2 segue a padronização dos exemplos anteriores.

Foram realizadas uma análise linear (necessária para a posterior redistribuição), admitindo seção retangular, e uma análise linear com redistribuição, com a consideração de seção T. Em ambos os casos, os esforços na viga V2 e nos pilares P4, P5 e P6 foram encontrados por meio do modelo de viga contínua, explicado no item 2.2.1.

O carregamento permanente distribuído $(\mathrm{g})$ é de $72,28 \mathrm{kN} / \mathrm{m}$ e o carregamento acidental distribuído (q) é de $31,70 \mathrm{kN} / \mathrm{m}$, ambos valores característicos.

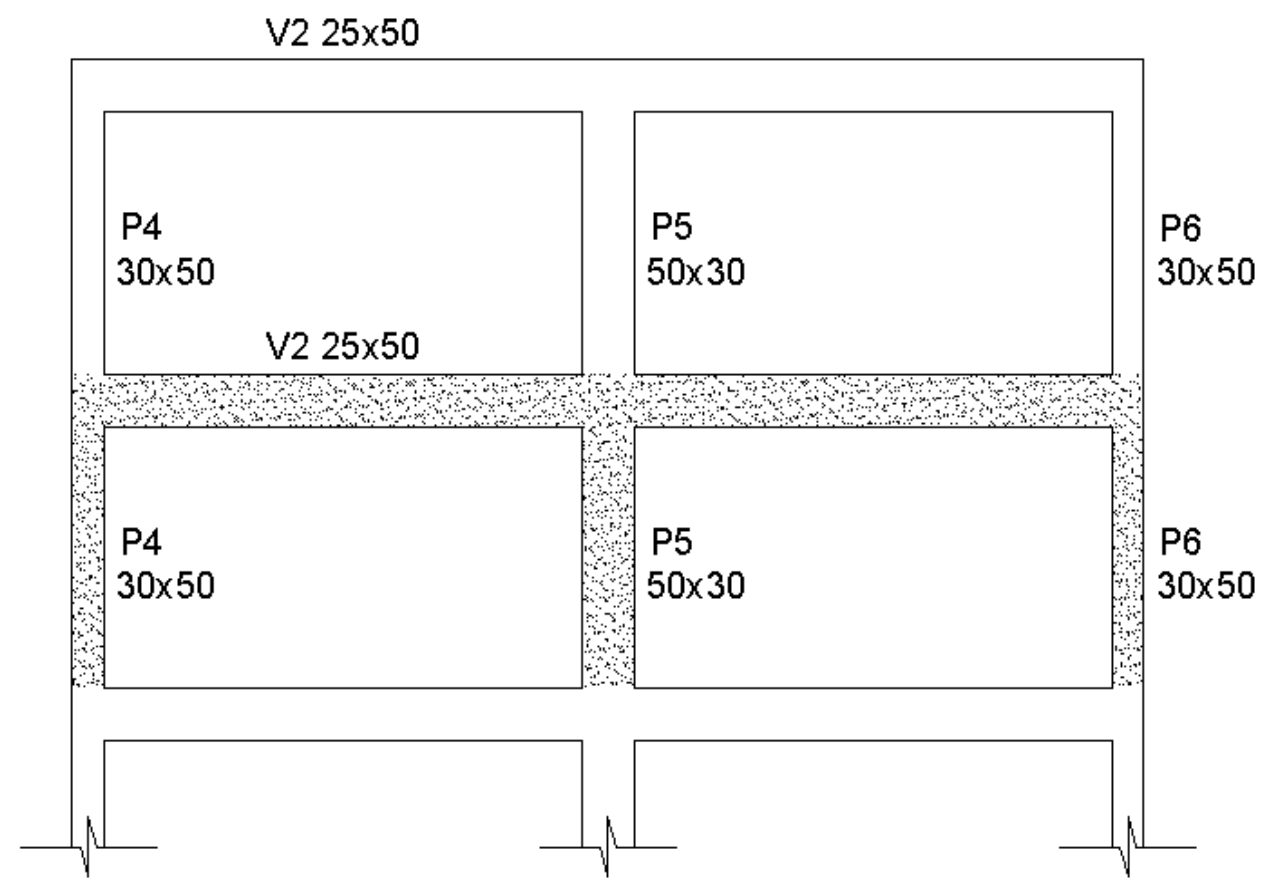

Figura 6.2 - Pórtico analisado em destaque

\subsection{Análise linear - Seção retangular}

Apresentam-se os esforços na viga V2, as respectivas armaduras, as verificações de ELS na $\mathrm{V} 2$, os esforços nos pilares e suas armaduras. 


\subsubsection{Esforços}

Tem-se na Figura 6.3 os esquemas estáticos para a viga V2, para as diferentes situações de tramos solicitados (casos $A, B$ e $C$ ), com a combinação última e o modelo clássico de viga contínua (sem as correções):

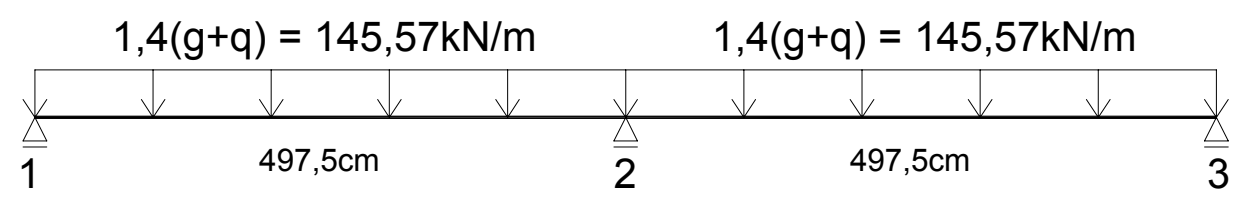

a) Caso $\mathrm{A}$

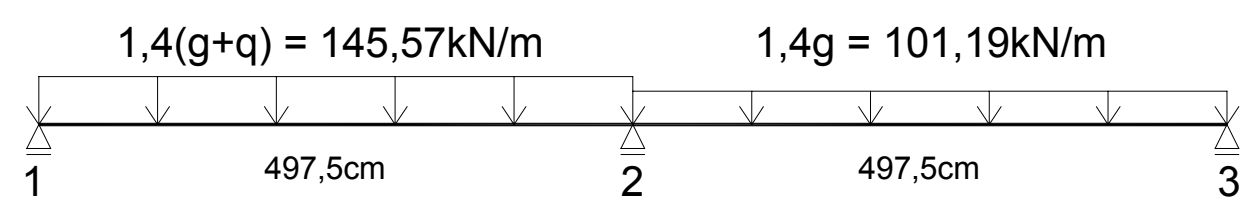

b) Caso B

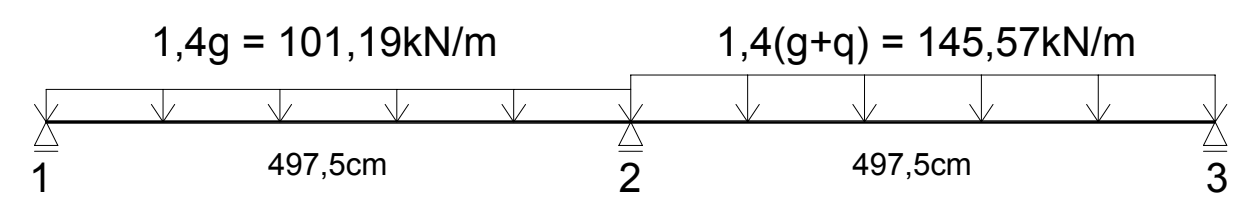

c) Caso C

Figura 6.3 - Modelo clássico de vigas contínuas com combinação última (valores de cálculo)

Na Figura 6.4 tem-se os tramos isolados da V2, com o carregamento de cálculo e o momento negativo junto aos apoios extremos provenientes da correção exigida pelo modelo de vigas contínuas, que prevê a transmissão de momentos entre a viga e os pilares de extremidade que Ihe servem de apoio. Este momento é dado nas equações (6.2) e (6.3), para os tramos com carregamento $1,4(\mathrm{~g}+\mathrm{q})$ e $1,4 \mathrm{~g}$, respectivamente. O carregamento distribuído está em $\mathrm{kN} / \mathrm{m}$ e os momentos, em kN.m.

A Eq. (6.1) traz o valor do momento de engastamento perfeito nas extremidades de um tramo de comprimento $L$, solicitado por um carregamento distribuído $p=1,4(g+q)$ ou $p=1,4 g$, necessário à correção dos momentos da viga junto aos pilares extremos.

$M_{\text {eng }}=\left(p L^{2}\right) / 12$ 


$$
\begin{aligned}
& M_{d, \text { viga }}=\frac{\left(1,4557 \times 497,5^{2}\right)}{12} \times \frac{(2 \times 3 \times 750)}{[(2 \times 3 \times 750)+(4 \times 523)]}=20490 \mathrm{kN} \cdot \mathrm{cm}=204,90 \mathrm{kN} \cdot \mathrm{m} \\
& M_{d, \text { viga }}=\frac{\left(1,0119 \times 497,5^{2}\right)}{12} \times \frac{(2 \times 3 \times 750)}{[(2 \times 3 \times 750)+(4 \times 523)]}=14244 \mathrm{kN} \cdot \mathrm{cm}=142,44 \mathrm{kN} \cdot \mathrm{m}
\end{aligned}
$$

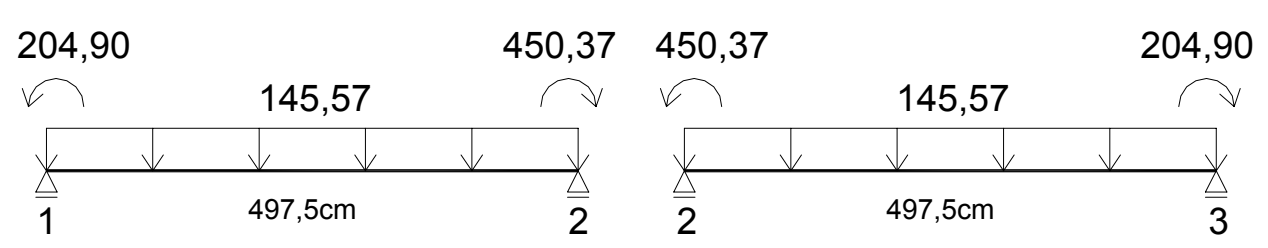

a) Caso $A$

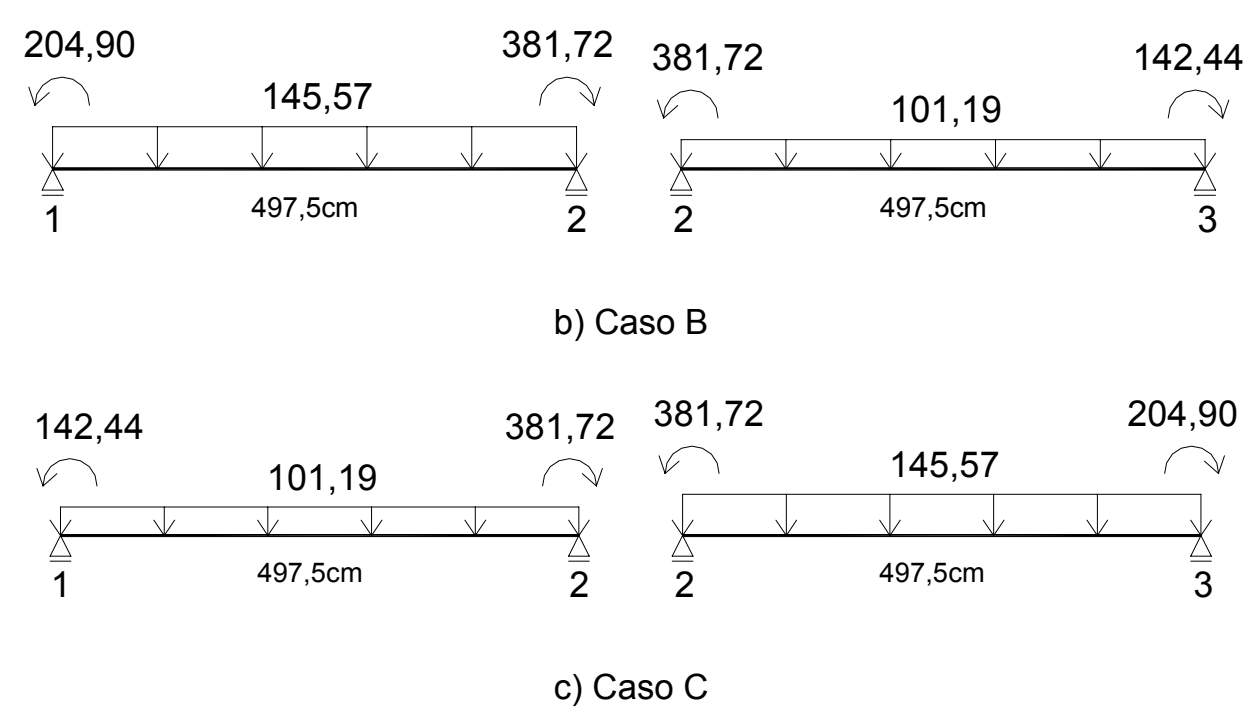

Figura 6.4 - Esquema estático para a correção do momento negativo devido à solidariedade com os pilares de extremidade (valores de cálculo)

O modelo clássico deve ser ainda corrigido quanto aos momentos positivos, que não devem ser menores que os que se obtêm com o engastamento perfeito da viga no seu apoio interno (ver Figura 6.5).

Ao se traçar a envoltória dos momentos fletores e dos esforços cortantes, provenientes do modelo clássico, da correção de momentos negativos junto aos pilares de extremidade e da correção de momentos positivos para que não sejam menores que os obtidos com o engastamento perfeito do apoio interno, sempre para os três casos de carregamento $(A, B$ e C), têm-se os diagramas indicados na Figura 6.6 e na Figura 6.7: 


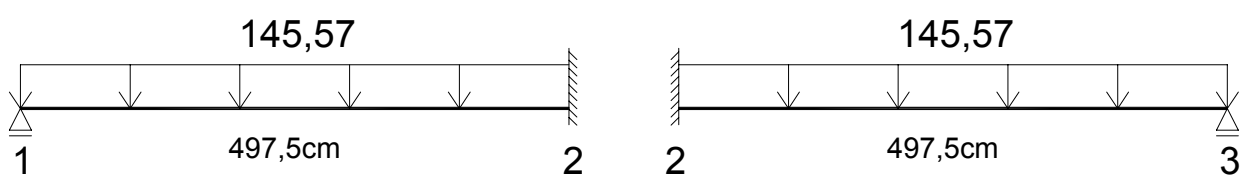

a) Caso $A$

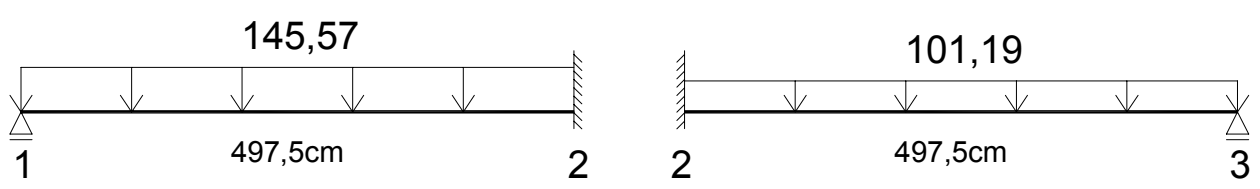

b) Caso B

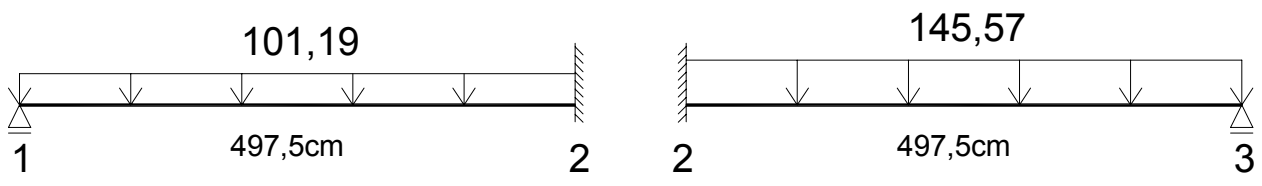

c) Caso C

Figura 6.5 - Esquema estático para a correção do momento positivo devido ao engastamento perfeito dos apoios internos (valores de cálculo)

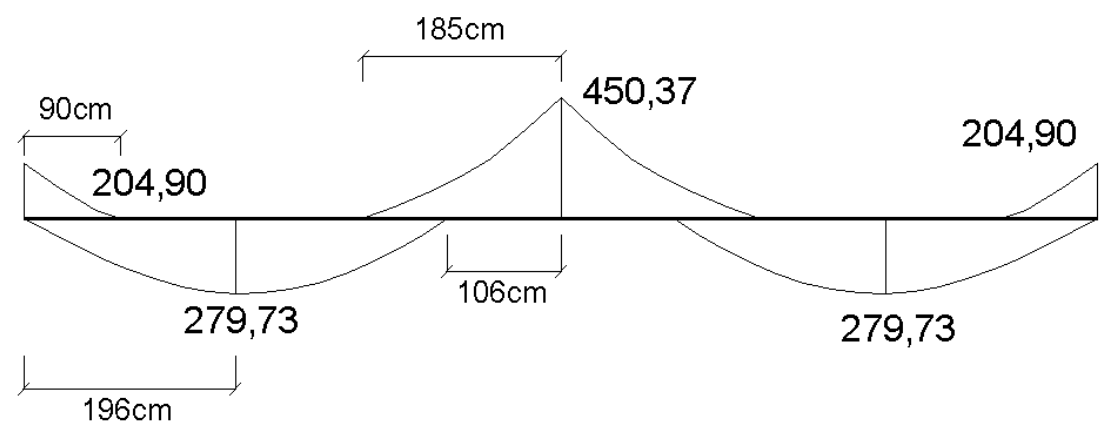

Figura 6.6 - Envoltória de momentos fletores (kN.m)

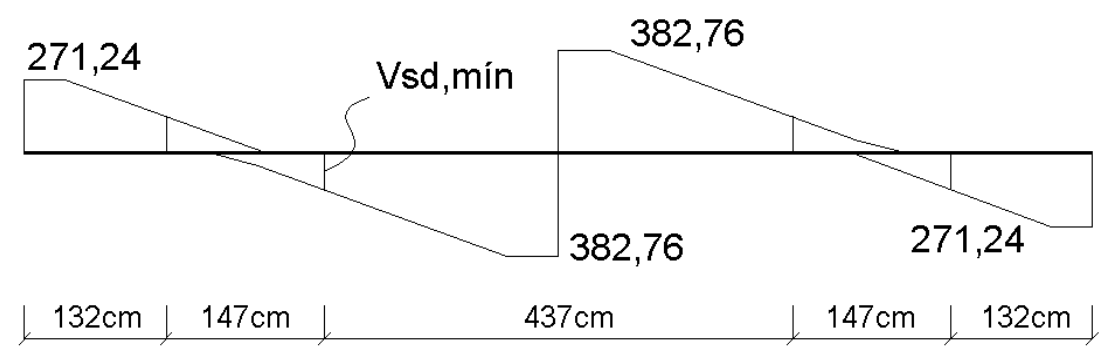

Figura 6.7 - Envoltória de esforços cortantes (kN)

\subsubsection{Flexão}

Seção 1 = Seção 3 
$M_{d}=204,90 k N \cdot m ; x / d=0,375 ; A_{s}=12,05 \mathrm{~cm}^{2}(4 \phi 19,6)$

Seção 4 = Seção 5 (seções de momento máximo positivo)

$M_{d}=279,73 \mathrm{kN} \cdot \mathrm{m} ; \mathrm{x} / \mathrm{d}=0,562 ; A_{\mathrm{s}}=18,04 \mathrm{~cm}^{2}(4 \phi 24,0)$

Seção 2

$M_{d}=450,37 \mathrm{kN} . \mathrm{m} ; \mathrm{x} / \mathrm{d}=0,500 ; A_{s}=26,65 \mathrm{~cm}^{2}(4 \phi 29,1) ; A_{s}^{\prime}=10,59 \mathrm{~cm}^{2}(4 \phi 18,4)$

\subsubsection{Cisalhamento}

Cálculo da armadura com diâmetro fictício e espaçamento máximo entre estribos:

Trechos de $147 \mathrm{~cm}: V_{\text {Sd, } \min }=134,66 \mathrm{kN} \rightarrow \mathrm{a}_{\mathrm{sw}} / \mathrm{s}=1,28 \mathrm{~cm}^{2} / \mathrm{m} \rightarrow \phi 6,7 \mathrm{c} / 27$

Trechos de 132cm: $\bigvee_{\mathrm{Sd}}=271,24 \mathrm{kN} \rightarrow \mathrm{a}_{\mathrm{sw}} / \mathrm{s}=5,08 \mathrm{~cm}^{2} / \mathrm{m} \rightarrow \phi 12 \mathrm{c} / 22$

Trecho de 437cm: $V_{\mathrm{Sd}}=382,76 \mathrm{kN} \rightarrow \mathrm{a}_{\mathrm{sw}} / \mathrm{s}=8,17 \mathrm{~cm}^{2} / \mathrm{m} \rightarrow \phi 12 \mathrm{c} / 13$

\subsubsection{Verificações de ELS na V2}

Os esforços necessários à verificação de ELS são calculados por meio das mesmas considerações feitas para o ELU, na Figura 6.3, Figura 6.4 e Figura 6.5. Porém, utilizando as devidas combinações de carregamento para os casos A, B e C.

a) ELS-F (Combinação rara)

Alternando nos tramos os carregamentos $\mathrm{g}+\mathrm{q}=103,98 \mathrm{kN} / \mathrm{m}$ e $\mathrm{g}=72,28 \mathrm{kN} / \mathrm{m}$.

Há a formação de fissuras.

b) ELS-DEF (Combinação quase-permanente)

Alternando nos tramos os carregamentos $\mathrm{g}+0,3 \mathrm{q}=81,79 \mathrm{kN} / \mathrm{m}$ e $\mathrm{g}=72,28 \mathrm{kN} / \mathrm{m}$.

$\mathrm{a}_{\mathrm{t}}=1,62 \mathrm{~cm}<\frac{\mathrm{L}}{250}\left(=\frac{497,5}{250}=1,99 \mathrm{~cm}\right)$

c) ELS-W (Combinação freqüente)

Alternando nos tramos os carregamentos $\mathrm{g}+0,4 \mathrm{q}=84,96 \mathrm{kN} / \mathrm{m}$ e $\mathrm{g}=72,28 \mathrm{kN} / \mathrm{m}$. 
Seção $2: \mathrm{w}=0,16 \mathrm{~mm}<\mathrm{W}_{\lim }(0,4 \mathrm{~mm}$ para classe de agressividade ambiental $\mathrm{I})$.

\subsubsection{Esforços nos pilares e suas armaduras}

O detalhamento padrão dos pilares é dado na Figura 6.8. Optou-se por utilizar dois estribos retangulares, devido ao fato de que o espaçamento entre as barras longitudinais ultrapassa a distância de $20 \phi_{\mathrm{t}}$.

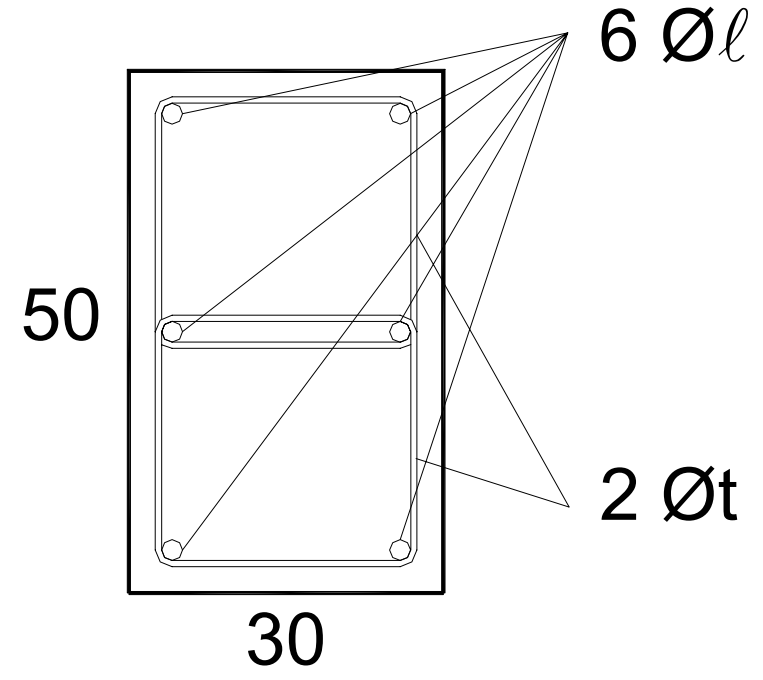

Figura 6.8 - Detalhamento padrão da seção transversal dos pilares

a) $\mathrm{P} 4=\mathrm{P} 6$

Estes dois pilares estão submetidos à flexão normal composta, pois absorvem momento advindo da flexão da viga V2. No tramo analisado, ou seja, o do último pavimento-tipo, tem-se um momento de topo transmitido pela V2 do último pavimento-tipo e um momento de base transmitido pela V2 do penúltimo pavimento-tipo, cujos valores são iguais (ver Figura 6.9).

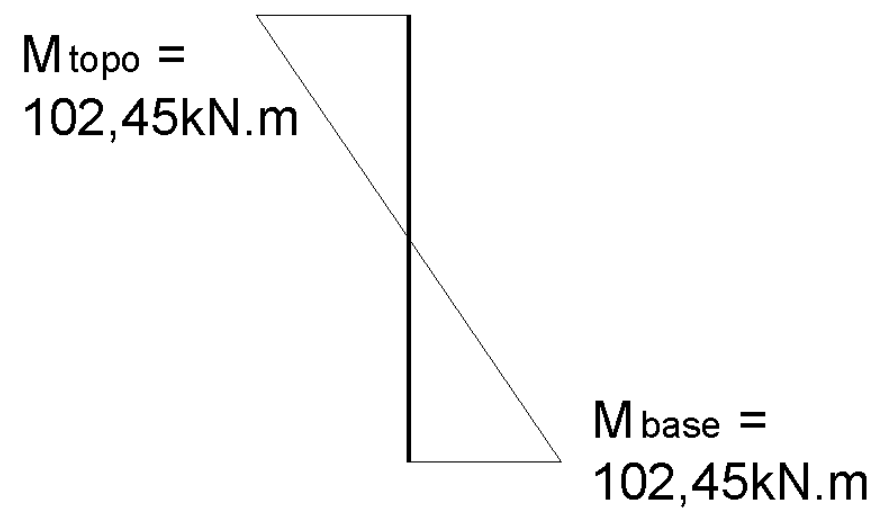

Figura 6.9 - Momentos do P4 no tramo que suporta o último pavimento-tipo 


$$
\begin{aligned}
& M_{\text {topo }}=M_{\text {inf }}=M_{\text {eng }} \cdot \frac{3 r_{\text {inf }}}{3 r_{\text {sup }}+3 r_{\text {inf }}+4 r_{\text {vig }}}=102,45 \mathrm{kN} \cdot \mathrm{m} \\
& M_{\text {base }}=M_{\text {sup }}=M_{\text {eng }} \cdot \frac{3 r_{\text {sup }}}{3 r_{\text {sup }}+3 r_{\text {inf }}+4 r_{\text {vig }}}=102,45 \mathrm{kN} \cdot \mathrm{m}
\end{aligned}
$$

O esforço normal (reação de apoio) vem das envoltórias de carregamento das vigas V2 e V4, no caso do P4, e das vigas V2 e V6, no caso do P6, além de seus pesos próprios. A parcela de força normal da cobertura foi considerada como $60 \%$ do esforço normal encontrado no pavimento-tipo.

A seguir indicam-se os esforços considerados e as respectivas armaduras:

$\mathrm{N}_{\mathrm{d}}=1060 \mathrm{kN} ; \mathrm{M}_{\mathrm{dx}}=102,45 \mathrm{kN} \cdot \mathrm{m} ; \mathrm{A}_{\mathrm{s}}=6 \mathrm{~cm}^{2}\left(\phi_{\ell}=11,3 \rightarrow\right.$ armadura mínima $)$

Estribos $\rightarrow \phi_{\mathrm{t}}=5,0 \mathrm{c} / 13$

Obs.: x é a direção da menor dimensão da seção transversal do pilar.

b) P5

Pelo modelo de viga contínua, este pilar pode ser considerado como solicitado por uma compressão centrada. No entanto, ele é analisado à flexão composta normal, dada a necessidade de levar em conta as excentricidades acidentais. O esforço normal (reação de apoio) no P5 vem das envoltórias de carregamento das vigas V2 e V5 e de seu peso próprio. A parcela de força normal da cobertura foi considerada como $60 \%$ do esforço normal encontrado no pavimento-tipo.

Os esforços considerados e as respectivas armaduras são:

$N_{d}=2928 \mathrm{kN} ; M_{d x}=70,27 \mathrm{kN} \cdot \mathrm{m}$ (excent. mínima ou acidental); $A_{s}=30,19 \mathrm{~cm}^{2}\left(\phi_{\ell}=25,3\right)$

Estribos $\rightarrow \phi_{\mathrm{t}}=6,3 \mathrm{c} / 20$

\subsection{Análise linear com redistribuição - Seção T}

O intuito deste exemplo, além de mostrar a redistribuição de momentos nos pilares, é mostrar particularidades da redistribuição realizada com a consideração de uma envoltória de carregamentos. A NBR 6118:2003 alerta: "Cuidados especiais devem ser tomados com relação a carregamentos de grande variabilidade", porém não fornece diretrizes acerca do assunto. 


\subsubsection{Esforços}

Park \& Paulay (1975) indicam como realizar alguns ajustes, que serão explicados ao mesmo tempo em que forem aplicados neste exemplo. O procedimento consiste em fazer descer a curva de momentos fletores do caso A, que apresenta o máximo momento nos apoios, e fazer subir a curva de momentos fletores dos casos $\mathrm{B}$ ou $\mathrm{C}$, que apresentam o máximo momento nos vãos, com uma mesma porcentagem aplicada aos picos de momentos nos apoios para ambas operações e sempre mantendo o equilíbrio estático. Esse equilíbrio pode ser obtido pela análise do tramo isolado, como foi anteriormente mostrado na Figura 4.8, o que, para um tramo submetido a uma ação distribuída p, significa ter a soma entre o momento no meio do vão e a média dos momentos nos apoios extremos, igual $a\left(p \ell^{2}\right) / 8$.

A redução dos momentos nos apoios do caso A será de $25 \%$ ( $\delta=0,75$, ou seja, a máxima redistribuição para melhor aproveitar a seção $T$ ), o que define o pico do novo momento de projeto. O aumento dos momentos nos apoios do caso $B$ ou $C$ deve ser também de $25 \%$, ou até o novo pico definido com a redução da curva do caso A, o que for menor. Esse acréscimo define os momentos negativos fora das seções onde ocorrem os picos.

A seção T foi calculada, na Eq.(6.7), com a distância "a" entre pontos de momentos nulos advinda da análise linear (ver Figura 6.6). Após a redistribuição, notar-se-á a possibilidade de ter uma largura $b_{f}$ maior. No entanto, essa diferença é pequena, e não acarreta prejuízo à segurança.

$b_{f}=b_{w}+2 \cdot(0,10 a)=25+(2 \cdot 0,10 \cdot 392)=103 \mathrm{~cm}$

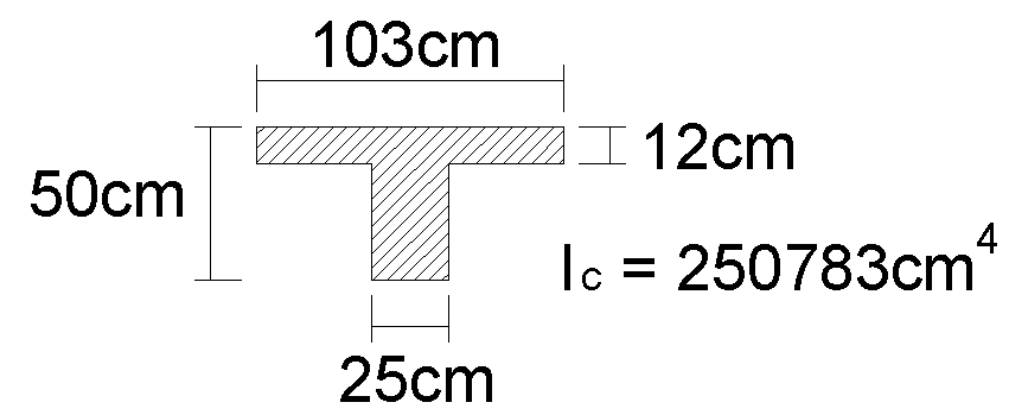

Figura 6.10 - Seção T com largura colaborante da laje na viga V2

Com a mudança de inércia da seção retangular, para a seção $T$, mudaram também os momentos corrigidos nos apoios, juntos aos pilares extremos solidários à viga V2. Nos tramos com carregamento $1,4(\mathrm{~g}+\mathrm{q})$ o momento passou de 204,90 kN.m para 207,34 kN.m. Já nos tramos de carregamento $1,4 \mathrm{~g}$, o momento passou de $142,44 \mathrm{kN} . \mathrm{m}$ para $144,13 \mathrm{kN} . \mathrm{m}$. Na 
análise com as combinações de serviço, essa mudança de inércia não altera, neste caso, os momentos máximos nos apoios e nos vãos, que são usados para a verificação dos ELS.

A Figura 6.11 mostra a redução dos picos de momento nos apoios para o caso $A$, em $25 \%$, e a conseqüente correção dos momentos nos vãos.

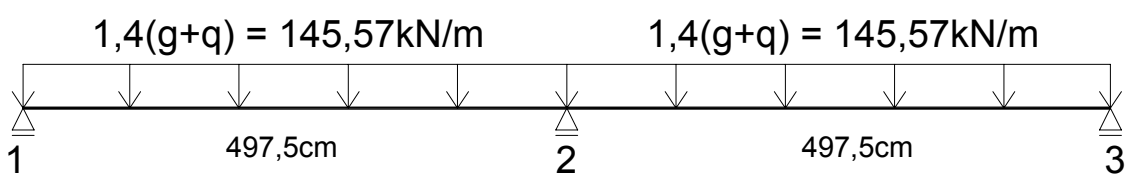

\begin{tabular}{c}
$\begin{array}{c}0,75 \times 450,37 \\
=337,78\end{array}$ \\
\hline
\end{tabular}

a) Modelo clássico de vigas contínuas

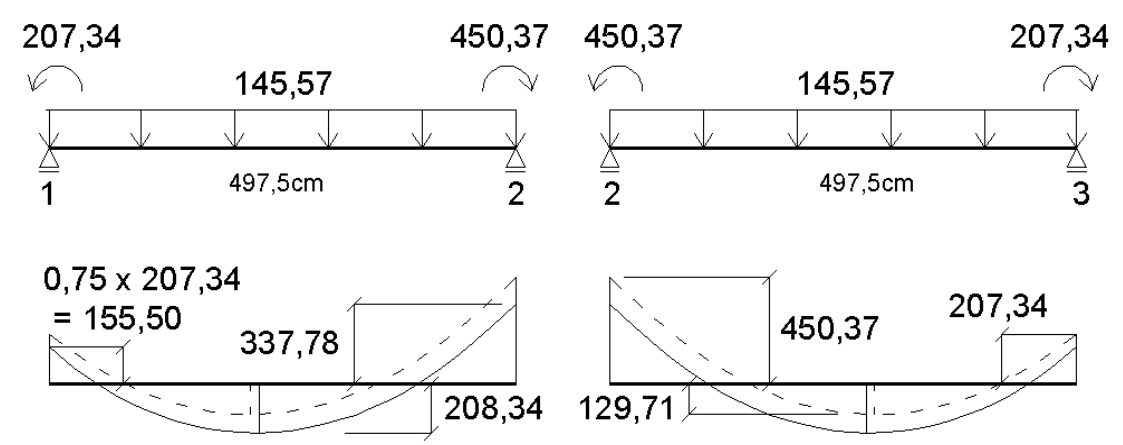

b) Correção do momento negativo devido à solidariedade com os pilares de extremidade
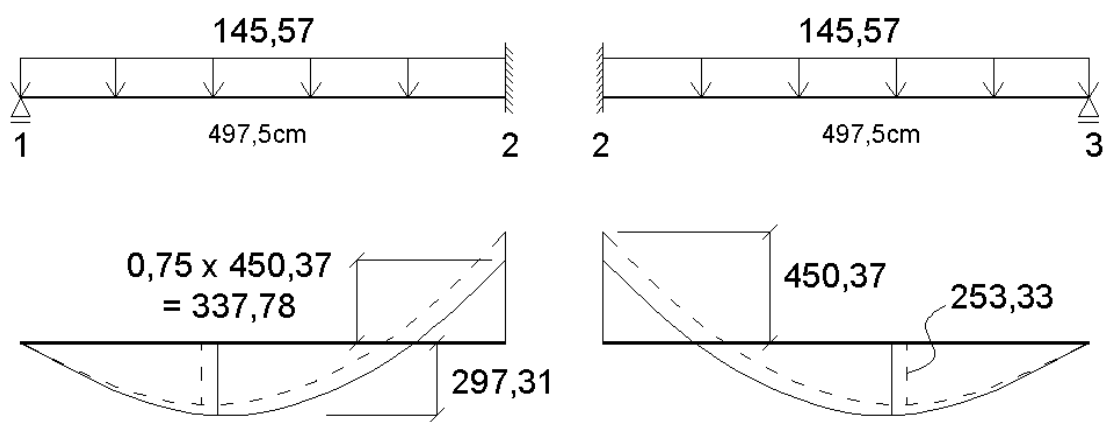

c) Correção do momento positivo devido ao engastamento perfeito do apoio interno

Figura 6.11 - Redução de $25 \%$ nos picos de momentos negativos do caso A

Na Figura 6.12 tem-se a redistribuição dos momentos com os acréscimos dos momentos nos apoios para o caso B (o caso C é simétrico), em que nota-se não ser possível aumentá-los em $25 \%$, uma vez que há a limitação do pico do momento de projeto encontrado com a redução 
do caso A. Devido a essa limitação, os momentos chegam até mesmo a ser reduzidos neste caso, exceto o momento no apoio da seção 3 (ver Figura 6.12 - b), e o da seção 2, na análise do segundo tramo na Figura 6.12 - c, que aumentaram até o valor do momento de projeto.

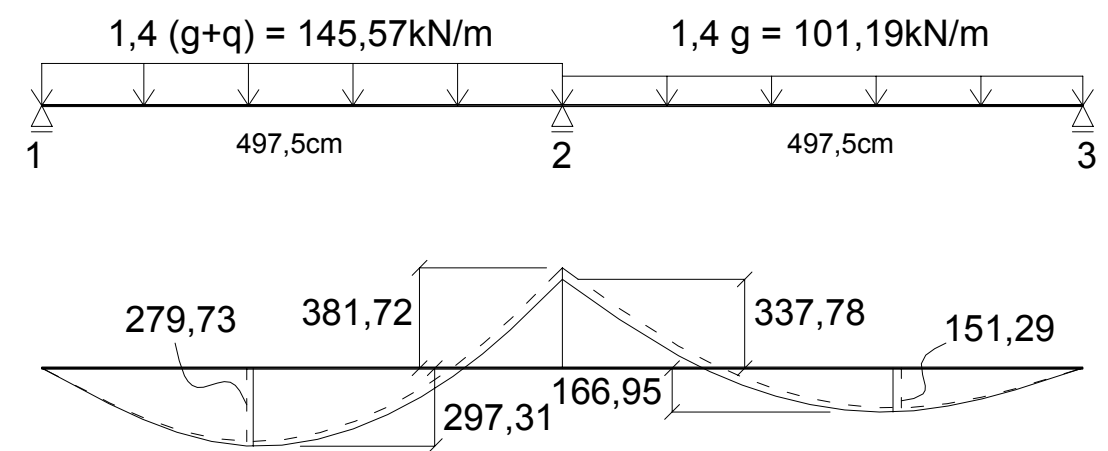

a) Modelo clássico de vigas contínuas

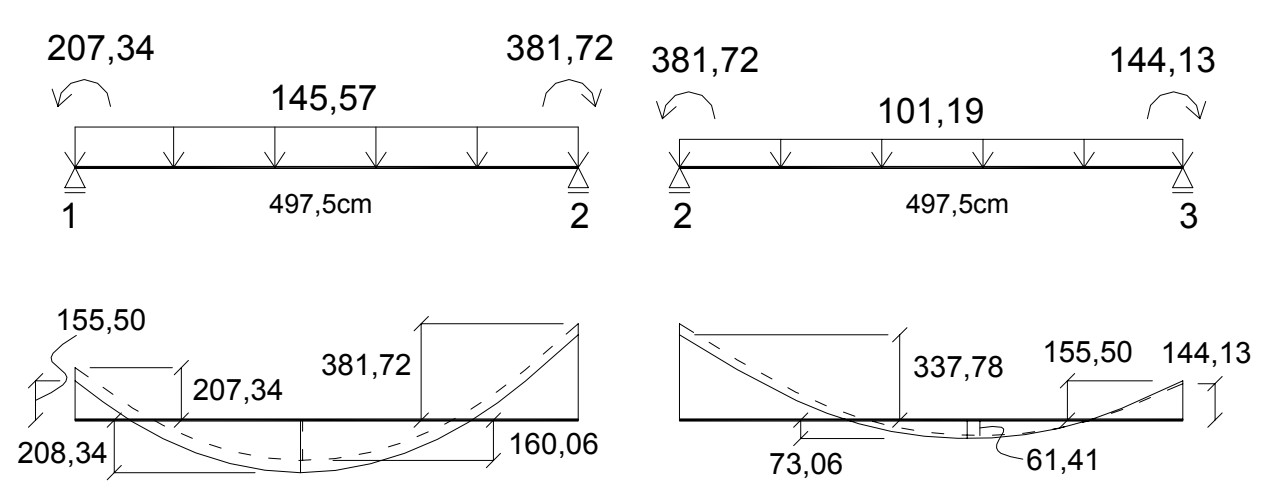

b) Correção do momento negativo devido à solidariedade com os pilares de extremidade

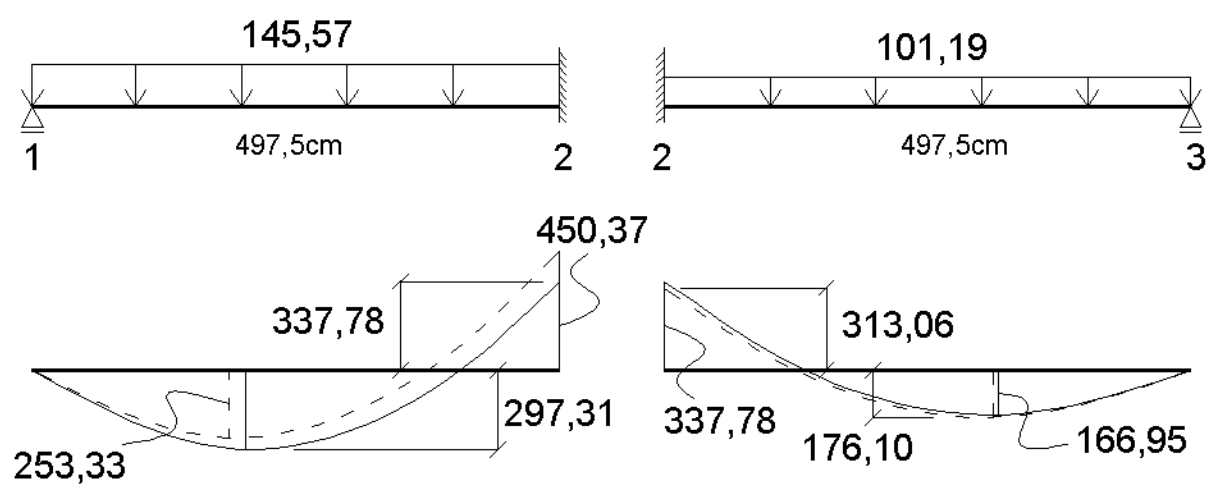

c) Correção do momento positivo devido ao engastamento perfeito dos apoios internos

Figura 6.12 - Acréscimo de $25 \%$ nos picos de momento negativo ou até o momento de projeto, para o caso B

Quanto aos momentos nos vãos, têm-se as seguintes prescrições: 
- Caso A: o máximo momento no vão, calculado antes da redução dos picos de momento nos apoios, deve sofrer um aumento de no mínimo o acréscimo encontrado com a correção dos momentos nos vãos, após essa redução dos picos, definindo assim o chamado momento de projeto;

- Casos B e C: o máximo momento nos vãos, calculado antes da elevação dos picos de momento nos apoios, deve sofrer uma redução de no máximo o decréscimo encontrado com a correção dos momentos nos vãos, após esta elevação dos picos, ou até chegar ao momento de projeto, o que for menor.

No presente exemplo, os momentos máximos nos vãos, dos casos $A, B$ e $C$, foram iguais a 297,31 kN.m. Portanto, não necessitam passar pelas verificações supramencionadas.

Os diagramas de momentos fletores e de esforços cortantes a serem utilizados no dimensionamento, com a redistribuição, são apresentados na Figura 6.13 e na Figura 6.14, respectivamente.

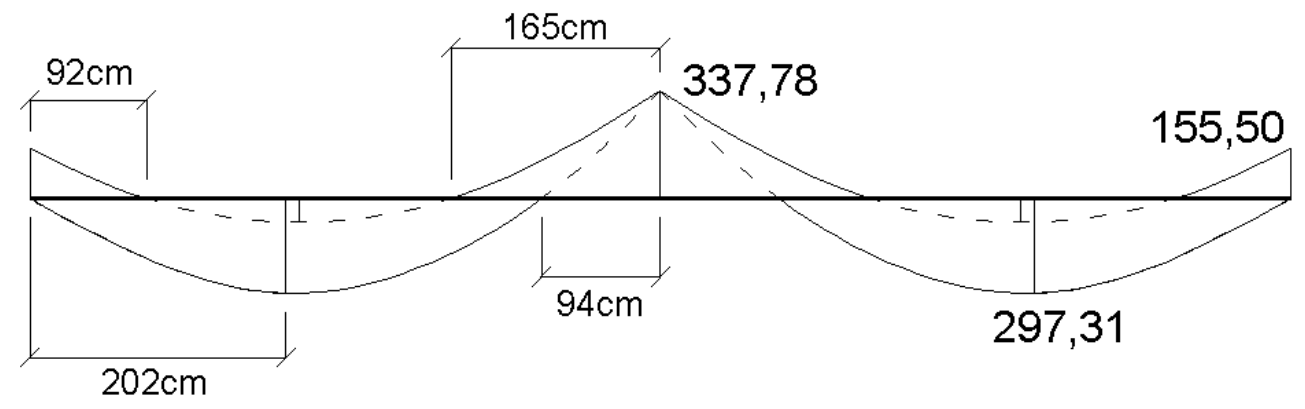

Figura 6.13 - Envoltória de momentos fletores (kN.m)

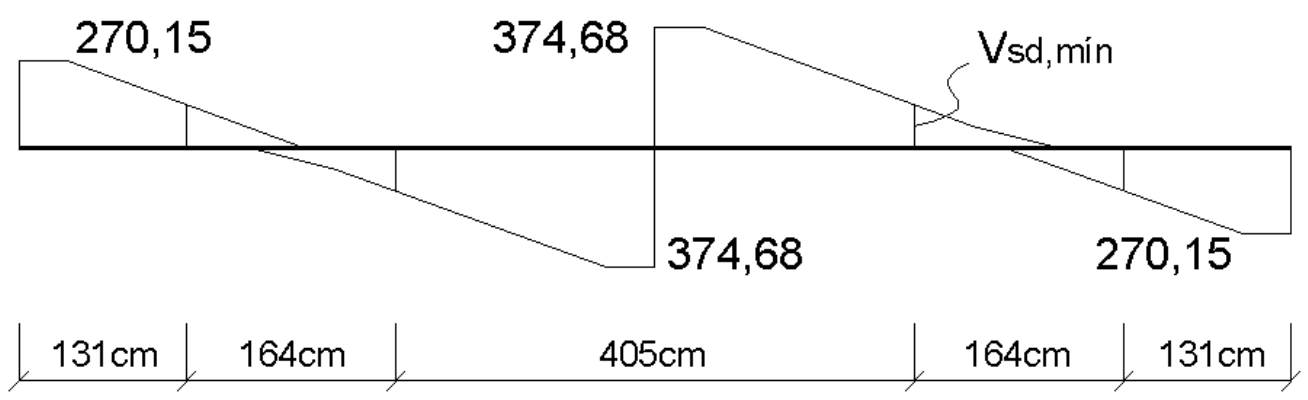

Figura 6.14 - Envoltória de esforços cortantes $(\mathrm{kN})$

\subsubsection{Flexão}

Seção 1 = Seção 3 
Como a mesa da seção T encontra-se tracionada, o cálculo é feito para a seção retangular de $25 \mathrm{~cm} \times 50 \mathrm{~cm}$. O valor de $\mathrm{x} / \mathrm{d}$, assim como no exemplo anterior, foi calculado para permitir a redistribuição $\operatorname{com} \delta=0,75$, e é igual a 0,250 nas seções 1,2 e 3 .

$M_{d}=155,50 \mathrm{kN} . \mathrm{m} ; \mathrm{x} / \mathrm{d}=0,250 ; A_{s}=8,63 \mathrm{~cm}^{2}(4 \phi 16,6) ; A_{s}^{\prime}=0,60 \mathrm{~cm}^{2}(4 \phi 4,4)$

Seção 4 = Seção 5 (seções de momento máximo positivo)

Pode-se considerar uma seção retangular de $103 \mathrm{~cm}$ x $50 \mathrm{~cm}$, já que com essa hipótese a linha neutra encontra-se na mesa da seção T.

$M_{d}=297,31 \mathrm{kN} \cdot \mathrm{m} ; \mathrm{x} / \mathrm{d}=0,118 ; A_{\mathrm{s}}=15,60 \mathrm{~cm}^{2}(4 \phi 22,3)$

Seção 2

$M_{d}=337,78 \mathrm{kN} . \mathrm{m} ; \mathrm{x} / \mathrm{d}=0,250 ; A_{s}=18,61 \mathrm{~cm}^{2}(4 \phi 24,3) ; A_{s}^{\prime}=10,58 \mathrm{~cm}^{2}(4 \phi 18,4)$

\subsubsection{Cisalhamento}

Cálculo da armadura com diâmetro fictício e espaçamento máximo entre estribos:

Trechos de $164 \mathrm{~cm}: V_{S d, \text { min }}=134,66 \mathrm{kN} \rightarrow \mathrm{a}_{\mathrm{sw}} / \mathrm{s}=1,28 \mathrm{~cm}^{2} / \mathrm{m} \rightarrow \phi 6,7 \mathrm{c} / 27$

Trechos de $131 \mathrm{~cm}: \mathrm{V}_{\mathrm{Sd}}=270,15 \mathrm{kN} \rightarrow \mathrm{a}_{\mathrm{sw}} / \mathrm{s}=5,05 \mathrm{~cm}^{2} / \mathrm{m} \rightarrow \phi 12 \mathrm{c} / 22$

Trecho de 405cm: $\mathrm{V}_{\mathrm{Sd}}=374,68 \mathrm{kN} \rightarrow \mathrm{a}_{\mathrm{sw}} / \mathrm{s}=7,95 \mathrm{~cm}^{2} / \mathrm{m} \rightarrow \phi 12 \mathrm{c} / 14$

\subsubsection{Verificações de ELS na V2}

a) ELS-F (Combinação rara)

O momento de fissuração é um pouco modificado, com a maior inércia da seção, porém, continua a haver fissuras.

b) ELS-DEF (Combinação quase-permanente)

Com a maior inércia da seção $\mathrm{T}$, e a maior armadura nos vãos, devida à redistribuição de momentos, nem seria necessária uma nova verificação do ELS-DEF. Houve uma redução de $18,5 \%$ na flecha. 
$a_{t}=1,32 \mathrm{~cm}<\frac{L}{250}\left(=\frac{497,5}{250}=1,99 \mathrm{~cm}\right)$

c) ELS-W (Combinação freqüente)

Seção $2: \mathrm{w}=0,22 \mathrm{~mm}<\mathrm{W}_{\lim }(0,4 \mathrm{~mm}$ para classe de agressividade ambiental $\mathrm{I})$.

\subsubsection{Esforços nos pilares e suas armaduras}

Serão considerados os pilares P4 = P6 e o P5.

a) $\mathrm{P} 4=\mathrm{P} 6$

No nó pertencente à interseção da extremidade da viga e o pilar extremo (ver Figura 6.15), há a necessidade de haver o equilíbrio dos momentos que nele atuam.
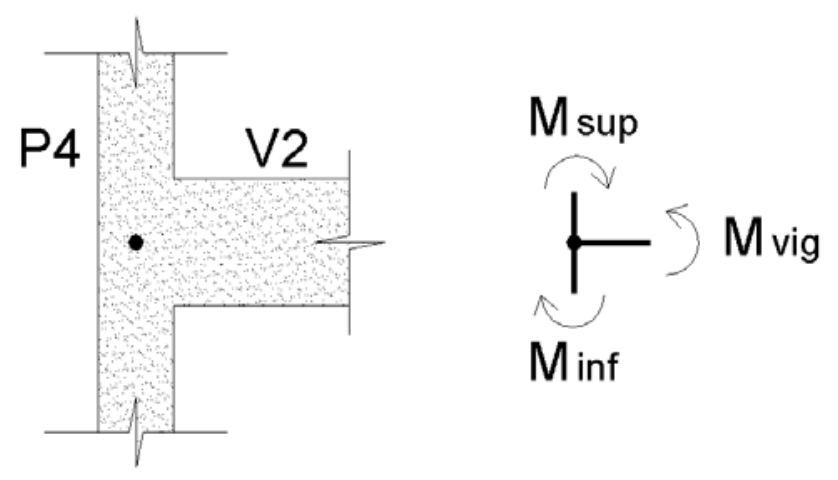

Minf

Figura 6.15 - Equilíbrio do nó de extremidade da V2 com o P4

Com a redistribuição dos momentos e a utilização da seção T, o $\mathrm{M}_{\text {vig }}$ passou de 204,90 kN.m para $155,50 \mathrm{kN} . \mathrm{m}$. $O \mathrm{M}_{\text {sup }}$ e $\circ \mathrm{M}_{\text {inf }}$ assumem proporções do valor de $\mathrm{M}_{\text {vig }}$, de acordo com a rigidez dos tramos superior e inferior do pilar $\left(r_{i}=l_{i} / \ell_{i}\right)$, respectivamente; ver equações (6.9) e (6.10).

$$
\begin{aligned}
& M_{\text {sup }}=M_{\text {vig }} \cdot\left(\frac{r_{\text {sup }}}{r_{\text {sup }}+r_{\text {inf }}}\right)=155,50 \cdot 0,5=77,75 \mathrm{kN} \cdot \mathrm{m} \\
& M_{\text {inf }}=M_{\text {vig }} \cdot\left(\frac{r_{\text {inf }}}{r_{\text {sup }}+r_{\text {inf }}}\right)=155,50 \cdot 0,5=77,75 \mathrm{kN} \cdot \mathrm{m}
\end{aligned}
$$

Os esforços considerados e as armaduras obtidas são: 
$\mathrm{N}_{\mathrm{d}}=1058 \mathrm{kN} ; \mathrm{M}_{\mathrm{dx}}=77,75 \mathrm{kN} \cdot \mathrm{m} ; \mathrm{A}_{\mathrm{s}}=6 \mathrm{~cm}^{2}\left(\phi_{\ell}=11,3 \rightarrow\right.$ armadura mínima $)$

Estribos $\rightarrow \phi_{\mathrm{t}}=5,0 \mathrm{c} / 13$

Obs.: x é a direção da menor dimensão da seção transversal do pilar.

b) P5

$N_{d}=2856 \mathrm{kN} ; M_{d x}=68,54 \mathrm{kN} \cdot \mathrm{m}$ (excent. mínima ou acidental); $A_{s}=27,72 \mathrm{~cm}^{2}\left(\phi_{\ell}=24,3\right)$

Estribos $\rightarrow \phi_{\mathrm{t}}=6,3 \mathrm{c} / 20$

\subsection{Consumo de aço}

Somando-se os consumos de aço, obtidos nos itens anteriores, com o detalhamento dos pilares e da viga, obtêm-se os valores indicados na Tabela 6.1 .

Tabela 6.1 - Consumo de aço $(\mathrm{kg})$

\begin{tabular}{|c|c|c|c|}
\hline & Análise Linear + Seção Retangular & Análise Linear c/ Redistribuição + Seção T & Diferença (\%) \\
\hline $\begin{array}{c}\text { Pilares } \\
\text { (P4 + P5 + P6) }\end{array}$ & 158,8 & 149,7 & 5,7 \\
\hline Viga (V2) & 343,9 & 275,7 & 19,8 \\
\hline Pilares + Viga & 502,7 & 425,4 & 15,4 \\
\hline
\end{tabular}

Percebe-se que a redistribuição de momentos trouxe uma pequena economia para os pilares, mas já significativa, apesar da utilização do modelo de vigas contínuas, que não prevê a transmissão de momentos para os pilares intermediários. Os esforços normais nessas peças foram praticamente os mesmos nos dois casos, já o momento $M_{d x}$, nos pilares de extremidade, foi reduzido em $24 \%$, para a análise linear com redistribuição e seção T.

Quanto às vigas, sabe-se que a utilização conjunta de seção $T$ e de análise linear com redistribuição traz uma boa economia. Além disso, com as diferentes combinações de carregamento acidental, é possível diminuir os picos de momentos nos apoios e nos vãos. Neste exemplo, só foi possível diminuir os momentos nos apoios, mas se a relação entre o carregamento acidental e o carregamento permanente fosse ainda maior, haveria a possibilidade de reduzir também os momentos nos vãos, na envoltória. A maior percentagem de redução no consumo de armadura para as vigas, em relação ao exemplo do capítulo 5 , se deve à existência de momentos fletores nos apoios junto aos pilares de extremidade, que também sofreram reduções. 


\section{ANÁLISE DE UM EDIFÍCIO POR VÁRIOS MODELOS ESTRUTURAIS}

Sabe-se, hoje em dia que, a análise de uma estrutura, via modelos que a representem como um todo, é a mais precisa e, portanto, a mais indicada. Deseja-se saber, porém, que tipos de erros são cometidos quando utilizados modelos mais simples. Assim, quando se dispõe de programas mais simples, que permitam a modelagem apenas de pórticos planos, por exemplo, ou dispõe-se apenas do cálculo manual, é necessário conhecer as limitações do uso de tais modelos. O exemplo visa comparar os modelos estruturais. Portanto, o tipo de análise será mantido o mesmo, no caso a análise linear. Foi utilizado, no exemplo, o programa Eberick, da AltoQI.

A estrutura a ser analisada é composta de sub-solo mais oito pavimentos, sendo um térreo, seis pavimentos-tipo e a cobertura. Foi adaptada de um projeto realizado pelo engenheiro Fernando R. Stucchi, professor da EPUSP, para um edifício de escritórios, em São Paulo. O pavimento-tipo é dado na Figura 7.1 e é igual ao térreo.

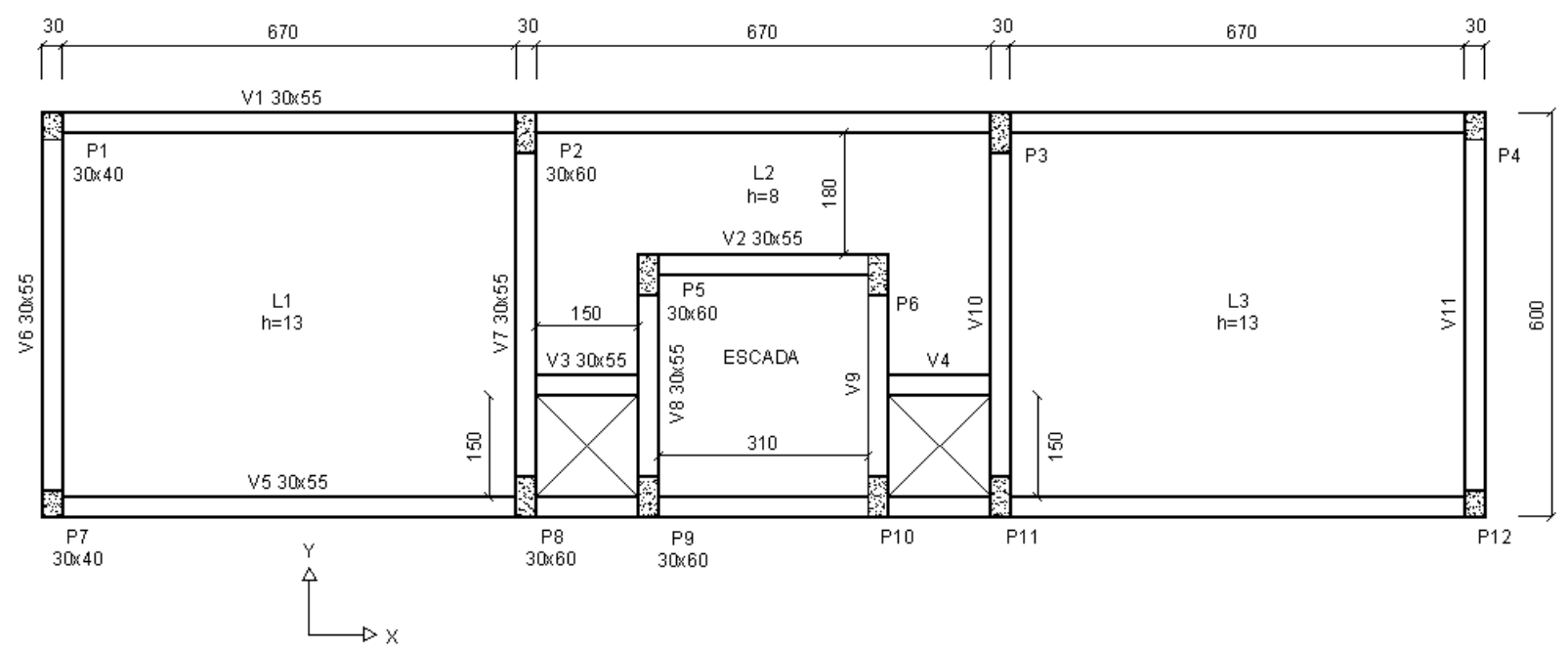

Figura 7.1 - Planta de forma do pavimento-tipo

Na cobertura existem ainda as lajes L4 e L5 das casas de máquina, localizadas sobre os poços de elevadores, com espessura de $20 \mathrm{~cm}$. Os pilares P5, P6, P9 e P10 recebem, no nível da cobertura, uma força concentrada vertical de $10 \mathrm{kN}$, proveniente do reservatório de água. As escadas foram consideradas integralmente apoiadas na V2 e em uma viga localizada a meia 
altura entre os pavimentos, a VE, que se apóia nos pilares P9 e P10. As alturas dos pavimentos podem ser vistas na Figura 7.2.

As vigas têm seção transversal de $30 \mathrm{~cm} \times 55 \mathrm{~cm}$, os pilares nos quatro cantos extremos têm seção $30 \mathrm{~cm} \times 40 \mathrm{~cm}$, e os demais têm seção $30 \mathrm{~cm} \times 60 \mathrm{~cm}$. A alvenaria tem $25 \mathrm{~cm}$ de largura e um peso específico de $16 \mathrm{kN} / \mathrm{m}^{3}$. No caso dos pavimentos térreo e tipo, as paredes situam-se sobre todas as vigas, com exceção da V2, com altura de $225 \mathrm{~cm}$. Sobre as vigas VE e o trecho da V5 entre os pilares P9 e P10, a alvenaria tem uma altura menor, de $85 \mathrm{~cm}$. Na cobertura há uma parede de $110 \mathrm{~cm}$ de altura no contorno do pavimento, e alvenaria de $225 \mathrm{~cm}$ de altura fechando as casas de máquinas e a caixa da escada. No sub-solo as paredes encontram-se no contorno do pavimento e fechando também os poços de elevadores e a caixa da escada.

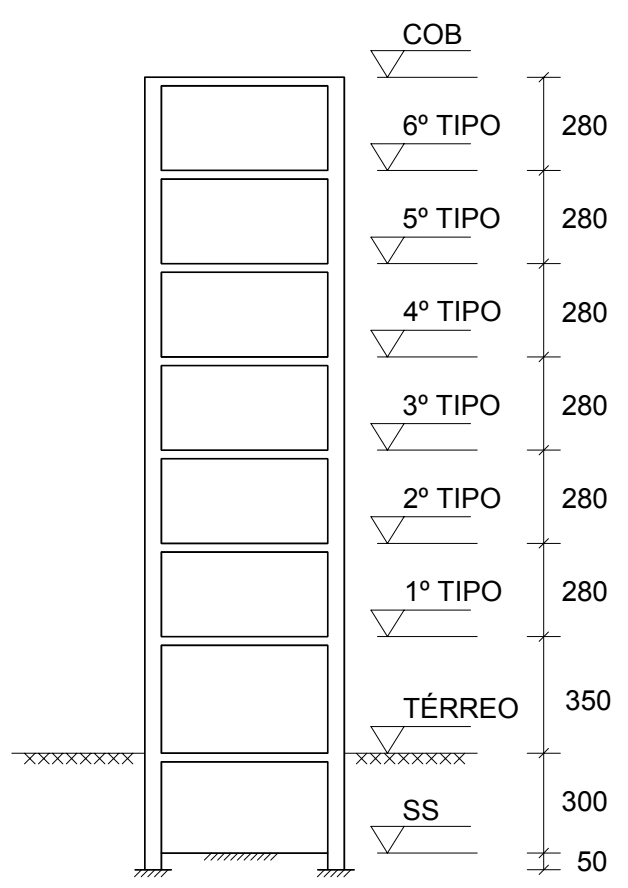

Figura 7.2 - Alturas dos pavimentos

O carregamento das lajes encontra-se resumido na Tabela 7.1. Os valores da escada consideram os pesos distribuídos de patamares e de lances inclinados, na área projetada verticalmente. Cada lance da escada é formado por 7 degraus, com $25 \mathrm{~cm}$ de largura e $17,5 \mathrm{~cm}$ de espelho, apoiados em uma laje de $8 \mathrm{~cm}$ de espessura. $O$ peso próprio da escada considera uma espessura média de $18,5 \mathrm{~cm}$ dos lances, e um patamar com laje de $8 \mathrm{~cm}$ de espessura. $\mathrm{Na}$ coluna "Divisórias", referente à escada, considera-se o peso de uma mureta de $175 \mathrm{~cm}$ de comprimento por $110 \mathrm{~cm}$ de altura, em cada lance, constituída por uma alvenaria de $1,9 \mathrm{kN} / \mathrm{m}^{2}$. 
Considera-se cada elevador com capacidade para seis pessoas, com peso total de $10 \mathrm{kN}$, que, distribuído na laje de $1,80 \mathrm{~m} \times 1,80 \mathrm{~m}$ da casa de máquinas, fornece o valor $3,1 \mathrm{kN} / \mathrm{m}^{2}$ indicado na coluna "Elevador", na Tabela 7.1.

Tabela 7.1 - Carregamento das lajes $\left(\mathrm{kN} / \mathrm{m}^{2}\right)$

\begin{tabular}{|c|c|c|c|c|c|c|}
\hline Pavimento & Laje & Peso próprio & Revestimento & Acidental & Divisórias & Elevador \\
\hline \multirow{4}{*}{ Cobertura } & L1 & 3,3 & 1,5 & 2,0 & - & - \\
\cline { 2 - 7 } & L2 & 2,0 & 1,5 & 2,0 & - & - \\
\cline { 2 - 7 } & L3 & 3,3 & 1,5 & 2,0 & - & - \\
\cline { 2 - 7 } & L4 & 5,0 & 1,5 & 7,5 & - & 3,1 \\
\cline { 2 - 7 } & L5 & 5,0 & 1,5 & 7,5 & - & 3,1 \\
\hline \multirow{3}{*}{ Tipo } & L1 & 3,3 & 1,5 & 2,0 & 1,0 & - \\
\cline { 2 - 7 } & L2 & 2,0 & 1,5 & 2,0 & - & - \\
\cline { 2 - 7 } & L3 & 3,3 & 1,5 & 2,0 & 1,0 & - \\
\hline Sub-solo & \multicolumn{7}{|c|}{ O piso do sub-solo descarrega diretamente no solo } & - \\
\hline Escada & L & 4,3 & 1,5 & 2,5 & 0,7 & - \\
\hline
\end{tabular}

A definição das ações horizontais será realizada no item 7.2.

Foram realizadas comparações diferentes dos modelos, uma para ações verticais e outra para ações horizontais, já que o modelo mais simples, Vigas Contínuas, não permite a avaliação dos efeitos das ações laterais em um edifício. Posteriormente foram feitos alguns comentários e apresentados alguns resultados de uma análise conjunta de ações verticais e horizontais.

\subsection{Análise das ações verticais}

Três modelos foram utilizados para a análise estrutural do edifício, quanto às ações verticais: Vigas Contínuas, Pórticos Planos e Pórtico Espacial. Os esforços foram obtidos por uma análise linear desses modelos.

As reações das lajes nas vigas foram obtidas de forma idêntica para os três modelos, para que se pudesse fazer uma melhor comparação entre eles. Foi considerado o processo de posição aproximada das charneiras plásticas, descrito no item 14.7.6.1 da NBR 6118:2003. Devido à diferença de espessura das lajes e de suas dimensões, consideram-se as lajes simplesmente apoiadas nas suas quatro bordas. Os vãos entre as vigas são dados pelas distâncias entre os centros dos apoios, e os pilares foram idealizados como engastados na fundação.

Uma tendência atual, porém não abordada neste trabalho, é a análise da interação soloestrutura. Para levá-la em conta, pode-se calcular os esforços nos pilares com a consideração de engaste na fundação e, com esses valores, fazer uma estimativa dos recalques segundo um dos métodos disponíveis na literatura técnica. Esses recalques seriam representados por deslocamentos impostos nos pilares junto à fundação, o que provocaria uma nova distribuição 
dos esforços. O processo então se repete até que haja a convergência dos valores de esforços, que são então utilizados no dimensionamento.

\subsubsection{Modelos}

a) Vigas Contínuas

O modelo Vigas Contínuas é o mais simples, em que elas são consideradas simplesmente apoiadas nos pilares e nas demais vigas. Ele é permitido, desde que acompanhado das correções descritas no item 2.2.1. As vigas analisadas foram V1, V5, V6 e V7 do pavimentotipo. A V3 pode ser considerada apoiada nas vigas V7 e V8 e causa uma ação concentrada nessas vigas.
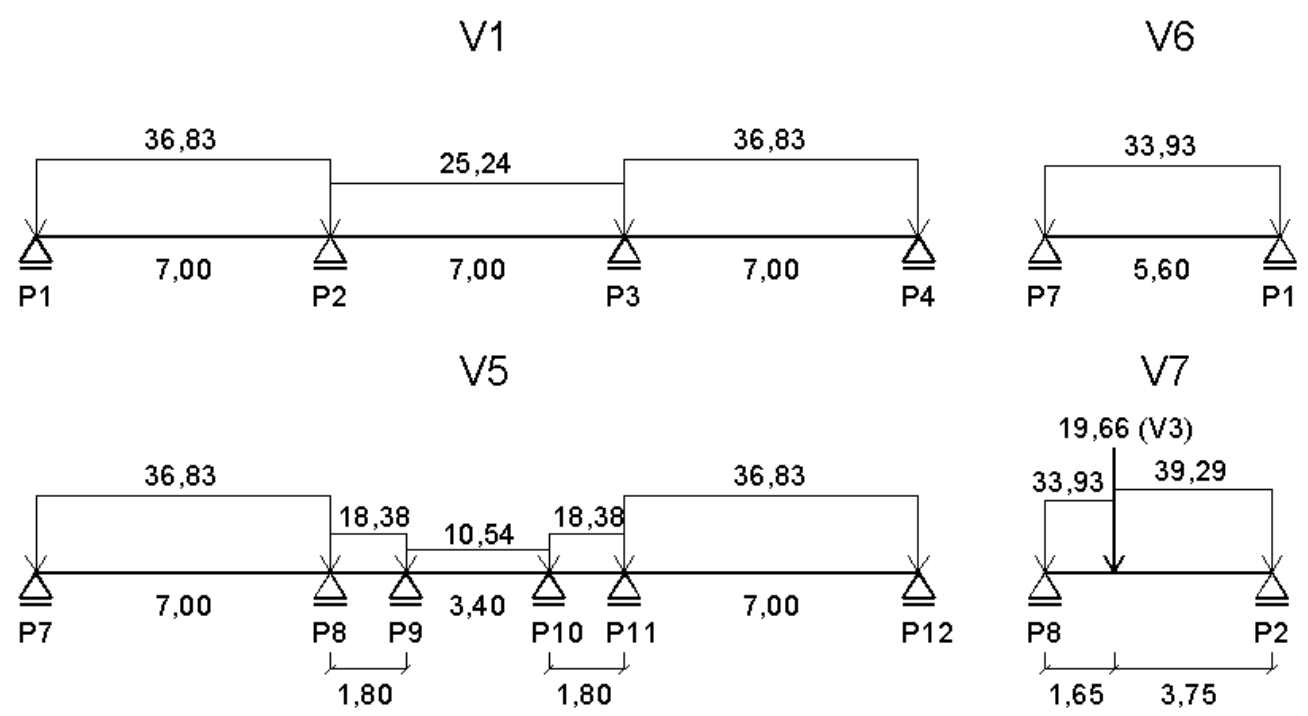

Figura 7.3 - Modelo Vigas Contínuas para vigas do pavimento-tipo e combinação última 1,4.g + 1,4.q (unidades: $\mathrm{kN}$ e $\mathrm{m}$ )

b) Pórticos Planos

Os pórticos planos analisados estão definidos na Figura 7.4 e na Figura 7.5. São eles:

$-P P 1: P 1+P 2+P 3+P 4+V 1$

- PP3: $P 7+P 8+P 9+P 10+P 11+P 12+V 5+V E$

- PP4: P7 + P1 + V6

- PP5: P8 + P2 + V7 
Neste modelo as vigas funcionam como apoios indeslocáveis para as lajes. As vigas que não formam pórticos planos, como a V3 e a V4, podem ser analisadas separadamente pelo modelo Vigas Contínuas. Os pilares pertencentes a mais de um pórtico plano, simultaneamente, devem ter seus esforços calculados a partir da somatória dos obtidos para cada pórtico, separadamente.

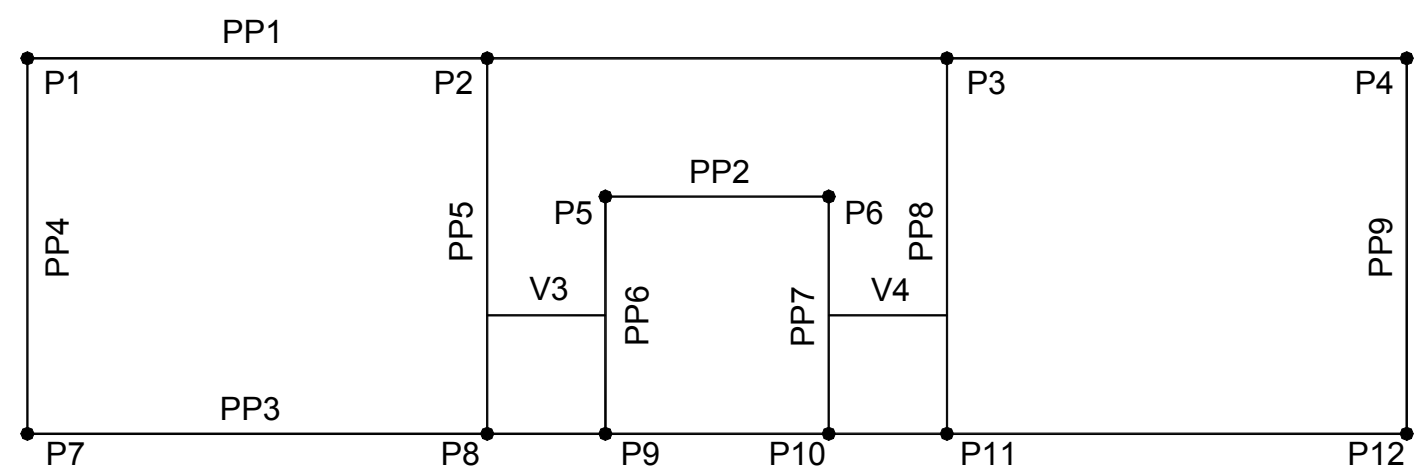

Figura 7.4 - Definição dos pórticos planos

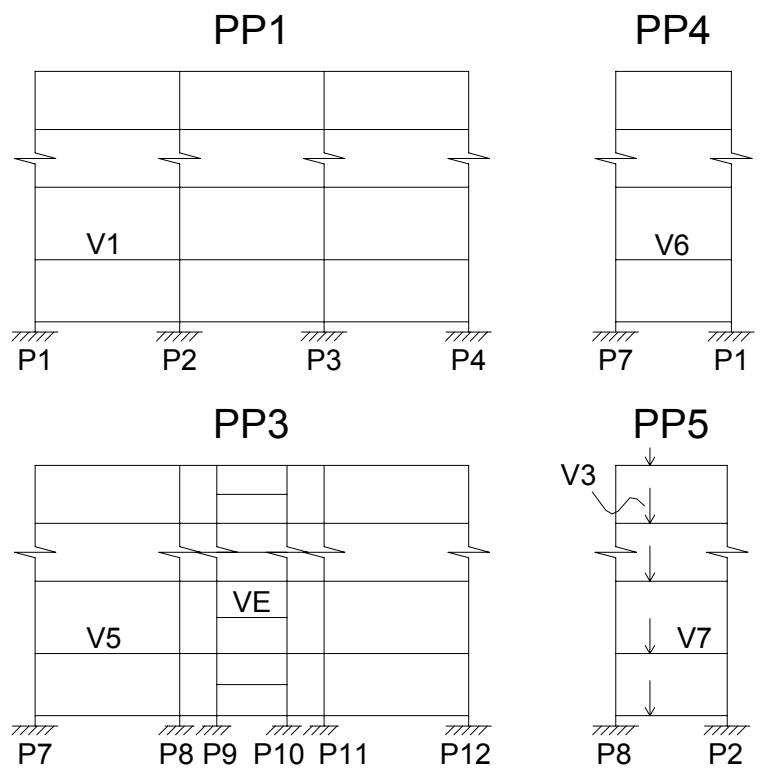

Figura 7.5 - Modelo Pórticos Planos

c) Pórtico Espacial

A modelagem do pórtico espacial foi realizada somente com o esqueleto composto por vigas e pilares (ver Figura 7.6). Desta maneira tem-se uma melhor comparação entre os modelos, pois, se a laje fosse modelada como grelha, haveria uma distribuição diferente das reações das lajes nas vigas. Os elementos lineares, vigas e pilares, apresentam ligações rígidas entre si, com trechos flexíveis, definidos pelas distâncias entre os eixos dos apoios. Na análise das ações 
laterais será modelado um pórtico espacial com a consideração de trechos rígidos nos encontros de vigas e pilares.

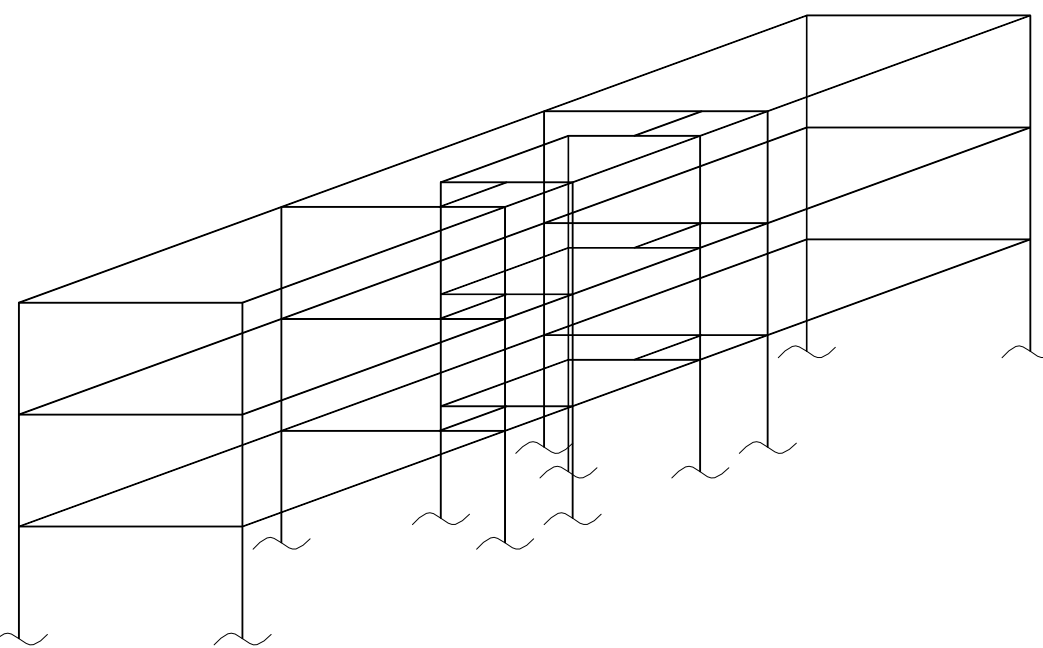

Figura 7.6 - Modelo Pórtico Espacial

\subsubsection{Resultados}

Serão comparados as forças normais junto à fundação e os momentos fletores nas vigas do pavimento térreo, para os três modelos considerados.

a) Forças normais junto à fundação

Estas forças normais referem-se a valores de cálculo. A combinação utilizada foi $1,4 \mathrm{~g}+1,4 \mathrm{q}$, e as diferenças percentuais, na Tabela 7.2, referem-se ao modelo Pórtico Espacial.

Tabela 7.2 - Forças normais junto à fundação $(\mathrm{kN})$

\begin{tabular}{|c|cccc|}
\hline Modelos / Pilares & P1 & P2 & P7 & P8 \\
\hline Vigas contínuas & 1742,9 & 2981,0 & 1708,4 & 3380,8 \\
Diferença (\%) & $-8,44$ & 4,00 & $-10,69$ & 51,82 \\
\hline Pórticos planos & 2007,6 & 3052,5 & 2016,2 & 2536,7 \\
Diferença (\%) & 5,47 & 6,49 & 5,41 & 13,91 \\
\hline Pórtico espacial & 1903,5 & 2866,4 & 1912,8 & 2226,9 \\
\hline
\end{tabular}

Nota-se que o modelo Pórticos Planos fornece resultados bem mais próximos dos obtidos com o Pórtico Espacial, do que o modelo Vigas Contínuas, exceto para o P2, e com valores sempre a favor da segurança. O modelo Vigas Contínuas considera que o P8 tem 52\% mais força normal que a relativa ao Pórtico Espacial, tornando-o um pilar bem mais carregado em relação aos outros.

b) Momentos fletores nas vigas do pavimento térreo 
Foi escolhido o pavimento térreo - cuja diferença em relação ao pavimento-tipo reside apenas na altura dos pilares - para analisar os momentos fletores nas vigas, pois foi nelas que, em geral, ocorreram os maiores valores referentes ao modelo Pórtico Espacial. Na Figura 7.7 têmse os diagramas de momento fletor da V1, para os diferentes modelos. Da Tabela 7.3 à Tabela 7.6, apresentam-se os resultados da mesma V1 e das V5, V6 e V7, respectivamente, cujos valores referem-se aos máximos momentos, observados nos apoios e nos vãos.

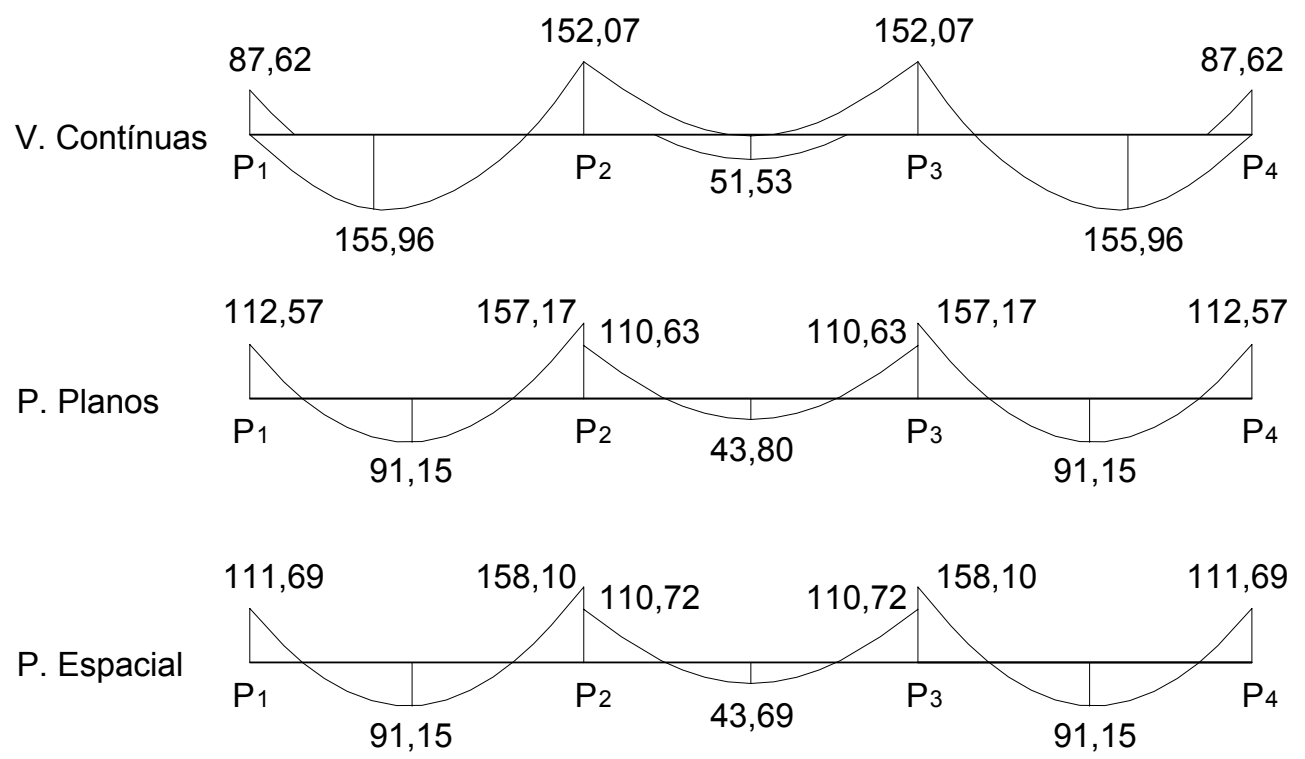

Figura 7.7 - Momentos fletores da V1 no pavimento térreo (kN.m)

Mais uma vez a combinação analisada foi $1,4 \mathrm{~g}+1,4 \mathrm{q}$, e as diferenças percentuais referem-se ao modelo Pórtico Espacial.

Tabela 7.3 - Momentos fletores da V1 (kN.m)

\begin{tabular}{|c|ccccccc|}
\hline Modelos & P1 & Vão & P2 & Vão & P3 & Vão & P4 \\
\hline Vigas contínuas & 87,62 & 155,96 & 152,07 & 51,53 & 152,07 & 155,96 & 87,62 \\
Diferença (\%) & $-21,55$ & 71,10 & $-3,81$ & 17,94 & $-3,78$ & 71,10 & $-21,59$ \\
\hline Pórticos planos & 112,57 & 91,15 & 157,17 & 43,80 & 157,17 & 91,15 & 112,57 \\
Diferença (\%) & 0,79 & 0,00 & $-0,59$ & 0,25 & $-0,56$ & 0,00 & 0,73 \\
\hline Pórtico espacial & 111,69 & 91,15 & 158,10 & 43,69 & 158,05 & 91,15 & 111,75 \\
\hline
\end{tabular}

Tabela 7.4 - Momentos fletores da V5 (kN.m)

\begin{tabular}{|c|ccccccccccc|}
\hline Modelos & P7 & Vão & P8 & Vão & P9 & Vão & P10 & Vão & P11 & Vão & P12 \\
\hline Vigas contínuas & 87,62 & 143,59 & 182,43 & 2,48 & $14,35^{*}$ & 29,58 & $14,35^{*}$ & 2,48 & 182,43 & 143,59 & 87,62 \\
Diferença (\%) & $-22,49$ & 52,76 & 20,97 & - & 222,34 & 754,91 & 222,34 & - & 21,01 & 52,76 & $-22,52$ \\
\hline Pórticos planos & 113,60 & 93,53 & 151,18 & - & 10,04 & 5,24 & 10,04 & - & 151,18 & 93,53 & 113,6 \\
Diferença (\%) & 0,50 & $-0,50$ & 0,25 & - & $-14,41$ & 51,45 & $-14,41$ & - & 0,29 & $-0,50$ & 0,45 \\
\hline Pórtico espacial & 113,04 & 94,00 & 150,80 & - & 11,73 & 3,46 & 11,73 & - & 150,75 & 94,00 & 113,09 \\
\hline
\end{tabular}

* Momentos positivos, ao contrário do que ocorre nestes apoios com os demais modelos 
Tabela 7.5 - Momentos fletores da V6 (kN.m)

\begin{tabular}{|c|ccc|}
\hline Modelos & P7 & Vão & P1 \\
\hline Vigas contínuas & 70,93 & 133,01 & 70,93 \\
Diferença (\%) & $-10,90$ & 130,56 & $-12,00$ \\
\hline Pórticos planos & 80,10 & 57,70 & 80,10 \\
Diferença (\%) & 0,62 & 0,02 & $-0,62$ \\
\hline Pórtico espacial & 79,61 & 57,69 & 80,60 \\
\hline
\end{tabular}

Tabela 7.6 - Momentos fletores da V7 (kN.m)

\begin{tabular}{|c|ccc|}
\hline Modelos & P8 & Vão & P2 \\
\hline Vigas contínuas & 98,55 & 156,09 & 94,31 \\
Diferença (\%) & $-14,98$ & 148,35 & $-8,65$ \\
\hline Pórticos planos & 110,14 & 63,10 & 109,68 \\
Diferença (\%) & $-4,99$ & 0,40 & 6,24 \\
\hline Pórtico espacial & 115,92 & 62,85 & 103,24 \\
\hline
\end{tabular}

Verifica-se que, nos apoios, os momentos são sempre negativos, com exceção dos apoios P9 e P10 da V5, para o modelo Vigas Contínuas, nos quais as fibras inferiores é que se encontram tracionadas. Nos vãos os momentos são sempre positivos, com exceção entre os pilares P8 e P9 e entre P10 e P11, da V5, para os modelos Pórticos Planos e Pórtico Espacial, nos quais as fibras superiores é que se encontram tracionadas.

Comparando-se os modelos quanto aos momentos fletores nas vigas, observa-se uma boa aproximação entre os modelos Pórticos Planos e Pórtico Espacial. Nas vigas V1 e V6, a diferença dos momentos fletores não ultrapassa $1 \%$, entre os dois modelos. Já no modelo Vigas Contínuas, nota-se uma tendência de subestimar os momentos negativos nos apoios, e de superestimar acentuadamente os momentos positivos dos vãos, em relação ao modelo Pórtico Espacial. A V5 apresenta peculiaridades, como um momento fletor positivo, no seu vão central, $755 \%$ maior para o modelo Vigas Contínuas, o que corrobora com a afirmação de que este modelo mais simples apresenta resultados satisfatórios apenas para vigas com vãos aproximadamente iguais em comprimento e carregamento.

\subsection{Análise das ações horizontais}

Antes de descrever os modelos adotados, calculam-se as ações laterais atuantes. O cálculo das ações decorrentes do vento foi realizado de acordo com a NBR 6123:1988, e tem seus principais valores resumidos na Tabela 7.7. 
Tabela 7.7 - Ações do vento

\begin{tabular}{|c|c|c|c|c|c|c|c|c|c|c|c|c|c|}
\hline & & & & & & & & \multicolumn{3}{|c|}{ Vento X } & \multicolumn{3}{|c|}{ Vento Y } \\
\hline Pavimento & $H(m)$ & $S_{1}$ & $S_{2}$ & $\mathrm{~S}_{3}$ & $\mathrm{~V}_{0}(\mathrm{~m} / \mathrm{s})$ & $V_{k}(m / s)$ & $q\left(k N / m^{2}\right)$ & $A_{e}\left(m^{2}\right)$ & $\mathrm{C}_{\mathrm{a}}$ & $\mathrm{V}_{\mathrm{x}}(\mathrm{kN})$ & $A_{e}\left(m^{2}\right)$ & $\mathrm{C}_{\mathrm{a}}$ & $\overline{V_{y}(k N)}$ \\
\hline SS & 0 & 1 & 0 & 1 & 40 & 0 & 0 & 0 & 0,79 & 0 & 0 & 1,33 & 0 \\
\hline Térreo & 0 & 1 & 0 & 1 & 40 & 0 & 0 & 10,5 & 0,79 & 0 & 37,3 & 1,33 & 0 \\
\hline T1 & 3,5 & 1 & 0,73 & 1 & 40 & 29,22 & 0,52 & 18,9 & 0,79 & 7,82 & 67,1 & 1,33 & 46,71 \\
\hline$\overline{T 2}$ & 6,3 & 1 & 0,79 & 1 & 40 & 31,45 & 0,61 & 16,8 & 0,79 & 8,05 & 59,6 & 1,33 & 48,09 \\
\hline T3 & 9,1 & 1 & 0,82 & 1 & 40 & 32,93 & 0,66 & 16,8 & 0,79 & 8,82 & 59,6 & 1,33 & 52,73 \\
\hline T4 & 11,9 & 1 & 0,85 & 1 & 40 & 34,05 & 0,71 & 16,8 & 0,79 & 9,43 & 59,6 & 1,33 & 56,38 \\
\hline T5 & 14,7 & 1 & 0,87 & 1 & 40 & 34,96 & 0,75 & 16,8 & 0,79 & 9,95 & 59,6 & 1,33 & 59,44 \\
\hline T6 & 17,5 & 1 & 0,89 & 1 & 40 & 35,73 & 0,78 & 16,8 & 0,79 & 10,39 & 59,6 & 1,33 & 62,09 \\
\hline Cob & 20,3 & 1 & 0,91 & 1 & 40 & 36,40 & 0,81 & 8,4 & 0,79 & 5,39 & 29,8 & 1,33 & 32,22 \\
\hline
\end{tabular}

A altura $\mathrm{H}$ dos pavimentos é dada em relação ao nível do solo, ou seja, a partir do pavimento térreo, sendo admitida nula para o pavimento térreo e para o sub-solo (ver Figura 7.2). $O$ fator $S_{1}$ é o fator topográfico, tomado igual a 1 para terrenos planos. $O$ fator $S_{2}$ é o fator de rugosidade, que depende da categoria do terreno, da classe da edificação e da altura sobre o terreno do pavimento considerado. Neste exemplo foi considerada a categoria IV, para terrenos com obstáculos numerosos e pouco espaçados em zona urbanizada, e classe $\mathrm{B}$, para edificações com maior dimensão entre 20 e $50 \mathrm{~m}$. O fator $S_{3}$ é o fator estatístico, que depende do tipo de utilização da edificação. Para hotéis, residências, comércio e indústria com alto fator de ocupação esse fator é igual a 1. A velocidade característica $V_{k}$ é dada pelo produto de $S_{1}$, $S_{2}, S_{3}$ e $V_{0}$. A velocidade básica $V_{0}$, cujo valor é $40 \mathrm{~m} / \mathrm{s}$ para São Carlos, varia de acordo com a região do país e é fornecida pelo mapa de isopletas. A pressão q é dada por $0,613 . V_{k}{ }^{2}$, com unidades em N/m² e m/s. O coeficiente de arrasto, $C_{a}$, foi calculado pelo ábaco da Figura 4 da NBR 6123:1988, que se refere a edificações paralelepipédicas submetidas a vento de baixa turbulência. $A_{e}$ é a área de influência em que o vento atua. $A$ força de arrasto é calculada pelo produto de $\mathrm{q}, \mathrm{C}_{\mathrm{a}}$ e $\mathrm{A}_{\mathrm{e}}$.

O desaprumo pode ter seus efeitos traduzidos por ações laterais equivalentes, dadas para cada pavimento i por $\left(P_{\mathrm{ki}} \times \theta_{\mathrm{a}}\right)$. $P_{\mathrm{ki}}$ é o valor característico da carga total de cada pavimento e $\theta_{\mathrm{a}}$ é o ângulo de desaprumo, que deve ser calculado para cada direção, em função do número $n$ de prumadas de pilares e de $\theta_{1}$. Esse número $n$ foi tomado igual a 4 na direção $x$ e igual a 2 na direção $y$, de forma que resultasse nos valores mais desfavoráveis de $\theta_{\mathrm{a}}$. $\theta_{1}$ é calculado em função da altura total da edificação, $\mathrm{H}$, em metros, de acordo com a Eq.(7.1). O valor mínimo estabelecido para $\theta_{1}$, para estruturas de nós fixos, é de $1 / 400$.

$\theta_{1}=\frac{1}{100 \sqrt{\mathrm{H}}}$ 
$\theta_{\mathrm{a}}=\theta_{1} \sqrt{\frac{1+1 / \mathrm{n}}{2}}$

A Tabela 7.8 fornece os valores de ações laterais provocadas pelo desaprumo, em cada pavimento.

Tabela 7.8 - Ações decorrentes do desaprumo

\begin{tabular}{|cccccc|}
\cline { 3 - 6 } \multicolumn{1}{c|}{} & \multicolumn{2}{c|}{ Desaprumo $X$} & \multicolumn{2}{c|}{ Desaprumo $\mathbf{Y}$} \\
\hline Pavimento & $\mathbf{P}_{\mathbf{k}} \mathbf{( k N )}$ & $\theta_{\mathbf{a}}$ & $\left.\mathbf{D}_{\mathbf{x}} \mathbf{( k N}\right)$ & $\theta_{\mathbf{a}}$ & $\mathbf{D}_{\mathbf{y}} \mathbf{( k N )}$ \\
\hline SS & 831,6 & 0,00198 & 1,64 & 0,00217 & 1,80 \\
\hline Térreo & 1945,0 & 0,00198 & 3,84 & 0,00217 & 4,21 \\
\hline T1 & 1968,9 & 0,00198 & 3,89 & 0,00217 & 4,26 \\
\hline T2 & 1935,4 & 0,00198 & 3,83 & 0,00217 & 4,19 \\
\hline T3 & 1935,4 & 0,00198 & 3,83 & 0,00217 & 4,19 \\
\hline T4 & 1935,4 & 0,00198 & 3,83 & 0,00217 & 4,19 \\
\hline T5 & 1935,4 & 0,00198 & 3,83 & 0,00217 & 4,19 \\
\hline T6 & 1935,4 & 0,00198 & 3,83 & 0,00217 & 4,19 \\
\hline Cob & 1769,4 & 0,00198 & 3,50 & 0,00217 & 3,83 \\
\hline
\end{tabular}

De acordo com a NBR 6118:2003, pode ser considerado, entre o vento e o desaprumo, somente aquele que provoca o maior momento total na base da construção. Portanto, será considerado o vento, que forneceu maiores valores de ações laterais.

Entre os modelos adotados para a análise da estrutura, frente às ações laterais, tem-se o de Pórticos Planos Associados, o Pórtico Espacial, o Pórtico Espacial com Lajes e o Pórtico Espacial com Lajes e Trechos Rígidos.

\subsubsection{Modelos}

a) Pórticos Planos Associados

O modelo Pórticos Planos Associados foi idealizado conforme a descrição do item 2.2.2 (ver Figura 2.7). Os pórticos planos foram conectados por barras consideradas com um metro de comprimento, um metro de largura e $13 \mathrm{~cm}$ de altura. As ações do vento são aplicadas integralmente no primeiro pilar da associação de pórticos, nos correspondentes pavimentos. $\mathrm{Na}$ direção x tem-se a associação de PP1, PP2 e PP3 e, na direção y, tem-se a associação dos pórticos de PP4 a PP9 (ver Figura 7.4 para a identificação dos pórticos). A Figura 7.8 mostra a barra que liga o PP4 ao PP5 no topo do edifício, modelada no Eberick. 


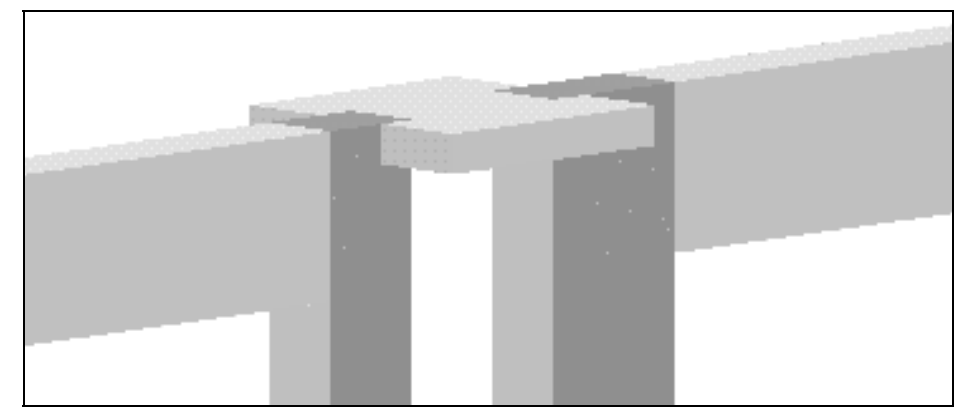

Figura 7.8 - Modelo Pórticos Planos Associados: conexão do PP4 com o PP5

\section{b) Pórtico Espacial}

O modelo é o mesmo descrito para as ações verticais, composto apenas por pilares e vigas. As ações laterais são aplicadas como forças concentradas nos pilares, no nível de cada pavimento, de forma ponderada em relação à rigidez de cada pilar, conforme a Eq.(7.3). $\mathrm{l}_{\mathrm{i}}$ é a inércia do pilar genérico i, na direção da ação do vento $V_{j}$ do pavimento genérico j, e $n$ é o número de pilares no pavimento considerado.

$$
F_{i}=V_{j} \cdot \frac{I_{i}}{\sum_{1}^{n} I_{i}}
$$

\section{c) Pórtico Espacial com Lajes}

Neste modelo incluem-se as lajes, com a finalidade de mostrar a influência que elas exercem sobre a compatibilização de deslocamentos horizontais em um mesmo pavimento. As forças do vento são aplicadas da mesma forma que no modelo anterior, ou seja, concentradas nos pilares, de acordo com a rigidez desses elementos. A Figura 7.9 mostra a renderização do modelo Pórtico Espacial com Lajes.

\section{d) Pórtico Espacial com Lajes e Trechos Rígidos}

Este modelo assemelha-se ao anterior, porém com a existência de trechos rígidos na interseção de vigas e pilares, conforme o explicitado no item 2.3. Os trechos rígidos modelados no Eberick (linhas duplas) estão na Figura 7.10 , possuindo $8,5 \mathrm{~cm}$ para os pilares de seção $30 \times 40$, e $28,5 \mathrm{~cm}$ para os pilares de seção $30 \times 60$. 


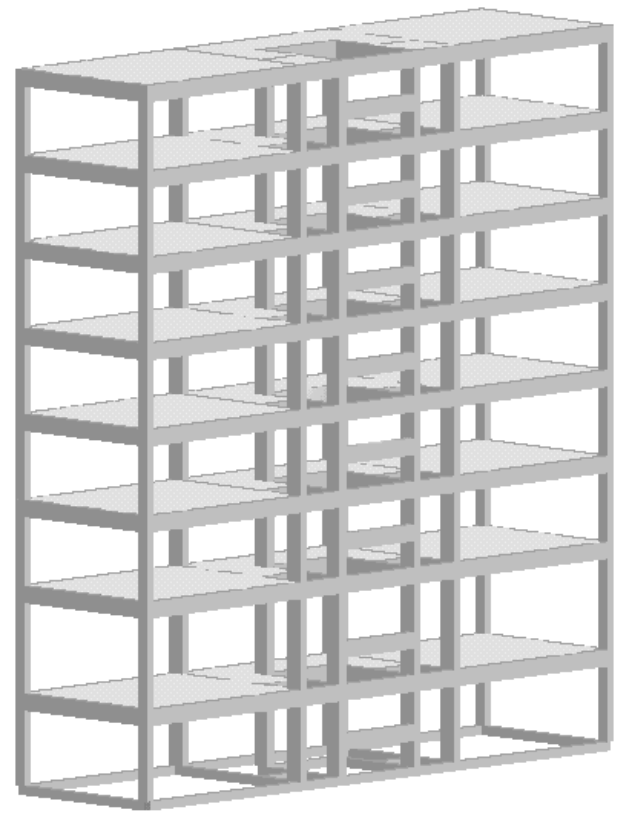

Figura 7.9 - Renderização do modelo Pórtico Espacial com Lajes
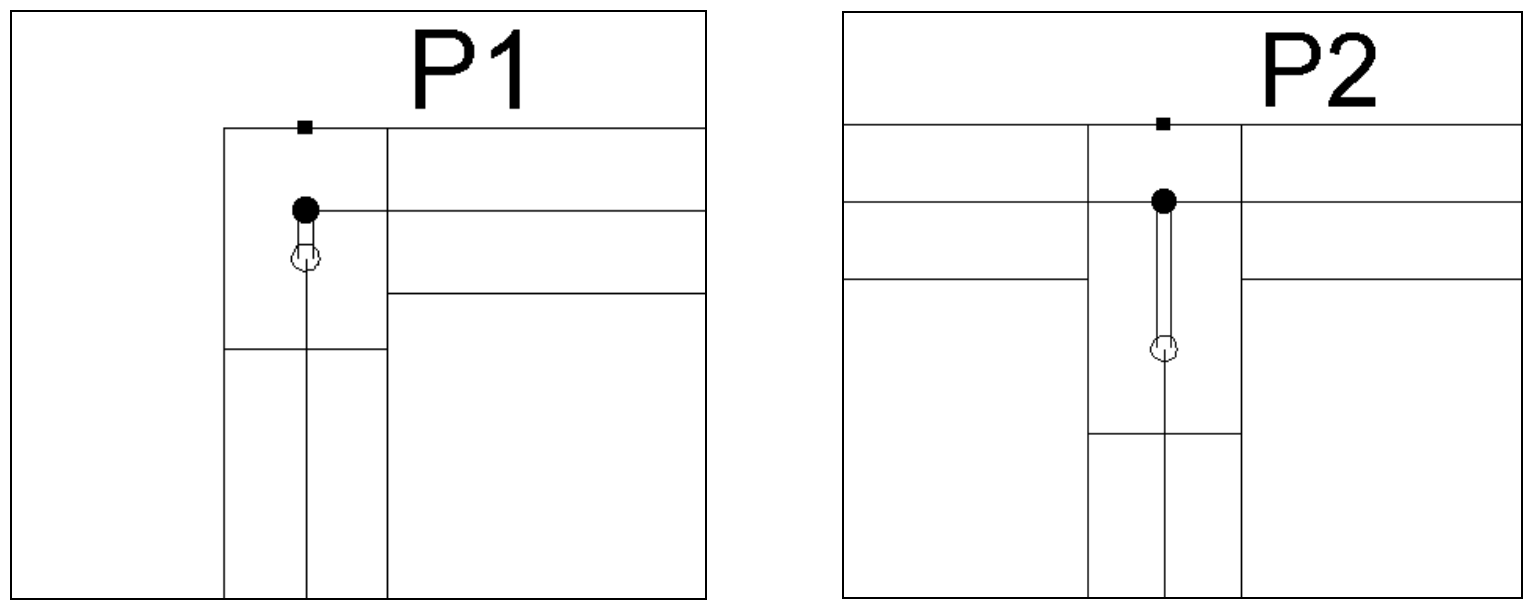

Figura 7.10 - Trechos rígidos dos pilares P1 e P2

\subsubsection{Resultados}

a) Deslocamentos horizontais no topo da estrutura

O deslocamento horizontal da estrutura constitui-se um importante resultado a ser determinado pela análise estrutural, tanto para a verificação de estado limite de serviço como para a verificação da estabilidade global do edifício.

A Tabela 7.9 contém os valores máximos e mínimos dos deslocamentos na cobertura, para os diferentes modelos, pois os pontos dos pavimentos não se deslocam de maneira uniforme. As combinações de ações utilizadas nas direções $x$ e $y$, respectivamente, foram $V_{x}$ e $V_{y}$, e 
portanto, fornecem valores característicos de deslocamentos. Foi considerada a nãolinearidade física de forma simplificada, conforme explicitado no item 3.4.1-a, com as rigidezes 0,3 $\mathrm{E}_{\mathrm{ci}} \mathrm{I}_{\mathrm{c}}$ para lajes, 0,4 $\mathrm{E}_{\mathrm{ci}} \mathrm{I}_{\mathrm{c}}$ para vigas e 0,8 $\mathrm{E}_{\mathrm{ci}} \mathrm{l}_{\mathrm{c}}$ para pilares. A diferença percentual refere-se aos valores máximos, quando comparados com o modelo Pórtico Espacial com Lajes e Trechos Rígidos.

Tabela 7.9 - Deslocamentos horizontais no topo da estrutura $(\mathrm{cm})$

\begin{tabular}{|c|ccc|ccc|}
\hline \multirow{2}{*}{ Modelos } & \multicolumn{3}{|c|}{ Direção X } & \multicolumn{3}{c|}{ Direção Y } \\
\cline { 2 - 7 } & Máx. & Mín. & Diferença (\%) & Máx. & Mín. & Diferença (\%) \\
\hline Pórticos planos associados & 0,45 & 0,44 & 15,38 & 2,51 & 2,48 & 24,88 \\
Pórtico espacial & 0,40 & 0,33 & 2,56 & 2,82 & 1,91 & 40,30 \\
Pórtico espacial com lajes & 0,39 & 0,32 & 0,00 & 2,45 & 2,45 & 21,89 \\
Pórtico espacial com lajes e & 0,39 & 0,33 & - & 2,01 & 2,01 & - \\
trechos rígidos & \multicolumn{2}{|c|}{-} & &
\end{tabular}

Apesar do edifício analisado ter seus pilares posicionados sempre com a maior inércia na direção y, têm-se deslocamentos bem maiores nesta direção, uma vez que a área lateral do prédio que recebe o vento é bem superior à da direção $x$.

Os resultados foram bem coerentes para os diversos modelos, com exceção do Pórtico Espacial, que modelado apenas com o esqueleto de vigas e pilares, apresentou deslocamentos bem variados em um mesmo pavimento, na direção y (ver Figura 7.11). Este modelo deve ser utilizado apenas se houver a possibilidade, no programa utilizado, de compatibilizar os deslocamentos dos nós dos pavimentos, com a implementação do nó mestre (ver item 2.2.3), por exemplo. Os dois outros modelos de pórtico espacial, em que foram inclusas as lajes, apresentaram deslocamentos mais uniformes ao longo dos pavimentos, confirmando o funcionamento das lajes como diafragmas rígidos.

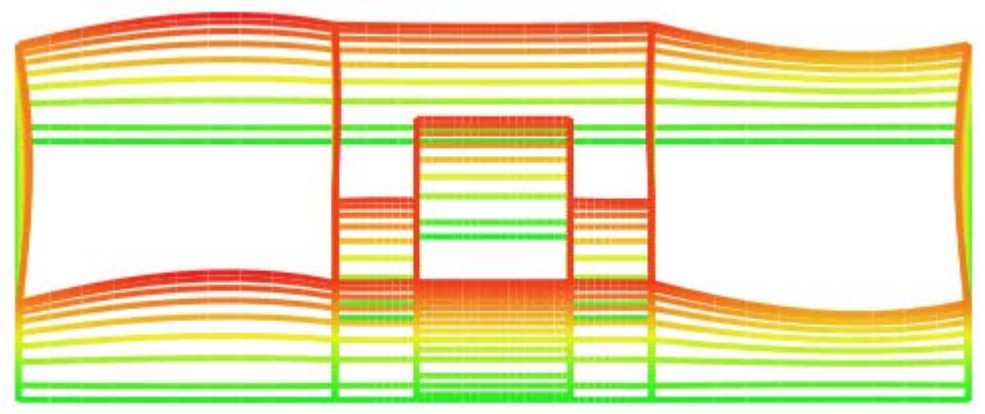

Figura 7.11 - Modelo Pórtico Espacial: vista superior dos deslocamentos devidos ao vento da direção y (deslocamentos aumentados em 100 vezes e legenda em $\mathrm{cm}$ )

O modelo Pórticos Planos Associados apresentou bons resultados em relação ao Pórtico Espacial com Lajes, com 15,38\% de diferença na direção x e 2,45\% na direção y. Esta maior 
diferença na direção $x$ deve-se em parte aos pequenos valores de deslocamentos nesta direção. Além disso, o comportamento das lajes como diafragmas rígidos foi bem reproduzido pelas barras de alta rigidez axial que ligam os pórticos planos, pois os deslocamentos máximos e mínimos tiveram pouca diferença entre si. Já em relação ao modelo Pórtico Espacial com Lajes e Trechos Rígidos essa diferença na direção $Y$ foi de $24,88 \%$.

Quanto à utilização de trechos rígidos, houve uma diferença entre os modelos Pórtico Espacial com Lajes e Pórtico Espacial com Lajes e Trechos Rígidos, na direção y, ao contrário do que aconteceu na direção $x$. Isto se deve ao fato de que os trechos rígidos estão todos definidos na direção y. A não utilização dos trechos rígidos acarreta em um deslocamento $22 \%$ maior (direção y) no topo do edifício, por parte do modelo Pórtico Espacial com Lajes, o que pode ser relevante na estabilidade global e no estado limite de serviço.

O Pórtico Espacial com Lajes e Trechos Rígidos pode ser considerado como o melhor modelo entre os apresentados neste exemplo. A Figura 7.12 mostra a torção existente no edifício, devida à assimetria na direção $X$, e na Figura 7.13 tem-se o deslocamento compatibilizado dos pavimentos na direção $Y$.
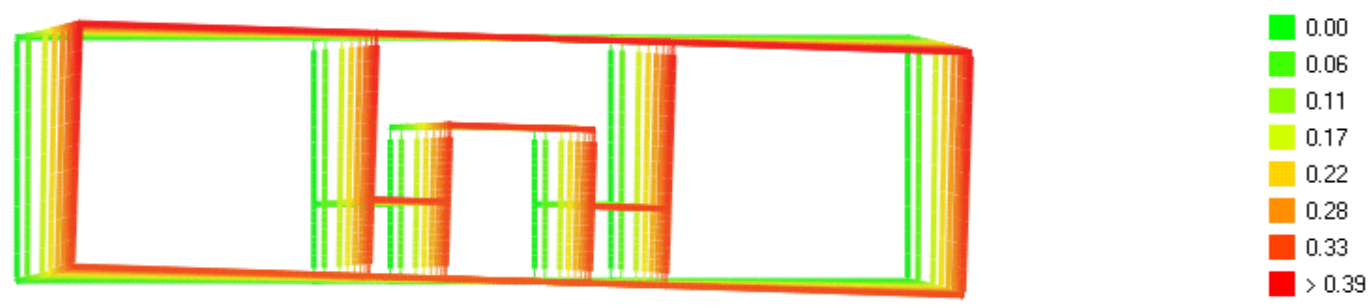

Figura 7.12 - Modelo Pórtico Espacial com Lajes e Trechos Rígidos: vista superior dos deslocamentos devidos ao vento da direção x (deslocamentos aumentados em 400 vezes e legenda em $\mathrm{cm}$ )
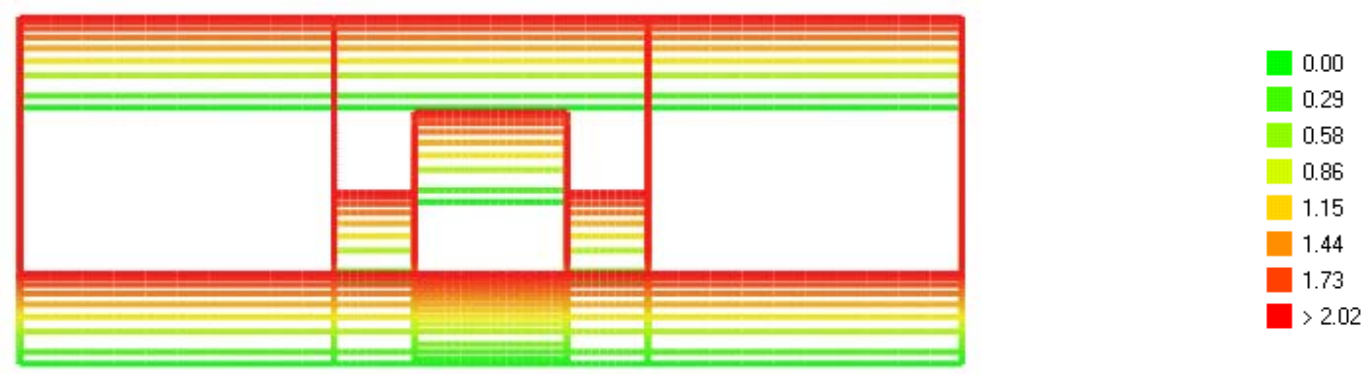

Figura 7.13 - Modelo Pórtico Espacial com Lajes e Trechos Rígidos: vista superior dos deslocamentos devidos ao vento da direção y (deslocamentos aumentados em 100 vezes e legenda em $\mathrm{cm}$ )

A altura total do edifício é de $2380 \mathrm{~cm}$, o que torna o deslocamento limite igual a $1,40 \mathrm{~cm}$ $(\mathrm{H} / 1700)$, de acordo com a tabela 13.2 da NBR 6118:2003. Os valores a serem comparados com o deslocamento limite são os da combinação freqüente $\left(\psi_{1}=0,30\right)$, considerando que 
apenas as forças do vento estão atuando. Por se tratar de uma análise linear, pode-se multiplicar diretamente os valores de deslocamentos da Tabela 7.9 por 0,30 , que mostram então ser menores que o valor limite para deslocamentos.

A Tabela 7.10 mostra os valores de $\gamma_{z}$ para os diferentes modelos, que não foram muito diferentes entre si ao se considerar no cálculo o valor médio dos deslocamentos horizontais nos pavimentos. O edifício pode ser considerado uma estrutura de nós fixos.

Tabela 7.10 - Valores de $\gamma_{z}$

\begin{tabular}{|c|c|c|}
\hline Modelos & Direção X & Direção Y \\
\hline Pórticos planos associados & 1,06 & 1,05 \\
Pórtico espacial & 1,05 & 1,05 \\
Pórtico espacial com lajes & 1,04 & 1,05 \\
Pórtico espacial com lajes e & 1,04 & 1,04 \\
trechos rígidos & & \\
\hline
\end{tabular}

b) Forças normais junto à fundação

A Tabela 7.11 fornece os valores das forças normais junto à fundação, para as ações do vento na direção $y$, a qual propicia maiores esforços. Novamente, as forças do vento foram consideradas com seus valores característicos. As diferenças percentuais são em relação ao modelo Pórtico Espacial com Lajes e Trechos Rígidos.

Tabela 7.11 - Forças normais junto à fundação, devidas ao vento em y $(\mathrm{kN})$

\begin{tabular}{|c|cccc|}
\hline Modelos / Pilares & P1 & P2 & P7 & P8 \\
\hline $\begin{array}{c}\text { Pórticos planos } \\
\text { associados } \\
\text { Diferença (\%) }\end{array}$ & 103,8 & 128,3 & $-103,8$ & $-129,4$ \\
\hline Pórtico espacial & 17,16 & $-3,02$ & $-17,55$ & 23,34 \\
Diferença (\%) & $-0,34$ & 0,60 & 0,34 & 0,77 \\
\hline Pórtico espacial c/ lajes & 102,6 & 127,6 & $-102,4$ & $-159,6$ \\
Diferença (\%) & 15,80 & $-3,55$ & $-15,97$ & 5,45 \\
\hline $\begin{array}{c}\text { Pórtico espacial c/ lajes e } \\
\text { trechos rígidos }\end{array}$ & 88,6 & 132,3 & $-88,3$ & $-168,8$ \\
\hline
\end{tabular}

Os pilares P7 e P8 oferecem resistência ao vento da direção y, e sentido norte, por meio de tração axial ao invés de compressão. Todavia, ao se analisar a estrutura considerando a atuação simultânea de ações verticais e horizontais, volta a haver compressão nesses pilares, como será visto no item 7.3. 
Nos modelos Pórtico Espacial e Pórtico Espacial com Lajes e Trechos Rígidos, que obtiveram resultados muito próximos, nota-se que as maiores forças normais se concentraram nos pilares mais centrais: o P2 e o P8. Esses dois pilares possuem maior inércia na direção y e, portanto, recebem maiores parcelas da força do vento.

c) Momentos fletores das vigas do pavimento térreo

As vigas analisadas continuam sendo a $\mathrm{V} 1$, a $\mathrm{V} 5$, a $\mathrm{V} 6$ e a $\mathrm{V} 7$, agora com o edifício submetido ao vento da direção y, com seu valor característico. As vigas V1 e V5, que se encontram em uma posição perpendicular à direção do vento, não são submetidas a momentos fletores. Os momentos fletores das vigas V6 e V7 seguem a configuração da Figura 7.14, com um momento positivo junto ao apoio esquerdo, um momento negativo junto ao apoio direito, e uma variação linear entre ambos os momentos.

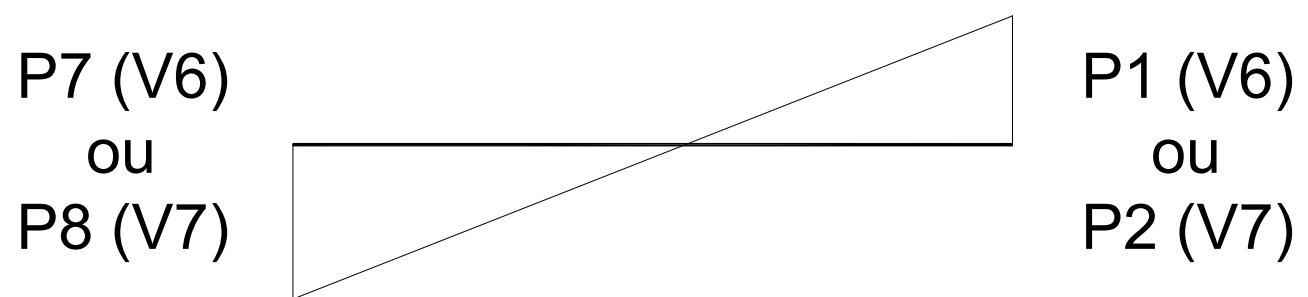

Figura 7.14 - Configuração dos momentos fletores das vigas V6 e V7

A Tabela 7.12 e a

Tabela 7.13 apresentam os momentos fletores da V6 e da V7, respectivamente. A diferença percentual refere-se aos resultados do modelo Pórtico Espacial com Lajes e Trechos Rígidos.

Tabela 7.12 - Momentos fletores da V6 (kN.m)

\begin{tabular}{|c|cc|}
\hline Modelos & P7 & P1 \\
\hline $\begin{array}{c}\text { Pórticos planos } \\
\text { associados } \\
\text { Diferença (\%) }\end{array}$ & 54,12 & 53,76 \\
\hline Pórtico espacial & 51,17 & 51,17 \\
Diferença (\%) & 14,32 & 14,32 \\
\hline Pórtico espacial com & 52,47 & 52,47 \\
lajes & 17,23 & 17,23 \\
\hline Diferença (\%) & 44,76 & 44,76 \\
\hline Pórtico espacial com \\
lajes e trechos rígidos
\end{tabular}


Tabela 7.13 - Momentos fletores da V7 (kN.m)

\begin{tabular}{|c|cc|}
\hline Modelos & P8 & P2 \\
\hline $\begin{array}{c}\text { Pórticos planos } \\
\text { associados } \\
\text { Diferença (\%) }\end{array}$ & 69,20 & 68,88 \\
\hline Pórtico espacial & 6,44 & 3,95 \\
Diferença (\%) & 3,91 & 68,71 \\
\hline Pórtico espacial com & 68,22 & 68,09 \\
lajes & 2,96 & 2,76 \\
\hline Diferença (\%) & 66,26 & 66,12 \\
\hline Pórtico espacial com \\
lajes e trechos rígidos
\end{tabular}

Quase todos os modelos apresentaram resultados bem próximos. $\mathrm{Na} \mathrm{V} 7$, por exemplo, os valores não diferem em mais que 5\%. A exceção foi o modelo Pórtico Espacial com Lajes e Trechos Rígidos, que, na V6, fez com que os demais modelos apresentassem valores maiores, entre 14 e 21\%. No entanto, pode-se notar uma boa padronização dos resultados dos diferentes modelos, para momentos fletores em vigas causados por ações de vento.

\subsection{Análise das ações verticais e horizontais}

O intuito deste exemplo era comparar os modelos estruturais, tanto para ações verticais como para ações horizontais. No entanto, uma vez dispondo de avançadas ferramentas computacionais, a melhor análise estrutural é aquela que considera a atuação simultânea de ações verticais e laterais. Para a verificação do deslocamento horizontal no topo do edifício, por exemplo, deve-se considerar apenas a atuação das ações do vento (ou do desaprumo, em caso de constituir-se na ação mais crítica). Porém, no cálculo de momentos fletores em vigas e esforços axiais em pilares, para a verificação de estado limite último, deve-se utilizar a combinação última pertinente, que engloba as ações permanentes, as ações acidentais, as ações do vento e outras, quando for o caso.

A combinação última para o edifício em questão, considerando o vento da direção y (mais crítico), é a seguinte: $1,4 \mathrm{~g}+1,4 \mathrm{q}+0,84 \mathrm{~V}_{\mathrm{y}}$. Considerou-se a ação do vento como a ação acidental secundária $\left(\psi_{0} \gamma_{q}=0,6 \cdot 1,4=0,84\right)$, apesar de, comumente, sua consideração como ação acidental principal suscitar maiores esforços na estrutura. A partir do modelo Pórtico Espacial com Lajes e Trechos Rígidos, e da combinação última citada, têm-se os esforços normais dos pilares, junto à fundação, indicados na Tabela 7.14. Mostra-se também as forças normais provenientes exclusivamente das ações verticais e a diferença devida à inclusão do vento na combinação. Analogamente têm-se os momentos fletores das vigas analisadas do 
pavimento térreo, na Figura 7.15 e na Tabela 7.15, cuja diferença apresentada também referese à combinação $1,4 \mathrm{~g}+1,4 \mathrm{q}$.

Tabela 7.14 - Forças normais junto à fundação (kN)

\begin{tabular}{|c|cccc|}
\hline Combinação & P1 & P2 & P7 & P8 \\
\hline $1,4 g+1,4 q+0,84 V_{y}$ & 1944,6 & 2902,6 & 1845,0 & 2050,0 \\
$1,4 g+1,4 q$ & 1870,2 & 2791,5 & 1919,2 & 2191,8 \\
Diferença (\%) & 3,98 & 3,98 & $-3,87$ & $-6,47$ \\
\hline
\end{tabular}

Conforme o esperado, as forças normais nos pilares $\mathrm{P} 1$ e $\mathrm{P} 2$ sofreram um pequeno acréscimo, de aproximadamente $4 \%$, devido à inclusão da ação do vento na combinação última. Pelo mesmo motivo, os pilares P7 e P8 tiveram seus esforços normais reduzidos, em 3,87 e 6,47\% respectivamente. Vê-se que os grandes responsáveis pelas forças normais junto à fundação são as ações verticais.

No que concerne aos momentos fletores nas vigas do pavimento térreo, houve diferenças irrisórias (menos que $0,5 \%$ ) entre os resultados obtidos pelas combinações $1,4 \mathrm{~g}+1,4 \mathrm{q}+$ $0,84 \bigvee_{y}$ e $1,4 \mathrm{~g}+1,4 q$, para as vigas $\mathrm{V} 1$ e $\mathrm{V} 5$. Isto se deve ao fato de que o vento da direção y pouco influi nos momentos nessas vigas. Nas vigas V6 e V7, que possuem seus eixos na direção $y$, as diferenças são maiores, principalmente nos momentos negativos junto aos apoios, da ordem de $50 \%$.

V1

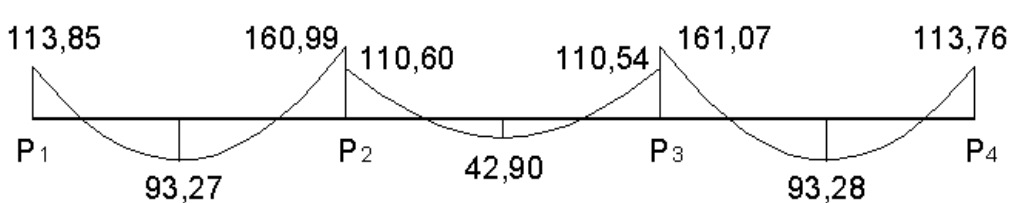

V5

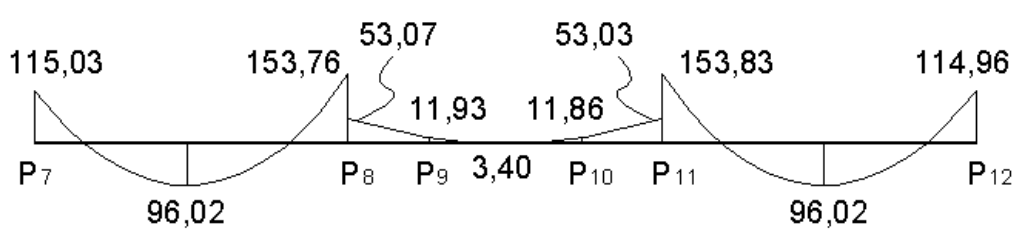

V6

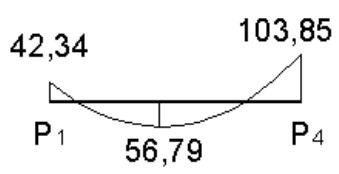

V7

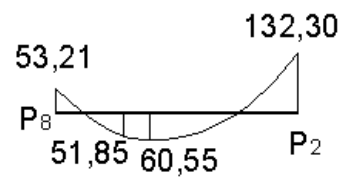

Figura 7.15 - Momentos fletores nas vigas do pavimento térreo (kN.m)

Tabela 7.15 - Momentos fletores nas vigas V6 e V7

\begin{tabular}{|c|ccc|ccc|}
\hline \multirow{2}{*}{ Combinação } & \multicolumn{3}{|c|}{ V6 } & \multicolumn{3}{c|}{ V7 } \\
\cline { 2 - 7 } & $\mathbf{P 1}$ & Vão & $\mathbf{P 4}$ & $\mathbf{P 8}$ & Vão & $\mathbf{P 2}$ \\
\hline $1,4 \mathrm{~g}+1,4 \mathrm{q}+0,84 \mathrm{~V}_{\mathrm{y}}$ & 42,34 & 56,79 & 103,85 & 53,21 & 60,55 & 132,30 \\
$1,4 \mathrm{~g}+1,4 \mathrm{q}$ & 79,93 & 55,03 & 66,26 & 108,87 & 57,05 & 76,76 \\
Diferença $(\%)$ & $-47,03$ & 3,20 & 56,73 & $-51,13$ & 6,13 & 72,36 \\
\hline
\end{tabular}




\section{CONSIDERAÇÕES FINAIS}

Obviamente, a análise estrutural trata-se de um conjunto de assuntos bastante extenso para se abordar em um trabalho como este. No entanto, espera-se que a contribuição aqui apresentada cumpra seu objetivo, que é o de trazer alguns esclarecimentos aos projetistas acerca do capítulo 14 da NBR 6118:2003.

Os capítulos dois e três apresentaram conceitos básicos para o bom entendimento da análise estrutural empregada pela NBR 6118:2003. A análise não-linear, para os diversos pares de elementos estruturais e modelos não-lineares, baseados em diagramas tensão versus deformação ou em diagramas momento versus curvatura, é considerada com detalhes em outros trabalhos, e tornaria este muito extenso, se fosse aqui abordada.

\subsection{Conclusões}

No capítulo quatro, mostrou-se como proceder na redistribuição de momentos de uma viga, seja com a análise linear com redistribuição, seja com a análise plástica. No exemplo considerado, foi fixado o valor do coeficiente de redistribuição, $\delta$, com a finalidade de obter a relação desejada entre momento positivo e negativo, para em seguida verificar a capacidade de redistribuição da seção, com o uso de armadura simples. Ambos os tipos de análise se mostraram simples de utilizar, dado que a estrutura analisada também tinha um caráter simples. Porém, usualmente, o emprego da análise linear com redistribuição é mais simples que o da análise plástica. Nos casos de pórticos planos ou de estruturas mais complexas, as análises linear com redistribuição e plástica passam a exigir programas computacionais, que sejam capazes de mostrar como se redistribuem os esforços, uma vez reduzidos os picos de momentos.

No caso específico, em que se manteve a consideração da seção retangular da viga, a economia de armadura, que foi de apenas $0,46 \%$, não constitui grande atrativo para a utilização de outro tipo de análise que não a linear. No entanto, há que se ponderar outras vantagens, entre as quais destaca-se a possibilidade de distribuir melhor as armaduras ao longo da viga, evitando assim o acúmulo de barras em uma mesma seção. Além disso, uma vez familiarizados com os conceitos de análise linear com redistribuição e de análise plástica, 
os projetistas, auxiliados por programas que considerem tais tipos de análise, notarão a possibilidade de se ter um maior controle sobre a maneira como a estrutura trabalha.

$\mathrm{Na}$ verificação dos estados limites de serviço, ficou claro que os esforços provêm das combinações de serviço, e que, portanto, não são afetados pela redistribuição. Com ela, as flechas passam a ser menores, já que a armadura nos vãos aumenta com a transferência de momentos. Por outro lado, a importância da verificação da abertura de fissuras nos apoios passa a ser maior, já que nesses pontos a armadura diminui. A análise plástica mostrou ser grande a capacidade de reduzir os momentos nos apoios, com o valor de $\delta$ chegando até quase 0,60 , nesse exemplo (ver Figura 8.1). Mostrou também que, se não fosse a capacidade de rotação plástica o fator a limitar uma maior redistribuição, a verificação da abertura de fissuras imporia o limite para um valor de $\delta$ pouco menor que 0,60 , para esse exemplo.

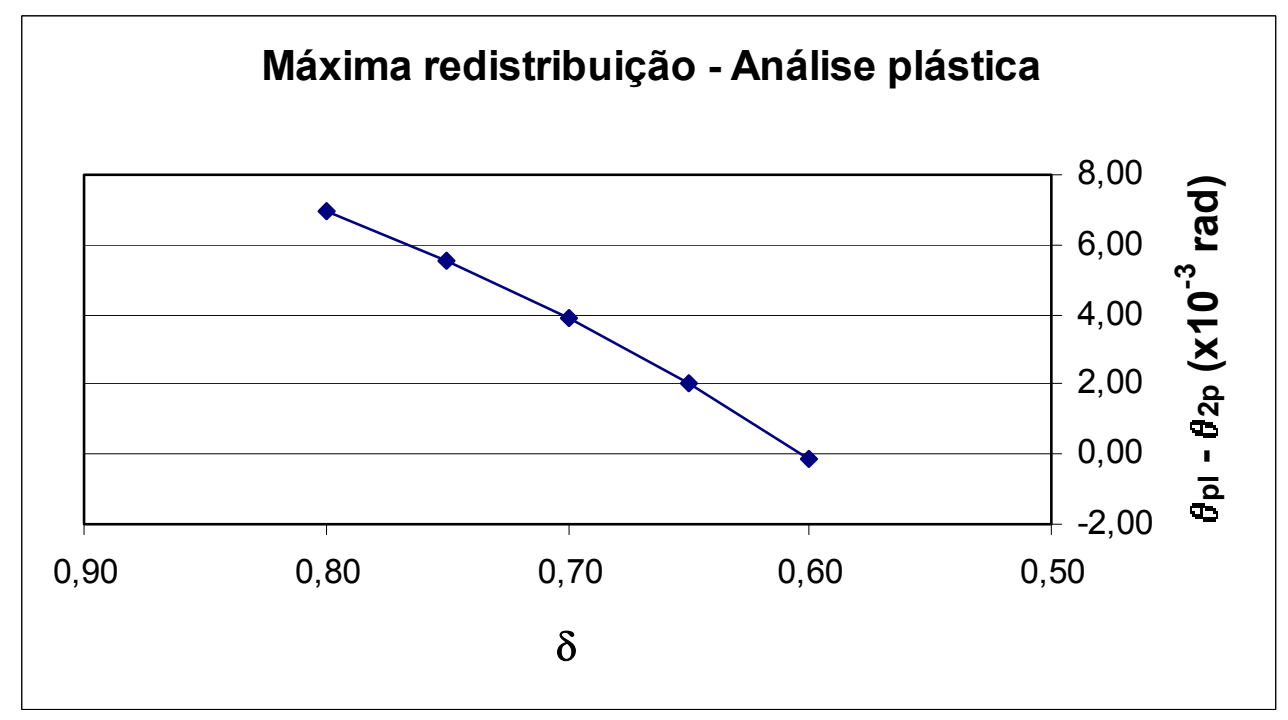

Figura 8.1 - Gráfico: $\delta$ versus Diferença entre a capacidade de rotação e a rotação plástica necessária No capítulo cinco, defende-se a consideração da seção $T$ em vigas com lajes adjacentes, e apresenta-se a armadura dupla como forma de permitir redistribuições de esforços controladas, com a imposição do valor necessário da posição relativa da linha neutra, nas seções de apoio. A seção $T$ permitiu maior economia de armadura, ao ser combinada com o aumento de momentos fletores nos vãos, proveniente de redistribuição, seja com a análise linear com redistribuição ou com a análise plástica, para as quais a economia de armadura ficou entre 12 e $14 \%$. Somente com análise linear e seção $\mathrm{T}$, a economia já foi próxima de $7 \%$. A análise plástica, para um mesmo valor de $x / d(0,250)$, permitiu maior redistribuição que a análise linear com redistribuição. Em termos de economia de armadura, a diferença entre a análise plástica e 
a análise linear com redistribuição foi inferior a 2\%. Na Figura 8.2 têm-se os diferentes consumos de armadura.

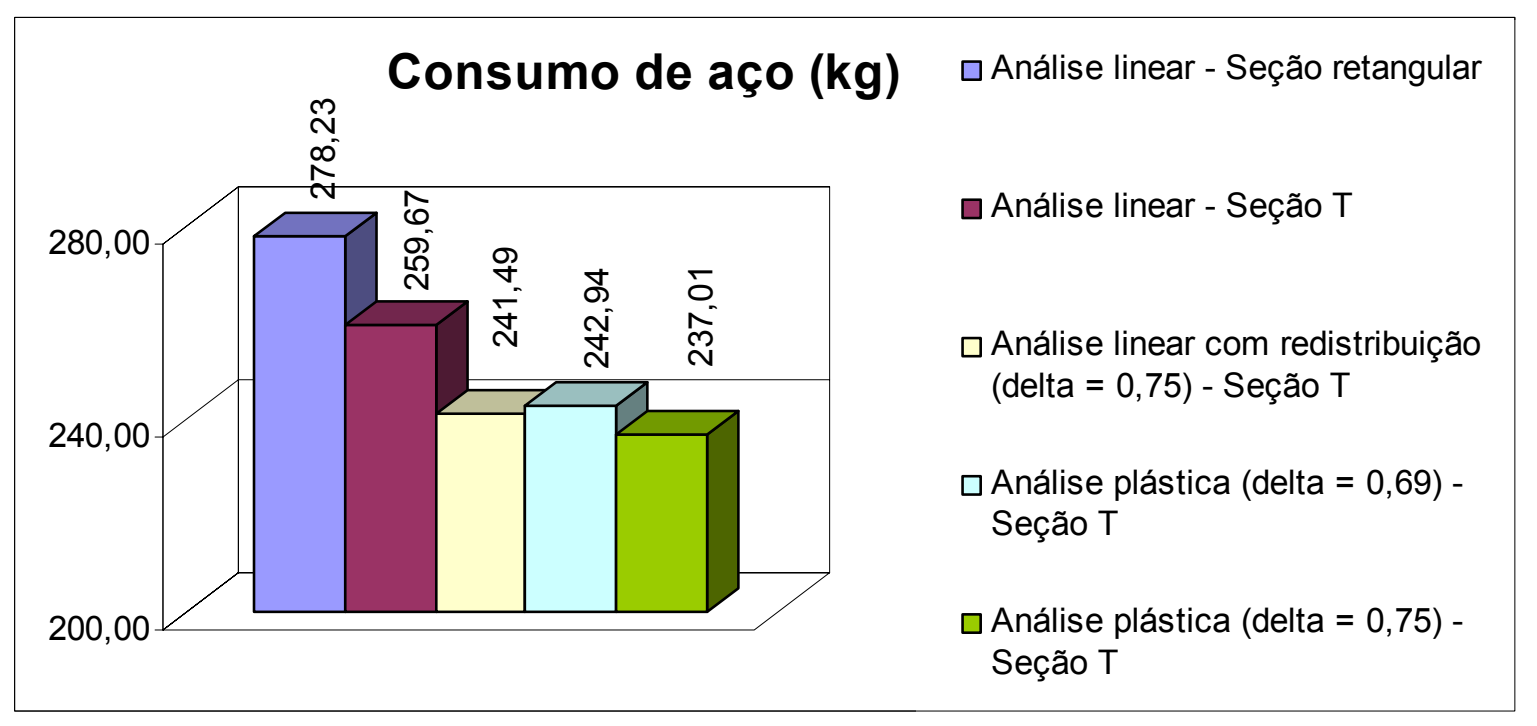

Figura 8.2 - Consumo de aço com os diferentes tipos de análise do capítulo cinco

Por meio da tabela 5.1, proveniente da análise plástica do capítulo cinco, é possível traçar uma superfície (ver Figura 8.3), com os eixos definidos pelos valores de x/d (eixo X), de $\delta$ (eixo Y) e da soma das áreas de armadura do apoio e do vão em $\mathrm{cm}^{2}$ (eixo Z). Vê-se que, para menores valores de $\mathrm{x} / \mathrm{d}$, maior é a capacidade de redistribuição, ou seja, menor é o valor de $\delta$. A soma das áreas de armadura cresce acentuadamente para menores valores de $x / d$ e de $\delta$, e de forma mais suave para maiores valores de $\mathrm{x} / \mathrm{d}$ e $\delta$. O ponto de menor área fica situado na região intermediária, ou no ponto mais baixo da "sela" formada pela superfície, ou seja, no ponto em que $x / d$ é igual a 0,25 e $\delta$ é igual a 0,69. No entanto, apesar da pequena diferença, a análise plástica com $\delta$ igual a 0,75 apresentou um menor consumo de armadura, como pôde ser visto na Figura 8.2, pois exige uma menor área de armadura positiva nos vãos, que, devido à sua necessidade de ancoragem nos apoios, acaba por ter maior comprimento e influencia o consumo total de aço de maneira mais incisiva.

Recomenda-se, portanto, a utilização conjunta das análises que permitem a redistribuição de momentos e da seção T em vigas. Alerta-se, também, para a necessidade de estudar, caso a caso, qual par de valores de $\mathrm{x} / \mathrm{d}$ e de $\delta$ fornece a menor área de armadura, pois, apesar da seção $T$ permitir maiores redistribuições, a máxima redistribuição nem sempre é a melhor. A análise linear com redistribuição, devido às limitações de $\delta$ em 0,75 e 0,90 , para estruturas de nós fixos e de nós móveis, respectivamente, permite menores redistribuições do que a análise plástica, porém sua utilização é mais interessante do ponto de vista prático. 


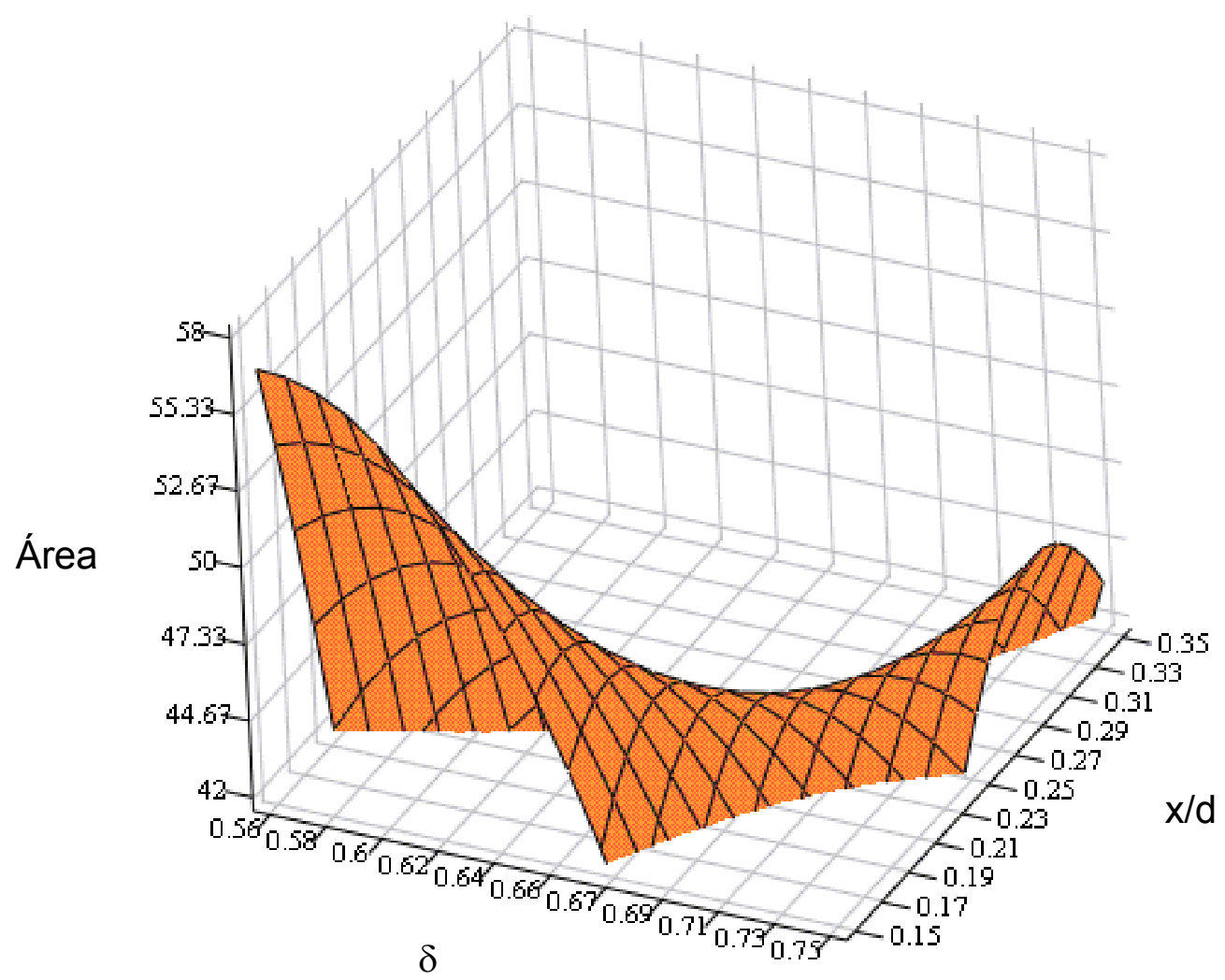

Figura 8.3 - Superfície de tendências dos valores de $x / d, \delta$ e área de armadura

No capítulo seis, volta-se a utilizar a seção $T$ na viga, em conjunto com a redistribuição de esforços realizada por meio da análise linear com redistribuição. Desta vez, os esforços obtidos para os pilares também são afetados, por existirem pilares apoiando as extremidades da viga analisada e por estar sendo aplicado o modelo de vigas contínuas, no cálculo dos esforços. Mostrou-se que, apesar da força normal nos pilares permanecer praticamente a mesma com a redistribuição, há uma redução nos momentos fletores desses elementos, propiciando uma pequena economia de armadura. Ressalta-se que a redistribuição de esforços nos pilares só é considerada se proveniente da redistribuição de esforços nas vigas a eles conectadas. Os momentos fletores nos pilares são ajustados pelo equilíbrio do nó de interseção da viga com o pilar. Portanto, a redução dos momentos fletores nos pilares depende da redistribuição realizada nas vigas e do modelo estrutural adotado.

No pórtico e no pavimento analisados, obteve-se uma economia de armadura de $5,7 \%$ para os pilares, $19,8 \%$ para a viga e $15,4 \%$ para o conjunto de ambos (ver Figura 8.4 ). 


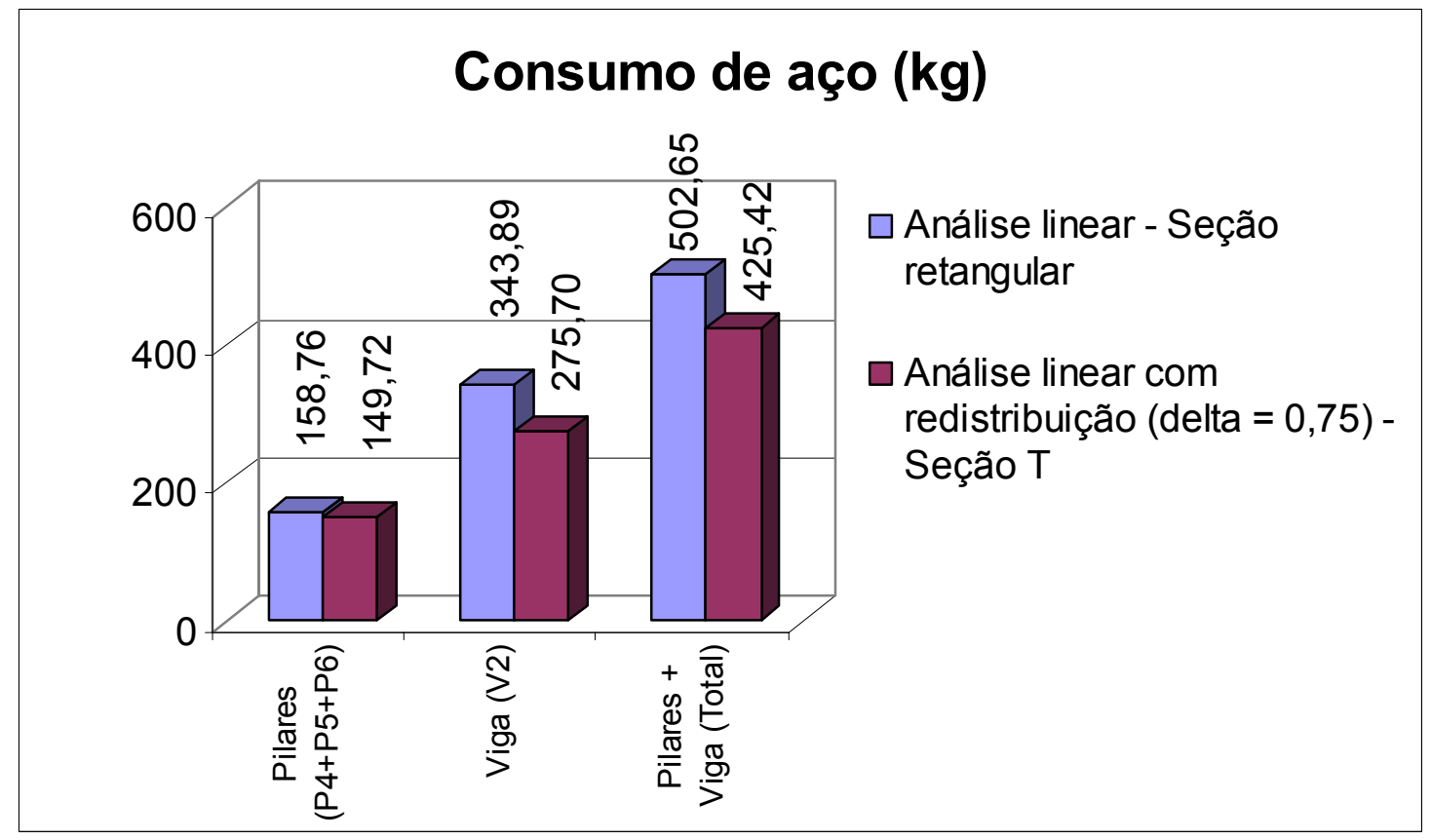

Figura 8.4 - Consumo de aço com os diferentes tipos de análise do capítulo seis

Ainda no capítulo seis, apresenta-se uma forma simples de se considerar a envoltória de carregamentos em uma análise linear com redistribuição, na qual se permite uma redução dos valores absolutos máximos, tanto dos momentos negativos como dos positivos. Se a relação entre o carregamento variável e o permanente fosse maior no exemplo realizado, os valores máximos dos momentos positivos também seriam maiores, o que propiciaria suas reduções com os ajustes propostos para a análise da envoltória de carregamentos e, portanto, uma maior economia em relação a uma análise linear com essa mesma relação.

No capítulo sete, foram analisados diferentes modelos estruturais, tomando-se por base a análise linear de um edifício de oito pavimentos mais o sub-solo. Na análise das ações verticais, o modelo Vigas Contínuas apresentou resultados mais díspares, em relação ao Pórtico Espacial, do que o de Pórticos Planos, tanto para as forças normais junto à fundação como para os momentos fletores analisados, do pavimento térreo. As forças normais de alguns pilares ficaram contra a segurança, em comparação com o Pórtico Espacial, e um deles apresentou uma força normal mais que $50 \%$ maior. No caso dos momentos fletores, a diferença do modelo Vigas Contínuas concentrou-se em momentos negativos menores e momentos positivos maiores, principalmente nas vigas cujos vãos eram mais irregulares. Recomenda-se, portanto, a utilização do modelo Vigas Contínuas somente para edifícios de menor porte, por exemplo até quatro andares, nos quais os tramos das vigas apresentem uma certa padronização, em termos de comprimento de vão e de carregamento. Este modelo tende a ser cada vez menos aplicado nas análises estruturais, pois não permite o cálculo dos 
esforços decorrentes de ações laterais, e a NBR 6118:2003 tornou obrigatória a consideração das ações do vento, em todas as edificações. Para o edifício analisado, o modelo Pórticos Planos mostrou-se satisfatório quanto à análise de forças normais e de momentos fletores, esforços de suma importância em um projeto de concreto armado. Sua utilização na análise de ações verticais só se torna inadequada em caso de haver grandes assimetrias na estrutura do edifício, o que gera esforços significativos decorrentes da torção do edifício, somente captados pelo Pórtico Espacial. Obviamente, sempre que possível, deve ser dada preferência à utilização do Pórtico Espacial.

$\mathrm{Na}$ análise das ações horizontais, destaca-se a necessidade de modelar as lajes no pórtico espacial, ou representá-las por meio das barras rígidas, como no modelo Pórticos Planos Associados, para que se possa medir de forma mais coerente os deslocamentos horizontais da estrutura. Em vista disso, o modelo Pórtico Espacial, constituído apenas pelo esqueleto formado por vigas e pilares, apresentou deslocamentos bem diferenciados em um mesmo pavimento (ver Figura 8.5), e deve ser evitado para esse tipo de cálculo. Os modelos se mostraram próximos entre si, quanto aos resultados dos deslocamentos laterais no topo do edifício, com exceção do deslocamento da direção y, no modelo Pórtico Espacial com Lajes e Trechos Rígidos. Os trechos rígidos foram todos implementados na direção y, devido à disposição dos elementos estruturais, o que causou uma redução de $18 \%$ no deslocamento do topo do edifício nesta direção, em relação ao modelo Pórtico Espacial com Lajes. Eles praticamente não afetaram a direção $x$. $A$ introdução de trechos rígidos conduz a resultados mais realistas, pois a interseção de vigas e pilares não se comporta como um trecho de barra flexível. Na verificação da estabilidade global, por meio do coeficiente $\gamma_{z}$, houve pouca variação entre os modelos, com valores de 1,06 a 1,04 na direção $x$, e de 1,05 a 1,04 na direção y. Neste caso, todos os modelos indicaram que o edifício é uma estrutura de nós fixos.

Na Figura 8.5, as siglas PPA-X, PE-X, PEL-X, PELTR-X, referem-se respectivamente aos resultados na direção $x$ dos modelos Pórtico Planos Associados, Pórtico Espacial, Pórtico Espacial com Lajes e Pórtico Espacial com Lajes e Trechos Rígidos. Analogamente têm-se os resultados da direção y. Os deslocamentos horizontais não foram exatamente os mesmos para todos os pontos do pavimento, por isso há um valor máximo e um valor mínimo.

Quanto às forças normais, a atuação isolada das ações horizontais pode causar a tração de alguns pilares, ou seja, um alívio no carregamento. No modelo Pórtico Espacial com Lajes e Trechos Rígidos, por exemplo, os pilares P2 e P8, por absorverem maior parte da ação do vento da direção y (maior inércia nessa direção, em relação ao P1 e ao P7), têm forças normais bem maiores, em módulo, no nível da fundação. Quanto aos momentos fletores, somente as 
vigas situadas na mesma direção do vento possuem valores diferentes de zero. No caso analisado (vento em y), os momentos da V6 e da V7 foram bem próximos para os diferentes modelos estudados, com exceção da V6 com o modelo Pórtico Espacial com Lajes e Trechos Rígidos, que suscitou diferenças de até $20 \%$. Em geral, para esforços normais em pilares e momentos fletores em vigas, podem ser aplicados os quatro modelos estruturais considerados na análise das ações horizontais.

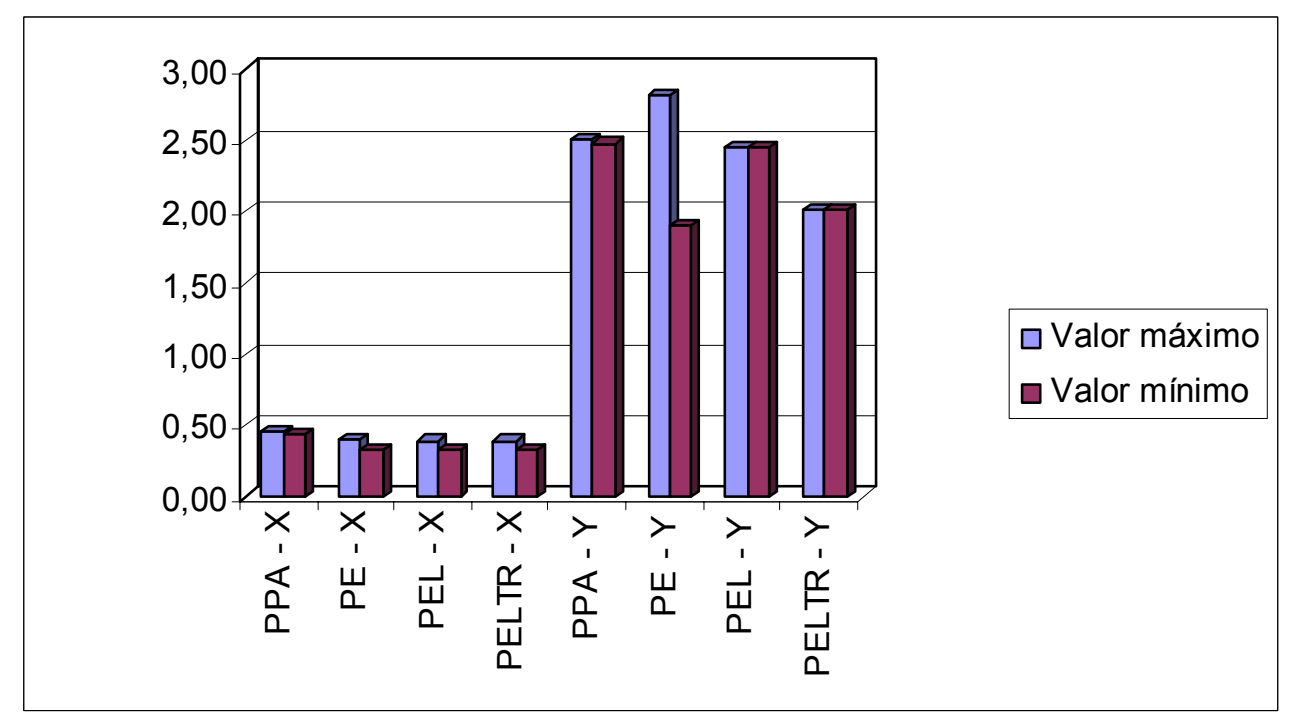

Figura 8.5 - Deslocamentos horizontais pelos diferentes modelos $(\mathrm{cm})$

É necessária, para a determinação dos esforços últimos, a consideração conjunta das ações horizontais e verticais, conforme o item 7.3.

Conclui-se, pelos resultados observados, que as novas prescrições da NBR 6118:2003, quanto à análise estrutural, apresentam-se coerentes, e introduzem importantes mudanças no projeto de estruturas de concreto armado.

\subsection{Sugestões de pesquisa}

Ainda é vasto o campo a ser explorado, nas pesquisas referentes à análise estrutural, segundo a abordagem da NBR 6118:2003. A seguir, são identificadas algumas maneiras de dar continuidade a este trabalho e áreas interessantes para maior aprofundamento.

- Pode-se estudar os diferentes tipos de análise estrutural para elementos de placa (lajes), realizando exemplos de maneira similar ao que foi realizado neste trabalho. A análise linear com redistribuição é semelhante à aqui apresentada, e a análise plástica pode considerar a teoria das charneiras plásticas. Em seguida, podem ser estudados também os modelos 
estruturais mais usuais para as lajes, que podem ser analisadas como elementos isolados apoiados, como uma grelha, ou podem ser discretizadas em elementos finitos.

- Uma outra possibilidade seria realizar um estudo semelhante para os elementos de volume.

- As idéias utilizadas na concepção dos exemplos dos capítulos quatro, cinco e seis poderiam ser estendidas para estruturas mais complexas, analisadas por modelos de pórticos planos ou de pórticos espaciais. A elaboração ou o refinamento de programas computacionais para tais fins seria de grande utilidade.

- A análise plástica de estruturas de concreto permite uma grande variabilidade de resultados, pois a localização das rótulas plásticas pode ser controlada pela disposição da armadura. Um estudo de otimização da análise plástica, para estruturas usuais, poderia apontar um caminho para a maior economia de armadura.

- O capítulo sete mostrou uma comparação entre alguns tipos de modelos estruturais para um edifício de características peculiares, que possuía uma de suas dimensões de fachada bem maior que a outra, e pequenas distâncias entre pilares, como no caso da viga V5. A análise de edifícios mais usuais, com variabilidade no número de andares, colaboraria para conclusões mais gerais. Uma outra possibilidade é a de estudar edifícios de formatos não usuais, com fachadas arredondadas, com reentrâncias, com cantos chanfrados etc.

- Um outro estudo possível consiste em comparar, por meio de ensaios, o tratamento analítico de estruturas simples, como a viga de dois tramos utilizada no capítulo quatro, pelos diferentes tipos de análise estrutural, com a análise através de modelos físicos, que também é mencionada no capítulo 14 da NBR 6118:2003.

Como se pode notar, a análise estrutural dispõe de muito espaço para seu desenvolvimento. 


\section{REFERÊNCIAS BIBLIOGRÁFICAS}

AMERICAN CONCRETE INSTITUTE. (1992). Building code requirements for reinforced concrete and commentary - ACI 318R-89 (revised 1992). Detroit.

ASSOCIAÇÃO BRASILEIRA DE NORMAS TÉCNICAS. NBR 6118:2003. Projeto de estruturas de concreto - Procedimento. Rio de Janeiro.

ASSOCIAÇÃO BRASILEIRA DE NORMAS TÉCNICAS. NB-1(1980). Projeto e execução de obras de concreto armado. Rio de Janeiro.

ASSOCIAÇÃO BRASILEIRA DE NORMAS TÉCNICAS. NBR 6123:1988. Forças devidas ao vento em edificações. Rio de Janeiro.

BRANCO, André L.L.V. (2002). Análise não-linear de pórticos planos, considerando os efeitos do cisalhamento no cálculo de esforços e deslocamentos. Dissertação (Mestrado). São Carlos, Escola de Engenharia de São Carlos - Universidade de São Paulo.

CEB-FIP Bulletin d'Information, n. 229. New developments in non-linear analysis methods, 1995.

CEB-FIP Model Code 1990 - Final draft. Bulletin d'Information, n. 203-205, 1991.

CORREAA, M.R.S. (1991). Aperfeiçoamento de modelos usualmente empregados no projeto de sistemas estruturais de edifícios. Tese (Doutorado). São Carlos, Escola de Engenharia de São Carlos - Universidade de São Paulo.

FUSCO, P.B. (1976). Estruturas de concreto: fundamentos do projeto estrutural. v.1. São Paulo, McGraw-Hill do Brasil, Editora da Universidade de São Paulo.

GIONGO, J.S. (2002). Projeto estrutural de edifícios. São Carlos, Universidade de São Paulo.

HAMBLY, E.C. (1976). Bridge deck behavior. London, Chapman \& Hall.

IBRACON - Comitê Técnico CT-301. (2003). Prática recomendada IBRACON - Comentários técnicos NB - 1. 
KOMATSU, José S. (1985). Cálculo elastoplástico de estruturas lineares de concreto. Dissertação (Mestrado). São Carlos, Escola de Engenharia de São Carlos - Universidade de São Paulo.

LEONHARDT, F.; MÖNNIG, E. (1977). Construções de concreto, volume 1: princípios básicos do dimensionamento de estruturas de concreto armado. Rio de Janeiro, Interciência.

LEONHARDT, F.; MÖNNIG, E. (1979). Construções de concreto, volume 4: verificação da capacidade de utilização. Rio de Janeiro, Interciência.

LOREDO-SOUZA, A.M.; BLESSMANN, J. (2003). Desenvolvimento da engenharia do vento no Brasil. In: Concreto Colloquia 2003. São Carlos.

MORETTO, O. (1970). Curso de hormigón armado. 2.ed. Buenos Aires, Libreria “EL ATENEO”.

NASH, W.A. (1982). Resistência dos materiais. 2.ed. São Paulo, McGraw-Hill do Brasil.

OLIVEIRA, Richard S. (2001). Análise de pavimentos de edifícios de concreto armado com a consideração da não-linearidade física - modelagem e metodologia de aplicação a projetos. Tese (Doutorado). São Carlos, Escola de Engenharia de São Carlos - Universidade de São Paulo.

PARK, R.; PAULAY, T. (1975). Reinforced concrete structures. New York, John Wiley \& Sons.

PRADO, José Fernão M.A.; GIONGO, J.S. (1997). Redistribuição de momentos fletores em vigas de edifícios. In: Jornadas Sul-Americanas de Engenharia Estrutural, 28, São Carlos, 1-5 set. Anais. p. 1555-1564.

PREECE, B.W.; DAVIES, J.D. (1964). Models for structural concrete. London, CR Books Limited.

SANCHES JR., Faustino (1998). Cálculo de esforços e deslocamentos em pavimentos de edifícios considerando-se modelos próprios para o concreto armado. Dissertação (Mestrado). São Carlos, Escola de Engenharia de São Carlos - Universidade de São Paulo.

SILVA, Roberto M. (1996). Análise não-linear de pórticos planos de concreto armado: modelagem numérica e avaliação dos métodos aproximados. Tese (Doutorado). São Carlos, Escola de Engenharia de São Carlos - Universidade de São Paulo. 
STRAMANDINOLI, J.S.B.; LORIGGIO, D.D. (2004). Análise de lajes de concreto armado por analogia de grelha [CD-ROM]. In: Jornadas Sul-Americanas de Engenharia Estrutural, 31, Mendoza. Anais.

TIMOSHENKO, S.P. (1953). History of strength of materials. New York, McGraw-Hill Book Company.

TIMOSHENKO, S.P.; GERE, J.E. (1994). Mecânica dos Sólidos. v.1. Rio de Janeiro, Livros Técnicos e Científicos.

TIMOSHENKO, S.P.; GOODIER, J.N. (1980). Teoria da Elasticidade. 3.ed. Rio de Janeiro, Editora Guanabara Dois.

TODHUNTER, I.; PEARSON, K. (1960). A history of the theory of elasticity and of the strength of materials. v.1. New York, Dover Publications.

TRINDADE, O.A. (1982). Cálculo das estruturas através de modelos físicos. Tese (Doutorado). São Paulo, Universidade Mackenzie. 


\section{BIBLIOGRAFIA COMPLEMENTAR}

ALTOQI TECNOLOGIA EM INFORMÁTICA LTDA. (2004). Curso sobre a NBR 6118:2003 Concreto armado. (Material de apoio às aulas). Florianópolis.

ALTOQI TECNOLOGIA EM INFORMÁTICA LTDA. (2004). Documentação técnica - Projeto estrutural de edificações em concreto armado. (Manual do Eberick V5). Florianópolis.

ALTOQI TECNOLOGIA EM INFORMÁTICA LTDA. (2004). Principais conceitos e aspectos da NBR 6118:2003 para o desenvolvimento de projetos. (Material didático do curso técnico AltoQi Eberick V5). Florianópolis.

BARBOZA, Aline S.R. (1992). Contribuição à análise estrutural de sistemas lajes-vigas de concreto armado mediante analogia de grelha. Dissertação (Mestrado). São Carlos, Escola de Engenharia de São Carlos - Universidade de São Paulo.

BORTOLIN, Admilson A. (1991). Sobre a racionalização e a automação do cálculo de edifícios de concreto armado. Dissertação (Mestrado). São Carlos, Escola de Engenharia de São Carlos - Universidade de São Paulo.

CARVALHO, Roberto Chust (1994). Análise não-linear de pavimentos de edifícios de concreto através da analogia de grelha. Tese (Doutorado). São Carlos, Escola de Engenharia de São Carlos - Universidade de São Paulo.

CILONI, Arquimedes D. (1993). Sobre o comportamento em serviço de estruturas planas de concreto armado. Tese (Doutorado). São Carlos, Escola de Engenharia de São Carlos Universidade de São Paulo.

FONTES, Fernando F.; PINHEIRO, Libânio M. (2004). Estabilidade global de edifícios: coeficiente gama Z [CD-ROM]. In: Jornadas Sul-Americanas de Engenharia Estrutural, 31, Mendoza. Anais.

GERE, J.M.; WEAVER, W. (1965). Analysis of framed structures. New York, Litton Educational Publishing.

LAIER, J. E.; BARREIRO, J. C. (2003) Complementos de resistências dos materiais - $2^{\mathrm{a}}$ parte. São Carlos, Universidade de São Paulo. 
LIMA, Juliana S. (1999). Estabilidade global de edifícios de concreto: avaliação dos efeitos de $2^{\mathrm{a}}$ ordem. São Carlos, EESC - USP.

NEAL, B.G. (1970). Plastic methods of structural analysis. London, Chapman \& Hall and Science Paperbacks.

PEREZ, G.B.; VASCONCELOS FILHO, A. (2000). Comparação de modelos clássicos para cálculo da estrutura de um edifício de andares múltiplos. In: Simpósio Mineiro de Mecânica Computacional, 4, Uberlândia, 1-3 maio. Anais. p. 259-266.

PINTO, Rivelli S. (1997). Não-linearidade física e geométrica no projeto de edifícios usuais de concreto armado. Dissertação (Mestrado). São Carlos, Escola de Engenharia de São Carlos Universidade de São Paulo.

PINTO, Rivelli S. (2002). Análise não-linear das estruturas de contraventamento de edifícios em concreto armado. Tese (Doutorado). São Carlos, Escola de Engenharia de São Carlos Universidade de São Paulo.

SILVA, M.A.F.; CARVALHO, R.C.; FIGUEIREDO FILHO, J.R. (2003). Principais modelos de cálculo utilizados na análise estrutural de edificações [CD-ROM]. In: Simpósio EPUSP sobre estruturas de concreto, 5, São Paulo. Anais.

TIMOSHENKO, S.P.; GERE, J.E. (1998). Mecânica dos Sólidos. v.2. Rio de Janeiro, Livros Técnicos e Científicos. 